Portland State University

PDXScholar

\title{
The Response of Mice to Infection by the Parasitic Nematode Trichinella: A Comparison of Trichinella Spiralis and Trichinella Pseudospiralis
}

\author{
Barry Clayton Anderson \\ Portland State University
}

Follow this and additional works at: https://pdxscholar.library.pdx.edu/open_access_etds

Part of the Biology Commons, and the Parasitology Commons Let us know how access to this document benefits you.

\section{Recommended Citation}

Anderson, Barry Clayton, "The Response of Mice to Infection by the Parasitic Nematode Trichinella: A Comparison of Trichinella Spiralis and Trichinella Pseudospiralis" (2002). Dissertations and Theses. Paper 1658.

https://doi.org/10.15760/etd.1657

This Dissertation is brought to you for free and open access. It has been accepted for inclusion in Dissertations and Theses by an authorized administrator of PDXScholar. Please contact us if we can make this document more accessible: pdxscholar@pdx.edu. 


\section{DISSERTATION APPROVAL}

The abstract and dissertation of Barry Clayton Anderson for the Doctor of

Philosophy in Environmental Sciences and Resources: Biology were presented

March 23, 2001, and accepted by the dissertation committee and the doctoral program.

\section{COMMITTEE APPROVALS:}

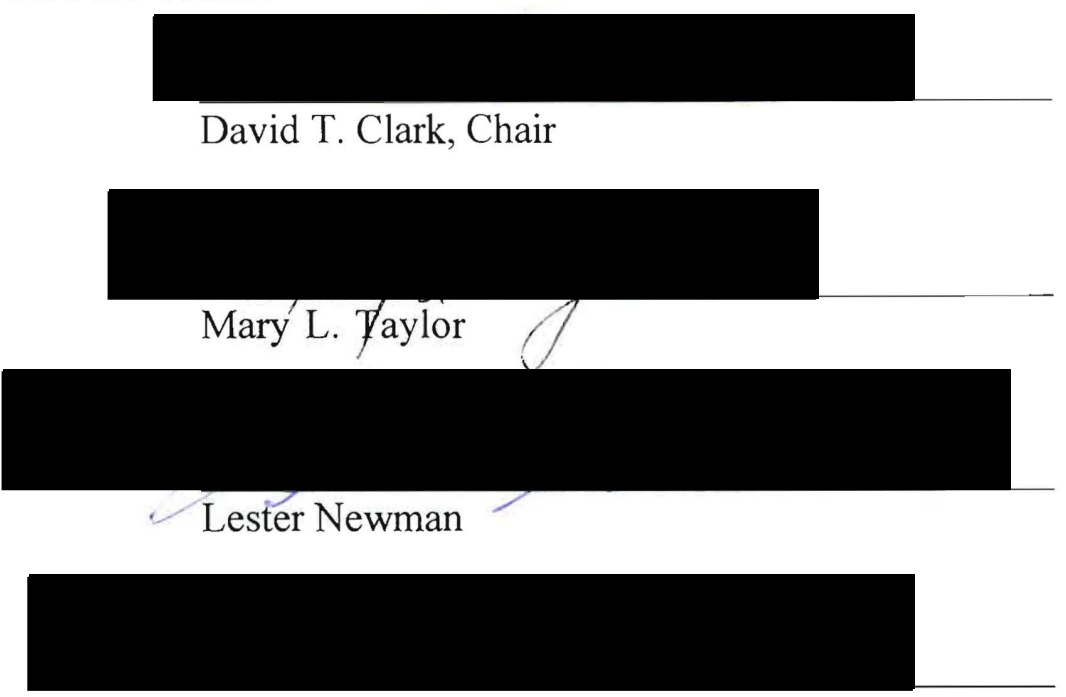

Richard Forbes

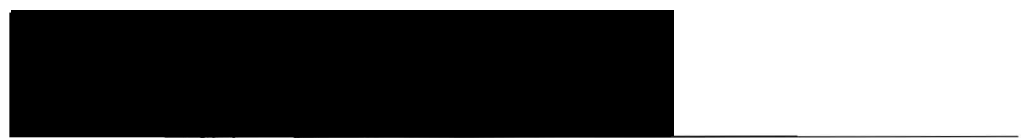

James R. Pratt

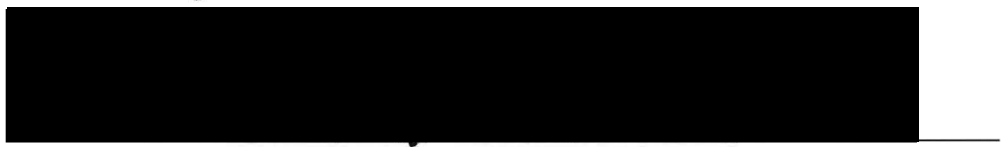

Pavel Smejtek

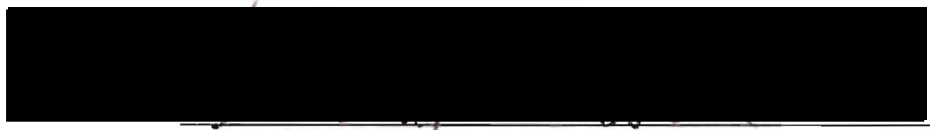

Gary Brodowicz

Representative of the Office of Graduate Studies

DOCTORAL PROGRAM APPROVAL:

Roy W. Koch, Director

Environmental Sciences and Resources Ph.D. Program 


\begin{abstract}
An abstract of the dissertation of Barry Clayton Anderson for the Doctor of Philosophy in Environmental Sciences and Resources: Biology presented
\end{abstract} 23 March 2001.

Title: The Response of Mice to Infection by the Parasitic Nematode Trichinella: A comparison of Trichinella spiralis and Trichinella pseudospiralis

The intracellular parasite Trichinella is a genus in phylum Nematoda that contains six named species including Trichinella spiralis and Trichinella pseudospiralis. These parasites infect a large variety of wild and domestic animals, human beings and a few species of birds. The parasitic strategies and the pathological effects on the host between Trichinella spiralis and Trichinella pseudospiralis are quite different.

The purpose of this study is to gain an understanding of the physiological, immunological and pathological differences between these two species of Trichinella using infections in the mouse as a model. In the course of this research I have attempted to answer the following questions: A) Is cortisol a factor in the differences of the host response to Trichinella spiralis or Trichinella pseudospiralis? B) Are there differences in leukocyte response in the peripheral blood of Trichinella infected mice? C) Are there differences in the up-regulation or down-regulation of cell surface molecules on leukocytes in the spleens of Trichinella infected mice? D) Is there a difference in the degree of muscle damage (as measured by creatine phosphokinase) when infections by 
the two species of Trichinella are compared? E) Are there differences in angiogenesis and collagen deposition in Trichinella infected mice and are these differences related to cortisol? F) Is nitric oxide a component in parasite killing and are there differences in nitric oxide production in host mice when the two species of Trichinella are compared?

My research has shown that there are significant differences in the parasitic strategies and pathological consequences in mice infected with one or the other of the two species of Trichinella. The two species appear to generate different immune and inflammatory responses from the host. Trichinella pseudospiralis is much less damaging to the host, generates a very different peripheral blood response, stimulates the production of substantially greater levels of serum cortisol, generates a significantly different profile in cytokine production, presents a very different cell surface antigen profile and does not produce a collagen nurse cell or generate an angiogenic response when compared to $T$. spiralis. In addition, I have shown a role for nitric oxide in parasite killing and a role for serum cortisol in larval survival. I have also shown that cortisol has no role in either collagen deposition or the angiogenic response in Balb/c mice under the experimental conditions detailed here. 
THE RESPONSE OF MICE TO INFECTION BY THE

PARASITIC NEMATODE TRICHINELLA:

A COMPARISON OF TRICHINELLA SPIRALIS AND

TRICHINELLA PSEUDOSPIRALIS

by

BARRY CLAYTON ANDERSON

A dissertation submitted in partial fulfillment of the requirements for the degree of

DOCTOR OF PHILOSOPHY

in

ENVIRONMENTAL SCIENCES AND RESOURCES: BIOLOGY

Portland State University

2002 


\section{DEDICATION}

This work is dedicated to the glory of God whose saving Grace has allowed me to overcome the spiritual and physical obstacles that I found along the path less taken. 
ACKNOWLEDGMENTS

MY GRATEFUL APPRECIATION TO:

DR. DAVID CLARK

AND THE MEMBERS OF THE COMMITTEE:

DR. MARY TAYLOR

DR. LESTER NEWMAN

DR. RICHARD FORBES

DR. JAMES R. PRATT

DR. PAVEL SMEJTEK

DR. GARY BRODOWICZ

ALSO

RANDY SMITH

AND ESPECIALLY TO MY WIFE CLAIRE AND MY MOTHER VIRGINIA (FOR THEIR INFINITE PATIENCE AND SUPPORT THROUGHOUT). 


\section{TABLE OF CONTENTS}

Dedication

Acknowledgments

List of Tables

iv

List of Figures $\quad \mathrm{V}$

$\begin{array}{ll}\text { Chapter One: General Introduction } & 1\end{array}$

The Taxonomy and Biology of Trichinella 1

The Host Parasite Relationship in Trichinella Infections 6

$\begin{array}{ll}\text { Research Focus } & 9\end{array}$

Chapter Two: Nitric Oxide and Creatine Phosphokinase in Mice Infected with Trichinella spiralis or Trichinella pseudospiralis 14

$\begin{array}{ll}\text { Materials and Methods } & 19\end{array}$

$\begin{array}{ll}\text { Serum Nitric Oxide Assay } & 19\end{array}$

Creatine Phosphokinase Assay 20

$\begin{array}{ll}\text { Results } & 23\end{array}$

$\begin{array}{ll}\text { Nitric Oxide } & 23\end{array}$

Creatine Phosphokinase $\quad 23$

$\begin{array}{ll}\text { Lipopolysaccharide } & 24\end{array}$ 
Discussion $\quad 28$

$\begin{array}{ll}\text { Nitric Oxide } & 28\end{array}$

Creatine Phosphokinase 33

$\begin{array}{ll}\text { Lipopolysaccharide } & 35\end{array}$

Chapter Three

Angiogenesis, Collagen Deposition, Larval Survival, Immune Cell Response in Mice Infected with Trichinella and in Trichinella-infected Adrenalectomized Mice

Introduction

Angiogenesis

Collagen Synthesis $\quad 39$

$\begin{array}{ll}\text { Larval Survival } & 40\end{array}$

Materials and Methods $\quad 41$

Peripheral Blood Counts $\quad 41$

Angiogenesis Assay $\quad 43$

Collagen Assay $\quad 43$

$\begin{array}{ll}\text { Results } & 45\end{array}$

$\begin{array}{ll}\text { Angiogenesis } & 45\end{array}$

Larval Counts $\quad 45$

Peripheral Blood Counts $\quad 56$

$\begin{array}{ll}\text { Collagen Deposition } & 58\end{array}$

$\begin{array}{ll}\text { Discussion } & 63\end{array}$ 
Chapter Four

Flow Cytometric Analysis of Cell Surface Antigens in Mice Infected with Trichinella.

Introduction: Flow Cytometry $\quad 81$

Cell Surface Antigens Assayed in This Study $\quad 84$

Materials and Methods $\quad 90$

$\begin{array}{ll}\text { Results } & 93\end{array}$

$\begin{array}{ll}\text { Discussion } & 132\end{array}$

$\begin{array}{ll}\text { The Antigen CD11b } & 132\end{array}$

$\begin{array}{ll}\text { The Antigen CD62L } & 135\end{array}$

$\begin{array}{ll}\text { The Antigen CD69 } & 138\end{array}$

$\begin{array}{ll}\text { The Antigen CD19 } & 142\end{array}$

The Antigen CD8 144

$\begin{array}{ll}\text { Summary and Conclusions } & 148\end{array}$

$\begin{array}{lr}\text { Literature Cited } & 154\end{array}$ 


\section{LIST OF TABLES}

Table 3.1

Analysis of Capillary Density in Mice Infected with Either T. spiralis or T. pseudospiralis.

Table 3.2

Peak Blood Cell Levels at Day 20 Post-Infection. 
Figure 2.1

Nitric Oxide

Figure 2.2

Nitric Oxide and Lipopolysaccharide

Figure 2.3

Creatine Phosphokinase

Figure 3.1

Neovascularization Day 15

Figure 3.2

Neovascularization Day 20

Figure 3.3

Neovascularization Day 25

Figure 3.4

Neovascularization Day 30

Figure 3.5

Neovascularization Day 45

Figure 3.6

Neovascularization Day 60

Figure 3.7

Neovascularization Day 75

Figure 3.8

Larval Counts

Figure 3.9

Collagen Deposition in T. pseudospiralisInfected ADX Mice

Figure 3.10

Collagen Deposition in T. pseudospiralis-Infected Mice 
Figure 3.11

Collagen Deposition in T. spiralis-Infected Mice

Figure 3.12

Collagen Deposition in T. spiralis-Infected ADX Mice

62

Figure 4.1

CD19 Up-regulation in Trichinella Infections

96

Figure $4.2 \mathrm{a}$

CD45/19 Total Cell Acquisition in Control Mice

97

Figure $4.2 b$

CD45/19 Quadrant Acquisition in Control Mice

98

Figure 4.3a

CD45/19 Total Cell Acquisition in T. pseudospiralisInfected Mice

99

Figure $4.3 \mathrm{~b}$

CD45/19 Quadrant Acquisition in T. pseudospiralisInfected Mice

Figure $4.4 \mathrm{a}$

CD45/19 Total cell Acquisition in T. spiralisInfected Mice

Figure $4.4 b$

CD45/19 Quadrant Acquisition in T. spiralisInfected Mice

Figure 4.5

CD11b Up-regulation in Trichinella Infections

Figure 4.6a

CD45/11b Total Cell Acquisition in Control Mice

Figure $4.6 \mathrm{~b}$

CD45/11b Quadrant Acquisition in Control Mice

Figure 4.7a

CD45/11b Total Cell Acquisition in T. pseudospiralisInfected Mice 
Figure $4.7 b$

CD45/11b Quadrant Acquisition in T. pseudospiralisInfected Mice.

Figure 4.8a

CD45/11b Total Cell Acquisition in T. spiralisInfected Mice

Figure $4.8 b$

CD45/11b Quadrant Acquisition in T. spiralisInfected Mice

Figure 4.9

CD62L Regulation in Trichinella-Infected Mice

Figure 4.10a

CD45/62L Total Cell Acquisition in Control Mice

Figure $4.10 \mathrm{~b}$

CD45/62L Quadrant Acquisition in Control Mice

Figure $4.11 \mathrm{a}$

CD45/62L Total Cell Acquisition in T. pseudospiralisInfected Mice

Figure $4.11 \mathrm{~b}$

CD45/62L Quadrant Acquisition in T. pseudospiralisInfected Mice

Figure 4.12a

CD45/62L Total Cell Acquisition in T. spiralisInfected Mice 
Figure $4.12 b$

CD45/62L Quadrant Acquisition in T. spiralisInfected Mice

Figure 4.13

CD69 Regulation in Trichinella Infections

Figure 4.14a

CD45/69 Total Cell Acquisition in Control Mice

Figure $4.14 b$

CD45/69 Quadrant Acquisition in Control Mice

Figure $4.15 \mathrm{a}$

CD45/69 Total Cell Acquisition in T. pseudospiralisInfected Mice

Figure $4.15 b$

CD45/69 Quadrant Cell Acquisition in T. pseudospiralisInfected Mice

Figure 4.16a

CD45/69 Total Cell Acquisition in T. spiralisInfected Mice

Figure 4.16b

CD45/69 Quadrant Acquisition in T. spiralisInfected Mice

Figure 4.17

CD8 Regulation in Trichinella Infections

Figure $4.18 \mathrm{a}$

CD3/8 Total Cell Acquisition in Control Mice

Figure $4.18 \mathrm{~b}$

CD3/8 Quadrant Acquisition in Control Mice

Figure $4.19 \mathrm{a}$

CD3/8 Total Cell Acquisition in T. pseudospiralisInfected Mice 
Figure 4.19b

CD3/8 Quadrant Acquisition in T. pseudospiralisInfected Mice

Figure $4.20 \mathrm{a}$

CD3/8 Total Cell Acquisition in T. spiralisInfected Mice

Figure $4.20 \mathrm{~b}$

CD3/8 Quadrant Acquisition in T. spiralisInfected Mice

Figure 4.21

The Effects of LPS on Select Cell Surface Antigens in BALB/c Mice 


\section{CHAPTER ONE}

\section{GENERAL INTRODUCTION}

\section{THE TAXONOMY AND BIOLOGY}

OF TRICHINELLA

The intracellular parasite Trichinella is the single known genus in the superfamily Trichocephaloidea, of the order Stichosomida, class Adenophorea, and phylum Nematoda. In this genus, there are six named species: Trichinella spiralis (Owen, 1835), Trichinella pseudospiralis (Garkavi, 1972), Trichinella britovi (Britov and Boev, 1972), Trichinella nativa (Brtiov and Boev, 1972), Trichinella nelsoni (Britov and Boev, 1972) and Trichinella murrelli (Pozio and La Rosa, 2000). There are only minor morphological differences between adults of the various species of Trichinella (Skvortsova and Veretennikova, 1997). Their identification, therefore, is based not on morphology but on differences in their physiology, environment and genetics. For example, T. pseudospiralis infects birds and lacks an encapsulated stage during the muscular phase of the life cycle.

Trichinella species are obligate parasites of many species of warm-blooded vertebrates. They have been found in most areas of the world and in most habitats occupied by mammals or birds. Trichinella has been found to naturally infect various animals including fox, wolf, horse, polar bear, civet cat, whale, seal, hyena, dog, pig and rodent in addition to human beings. Uniquely, $T$. pseudospiralis has been found to 
parasitize various species of meat-eating birds including the hawk, eagle and owl and is frequently found in scavengers such as the crow and vulture and has been reported to parasitize several species of mammal. Experimentally, T. pseudospiralis will infect chickens (Despommier, 1975).

The life cycle of the various Trichinella species consists of an intestinal phase and a muscle phase. As described by Despommier (1975), the cycle begins when the infectious (L1) larval stage housed in a nurse cell within a skeletal muscle fiber is ingested. The nurse cell is an important component of the host-parasite relationship with stimuli for development probably arising from both the parasite and the host. The mature nurse cell consists predominantly of collagen types IV and VI. (Polvere, et al 1997). One species, T. pseudospiralis, does not develop the collagen nurse cell or cyst. All species of Trichinella including $T$. pseudospiralis live within the host myofiber. Trichinella may live for months in short-lived animals and years in longer-lived animals.

When a host muscle fiber infected with mature L1 larvae is consumed by another animal, the myofiber is disrupted and the larval stage is released from the cyst by pepsin digestion in the new host's stomach. The L1 infectious stage is then carried to the small intestine. In the intestine, the larvae penetrate rows of columnar epithelial cells mostly in the jejunum and ileum. The mechanism of penetration is not fully understood; but the larvae of $T$. spiralis are known to secrete proteinases from the stycosome (Moczon and Wranicz, 1999). The cell membranes of adjacent epithelial cells fuse to form syncytia (Despommier, et al 1978). In the intestinal epithelial syncytia, the larvae consume nutrients and grow rapidly, requiring four molts to mature 
to the adult stage. The maturing larvae reach the adult stage in approximately 30 hours (Wright, 1979). Mating occurs upon reaching sexual maturity and spermatozoa have been found in the females approximately $37-40$ hours post-infection or 7-10 hours after maturity of the female is reached (Despommier, 1975). Trichinella females are one of the few nematodes that are larviparous. Depending on the host species and beginning at about 6 days post-infection, each female extrudes several hundred to a few thousand larvae over the course of the intestinal phase that may last another 10 days. Larval extrusion increases for five days then slowly decreases. The adult female worms are generally expelled by day 20 post-infection and the males of all species are expelled by 15-20 days post-infection.

The newborn larvae enter the lamina propria of the villus and most frequently penetrate the lymphatic vessels although they occasionally enter the capillaries. The larvae depart the lymph vessels and enter the general circulation through the thoracic duct. With the aid of its oral stylet, the newborn larvae exit the capillary or lymphatic vessel and penetrate a single muscle fiber of the host for the final development of the L1 larvae. Frequently, muscle fibers are parasitized by more than one larva.

Although the newborn L1 larvae may be transported in blood or lymph through several tissues, including the brain, lungs and smooth and cardiac muscle, it will only establish its intracellular niche in striated muscle. The specificity of Trichinella for skeletal muscle may be due to several factors. Hughes and Harley (1977) found that Trichinella larvae are electrotactic and migrate to striated muscle based on the electrical characteristics of the muscle. Experimentally, the larvae are attracted to a 
$120 \mathrm{mV}$ stimulus and repelled by a $90 \mathrm{mV}$ stimulus. Stewart and Carniga (1980). Despommier, et al (1978) suggested that those muscles most heavily vascularized were most frequently penetrated by the worm for its subsequent development. I have found that, in the mouse and rat, the most heavily parasitized skeletal muscles are the masseter, diaphragm, tongue and intercostal muscles.

After the newborn larvae penetrate the striated muscle fiber, they undergo a period of extremely active growth for approximately 12 days. It has been estimated that the larvae increase their body weight by approximately $40 \%$ per day during the first 6 to 8 days following muscle penetration (Despommier, 1975). Among the internal structures to develop during this time are the intestine and the stychosome. Within the stychosome are the stychocytes containing $\alpha$ and $\beta$ granules as seen with the electron microscope. These granules are known to contain immunogenic proteins that are secreted in the worm's saliva (Jasmer and Neary 1994; Ko, et al 1994; Gerencer, et al 1992).

Changes in the host muscle cell resulting from larval penetration include hypertrophy of muscle cell nuclei (Despommier, et al 1991) and degenerative changes in the host mitochondria (Wandurska-Nowak and Boczon, 1993). Membrane whorls appear within the sarcoplasm and one finds the apparent initiation of DNA synthesis within host muscle nuclei $(2 n \rightarrow 4 n)$ as measured by ${ }^{3} \mathrm{H}$-thymidine incorporation (Jasmer, 1993). Other changes include the development of a nurse cell around the L1 stage. Trichinella pseudospiralis is the only species of Trichinella that does not develop a nurse cell. Vassilatis, et al, 1992 noted the translocation of at least one worm 
excretory/secretory protein to the host nucleus. Transcript levels of the transcriptional regulatory factors MyoD1 and myogenin are altered indicating inactivation of certain host muscle genes that are involved in muscle cell differentiation (Jasmer, 1990).

Angiogenesis begins at approximately day 10 post-penetration resulting in neovascularization around the nurse cell (Baruch, et al 1991). The angiogenic factor vascular endothelial growth factor (VEGF) mRNA and the VEGF peptide itself have both been found within the myocyte following penetration by the larvae (Capo, et al 1998). By day 21, larval growth has essentially stopped for all species of Trichinella and the worm (now designated the L1 infectious stage) may remain within the host cell for months or years depending on several factors including the species of host and the host life span. Continuation of the Trichinella life cycle requires consumption of the L1 infectious stage by the appropriate host. The mechanisms responsible for many of the phenomena associated with the host-parasite relationship remain unclear. Very different sets of cellular phenomena are associated with $T$. pseudospiralis infections including the absence of both the nurse cell and angiogenic response. 


\section{THE HOST-PARASITE}

\section{RELATIONSHIP IN}

\section{TRICHINELLA INFECTIONS}

Most investigators agree that the earliest immune reactions to the presence and growth of the infective larvae are acute inflammatory responses in the intestine. These responses include the typical inflammatory reactions such as infiltration by polymorphonuclear cells (PMNs), macrophages and a significantly higher number of mast cells and eosinophils (mastocytosis and eosinophilia respectively) (Wakelin, et al 1982). With continuing inflammation, increased numbers of $\mathrm{CD}^{+}$and $\mathrm{CD}^{+} \mathrm{T}$ lymphocytes are found in the blood (Ivanoska, et al 1990). It is suspected that, as granulocytes accumulate in the intestine, vasoactive amines such as histamine and 5hydroxytryptamine (5-HT) are produced and secreted into the tissues. These substances may have a role in expulsion of the adult Trichinella after larvae are deposited and in the subsequent Th2 lymphocyte infiltration (Hermanek, et al 1994).

The responses of B-lymphocytes during the intestinal phase include secretion of antibodies primarily of the subclasses IgG2a in T. spiralis infections or IgG1 in $T$. pseudospiralis infections. (Ruitenberg, et al 1980). Complement may also play a role and it has been suggested that complement is activated primarily via the alternative pathway during Trichinella infections (Hong, et al 1992).

Newborn larvae are antigenically distinct from the adults with the exception of a single shared antigen of approximately 57kDa (Wakelin, et al 1994; Phillip, et al 1980). There is still some controversy as to the immunological distinctions between 
Trichinella species, but most investigators agree that no consistent antigenic differences are seen in the adult worms of different species. (Hegazy and Boulos, 1993; Ko, et al 1994; Wakelin, et al 1994;).

In many instances of parasitemia, the infection and subsequent tissue injury result in the activation of the inflammatory response. The acute inflammatory response is both localized and systemic. Frequently, serum clotting factors are produced that cause activation of the coagulation, kinin-forming and fibrinolytic pathways (Kuby, 1994). The release of various molecules including cytokines, chemokines and/or extracellular matrix $(E C M)$ components at the inflammation site often result in the margination of immune cells to the vascular endothelium. This is followed by the rapid extravasation of these leukocytes into the tissues at the site of injury. The infiltrating cells may include polymorphonuclear (PMN) cells, macrophages, basophils, eosinophils and lymphocytes. The recruitment of leukocytes and other cells such as fibroblasts to an area of inflammation is mediated by a number of molecules (both membrane-bound and soluble). These molecules can be both detected and quantified using immunochemistry as will be detailed in the following chapters.

In addition, the acute phase response to an infection commonly includes fever, leukocytosis, increased secretion of adrenocorticotropic hormone (ATCH) and cortisol. There is also increased production of serum amyloid A (SAA) and c-reactive protein (CRP) by hepatocytes in addition to nitric oxide (NO) production by a number of cell types including endothelial cells, lymphocytes and macrophages (Lincoln, 1997). The roles of cytokines, chemokines, ACTH, cortisol, SAA, NO, prostaglandins and CRP 
are uncertain in Trichinella infections. It is generally agreed, however, that there are complex and important interactions between the immune and endocrine systems and there may be a particularly vital role for the hypothalamic-pituitary-adrenal (HPA) axis in infected mammals.

This acute inflammatory reaction is the result, in part, of the activation of tissue macrophages and the release of TNF, IL-1 ( $\alpha$ and $\beta)$, Il-6, Il-8, interferon- $\gamma$ (IFN- $\gamma$ ) and other cytokines. These cytokines and chemokines are believed to be responsible for many of the systemic and localized effects observed during acute inflammation.

Regulation of $\mathrm{ACTH}$ is controlled by the trophic factor corticotropin-releasing factor (CRF) and by negative feedback from glucocorticoids. Corticotropin-releasing factor released by the hypothalamus is initiated by stress, disease and hypoglycemia. In addition to the negative feedback effect of glucocorticoids like cortisol, there exists a short negative feedback loop between the hypothalamus and the pituitary where increasing concentrations of ACTH suppress CRF secretion (Kannon, 1986). The hypothalamus, in turn, is also influenced by a number of inflammatory cytokines including interleukin-1 (IL-1) and tumor necrosis factor (TNF), and by the presence of exogenous endotoxins such as lipopolysaccharide (LPS) (Eskay, et al 1990). It is thought that the secretion of CRF, ACTH and cortisol may act to moderate the immune and/or inflammatory response and so help return the host organism to homeostasis (Griffin and Ojeda, 1992). 


\section{RESEARCH FOCUS}

There are physiological and biochemical differences in mice infected with Trichinella spiralis when compared to T. pseudospiralis (Despommier, et al 1975). For example, there are significant differences in the host macrophage response to $T$. spiralis compared to T. pseudospiralis in formalin-fixed, paraffin-embedded tissues using monoclonal antibodies against murine myloperoxidase. Experimental results have demonstrated that there is a very large cellular tissue response to the encysted $T$. spiralis and a substantially smaller response to T. pseudospiralis (Pruhiere, 1994). To explain these phenomena, some workers have speculated that $T$. pseudospiralis may mediate (or in some manner diminish) the host response (Gerencer, et al 1992; Boulos, et al 1993). The mechanisms for this immunosuppression remain unknown.

It has been also been shown that there is a significant increase in prostaglandin E2 (PGE2) in T. spiralis infected mice and a significant decrease in PGE2 in $T$. pseudospiralis infected mice when compared to uninfected controls (Mehdizadehkashi, 1995). Eicosinoids like PGE2 and the leukotrienes are lipid-derived molecules that are potent mediators of the inflammatory response in mammals. Increased eicosinoid levels may be associated with increases in serum cortisol and ACTH in mice (Thorburn, 1991; Thorburn, et al 1991) and in humans (Jorgensen and Sany, 1994; Panayi, 1993a; Panayi, 1993b).

T. pseudospiralis does not have an intracellular collagen nurse cell and does not stimulate angiogenesis in mice (Despommier, et al 1978). Furthermore, $T$. pseudospiralis does not alter the structure of the host myofiber in the same manner as 
does $T$. spiralis and the other encapsulating species of Trichinella such as T. nativa, $T$. britovi. T. mullerii and T. nelsoni (see above). The mechanisms underlying these differences are not entirely known.

Several investigators have observed that, in some hosts, the animal responds to chronic inflammation or to a persistent antigenic stimulation by a granulomatous reaction (Penrith and VanVollenhoven 1994; Tang and Eaton, 1995; Geboes, 1994; Stadecker and Flores-Villanueva, 1994; $\mathrm{Ng}$ and Loo, 1993). For example, there is a T cell mediated granulomatous inflammation to the presence of the antigens produced and secreted by the eggs of the parasite Schistosoma mansoni in the liver (Boros, 1994). I have found no evidence to support a granulomatous reaction in Trichinellainfected animals that might lead to nurse cell formation. One group of workers however, reported that $T$. pseudospiralis-infected mice treated with the immunostimulant, Levamisole, showed what appeared to be the beginning of a membranous structure around the muscle stage of the larvae (Hegazy and Boulos, 1993).

The Levamisole data suggest that the nurse cell may be a host-derived structure and that the formation of the nurse cell may be suppressed in T. pseudospiralis-infected mice. Elevated cortisol levels such as those found in T. pseudospiralis-infected animals can suppress collagen synthesis through the down-regulation of procollagen I transcription. (Guller, et al 1995; Delaney, et al 1995). It is also possible that $T$. pseudospiralis does not secrete a collagen cyst (if the cyst is worm-derived) or does 
not stimulate nurse cell collagen formation within the infected myofiber (if the cyst is host-derived).

The reported physiological and/or pathological differences between the two species of Trichinella may be based, at least in part, on differences in the host inflammatory and immune reaction to the presence of the parasite. These differences may include variations in the host levels of cytokines, chemokines or dissimilarities in the secreted products of the HPA axis. These contrasting observations may be the result of physiological differences between the two species of worm, or the differences may indicate an active moderation of the host response by the worm. Because cortisol suppresses the immune and inflammatory responses in mammals (Delaney, et al 1995; Haapasaari, et al 1995), it is possible that cortisol may have a role in suppressing the host immune and inflammatory reactions to the presence of Trichinella in mice.

My hypothesis is that the differences in the responses of mice to the two species of Trichinella are due to differences in the pathogenesis of the infection. I further hypothesize that $T$. pseudospiralis may be less damaging to the host than is $T$. spiralis. The unique pathology and extensive inflammatory and immune reactions in tissue infected with $T$. spiralis, but not seen in $T$. pseudospiralis infections, may be related directly to serum cortisol levels and/or to tissue damage and the subsequent woundhealing cascade.

The profound differences seen in the pathogenesis of the infection may be evolutionary divergence in the host-parasite relationship as it has developed over time. This postulated divergence suggests that $T$. pseudospiralis may be the most genetically 
distinct of the various Trichinella species. These differences in the relationship between T. spiralis and T. pseudospiralis and the host are measurable phenomenon. A number of ways to establish how the host responds to Trichinella infection will be outlined below. Therefore, in order to ascertain the causes of these differences between $T$. spiralis, T. pseudospiralis and the host, I attempted to answer the following questions:

- Is cortisol a factor in the differences of the host response to $T$. spiralis or $T$. pseudospiralis in $\mathrm{BALB} / \mathrm{c}$ mice?

- Are there differences in the leukocyte response in the peripheral blood of Trichinella-infected BALB/c mice when the two species of worm are compared?

- Are there differences in the up-regulation or down-regulation of cell surface molecules on splenic leukocytes in Trichinella-infected BALB/c mice?

- Is there a difference in the degree of damage to the host myofibers, as measured by serum creatine phosphokinase, when infections by the two species of Trichinella are compared?

- Are there differences in angiogenesis and collagen deposition in Trichinellainfected BALB/c mice and are these differences related to cortisol?

- Is nitric oxide a component in parasite killing in Trichinella infections and are there differences in the levels of nitric oxide in $T$. spiralis-infected animals when compared to animals infected by $T$. pseudospiralis?

In the following chapters, I present results on creatine phosphokinase (CPK) assays of the peripheral blood of Trichinella-infected mice and of uninfected controls. Creatine phosphokinase can be used to directly ascertain the degree of muscle damage 
in mammalian myocytes. In addition, the peripheral blood level of the inflammatory and antimicrobial molecule nitric oxide (NO) was assayed in both Trichinella-infected mice and in uninfected controls.

To determine the role of cortisol in nurse cell formation and collagen synthesis, formalin-fixed, paraffin-embedded muscle tissue stained with Masson's Trichrome was examined using Trichinella infected mice, uninfected controls and in Trichinellainfected mice that had undergone adrenalectomy (ADX). Counts of surviving larvae were performed in infected animals and compared to infected mice that had undergone adrenalectomy before infection. I also performed larval counts in adrenalectomized mice that had replacement cortisol (dexamethasone) therapy.

A method suitable to demonstrate and quantitate the angiogenic response in infected mice was utilized in live whole-mount tissue employing a florescently-labeled lectin against a specific molecule found only on endothelial cells.

Finally, I present results on the host immune and inflammatory response to the presence of the parasite using flow cytometric analysis of cell surface clusters of determinates (CD) molecules. Results include the response of $\mathrm{B}$ cells, $\mathrm{T}$ cells, monocytes/macrophages and granulocytes within the spleen employing flow cytometry and using monoclonal antibodies to the appropriate $\mathrm{CD}$ antigens in uninfected control mice and in mice infected with one of the two species of Trichinella. I also present data on leukocyte responses in peripheral blood that were assayed manually using standard staining techniques. 


\section{CHAPTER TWO}

\section{NITRIC OXIDE AND CREATINE PHOSPHOKINASE \\ IN MICE INFECTED WITH TRICHINELLA SPIRALIS}

\section{OR TRICHINELLA PSEUDOSPIRALIS}

The role of nitric oxide (NO) in the inflammatory response to infectious agents has been well documented (Klemm, et al 1995; Jacobs, et al 1995; Liew, et al 1997; Bogden, et al 1997; Mossalayi, et al 1999). Nitric oxide also has been demonstrated to have a role in the intestinal phase of Trichinella infections (Hogaboam, et al 1996).

Nitric oxide is a small, 30Da, multifunctional molecule with a half-life of approximately 30 seconds in biological systems. Nitric oxide (NO) is very toxic and is known to act as a mediator of cytotoxicity in host defense (Lincoln, 1997). As an uncharged gaseous molecule, it diffuses freely within cells and across cell membranes. Nitric oxide is produced by a number of different cell types including endothelial cells, neurons, certain lymphocytes and by activated macrophages (Lincoln, 1997).

Nitric oxide is synthesized by one of three isoforms of the enzyme nitric oxide synthase (NOS) (Ghosh, et al 1999; Pollack, et al 1991; Bredt, et al 1990). The Type I, Type II and Type III isoforms are distinguished from each other based on whether they are constitutively (cNOS) expressed or are induced (iNOS). Types I and III NOS are $\mathrm{Ca}^{2+}$ dependent and are expressed constitutively. Type II NOS is inducible and is $\mathrm{Ca}^{2+}$ independent. Cell types synthesizing Type II iNOS include macrophages, phagocytic mesangial cells, astrocytes, microglia, splenocytes, neutrophils and select subsets of T 
lymphocytes (Barnes and Liew, 1995). Natural killer cells and T helper 1 (Th1) cells both synthesize Type II iNOS but Th2 cells do not synthesize NO (Lincoln, 1997). In addition, a large number of non-immune cells types including hepatocytes, fibroblasts and endothelial cells can synthesize Type II iNOS (Kroncke, et al 1995).

Control of Type II iNOS is regulated by a number of cytokines and other agents (Murphy, et al 1993; Wynn, 1997). Activating or enhancing agents include TNF, IFN$\gamma, \mathrm{IL}-1, \mathrm{LL}-2$, certain heat shock proteins and low concentrations of NO (Kroncke, et al 1995). Contrarily, IL-4, IL-6, IL-8, high concentrations of NO or prostaglandin E2 (PGE2) may inhibit iNOS.

The cytotoxic effects of NO on target cells consist of damage to ion channels, transport proteins, mitochondrial membrane potential, Fe-sulfur and Zn-finger clusters in proteins, inhibition of mitochondrial enzymes and/or direct damage to DNA (Kroncke, et al 1995; Nussler and Billiar, 1993). Thus, NO may inactivate enzymes that are essential for energy metabolism and growth of invading parasites (James, 1995). Excess NO production by the iNOS can damage the host by killing lymphocytes, chondrocytes, pancreatic islets, vascular smooth muscle cells and hepatocytes (Nussler and Billiar, 1993). Although the toxic effect of $\mathrm{NO}$ on a variety of pathogens has been shown, no work has been reported on the possible role of NO in inflammation caused by the larval stage of the parasitic nematode Trichinella.

The role of NO in the inflammatory response to infectious agents has been well documented (Klemm, et al 1995; Jacobs, et al 1995; Liew, et al 1997; Bogden, et al 1997) In response to inflammatory stimuli, $\mathrm{NO}$ is produced in micro molar $(\mu \mathrm{M})$ 
amounts by macrophages and neutrophils, Th1 lymphocytes and by non-immune cells including endothelial cells. Nitric oxide, whether constitutively produced or induced, reacts rapidly with other molecules in biological fluids as detailed below:

$$
\begin{gathered}
\mathrm{NO}+\mathrm{O}_{2}^{-} \rightarrow \mathrm{ONO}_{2}^{-}+\mathrm{H}^{+} \rightarrow \mathrm{NO}_{3}^{-}+\mathrm{H}^{+} \text {or } \\
2 \mathrm{NO}+\mathrm{O}_{2} \rightarrow \mathrm{N}_{2} \mathrm{O}_{4}+\mathrm{H}_{2} \mathrm{O} \rightarrow \mathrm{NO}_{2}^{-}+\mathrm{NO}_{3}^{-} \text {or } \\
\mathrm{NO}+\mathrm{NO}_{2}^{-} \rightarrow \mathrm{N}_{2} \mathrm{O}_{3}+\mathrm{H}_{2} \mathrm{O} \rightarrow 2 \mathrm{NO}_{2}^{-}
\end{gathered}
$$

As can be seen, nitric oxide is present only transiently in serum and the final products of NO synthesis in vivo are nitrite and nitrate. Since the relative proportions of nitrite and nitrate are unpredictable, the best gauge of NO production is the sum of both nitrite and nitrate levels in serum (Ellis, et al 1998).

Stimulated macrophages appear to be a major effector cells in Trichinella infections and may be of particular importance in T. spiralis infected animals. Hirji, et al (1998) found that NO synthesis in rats could be initiated by stimulation of the macrophage CD8 marker. The CD8 marker of macrophages differs from the $T$ cell CD8 in its ligand-binding region. This finding indicates a role for both stimulated macrophages and NO production in the killing of parasites in vivo. The findings of Hirji, et al was confirmed by Taylor-Robinson et al (1996) who found that NO played a significant role in the parasitemia of mice infected with Plasmodium chabaudi.

Thomas, et al (1997) and Maeda and Akaike (1998) found that INF- $\gamma$ stimulated macrophages produced NO that severely damaged the microfilaria of Brugia malcyi in vitro. Knockout or genetically altered mice deficient in iNOS (iNOS-/-) 
displayed defective antimicrobial activity further demonstrating the importance of NO in parasite killing (Scharton-Kerston, et al 1997).

Certain parasites may be able to suppress NO synthesis (Ruhl and Collins, 1997). T. pseudospiralis has been reported to suppress the immune response in mammals (Alford, et al 1998). The results reported by Mehdizadehkashi (1995) showed a decreased level of prostaglandin E2 (PGE2) in T. pseudospiralis-infected mice and increased levels of PGE2 in T. spiralis- infected mice. High levels of PGE2 have been shown to be associated with low levels of NO and low levels of PGE2 have been associated with high levels of NO.

Creatine phosphokinase (CPK) is well accepted as an indicator molecule for ascertaining the level of muscle damage in mammals and in other species (Martin, et al 1997; Mizutani, et al 1996; Chen, et al 1997; Fukuuchi, et al 1996). In damaged muscle, the amount of CPK released may increase dramatically (Giltay, et al 1999; Pagel and Partridge, 1999). Creatine phosphokinase catalyzes the phosphorylation of adenosine-5'-diphosphate (ADP) to adenosine-5'-triphosphate (ATP) and free creatine (Qin, et al 1999; Felice and North, 1998). This reaction is monitored by following the formation of the end product, inorganic phosphate ( $\mathrm{Pi}$ ) (Ellis, et al 1998). Inorganic phosphate may then be quantitated. The level of inorganic phosphate released is equivalent to CPK activity and, therefore, can be correlated to the level of larval damage to the cell. 
The aim of this research is twofold. First, to discover if there are differences in the amount of NO produced between T. spiralis and T. pseudospiralis. Secondly, to measure the levels of CPK activity in mice infected with T. spiralis or T. pseudospiralis determine which of the two species is more damaging to host striated muscle. To answer these questions, I measured the levels of CPK and NO in the peripheral blood of mice after infection with T. spiralis or T. pseudospiralis and in uninfected control mice.

Because lipopolysaccharide (LPS) is a known stimulant of the innate inflammatory response (Wolf, et al 1996; Drenth, et al 1996), it was used as my positive control. 


\section{MATERIALS AND METHODS}

\section{SERUM NITRIC OXIDE ASSAY}

For each NO and CPK experiment, 15 BALB/cAnNTacfBR (BALB/c) inbred mice were used. The BALB/c mice were supplied by Taconic Laboratories, Inc.. All mice were female and approximately 3 months old. Five mice received $T$ spiralis larvae, five mice received $T$. pseudospiralis larvae and 5 mice were used as uninfected controls. The L1 infective stage used for infection were in the muscle of a maintenance infection in BALB/c mice. Larvae were counted manually in infected diaphragm tissue from the maintenance infections and fed to the recipient mice at 250 larvae per mouse. The postinfection blood samples were collected 14 days after infection. All mice were kept according to State of Oregon standards for the care of research animals. Food and water were supplied ad libitum. The mice were kept on a 12-hour day/night regimen and the bedding was pine shavings.

Blood samples $(500 \mu \mathrm{l} / \mathrm{mouse})$ were collected from infected and control mice using the tail clip technique. The blood from the caudal vessels was drawn into nonheparinized collection tubes. Blood samples were allowed to clot for 30 minutes at room temperature, ringed, and centrifuged at $500 \mathrm{xG}$ for 10 minutes at room temperature to separate the serum from the cells.

Serum $(150 \mu \mathrm{l})$ was carefully withdrawn and transferred to a Centriprep (Amicon) $10,000 \mathrm{mw}$ cutoff concentrator for ultra filtration. Samples were centrifuged for 45 minutes at $4^{\circ} \mathrm{C}$ at $3000 \mathrm{xG}$. The supernatant was transferred to a microfuge tube and 
placed at $4^{\circ} \mathrm{C}$. Each sample was assayed in triplicate using a colorimetric nitric oxide assay kit (Cayman Chemical). Following the directions of the manufacturer, a $40 \mu \mathrm{l}$ serum sample was diluted with $40 \mu$ l of assay buffer, $10 \mu \mathrm{l}$ of enzyme cofactor and $10 \mu \mathrm{l}$ of nitrate reductase. Both standards and unknown samples were added to a 96 well micro titer plate and incubated for 3 hours at room temperature with shaking at $30 \mathrm{rpm}$ on an Eberbach reciprocal shaker. At the end of 3 hours, Griess reagents numbers 1 and 2 were added to all samples and control wells. The color was allowed to develop for 10 minutes at room temperature. Plate contents were assayed at $640 \mathrm{~nm}$ using an automated micro plate reader (Biotek). The triplicate readings from each sample were averaged. A standard curve was developed using nitrite/nitrate standards (Cayman Chemical) and was run with each set of samples. The standard curve was used to ascertain NO levels as $\mu \mathrm{M}$ nitric oxide/mouse.

\section{CREATINE PHOSPHOKINASE ASSAY}

Mice were kept and infected in the same manner and in the same numbers as the

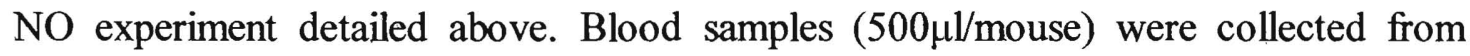
infected and control mice using the tail clip technique. The blood from the caudal vessels was drawn into heparinized collection tubes (Becton-Dickinson). Blood samples were centrifuged at $500 \mathrm{xG}$ for 10 minutes at room temperature. The serum was withdrawn into $15 \mathrm{ml}$ tubes and kept at $4^{\circ} \mathrm{C}$. The $\mathrm{CPK}$ assay was performed using a CPK assay kit (Sigma Diagnostics) and following the manufacturer's directions. Briefly, serum samples were diluted 1:3 with Tris- $\mathrm{HCl}$ buffer ( $\mathrm{pH}$ 7). One milliliter of creatine solution and $1 \mathrm{ml}$ of $\mathrm{H}_{2} \mathrm{O}$ was added to each tube. Tubes were held in a $37^{\circ} \mathrm{C}$ 
water bath for 5 minutes. To start the reaction, $100 \mu \mathrm{l}$ of ATP-glutathione solution was added to each tube. The tubes were held at $37^{\circ} \mathrm{C}$ for 30 minutes. The reaction was terminated by the addition of $1.6 \mathrm{ml}$ of cold $\left(4^{\circ} \mathrm{C}\right)$ trichloroacetic acid (TCA). All tubes were centrifuged at $1500 \times \mathrm{xG}$ for 5 minutes and the supernatant transferred to a cuvet containing $4 \mathrm{ml}$ of $\mathrm{H}_{2} \mathrm{O}, 1 \mathrm{ml}$ of acid molybdate and $250 \mu \mathrm{l}$ of Fiske and SubbaRow solution (1-amino-2-napthol-4-sulfonic acid containing $0.8 \%$ sodium sulfite/sodium bisulfite). The tubes were held for 5 minutes at room temperature to allow the hydrolysis of phosphocreatine. A standard curve was developed using a known inorganic phosphate standard. All tubes were assayed for inorganic phosphate at $630 \mathrm{~nm}$ in triplicate using a standard spectrophotometer and the results from each triplicate sample were averaged. All nitric oxide and creatine phosphokinase experiments were repeated four times in an identical manner for a total of 60 mice used for each assay.

Following the blood collections at day 14 post-infection and at an average of 31 days post-infection, all mice used in the CPK and NO experiments were sacrificed by cervical dislocation and the L1 infectious stage larvae present in whole mounts of the diaphragm were counted manually using a dissecting microscope at $30 \mathrm{x}$.

For each LPS-mediated CPK or NO assay, four mice were given LPS at dosages of $6.25,12.5,25.0$ or $50.0 \mathrm{mg} / \mathrm{kg} /$ mouse diluted in $250 \mu \mathrm{l}$ of normal saline in a single injection intraperitoneally (ip). A fifth mouse was given $250 \mu$ l of saline ip. Before any treatments, an initial blood sample was drawn from each mouse one week prior to LPS injection to serve as a baseline for NO and CPK. Blood was collected from the five 
mice at 6 hours post-injection. The LPS-mediated CPK or NO assays were prepared as detailed above. The LPS experiment was repeated once for a total of 10 mice.

All results for the nitric oxide, creatine phosphokinase and LPS assays were statistically analyzed using the student's t-test. 


\section{RESULTS}

\section{NITRIC OXIDE}

Levels of NO in the peripheral blood serum of infected animals were significantly different from controls $(\mathrm{P}<0.05)$. As shown in Figure 2.1, it can be seen that the levels of serum NO in control mice were consistently below $1 \mu \mathrm{M} \mathrm{NO} /$ sample (average $0.9 \mu \mathrm{M}$ $\mathrm{NO} /$ sample). In infected mice, those infected with T. pseudospiralis showed an average of $10.1 \mu \mathrm{M} \mathrm{NO} /$ sample while mice infected with $T$. spiralis had NO levels that averaged $6.3 \mu \mathrm{M} \mathrm{NO} /$ sample. The NO baseline results did not differ significantly from controls (data not shown). If the control animal level of NO is subtracted, T. pseudospiralis had approximately $2 \mathrm{X}$ the amount of NO/sample than did $T$. spiralis.

\section{CREATINE PHOSPHOKINASE}

As shown in Figure 2.2, there were significant $(\mathrm{P}<0.05)$ differences in the in the amount of CPK present in the serum of $T$. spiralis infected mice when compared with serum from mice infected with T. pseudospiralis. The level of CPK in uninfected control mice was substantially $(\mathrm{P}<0.05)$ lower than in infected animals. In $T$. spiralis infected mice, CPK levels averaged $20.1 \mu \mathrm{g} \mathrm{Pi} /$ sample. This contrasts with $T$. pseudospiralis infected mice that averaged $11.7 \mu \mathrm{g} \mathrm{Pi} /$ sample. Uninfected control mice and the LPS treated mice averaged 5.8 $\mu \mathrm{g}$ Pi/sample. The CPK baseline results did not differ significantly from the controls (data not shown). 


\section{LIPOPOLYSACCHARIDE}

As shown in Figure 2.3, dosage levels of LPS at $6.25,12.5,25.0$ or $50.0 \mathrm{mg} / \mathrm{kg} / \mathrm{mouse}$ resulted in the production of an average of $7.7,12.9,17.3$ and $21.8 \mu \mathrm{M} / \mathrm{NO} / \mathrm{blood}$ sample. Mice receiving LPS showed an increase in blood NO in a non-linear but still dose-related manner. Thus, it appears that the level of nitric oxide is approximately proportional to the degree of inflammation as caused by LPS.

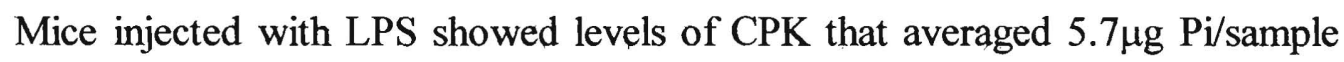
that is not significantly different from the control animals (data not shown) suggesting that LPS does not stimulate CPK production under the experimental conditions detailed here. 


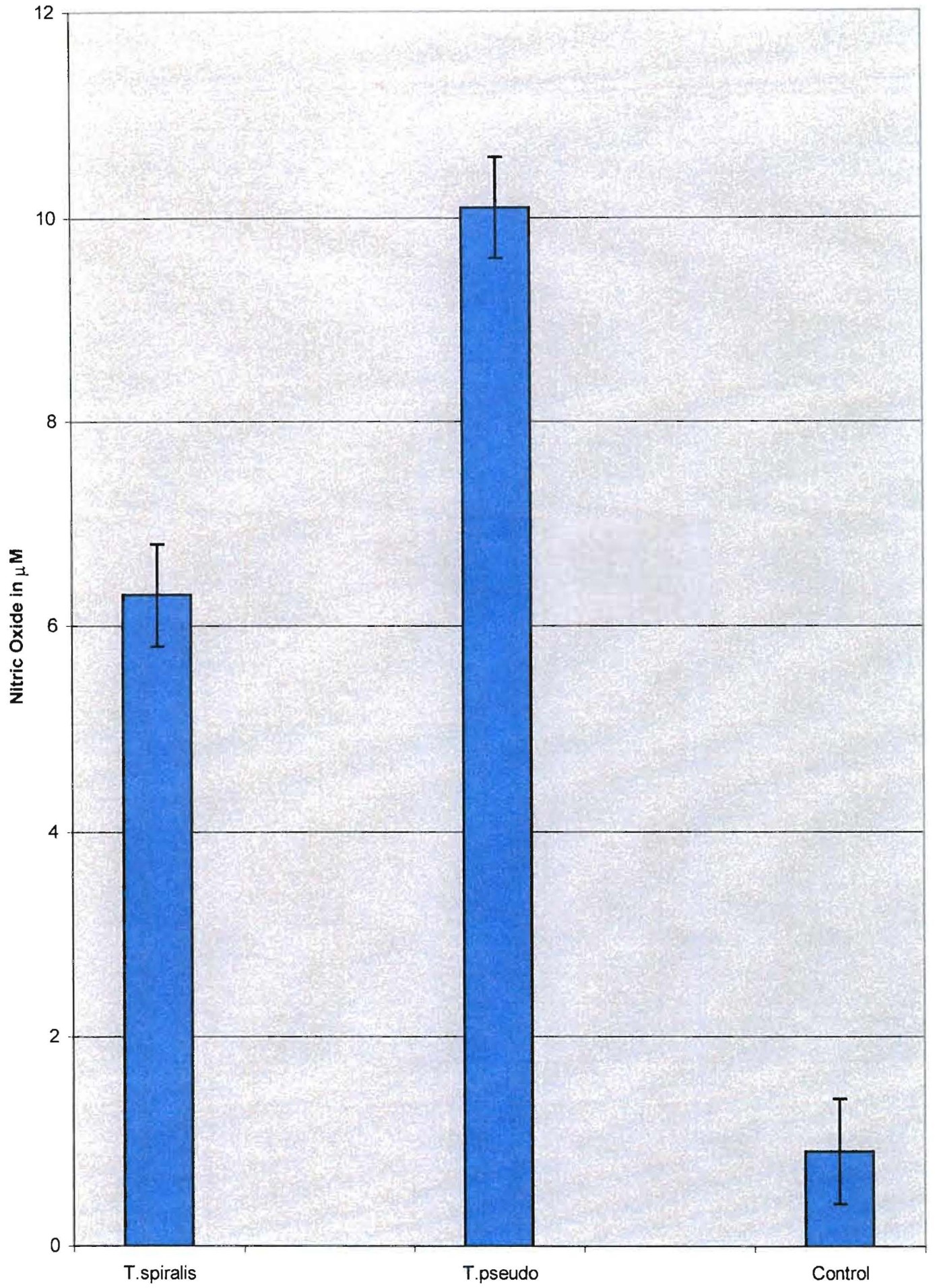

Figure 2.1: Nitric Oxide. Nitric oxide data represents the average of four expermients. $(n=60$. T.spiralis : mean $=6.26 ; \mathrm{SD}=0.336$. $T$.pseudospiralis : $m e a n=10.3$; $\mathrm{SD}=0.509$. Control: mean $=0.84, \mathrm{SD}=0.089$ ). 


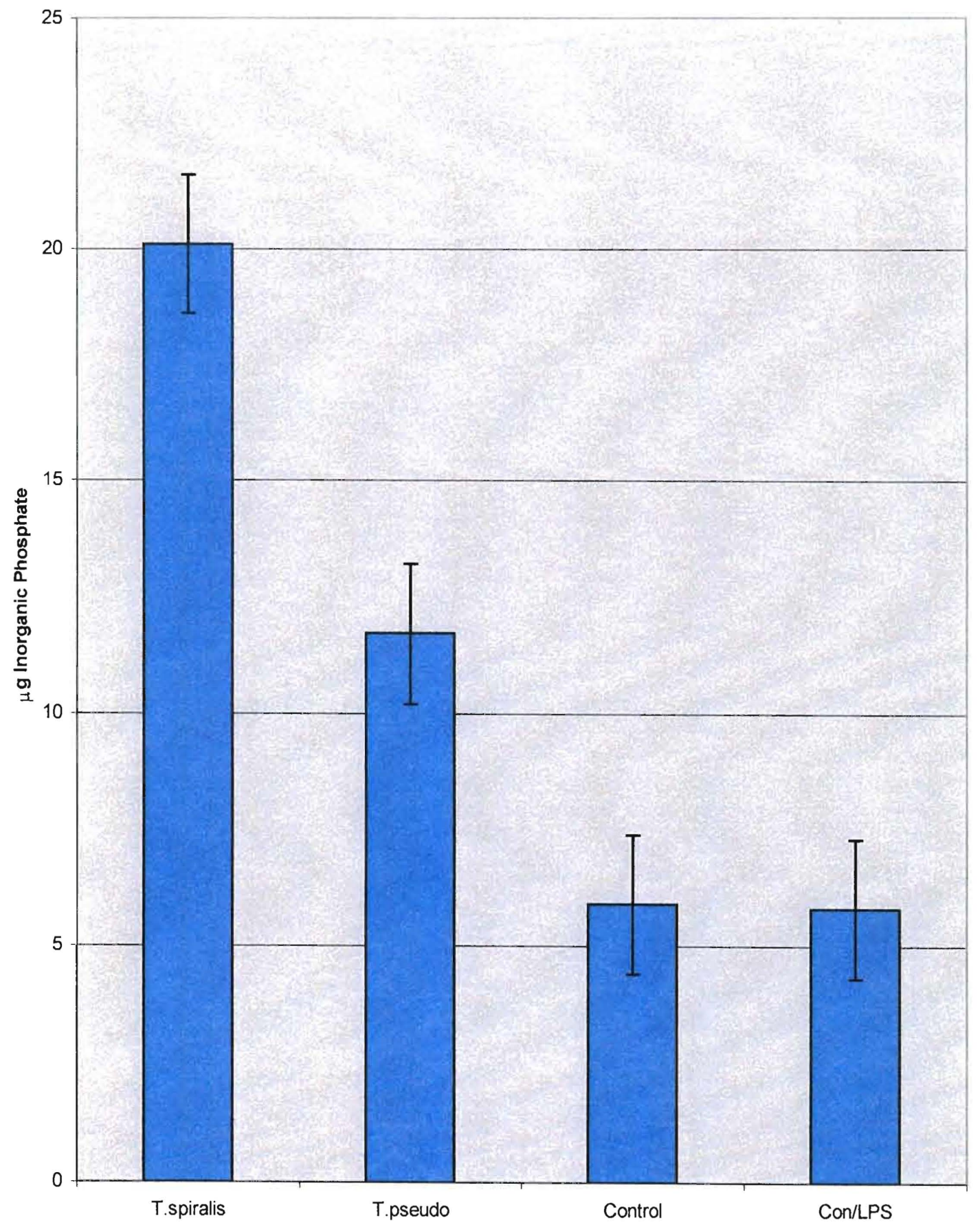

Figure 2.2: Creatine Phosphokinase in Trichinella -Infected Mice as determined by the measurement of inorganic phosphate. $n=60$. $T$.spiralis: mean=6.35, SD=0.129.

T.pseudospiralis: mean $=10.15, \mathrm{SD}=0.129$. Control: mean $=0.85, \mathrm{SD}=0.057$. 


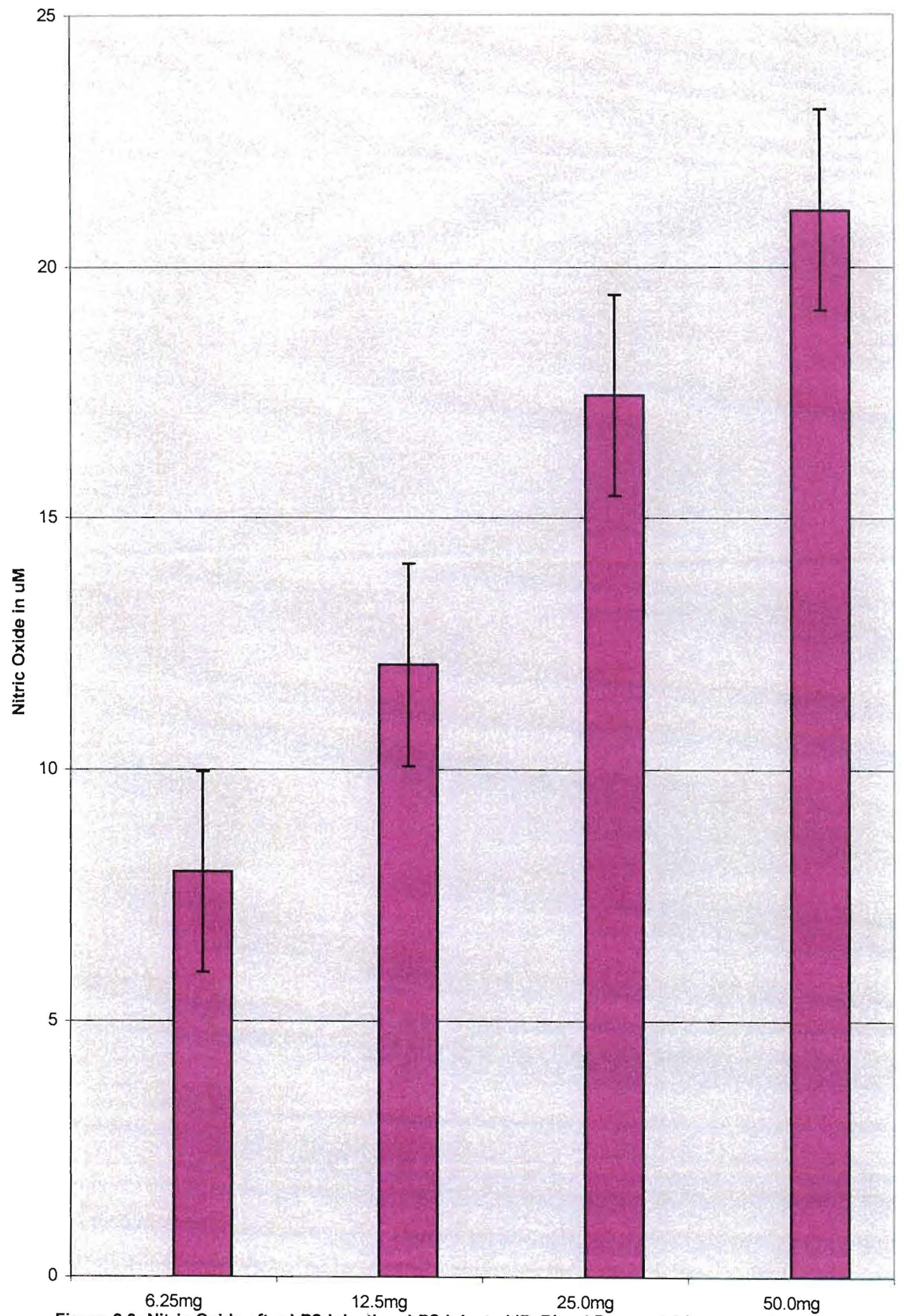

Figure 2.3: Nitric Oxide after LPS Injection. LPS injected IP. Blood Drawn at 6 hours postinjection. $n=8.6 .25 \mathrm{mg}$ : mean $=7.96, \mathrm{SD}=0.194 .12 .5 \mathrm{mg}$ : mean=12.06, $\mathrm{SD}=0.658$. $25.0 \mathrm{mg}$ : mean $=17.44, S D=0.456$. $50 \mathrm{mg}$ : mean $=21.14, \mathrm{SD}=0.965$. 


\section{DISCUSSION}

\section{NITRIC OXIDE}

The data shown in Figure 2.1 indicate that mice infected with T. pseudospiralis have a significantly $(\mathrm{P}<0.05)$ larger NO response than do mice infected with $T$. spiralis. Levels of NO averaged more than 11 times higher in T. pseudospiralis than in controls and an average of 2 times higher than in $T$. spiralis infected mice. Because PGE2 is known to have a down-regulating effect on NO production (Hrabak, et al 1998), one might postulate that $T$. spiralis infected mice would demonstrate a lower serum NO level than would mice infected with T. pseudospiralis due to the higher levels of PGE2 in mice infected with T. spiralis (Mehdizadehkashi, 1995). We have demonstrated that this is the case. In addition, there are substantial differences in NO production between infected animals and uninfected controls.

Nitric oxide can be used as an indicator of the degree of inflammation and is also an indicator of NO mediated cytotoxicity (Liew, et al 1997; Bogden, et al 1997; Hoagaboam, et al 1996). Our data supports these results and indicates a role for NO as a host defense mechanism against Trichinella. Our data also agrees with reports of other workers that NO is important in host defense against other helminthic parasites including cestodes (Kanazawa, et al 1993), trematodes (Oswald, et al 1994), and nematodes (Rajan, et al 1996; Marzio, et al 1990).

Macrophages are prominent responder cells in the muscle phase of Trichinella infections. Macrophages secrete NO as an important mediator of parasite killing in vivo. When other investigators used chloroquine to stop the macrophage production of 
NO by iNOS, parasite killing was severely compromised in animals infected with the protozoan parasite Trypanosoma cruzi (Hrabak, et al 1998). Hayashi, et al (1996) used aminoguanidine, a structural analog of L-arginine, to block NO synthesis in mice infected with Toxoplama. Blocking NO production in Toxoplasma-infected mice resulted in substantially increased parasite loads and lowered survival rates in infected animals. Our experiments with aminoguanidine in Trichinella infected mice (data not shown) resulted in increased parasitemia in both the intestinal and muscle phases. This finding further emphasizes the important role for NO mediated parasite killing in animals infected with Trichinella. Our findings with respect to the role of NO in parasite killing are supported by the work of Liew, et al (1999) in Leishmania infections; and by Burgner, et al (1999) and MacMicking, et al (1997) who reported NO protection against various viruses, bacteria, fungi, protozoa, helminths and tumor cells.

Trichinella spiralis infected animals have demonstrated levels of PGE2 that are considerably higher than those found in T. pseudospiralis. Hayashi, et al (1996) found that high NO production coupled with high PGE2 production acted to inhibit lymphocyte proliferation. We did not find this in Trichinella infections in BALB/c mice under the experimental conditions detailed here although, in T. spiralis infected mice, peripheral blood lymphocytes are present in significantly fewer numbers than those present in T. pseudospiralis infected mice (data not shown). This may be due to high PGE2 and low NO levels in $T$. spiralis infected mice when compared with $T$. pseudospiralis infected mice. In addition, Hayashi, et al (1996) found that inhibition of 
both NO and PGE2 with indomethacin restored the lymphocyte proliferative response and cytokine production, thus preventing cell death. They suggested that these contrasting effects of NO might contribute to the chronic state of some parasitic infections. McCann, et al (1997) found that NO directly influenced the production of hypothalamic-induced or derived peptides including the prostaglandins and the leukotrienes.

McCann, et al (1997) reported that NO stimulates the release of corticotrophinreleasing factor (CRF) and adrenocorticotropic hormone (ACTH) which, in turn, stimulates the release of cortisol. McCann further suggests that NO activates cyclo-and lipooxygenases thereby liberating PGE2 and leukotrienes respectively. Cortisol, in turn, down-regulates PGE2 production (Patel, et al 1999; Otsuki and Oku, 1995). This HPA axis feedback mechanism helps to explain our findings of high NO levels in $T$. pseudospiralis coupled with high cortisol levels and low PGE2 levels. It further helps to explain the lower NO and cortisol levels in T. spiralis coupled with high PGE2 levels.

The stimulated macrophage appears to be a major effector cell in Trichinella infections and may be of particular importance in $T$. spiralis infected animals. Hirji, et al (1998) found that NO synthesis in rats could be initiated by stimulation of the macrophage CD8 marker. The CD8 marker of macrophages differs from the $\mathrm{T}$ cell CD8 in its ligand-binding region. This finding indicates a role for both stimulated macrophages and NO production in the killing of parasites in vivo. This is further confirmed by the findings of Taylor-Robinson et al (1996) who found that macrophage- 
derived NO plays a significant role in the parasitemia of mice infected with Plasmodium chabaudi. In addition, Thomas, et al (1997) and Maeda and Akaike (1998) found that INF- $\gamma$ stimulated macrophages produced NO (specifically peroxynitrite) that was severely damaging to the microfilaria of Brugia malayi in vitro. Knockout mice deficient in iNOS (iNOS-/-) displayed defective antimicrobial activity further demonstrating the importance of NO in parasite killing (Scharton-Kerston, et al 1997).

Despite the importance of macrophage derived NO in parasite infections, my results showed T. spiralis infected mice exhibit lower than predicted NO levels in serum. There are several possible explanations for the NO levels measured in T. spiralis infected mice. The most reasonable explanation was fostered by Milana, et al (1995) who demonstrated that higher than normal levels of PGE2 suppress the iNOS in vivo. This research also showed that low levels of PGE2 stimulate the iNOS. In addition, Kunz, et al (1996) showed that high levels of glucocorticoids like cortisol suppress iNOS through PGE2. Conversely, high levels of IL-1 generally correlate to an increase in NO production in vivo (Kroncke, et al 1995). This latter role for IL-1 does not appear to be a factor in Trichinella-infected BALB/c mice. The low levels of PGE2 and the high levels of IL-1 $\beta$ in T. pseudospiralis infected mice and the high levels of PGE2 in T. spiralis infected mice (Mehdizadehkashi, 1995) may account for these observations. The seemingly paradoxical and conflicting roles of NO, PGE2 and IL-1 in inflammation and their relationship to the HPA axis has been documented by other researchers (Zidek and Masek, 1998). Despite this, NO appears to play a significant role in eliminating both species of Trichinella from BALB/c mice under the 
experimental conditions detailed here. Nitric oxide is, therefore, an important effector mechanism in the non-specific immune response against Trichinella in mice. 


\section{CREATINE PHOSPHOKINASE}

The level of muscle damage as measured by CPK was significantly higher in $T$. spiralis infected mice when compared to mice infected with T. pseudospiralis $(\mathrm{P}<$ 0.05 ) as illustrated in Figure 2.2. I had hypothesized that $T$. spiralis, because of the induction of changes to cellular architecture (Despommier, 1975) as described in the introduction, would cause more damage to muscle fibers than would T. pseudospiralis. My findings have confirmed that this is the case. There was an approximate increase of $170 \%$ in serum CPK $(20.1 \mu \mathrm{g}$ versus $11.7 \mu \mathrm{g})$ in $T$. spiralis infected mice when compared to T. pseudospiralis infected mice and an increase of approximately $345 \%$ $(20.1 \mu \mathrm{g}$ versus $5.8 \mu \mathrm{g})$ over controls. These data are supported by the findings of Gregor, et al (1999) and Yoshimura, et al (1999) in experiments with rats with artificially induced muscle damage. Measurement of CPK isoenzymes (CK-MB) has been shown to be an accurate diagnostic tool for ascertaining the level of ischemic damage in cardiac muscle (De Winter, et al 1998) and in amytrophic lateral sclerosis (ALS) damaged skeletal muscle in human beings (Felice and North, 1998).

Muscle damage, as it occurs in all Trichinella infections, may stimulate an inflammatory response that is both related and proportional to the severity of the damage (Nathan, et al 1997; Panteghini, et al 1999). Trichinella spiralis infected animals have more inflammatory cells around the L1 larvae than is seen in $T$. pseudospiralis infected animals. The presence of these cells could be related to the severity of the damage and may contribute to cytokine variations. The inflammatory cells in $T$. spiralis infected mice may secrete products that cause muscle damage, inhibit 
iNOS or modify the HPA axis. In addition, during the macrophage response to the presence of the parasite or parasite antigens, healthy cells may be damaged further exacerbating the inflammation and changing the CPK profile. Other workers have also noted a complex relationship between systemic inflammatory syndrome, muscle injury, cytokine release and the HPA axis in mammals (Martin, et al 1997; Bolton, 1996). Stewart, et al (1999) also noted a complex interplay between Th1 and Th2 subsets and cytokine release during Trichinella spiralis infections.

Trichinella spiralis and, to a lesser extent, T. pseudospiralis contribute to the ischemic (hypoxic) condition of Trichinella-infected myocytes. And, as stated above, the activity of CPK has been shown to be a reliable indicator of muscle damage (including ischemic damage) in vivo in human beings (Kawaguchi, et al 1997; Panteghinni, et al 1999; Kemp, et al 1998; Cuono, et al 1998) and in rodents (Knipper, et al 1996). Assays for CPK have also been used as a model system to measure ischemic injury in the skeletal muscle of BALB/c mice (Carter, et al 1998). Mizutani, et al (1996) found a correlation between virally induced endocarditis in BALB/c mice and increased CPK activity. Other researchers have found a strong correlation between Nematodirus and Strongyloides helminthic infections in mammals and CPK levels (Haroun, et al 1996). T. pseudospiralis has been shown to cause increases in CPK in human beings (Jongwutiwes, et al 1998). Cortisol, however, has no apparent effect on CPK production in vivo as suggested by Goddard, et al (1997) allowing us to rule out cortisol as a mediator molecule in CPK production in Trichinella infected mice. It is 
known, however, that CPK production can be linked to hypoxia and the uncoupling of the mitochondrial cycles (Kemp, et al 1998; Cuono, et al 1998; O'Gorman, et al 1996).

As was stated in the introduction, $T$. spiralis induces changes in the architecture of the infected myocyte including functional changes in the host mitochondria. This is not the case with $T$. pseudospiralis-infected animals. Therefore, I conclude that the presence of $\mathrm{CPK}$ in $T$. spiralis-infected BALB/c mice is directly proportional to the damage to the myocyte (including hypoxic damage) and that the myocyte damage caused by T. pseudospiralis is significantly less. Thus, this damage and the subsequent wound-healing cascade are the primary etiological events in the pathological and physiological sequelae seen in $T$. spiralis-infected mice but not in $T$. pseudospiralis infections.

\section{LIPOPOLYSACCHARIDE}

As seen in Figure 2.3, LPS induced NO production after an exposure time of 6 hours. This indicates that NO levels provide a reliable method to ascertain the degree of inflammation in vivo. Our data further shows that CPK is not influenced by LPS under these experimental conditions.

The measuring of $\mathrm{NO}_{3}^{-}$and $\mathrm{NO}_{2}^{-}$, the stable metabolites of $\mathrm{NO}$ synthesis in serum has been found to be a dependable indicator of the severity of the inflammatory response to parasites such as Eimeria tenella in vivo (Allen, 1997). Others have also shown the importance of cytokines like INF- $\gamma$, transforming growth factor- $\beta$ (TGF- $\beta$ ) and tumor necrosis factor (TNF) in up-regulating NO synthesis during parasitic infections (Diefenbach, et al 1998; Vieira, et al 1996). 
As hypothesized, LPS had a profound effect on NO production under the experimental conditions detailed here. As an exogenous priming agent, LPS stimulates an inflammatory response in vivo. This response includes the activation of the alternative complement cascade. The complement cascade in Trichinella-infected mice is activated primarily via the alternative pathway. Lipopolysaccharide reacts with LPS binding proteins produced by animals and human beings and this complex reacts with CD14 on monocytes and macrophages resulting in the release of IL-1, IL-6 TNF, NO and platelet activating factor (PAF). These cytokines and chemokines stimulate the production of prostaglandins and leukotrienes (Atlas, 1997). As discussed previously, NO production is stimulated by IL-1, TNF and PAF.

Under the experimental circumstances discussed here, LPS had no appreciable effect on CPK production in mice. This finding suggests that the mechanism(s) that stimulate CPK production may not be directly associated with IL-1, TNF or PAF and differs from the mechanism(s) that generate NO in vivo. Lipopolysaccharide is, therefore, an efficient positive control for measuring NO but not CPK production in vivo in $\mathrm{BALB} / \mathrm{c}$ mice. 
CHAPTER THREE

\author{
ANGIOGENESIS, COLLAGEN DEPOSITION, \\ LARVAL SURVIVAL, AND PERIPHERAL BLOOD COUNTS \\ IN MICE INFECTED WITH TRICHINELLA AND IN TRICHINELLA- \\ INFECTED ADRENALECTOMIZED MICE
}

\title{
INTRODUCTION
}

\begin{abstract}
ANGIOGENESIS
The intracellular parasite Trichinella spiralis, having entered the striated muscle niche, causes a number of profound changes to the striated muscle fiber. Trichinella pseudospiralis does not elicit these major changes but does cause minor changes. Despommier (1975) reported that T. spiralis elicits an angiogenic response beginning on day 12 post-muscle penetration and this response continues until a rete of new capillaries is formed around the nurse cell. Trichinella pseudospiralis does not cause the formation of a nurse cell with a capillary rete.

Angiogenesis leading toward neovascularization is considered an important factor for maintaining normal tissues and is especially important in tissues where rapid cell division and growth are occurring (Banda, et al 1982). For example, angiogenesis is significant for tumor growth and in wound healing. It is known that several growth factors are involved in stimulating the formation of new capillaries. These factors
\end{abstract}


include fibroblast growth factor (FGF), angiogenin, transforming growth factors $\alpha$ and $\beta$ (TGF- $\alpha$, and TGF- $\beta$ ), tumor necrosis factor (TNF) and vascular endothelial growth factor (VEGF) (Leibovich et al, 1987). In Trichinella spiralis-infected mice, VEGF mRNA is present in the sarcoplasm as early as day 7 post-penetration and is still detectable after 8 months (Capo, et al 1998). The capillary rete is in close proximity to the collagen nurse cell allowing exchange of nutrients and metabolic waste products. The collagen of the nurse cell may act as scaffolding for the dividing and migrating endothelial cells that will form the capillary rete.

One of the stimulators of angiogenesis is the macrophage secreted TNF. The macrophage production of TNF can be stimulated by pathogens including viruses, bacteria, fungi, protozoa, and helminths. Macrophages and granulocytes (including neutrophils) are attracted to wounds (Folkman and Klagsburn, 1987) and may respond to the type of cellular injury seen in Trichinella infections as can be observed by identifying these cells in and around the nurse cell complex.

Responding macrophages and granulocytes may induce VEGF production through the release of inflammatory cytokines. In addition, hypoxia within the infected myofiber may induce the production of VEGF. Since T. pseudospiralis does not seem to induce angiogenesis and, because serum cortisol levels are up to four times higher in T. pseudospiralis infected animals, I investigated the possibility that cortisol has a role in suppressing the wound healing response in mice infected with Trichinella. To accomplish this I utilized a florescently-labeled lectin obtained from Griffonia simplicifolia -1 (GS-1) to analyze the extent of angiogenesis and neovascularization in 
Trichinella infected mice. This thiamine-labeled lectin is a marker for microvasculature and capillaries in skeletal muscle (Hansen-Smith, et al 1992a, Hansen-Smith, et al 1992b; Hansen-Smith, et al 1998). Specifically, GS-1 has an affinity for Nacetylgalactosamine groups.

\section{COLLAGEN SYNTHESIS}

Collagen synthesis is an essential part of the wound healing mechanism in vertebrates. Collagen synthesis is also part of the survival strategy of Trichinella spiralis and other encapsulating species of Trichinella and forms the nurse cell that surrounds the larvae. Collagen synthesis and deposition is inhibited by glucocorticoids (Delaney, et al 1995a; Guller, et al 1995) while collagenase activity is up-regulated (Delaney, et al 1995b). The unencapsulated T. pseudospiralis, using an unidentified mechanism, stimulates the host to increase the production of the glucocorticoid cortisol more than four fold over the level found in uninfected control mice. Because of the effect of cortisol on collagen synthesis, I examined muscle tissue in unadrenalectomized mice infected with Trichinella and in Trichinella-infected adrenalectomized mice using Masson's Trichrome. This staining method is used for (among other functions) the detection of all types of collagen. 


\section{LARVAL SURVIVAL}

Postulating that the glucocorticoid cortisol may have a role in larval survival for Trichinella and particularly the unencysted $T$. pseudospiralis, I compared the numbers of surviving larvae in mice with normal adrenal function with mice that had been adrenalectomized $(\mathrm{ADX})$ and thus have no endogenous cortisol. I also examined the effects of replacing cortisol in infected $\mathrm{ADX}$ mice with the synthetic drug dexamethasone. Dexamethasone produces a cortisol-like effect in mammals. 


\section{MATERIAL AND METHODS}

\section{PERIPHERAL BLOOD COUNTS}

Three month old female BALB/c mice were used for all experiments. For all experiments involving adrenalectomy, 18 unadrenalectomized control mice were infected orally with 250 LI stage Trichinella from previously infected mice. Nine mice received T. spiralis and nine received T. pseudospiralis. A second group of 18 mice underwent adrenalectomy. These adrenalectomized mice were allowed to recover for 30 days before infection. Following recovery, the second group of mice was infected in an identical manner as described above (i.e.: nine mice with $T$. spiralis and nine mice with T. pseudospiralis). A third group of 18 mice also underwent adrenalectomy and following a 30 day recovery period, were infected as above. Beginning 7 days postinfection, 9 mice in this third group of $\mathrm{ADX}$ mice received $16 \mu \mathrm{g}$ dexamethasone (dissolved in $250 \mu \mathrm{l}$ of $10 \% \mathrm{v} / \mathrm{v}$ ethanol with $90 \% \mathrm{v} / \mathrm{v}$ normal saline)/mouse/day. The other 9 mice received $250 \mu$ l of $10 \% \mathrm{v} / \mathrm{v}$ ethanol with $90 \% \mathrm{v} / \mathrm{v}$ normal saline without dexamethasone intraperitoneally (IP) daily for the course of the infection. Because dexamethasone is approximately 30 times stronger than cortisol (Casini-Raggi, et al 1995; Guthrie, 1991; Lane, et al 1990), I adjusted the standard dose of dexamethasone from the normal $480 \mu \mathrm{g} . \mathrm{kg} /$ day/mouse to $16 / \mu \mathrm{g} / \mathrm{kg} /$ day $/$ mouse.

All mice were bled by the tail clip method at $10,15,20,30,45,60,75,90$, and 105 days post-infection and blood was collected in non-heparinized microtubes (Becton-Dickinson). One drop of blood from each mouse at each time point was used 
to prepare a blood smear. The remaining blood was allowed to clot for 30 minutes at room temperature. The tubes were ringed, and centrifuged at $500 \mathrm{xG}$ for 10 minutes at room temperature to separate the serum from the cells. Serum was carefully withdrawn and transferred to a 30,000mw cutoff Centriprep concentrator (Amicon) for ultrafiltration. The supernatant was transferred to a microfuge tube and placed at $4^{\circ} \mathrm{C}$. Fifty microliters of each serum sample was sent on ice to IDEXX Corp. for cortisol assay.

The blood smears prepared at each of these nine time points were stained with modified Wright's stain (DifQuik) for standard leukocyte counts and morphological analysis following the protocols of Cochran, (1999, personal communication) and Hoppman, (1999, personal communication) to determine the numbers of responding peripheral blood leukocytes. Mice were killed following the blood collection at each of these time points and the diaphragm of each mouse was removed for subsequent analysis (see below).

Before either the angiogenesis or collagen assays were performed, Trichinella larvae present in each diaphragm of each mouse and at each time point, were counted manually. Following the larval count, the diaphragms were cut in half and washed in sterile normal saline or in sterile Hank's balanced salts solution (HBSS). One half the diaphragm was used for the angiogenesis assay and the other $1 / 2$ was used for the collagen assay (see below). 


\section{ANGIOGENESIS ASSAY}

A rhodamine-labeled lectin from Griffonia simplicifolia-1 (GS-1) (Sigma Chemical Co.) was diluted in normal saline containing $0.001 \mathrm{M} \mathrm{N}$-acetylgalactosamine (N-agn) to a final lectin concentration of $25 \mu \mathrm{g} / \mathrm{ml}$. The rhodamine-labeled lectin $/ \mathrm{N}$-agn mixture was added directly to $1 / 2$ the diaphragm in a sterile $15 \mathrm{ml}$ polypropylene tube and held for 60 minutes at $37^{\circ} \mathrm{C}$. The treated tissues were then whole-mounted on freshly prepared poly-l-lysine coated slides. Photomicrographs were obtained using a Nikon camera attached to a Zeiss microscope. Both transmitted and epiflorescent light was used. Epiflorescent photomicrographs were taken at $1000 \mathrm{x}$ and subsequently analyzed for lectin binding. Capillary density was determined for each specimen at each of the nine time points. Capillary density as discernible with the lectin was quantified visually as 0 for no lectin binding to $++1+$ for maximum lectin binding.

\section{COLLAGEN ASSAY}

To determine collagen deposition in muscle, the remaining $1 / 2$ diaphragm (see above) was placed for 6 hours in Bouin's fixative $(25 \mathrm{ml} 10 \%$ formalin, $5 \mathrm{ml}$ glacial acetic acid and $75 \mathrm{ml}$ saturated aqueous picric acid). After fixation, tissues were washed thoroughly with running tap water for $24-36$ hours. Tissues were dehydrated in graded ethanol to xylene and embedded with paraffin. Tissue blocks were sectioned into $7 \mu \mathrm{m}$ sections with a microtome. Sections were placed on freshly prepared poly-llysine coated slides. The slides were heated to melt the paraffin and affix the tissue to the slide. The slides were then rehydrated from xylene through graded ethanol to water. 
Sections were stained with freshly prepared Masson's Trichrome (Sigma Chemical Co.) following the manufacturer's directions. The stained slides were then examined for the presence of collagen. Transmitted light photomicrographs were taken of each specimen at a magnification of $1000 \mathrm{x}$. The results presented are the average of two separate experiments for a total of 108 mice. 


\section{RESULTS}

\section{ANGIOGENESIS}

As shown in Table 3.1, the beginning of endothelial cell growth and the formation of new capillaries appear at approximately day 15 post-infection in $T$. spiralis-infected mice and capillary density gradually increases reaching its maximum at approximately day 75 post-infection. The rhodamine-labeled lectin was also found binding to capillaries at the periphery of the muscle fiber. As hypothesized, $T$. pseudospiralis-infected mice showed no evidence of neovascularization. Mouse diaphragm examined microscopically at each of the nine time points indicated above showed no obvious differences in neovascularization patterns between mice with normal adrenal function and those that underwent adrenalectomy regardless of the species of Trichinella infecting the host. As can be seen in Figures 3.1 through 3.7, the progress of neovascularization is evident in $T$. spiralis-infected animals. The vascular rete is complete at approximately 75 days post-infection. No non-vascular binding to muscle fibers or to other cells in the observed field was seen.

\section{LARVAL COUNTS}

Total larval counts in diaphragm are summarized in Figure 3.8. It can be seen that $T$. spiralis-infected mice averaged 910 (range $=895-920$ ) larvae in unadrenalectomized mice, 637 (range $=620-655$ ) larvae in ADX mice and 1115 larvae (range $=1110-1140)$ in $\mathrm{ADX}$ mice with dexamethasone. $T$. pseudospiralis-infected mice averaged 805 larvae (range 800-813) in unadrenalectomized mice, 295 larvae 
(range $=280-301)$ in $\mathrm{ADX}$ mice and 1038 larvae (range 1025-1050) in ADX mice receiving dexamethasone. Saline- treated infected ADX mice had larval counts of 875 for T. spiralis (range 870-880) and 810 for $T$. pseudospiralis (range $=805-820$ ) which is not significantly different from the unadrenalectomized mice. The unexpected finding was the reduction in larval survival in ADX mice. This was notably more evident in $T$. pseudospiralis-infected animals. Conversely, a small number of the dexamethasone treated mice died of trichinellosis during the experiments and, at necropsy, showed lethal parasite loads of over 1500 larvae/diaphragm/mouse. In addition, examination of the small intestine at necropsy showed that the administration of dexamethasone also increased the numbers of surviving adults in both $T$. spiralis and $T$. pseudospiralisinfected animals. Adrenalectomized mice also had decreased intestinal worm burden when compared to unadrenalectomized mice (data not shown). Gross examination of both muscle and intestine in dexamethasone-treated mice showed a noticeable reduction in inflammation in infected mice. This reduction in inflammation was not apparent in non-dexamethasone-infected animals. 
Table 3.1. Analysis of Capillary Density in Mice Infected With Either T. spiralis or T. pseudospiralis And in Uninfected Controls.

$\mathrm{ADX}=$ adrenalectomized. $\mathrm{N}=108$.

Day animal sacrificed

\begin{tabular}{|c|c|c|c|c|c|c|c|c|}
\hline & 0 & 10 & 15 & 20 & 30 & 45 & 60 & 75 \\
\hline T. spiralis & 0 & 0 & + & + & ++ & ++ & +++ & +++++ \\
\hline T. pseudo & 0 & 0 & 0 & 0 & 0 & 0 & 0 & 0 \\
\hline $\begin{array}{l}\text { T. spiralis } \\
\text { ADX }\end{array}$ & 0 & 0 & + & + & ++ & ++ & +++ & +++++ \\
\hline $\begin{array}{l}\text { T. pseudo } \\
\text { ADX }\end{array}$ & 0 & 0 & 0 & 0 & 0 & 0 & 0 & 0 \\
\hline $\begin{array}{l}\text { Uninfected } \\
\text { Controls }\end{array}$ & 0 & 0 & 0 & 0 & 0 & $\begin{array}{l}\text { Not } \\
\text { Done }\end{array}$ & $\begin{array}{l}\text { Not } \\
\text { Done }\end{array}$ & 0 \\
\hline
\end{tabular}




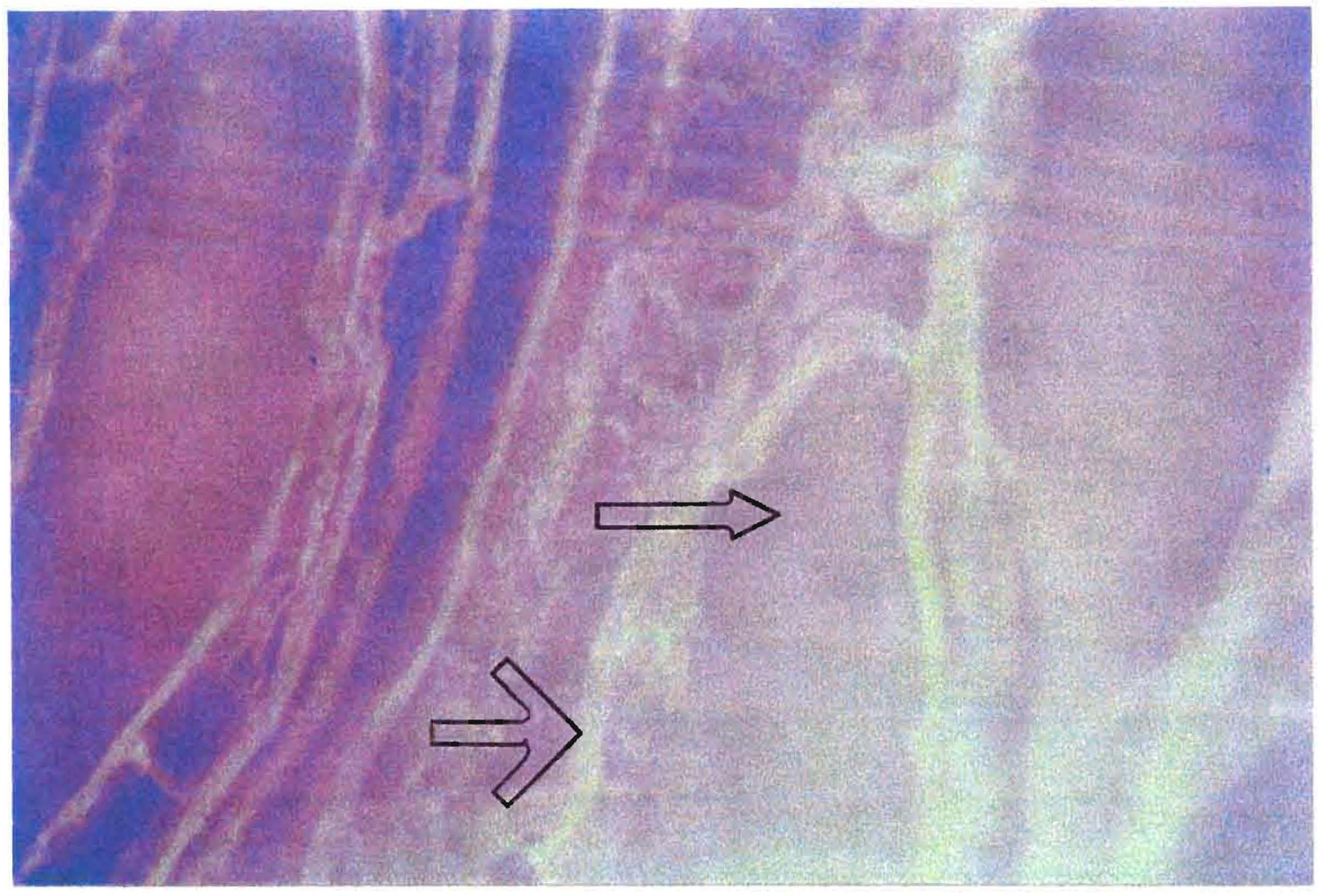

Figure 3.1. The T. spiralis Cyst at Day 15 Post-Infection. Capillaries are present along the myofiber but angiogenesis has not begun. Small arrow depicts the collagen nurse cell. Large arrow depicts the capillaries. Magnification is $1000 \mathrm{X}$. Capillary density is 0 . 


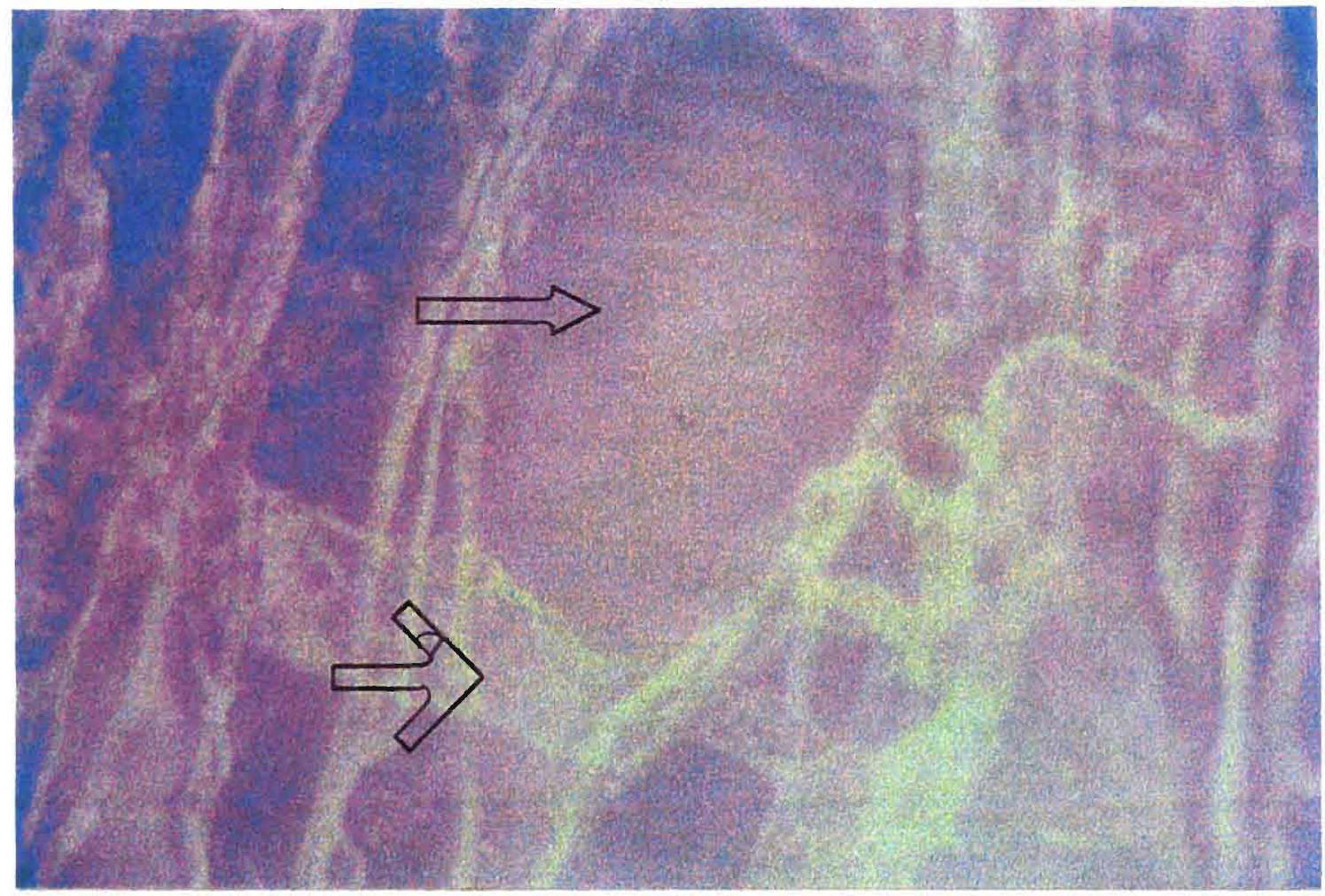

Figure 3.2. Neovascularization of the T. spiralis Nurse Cell at Day 20 Post-Infection. Small arrow depicts the nurse cell. Large arrow depicts the beginning of the capillary rete. Magnification is $1000 \mathrm{X}$. Capillary density is + . 


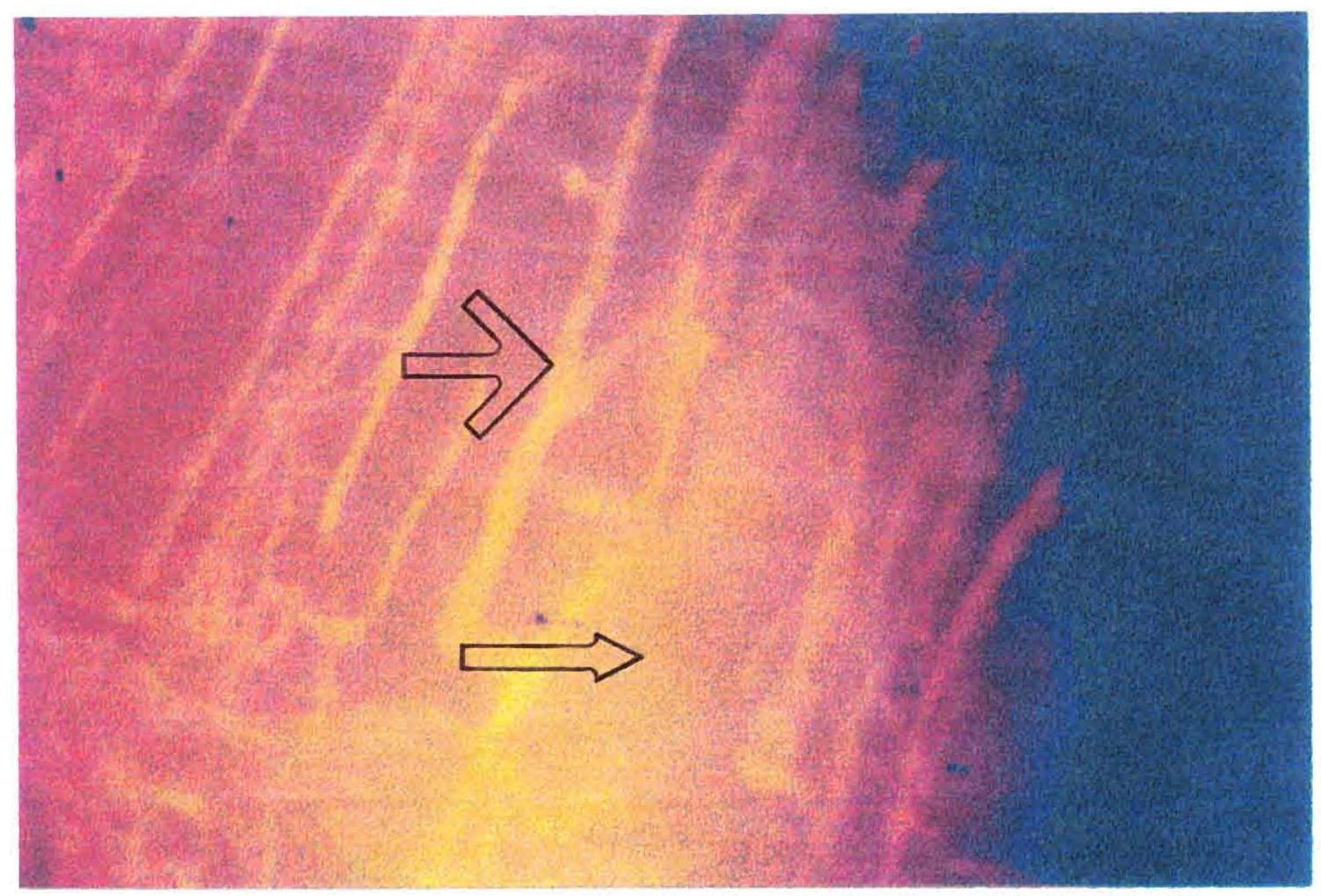

Figure 3.3. Neovascularization of the T. spiralis Nurse Cell at Day 25 Post-Infection. Small arrow depicts the nurse cell. Large arrow depicts the capillary rete. Magnification is $1000 \mathrm{X}$. Capillary density is $+1 / 2$. 


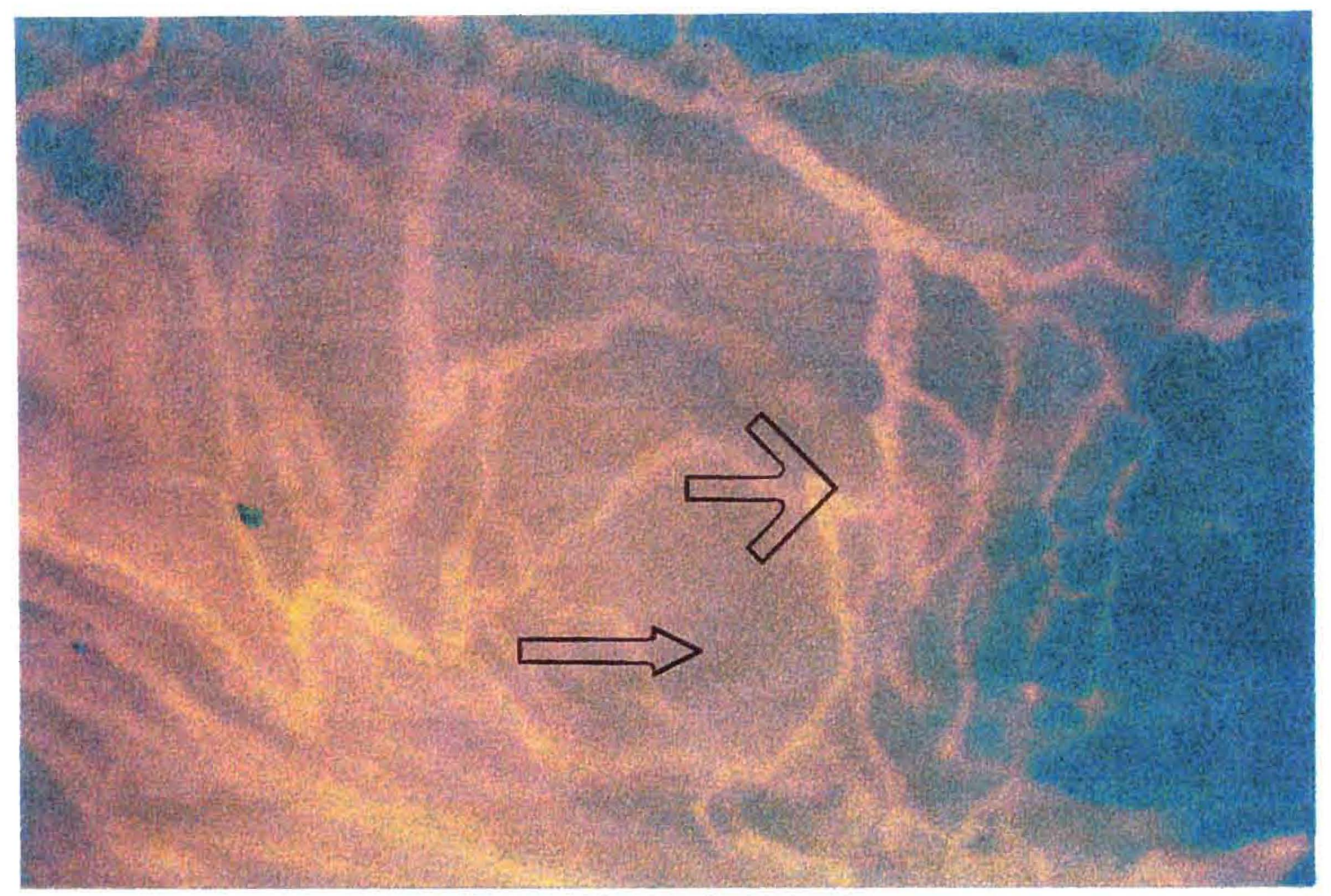

Figure 3.4. Neovascularization of the $T$. spiralis Nurse Cell at Day 30 Post-Infection. Small arrow depicts the nurse cell. Large arrow depicts the capillary rete. Magnification is $1000 \mathrm{X}$. Capillary density is ++ . 


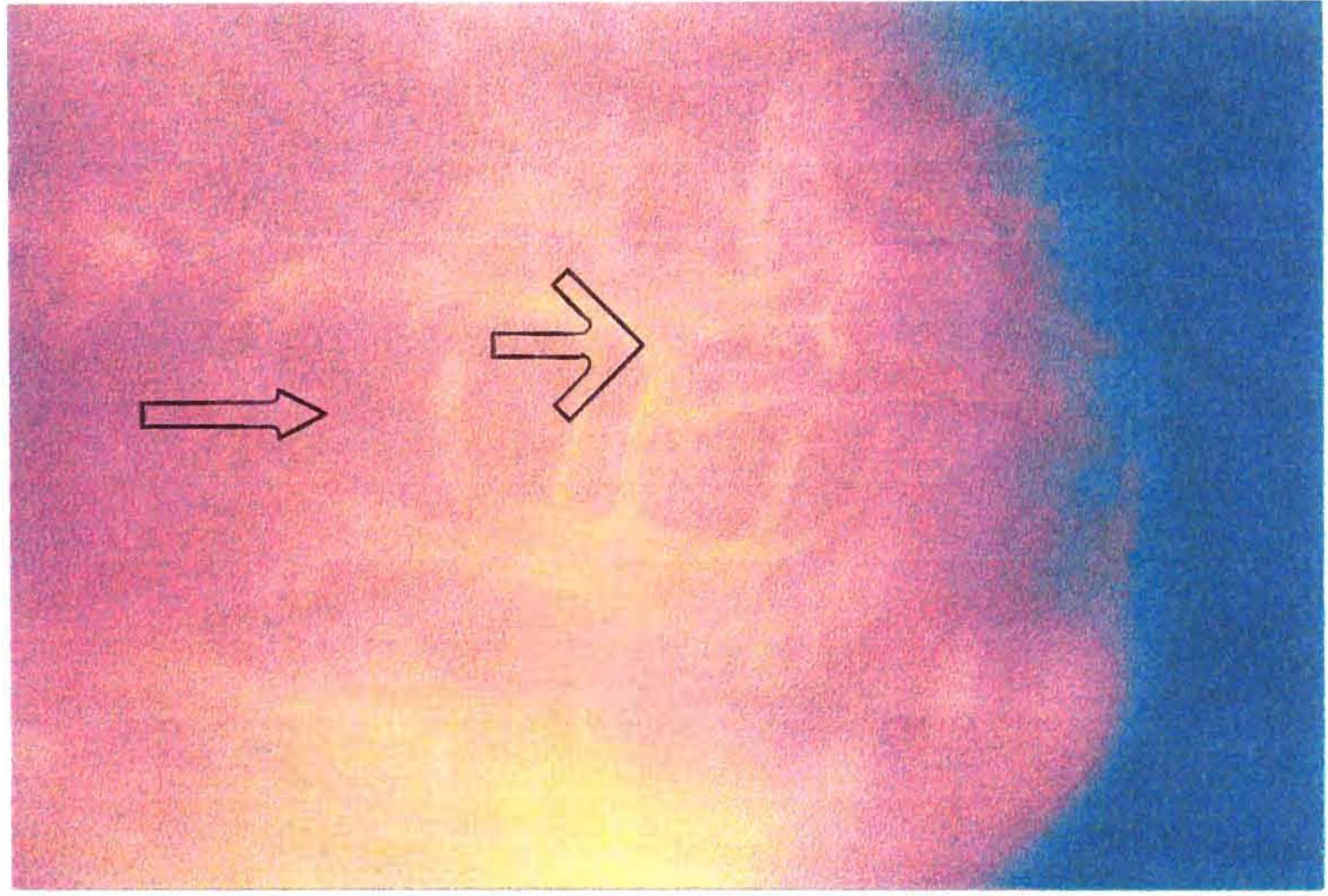

Figure 3.5. Neovascularization of the T. spiralis Nurse Cell at Day 45 Post-Infection. Small arrow depicts the nurse cell. Large arrow depicts the capillary rete. Magnification is $1000 \mathrm{X}$. Capillary density is ++ . 


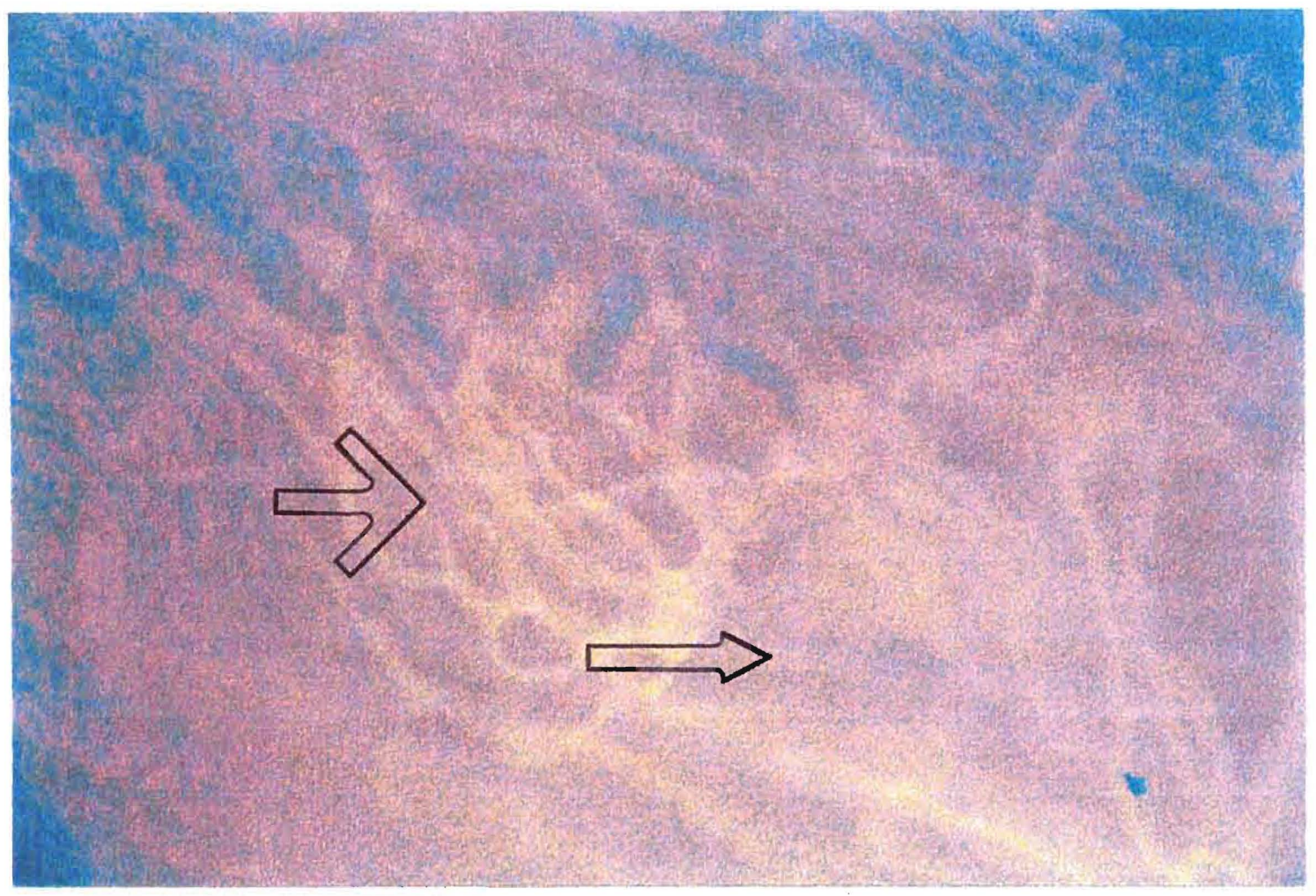

Figure 3.6. Neovascularization of the T. spiralis Nurse Cell at Day 60 Post-Infection. Small arrow depicts the nurse cell. Large arrow depicts the capillary rete. Magnification is $1000 \mathrm{X}$. Capillary density is +++ . 


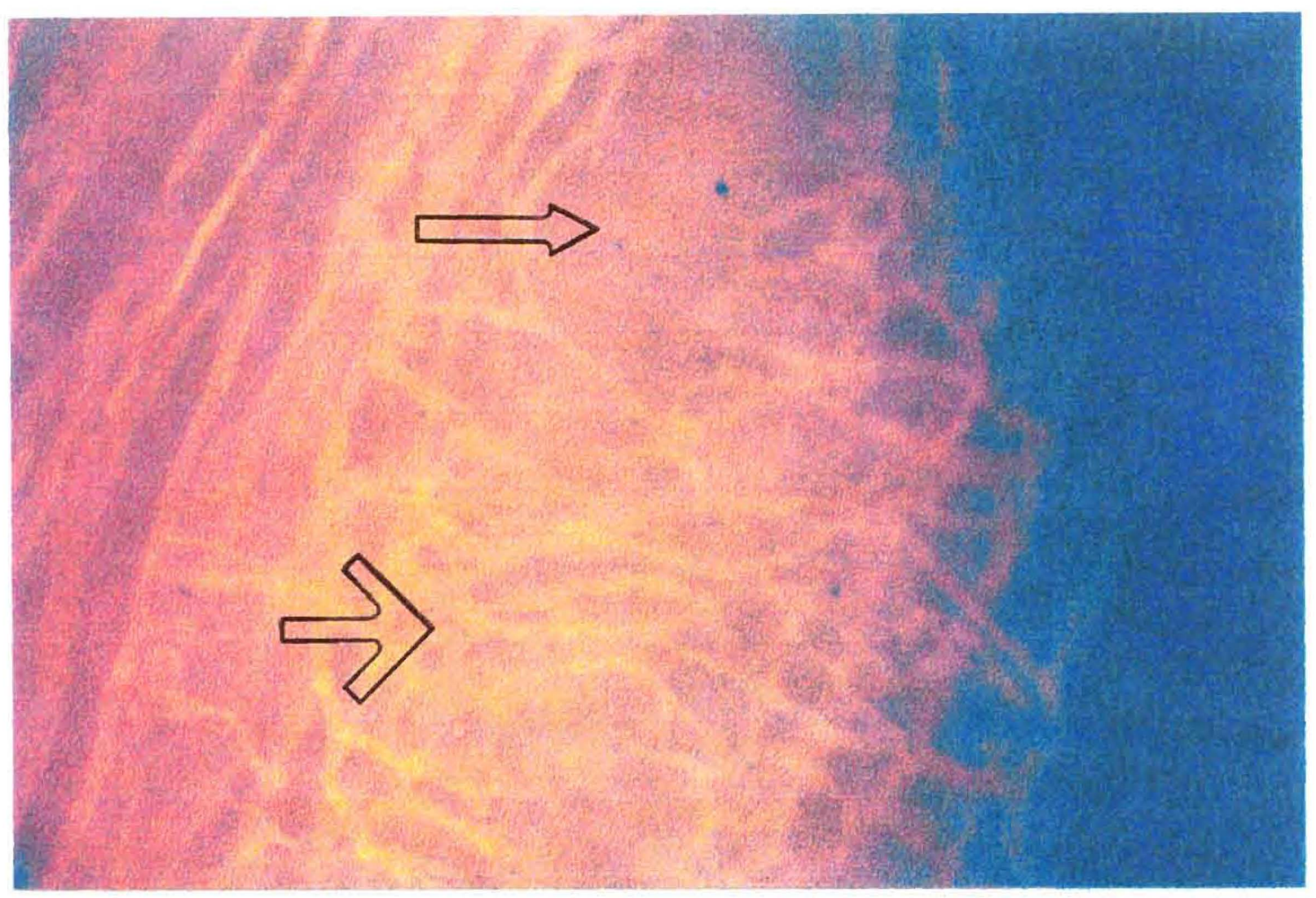

Figure 3.7. Neovascularization of the T. spiralis Nurse Cell at day 75 Post-Infection. Small arrow depicts the nurse cell. Large arrow depicts the capillary rete. Magnification is $1000 \mathrm{X}$. Capillary density is ++++ . The capillary rete is complete. 


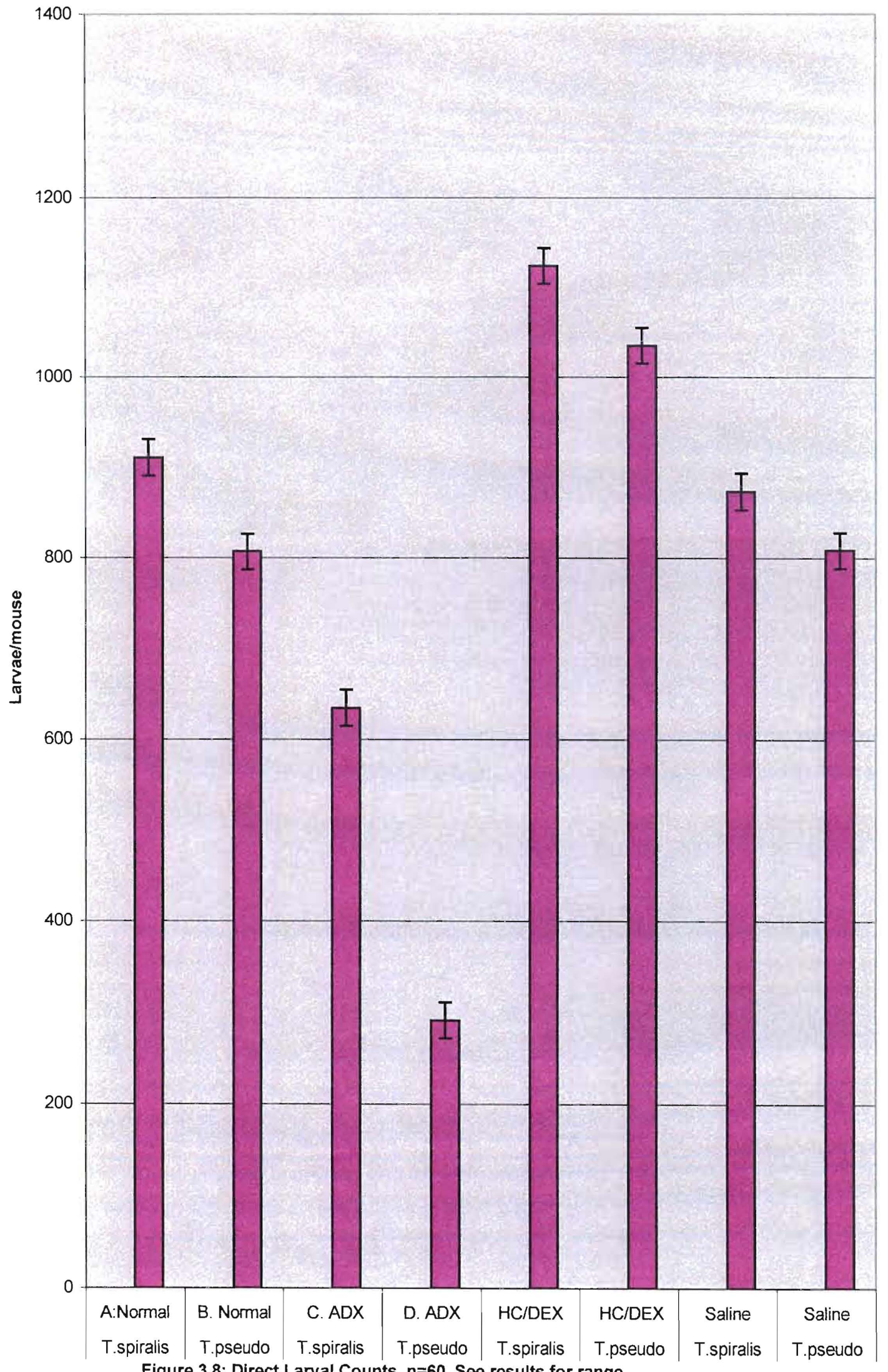

Figure 3.8: Direct Larval Counts. $n=60$. See results for range. 


\section{PERIPHERAL BLOOD COUNTS}

As can be seen in Table 3.2, there are considerable differences in the peripheral peak blood cell counts between the infected animals and the uninfected controls. The greatest leukocyte response in peripheral blood is seen in mice infected with $T$. pseudospiralis with a peak total white count increasing more than five-fold from 1,700 cells $/ \mu$ l to more than 10,000 cells $/ \mu$ l at day 20 post infection. With the exception of eosinophils and monocytes, $T$. pseudospiralis elicits a substantially greater immune cell response in peripheral blood than does $T$. spiralis. Only eosinophils and monocytes are significantly elevated in T. spiralis when compared to T. pseudospiralis. 
Table 3.2: Peak blood cell levels and serum cortisol at day 20 post-Trichinella infection. Cells were stained with modified Wright's Stain and counted manually. Results are based on the averages of four separate experiments $(n=108)$. Three slides were made for each sample. Cortisol measurements were performed by IDEXX Corp.

\begin{tabular}{|l|l|l|l|}
\hline PROFILE & T. SPIRALIS & T. PSEUDOSPIRALIS & CONTROL \\
\hline TOTAL WBC & $7900 / \mu \mathrm{l}$ & $10000 / \mu \mathrm{l}$ & $1700 / \mu \mathrm{l}$ \\
\hline NEUTROPHILS & $3901 / \mu \mathrm{l}$ & $5060 \mu \mathrm{l}$ & $323 / \mu \mathrm{l}$ \\
\hline LYMPHOCYTES & $3456 / \mu \mathrm{l}$ & $4390 / \mu \mathrm{l}$ & $1343 / \mu \mathrm{l}$ \\
\hline MONOCYTES & $384 / \mu \mathrm{l}$ & $323 / \mu \mathrm{l}$ & $17 / \mu \mathrm{l}$ \\
\hline EOSINOPHILS & $349 / \mu \mathrm{l}$ & $220 / \mu \mathrm{l}$ & $17 / \mu \mathrm{l}$ \\
\hline BASOPHILS & $0 / \mu \mathrm{l}$ & $0 / \mu \mathrm{l}$ & $0 / \mu \mathrm{l}$ \\
\hline & & & \\
\hline CORTISOL & $<0.2 \mu \mathrm{g} / \mathrm{dl}$ & $0.7 \mu \mathrm{g} / \mathrm{dl}$ & $<0.1 \mu \mathrm{g} / \mathrm{dl}$ \\
\hline
\end{tabular}




\section{COLLAGEN DEPOSITION}

Collagen deposition around the nurse cell in Trichinella-infected mice, Trichinella-infected ADX mice and in Trichinella-infected ADX mice given replacement steroid treatment is shown in Figures 3.9 through 3.12. Masson's trichrome was used to detect collagen around the larvae in the intracellular niche. It can be seen that adrenalectomy does not change collagen deposition in Trichinella spiralis or T. pseudospiralis infected mice. Although not shown, dexamethasone made no difference in collagen deposition in ADX mice infected with either T. spiralis or $T$. pseudospiralis. No nurse cell formation was observed in T. pseudospiralis infected mice under any of the experimental conditions detailed here. 


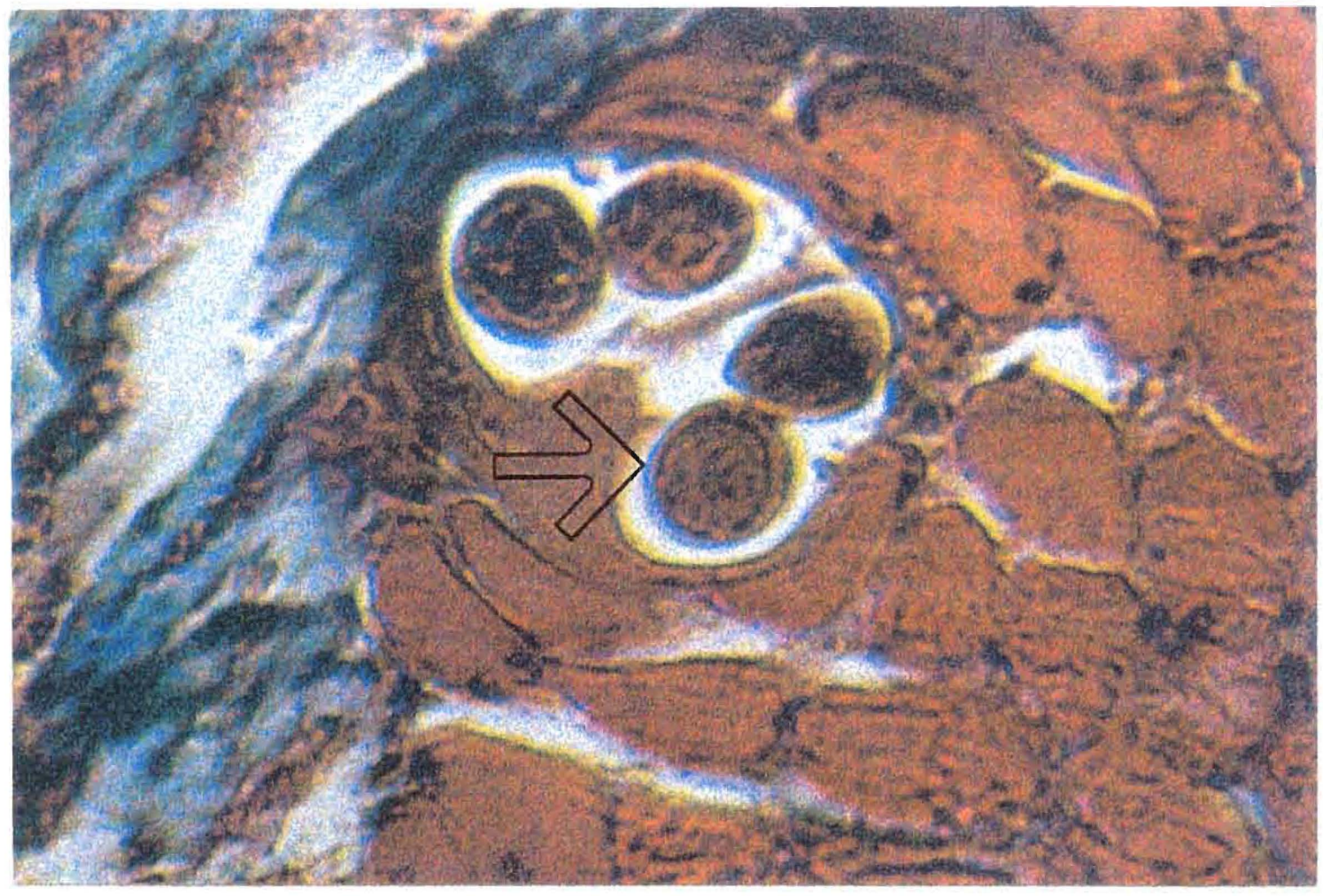

Figure 3.9. Masson's Trichrome stain of adrenalectomized BALB/c mouse diaphragm infected with $T$. pseudospiralis at day 35 post-infection. Large arrow depicts worm. Magnification is $1000 X$. 


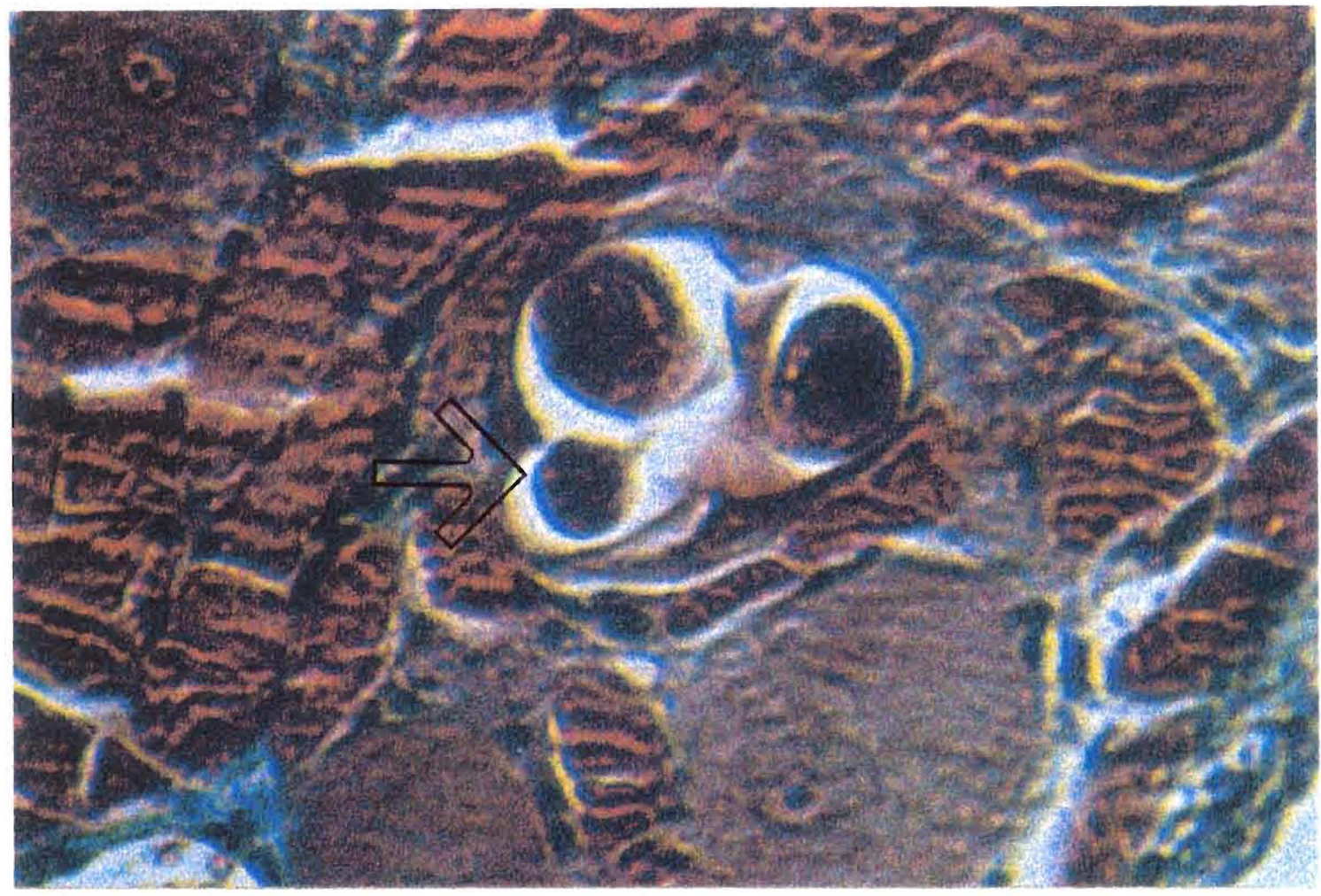

Figure 3.10. Masson's Trichrome stain of normal BALB/c mouse diaphragm infected with $T$. pseudospiralis at day 35 post-infection. Large arrow depicts worm. Magnification is $1000 \mathrm{X}$. 


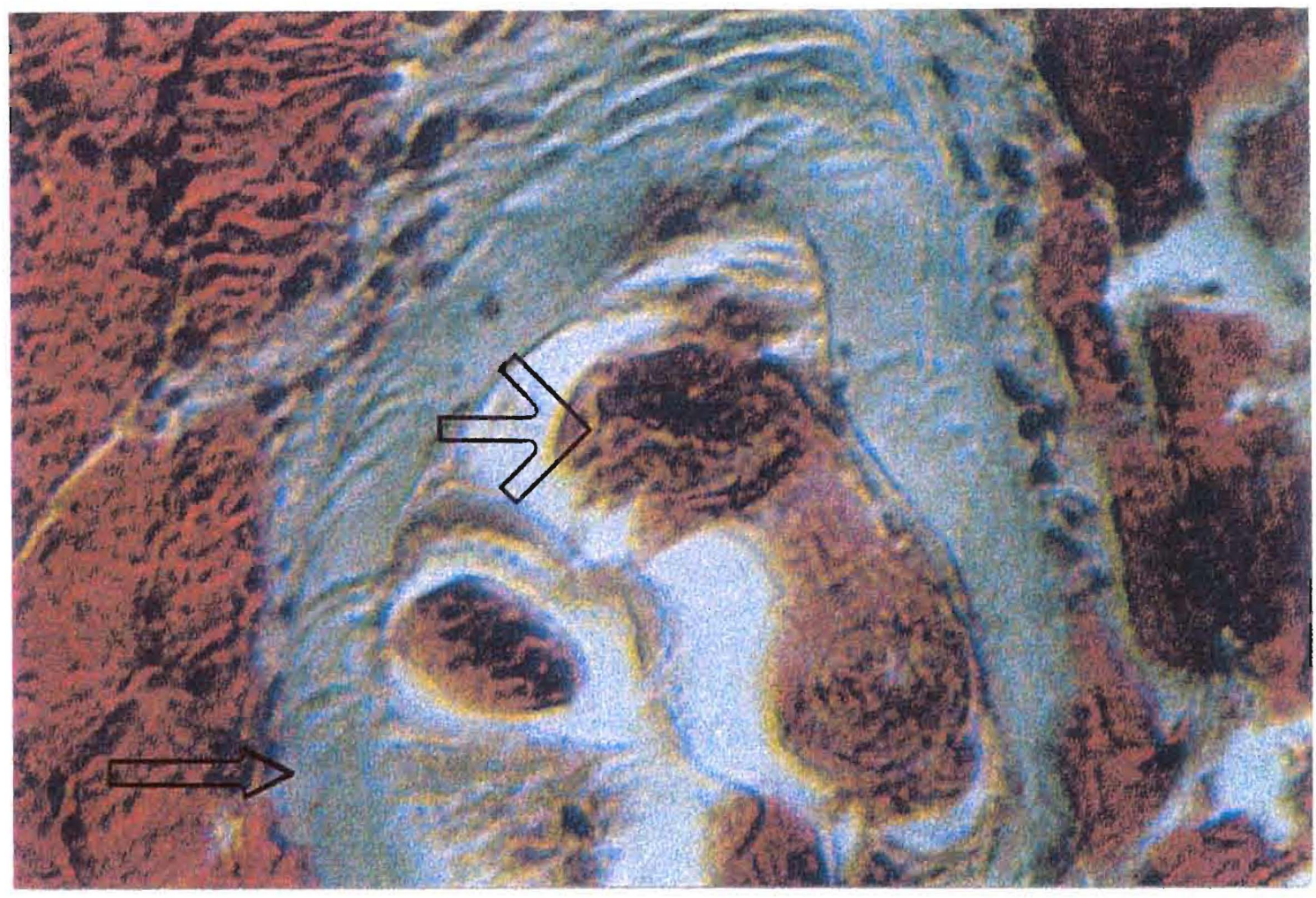

Figure 3.11. Masson's Trichrome stain of normal BALB/c mouse diaphragm infected with $T$. spiralis at day 35 post-infection. Large arrow depicts worm. Small arrow depicts collagen deposition. Magnification is 1000X. 


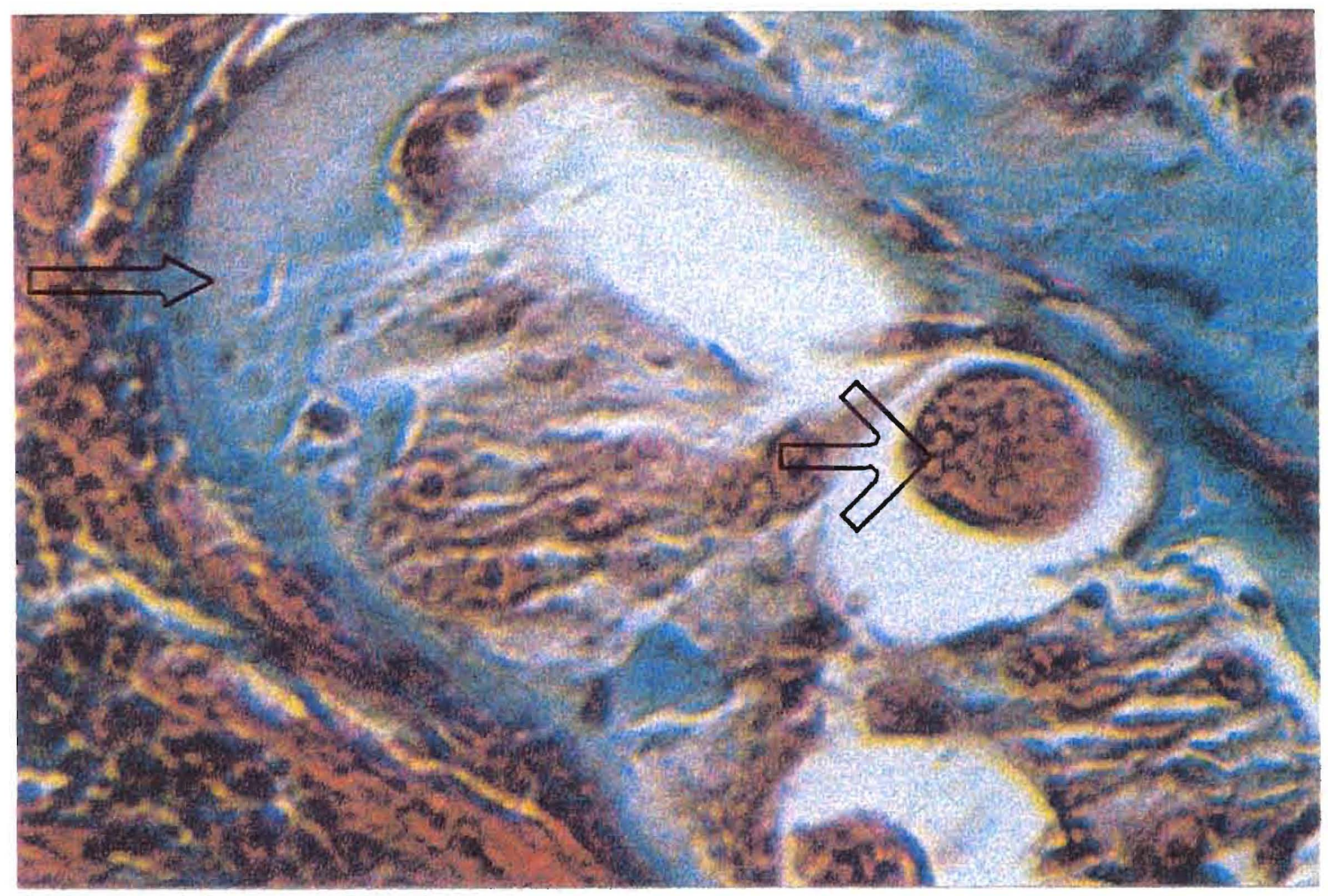

Figure 3.12. Masson's Trichrome stain of adrenalectomized BALB/c mouse diaphragm infected with $\boldsymbol{T}$. spiralis at day 35 post-infection. Large arrow depicts worm. Small arrow depicts collagen deposition. Magnification is 1000X. 


\section{DISCUSSION}

The collagen and angiogenic response in the skeletal muscle of BALB/c mice infected with either Trichinella spiralis or T. pseudospiralis was monitored over a period of 105 days using Masson's Trichrome or the lectin derived from Griffonia simplicifolia-1 (GS-1) respectively. No evidence of collagen deposition or angiogenesis was found in muscle cells infected with T. pseudospiralis infected ADX mice or in ADX mice treated with dexamethasone in this study. No differences were noted in collagen deposition or angiogenesis in T. spiralis-infected mice or T. spiralis-infected ADX mice. This is in contrast to the report by Hegazy and Boulos (1993) of the visualization of a membrane forming around $T$. pseudospiralis following Levamisole treatment (see Chapter I). Therefore, the absence of cortisol had no apparent effect on the formation of the nurse cell or neovascularization in Trichinella-infected mice.

The use of Masson's trichrome, which stains all types of collagen, demonstrated that collagen deposition in Trichinella infections was not dependent on or connected with the presence or absence of cortisol in the host's blood. Trichinella spiralisinfected $\mathrm{ADX}$ animals that received dexamethasone showed no changes in nurse cell formation or in angiogenic response.

The nurse cell found in $T$. spiralis infected animals appears to be species specific to T. spiralis and other encapsulating Trichinella. The enlarged nuclei of muscle cells infected with $T$. spiralis have been shown to be transcriptionally active for 
Type IV and VI collagen (Polvere, et al 1997) suggesting that it is the host that produces the collagen that helps formulate the nurse cell. The nurse cell and enclosed parasite then form a complex that acts to maintain the larvae. And, although worm secreted antigens have been found in the nucleoplasm of infected muscle cells, it is uncertain whether these peptides have an active role in nurse cell formation (Vassilatis, et al 1992, Vasselitis, et al 1996). It has been shown, however, that the excretory/secretory products of both $T$. spiralis and T. pseudospiralis induce type IV collagen synthesis in murine 3T3 fibroblasts in vitro (Haehling, et al 1995). Despite these findings in vitro, my observations indicate that it is the host that deposits the collagen that becomes the nurse cell complex and that this phenomenon never occurred in $T$. pseudospiralis infected mice in vivo under the experimental conditions detailed here. It seems unlikely, however, that the host alone secretes a collagen-nurse cell complex that has such fortuitous benefits for survival of the enclosed worm.

The sequence of cellular events leading to collagen deposition and angiogenesis around the encapsulating species of Trichinella remain uncertain. However, because angiogenesis is only seen in the encapsulating species of Trichinella, this is strongly suggestive of a complex relationship between the collagen architecture, the ECM, the wound healing cascade and angiogenesis in Trichinella-infected BALB/c mice.

Since cortisol is a normal part of the HPA axis in mammals, cortisol would be expected to play a role in suppressing the inflammatory response and in restoring homeostasis in animals infected with parasites. Trichinella pseudospiralis does not form this nurse cell as was previously described. Other investigators that have reported 
that collagen synthesis in vivo is suppressed by various immunosuppressive agents including cortisol and dexamethasone. (Delaney et al 1995a; Guller, et al 1995; Delaney, et al 1995b; Haapasaari, et al 1995). However, despite the role of cortisol in suppressing collagen synthesis as discussed below, cortisol does not appear to be a factor in nurse cell formation. In addition, dexamethasone did not suppress nurse cell formation in $T$. spiralis-infected mice under the conditions detailed here (data not shown).

As the level of IL-1 $\beta$ and other cytokines and chemokines rise during an inflammatory reaction, the hypothalamus stimulates the production of cortisol by way of CRF and ACTH and cortisol then acts to suppress both the innate and adaptive immune responses. Suppression of the innate immune response includes the slowing or cessation of collagen synthesis by various cell types including fibroblasts (Davis, et al 1997; Crofford, et al 1997; Swolin-Eide and Ohlsson, 1998). However, my research shows that IL-1-induced cortisol synthesis appears to play no obvious role in the production or suppression of the collagen nurse cell in Trichinella infections and is therefore, not a factor in the absence of the nurse cell in $T$. pseudospiralis infected $\mathrm{BALB} / \mathrm{c}$ mice.

There appears to be a role for IL-1 $\beta$ in collagen synthesis and wound repair. Lertchirakarn, et al (1998) found that IL-1 $\beta$ induced collagen synthesis in fibroblasts but this synthesis is tissue specific. This effect is probably due to IL-1 $\beta$ induced PGE2 synthesis in certain cell types but not in others (Lertchirakarn, et al 1998). Mehdizadehkashi (1995) found that PGE2 levels were significantly higher in $T$. spiralis 
infected mice than in T. pseudospiralis infected mice. Frisbie and Nixon (1997) found that corticosteroids like cortisol inhibit PGE2 synthesis and that IL-1 $\beta$ induced collagen degradation may be inhibited by corticosteroids. IL-1 $\beta$ is also known to decrease the formation of granulomatous tissue in the wound healing process when administered in vivo. (Rapala, et al 1997).

Because of the presence of high levels of PGE2 in $T$. spiralis infected mice, I maintain that PGE2 may be one of the major controlling mechanisms in collagen synthesis in Trichinella infected mice under the experimental condition detailed here. It is reasonable to assert, therefore, that cortisol suppresses the synthesis of PGE2 in $T$. pseudospiralis infected BALB/c mice. If this is the case, it may be the absence of PGE2 that prevents nurse cell formation in T. pseudospiralis-infected mice and the presence of high levels of PGE2 in T. spiralis-infected mice that contributes to nurse cell formation.

The data from mice with adrenalectomy with or without dexamethasone treatment showed no detectable differences between treated and untreated mice. Angiogenesis and collagen synthesis may be linked to each other and to the severity of the of the muscle damage and to the subsequent presence of angiogenic factors like TNF, VEGF, extracellular matrix (ECM) components and/or infected muscle cell hypoxia. Another possibility is that there may be some, as yet unidentified, angiogenic mechanism present in $T$. spiralis but not in $T$. pseudospiralis. It is known that the VEGF peptide and mRNA for VEGF is present in the sarcoplasm of $T$. spiralis infected myocytes as early as day 7 post-penetration (Capo, et al 1998). These workers have 
speculated that it is muscle hypoxia that leads to the up-regulation of VEGF in infected cells. This is an interesting speculation but does not answer the question as to why the rapidly growing $T$. pseudospiralis does not appear to elicit an equivalent hypoxic condition and, therefore, stimulate the production of angiogenic peptides like VEGF with subsequent neovascularization of the muscle cell. An assay for VEGF mRNA or the VEGF peptide in $T$. pseudospiralis-infected myocytes may help to answer this question.

Also of interest is the fact that the degree of damage to the mitochondrial cycles as described previously (see Chapter 1 ) is more severe in $T$. spiralis-infected mice. The uncoupling of the mitochondrial cycles may contribute to the activation of the VEGF gene(s) in the myofibers of $T$. spiralis but not in $T$. pseudospiralis-infected-mice where mitochondrial and other damage is considered to be less severe. This assumption, if true, would suggest that it is damage and not worm growth that places oxygen demands on the myocyte that are answered by the up-regulation of angiogenic factors like VEGF. It must also be recognized that the angiogenic peptide TNF that is heavily secreted by activated macrophages may also have a role in stimulating angiogenesis. Of particular interest are the very large numbers of tissues macrophages present around the T. spiralis nurse cell but not around T. pseudospiralis.

Saito, et al (1998) and Kusano, et al (1998) found that monoclonal antibodies against matrix metalloproteases (MMP) completely inhibited IL-1 $\beta$ and plasminogen induced collagen degradation. Matrix metalloproteases like collagenase and stromalysin are activated following the type of injury to basement membranes as might be found in 
Trichinella infections (Acott, 1997, personal communication). Thus, there may be a relationship between collagen degradation via MMP and IL-1 $\beta$ levels in host serum. Collagen degradation is an essential early step in wound repair mechanisms. In vitro, collagen has been shown to increase in response to IL-1 $\beta$ levels in rat cardiac microvasculature endothelial cells (Okada, et al 1998). Rosenquist, et al (1996) found that endogenous PGE2 production had a stimulating effect on collagen deposition during inflammatory responses. Mice infected with $T$. spiralis but not $T$. pseudospiralis demonstrate high PGE2 levels Conversely, Graham, et al (1997) found that corticosteroids suppress both type I collagen synthesis and collagenase production in human intestinal smooth muscle cells in vitro and may thus promote healing in inflamed tissues. Trichinella pseudospiralis stimulates very high levels of cortisol in the host when compared to T. spiralis-infected mice.

The presence of certain types of ECM components or collagen fragments may influence the type of $T$ helper response (Th1 versus Th2) in vivo. The presence of ECM fragments might be expected due to an injury or other inflammatory event. The more severe the damage, the greater the number of ECM fragments that might be expected at the injury site. Interferon- $\gamma$ and collagen tend to generate a primary Th1 response whereas IL-4 and IL-10 tend to generate a primary Th2 response (Lawrence, et al 1998; Mauri, et al 1996). Thus, the induction of one type of T helper cell appears to suppress induction of the other type and both types may be dependent on the presence of certain stimulatory molecules like those from the ECM. 
Most researchers have found that, at least in the intestinal phase, the Th2 response dominates in mice infected with $T$. spiralis. I maintain that my data (based on NO production) indicate that, in the muscle phase, a Th1 response is most likely in $T$. pseudospiralis-infected-mice. If a Th1 response is also prominent in T. spiralis, NO production may be reduced or eliminated by the presence of PGE2. Whether the primary Th2 response remains an important factor in Trichinella-infected mice following the intestinal phase is unknown. An assay for the chemokine eotaxin that is produced only by Th2 cells would be instructive in determining $\mathrm{T}$ helper responses in Trichinella infections. Eotaxin is a chemoattractant and an activator of eosinophils, a granulocyte with an important role in the host response to parasitic infections like Trichinella.

Muscle damage that induces a wound-healing response in T. spiralis infected animals may account for some of the phenomena observed. The presence of collagen, fibronectin and such ECM macromolecules as proteoglycans and glycosaminoglycans and/or the degradation of hyaluronan may stimulate endothelial cell growth. These molecules are, in turn, chemoattractive and stimulate the production of angiogenic cytokines such as TGF- $\beta$ and TNF by responding macrophages. It is plausible that the more severe damage seen in T. spiralis infections results in an angiogenic response not seen in T. pseudospiralis infected animals due, at least in part, to the presence of these angiogenic molecules. This is in addition to the effects of hypoxia and the production of VEGF by infected and damaged myocytes. 
Kilcullen, et al (1998) reported that the presence and proliferation of macrophages at the site of wound repair is positively correlated to the proliferation of mesenchymal cells (especially fibroblasts). Proliferation of macrophages is also correlated with increases in reparative collagen, angiogenesis and the overall inflammatory responses to wounds in vivo. This report supports findings of a pronounced cellular infiltrate of macrophages in $T$. spiralis infected mice and a very sparse infiltrate of macrophages in T. pseudospiralis infected mice as measured immunohistochemically by myeloperoxidase assay (Prulhiere, 1994).

Other researchers have found that modulations of cytoskeletal and adhesion proteins during wound healing are critical events in the angiogenic cascade induced, in part, by collagen (Deroanne, et al 1996). Trichinella spiralis causes severe damage to skeletal muscle during invasion and modification of the myofiber following infection. It is reasonable to conjecture, therefore, that the generation of extracellular matrix fragments would be much more pronounced in T. spiralis than in T. pseudospiralis infected mice. The results of the research presented here support this assumption. Indeed, it has been noted that moderation of the ECM fragments in vitro results in the impairment of neovascularization (Kuzyua, et al 1998).

Other researchers have a suggested a role for TGF- $\beta 1$ and type 1 collagen in wound healing in mice in vivo and that defective collagen deposition markedly reduces effective wound healing and subsequent neovascularization (Reed, et al 1998; DaCosta, et al 1998). Despite these findings, the precise sequence of events leading to angiogenesis in vivo remains unclear. Haas, et al (1998) maintain that IL-1 and PGE2 
stimulate the endothelial cell production of matrix metalloproteases and that these events may be mediated by inflammatory cytokines and by the presence of macrophages at the site of the injury. This would tend to support the results reported here because of the very large number of responding macrophages at the site of myocyte injury in T. spiralis infected animals as mentioned above. Indeed, if matrix metalloproteases are necessary for angiogenesis and PGE2 and IL-1 are required for the production of these MMP, then this further substantiates my hypothesis that angiogenesis may be directly related to tissue injury, collagen deposition and the wound-healing mechanism in T. spiralis infected mice but not in T. pseudospiralis infected mice.

The evidence from Sephel, et al (1996) that endothelial cells are sequestered from stroma or provisional matrix by the basement membrane (BM) further supports the findings here. After breach of the membrane by the worm and the subsequent exposure to the matrix, endothelial cells migrate and proliferate. I suggest that it is the endothelial cell recognition of matrix architecture and specific matrix ligands that, in part, stimulates their expansion and proliferative behavior in vivo.

Researchers have found that the angiogenic response to injury in other mammals is non-specific (Malekan, et al 1998). Vascular endothelial growth factor (VEGF) is a key mediator of angiogenesis in vivo and is produced locally by injured cells including cells infected with Trichinella (Capo, et al 1998; Grad, et al 1998). In addition, there may be a complex mix of cytokines secreted following injury that have been dubbed the platelet-derived wound healing formula (PDWHF). This mix is known 
to contain platelet-derived angiogenic factor (PDAF), platelet-derived growth factor (PDGF), TGF- $\beta$, platelet factor IV and a selection of cytokines like IL-1 $\beta$ and TNF (Hiraizumi, et al 1996; Kurdy, et al 1996; Lee, et al 1998). The relative levels of these and other cytokines may vary during the course of the infection (Ramaswamy, et al 1996). Conclusions by these and other researchers (Ilan, et al 1998; Munno, et al 1998) lend credence to my hypothesis that it is the differences in degree of muscle damage and subsequent divergent inflammatory events during Trichinella infections that dictate the observed pathological outcomes. These events may, in part, determine the differences seen in the establishment of the specific intracellular niches for $T$. spiralis and T. pseudospiralis.

In conclusion, I have found no links between cortisol in angiogenesis or collagen deposition although it is possible that the high levels of serum cortisol may play some role in suppressing both angiogenesis and collagen synthesis. Taken together, my data suggest a complex set of events leading to the formation of the nurse cell in $T$. spiralis infected mice. The establishment of the intracellular niche, therefore, is substantially different from that seen in $T$. pseudospiralis infections. I suggest, based on my observations, that collagen deposition and angiogenesis may be linked to each other and to the wound healing response resulting from the pronounced muscle damage and hypoxia seen in T. spiralis infections but not in T. pseudospiralis infections. I base this suggestion on the data gathered from the infected adrenalectomized mice and in ADX mice that had dexamethasone replacement treatments in which no change in total collagen was noted and no differences in the angiogenic responses were observed 
Examination of tissues for larval establishment revealed that larval numbers are greatly reduced in Trichinella-infected animals that had undergone adrenalectomy. However, this reduction in muscle larvae is significantly more pronounced in $T$. pseudospiralis infected mice than in $T$. spiralis infections. This result might be predicted because cortisol levels in T. pseudospiralis infected animals are almost fourfold higher than in T. spiralis although T. spiralis also has higher than control levels of cortisol as can be seen in Table 3.2. Because cortisol broadly suppresses the immune response in mammals as previously discussed, it is reasonable to hypothesize decreases in larval numbers in adrenalectomized animals. Other researchers have found that natural anti-inflammatory agents like cortisol down-regulate excessive inflammatory reactions against infectious agents and reduce the systemic inflammatory response syndrome (SIRS) in vivo (Iwagaki, et al 1997). Without cortisol to inhibit immune cell proliferation and inflammatory cytokine production, I observed an increase in parasite killing as measured by surviving larval numbers as seen in Figure 3.8. This reaction was reversed by the administration of dexamethasone. In fact, dexamethasone is a more potent inhibitor of the immune system than is cortisol even when the dose is adjusted to compensate for the 30 -fold difference in pharmacological action between the two steroids (Casini-Raggi, et al 1995; Guthrie, 1991; Lane, et al 1990). This becomes especially apparent as larval numbers in dexamethasone treated animals are examined. Indeed, the infection was so severe in a number of mice that they died of trichinellosis. This was particularly true at about day 15 post-infection in $T$. spiralis infected mice as larvae became established in the intracellular niche with the subsequent muscle damage 
that predictably accompanies these events. With this information in mind, it is reasonable to assert that low cortisol may be associated with a higher inflammatory reaction resulting in lower infectivity. Conversely, higher cortisol levels are associated with lower inflammatory reactions resulting in higher infectivity.

These basic assumptions are supported by the larval counts in mice infected with T. spiralis or T. pseudospiralis and in infected mice with surgically removed adrenal glands. I have observed that adrenalectomy also reduces the number of intestinal-phase adult worms and that this trend is reversed through the administration of dexamethasone. These phenomena were apparent for both species of worm although the reductions were less remarkable for $T$. spiralis. I suggest, therefore, that serum cortisol may play an important role in reducing the host immune and inflammatory responses in mice infected with Trichinella regardless of the species of worm. I further theorize that $T$. pseudospiralis is much more dependent on host serum cortisol than is $T$. spiralis. This may be due to the fact that $T$. pseudospiralis is unencysted and is therefore more exposed to the host cellular response than is $T$. spiralis. Conversely, $T$. spiralis may be more dependent on PGE2 to moderate the immune response. Prostaglandin E2 is believed to counteract ongoing inflammatory responses in vivo (Haveman et al 1999). However the mechanisms by which these two endogenous bioactive substances act are different. This is further evidence that the two species of Trichinella are eliciting quite different responses from the host

The results from an IL-1 $\beta$ assays (data not shown) indicate that both species of worm stimulate the host to produce elevated amounts of this lymphokine. The levels of 
IL-1 $\beta$ are important in my research as another indicator of the degree of the inflammatory and adaptive immune responses in mice infected with one of the two species of worm. The Il-1 $\beta$, NO, and CPK data are all in agreement that the host is generating a significantly more massive response to Trichinella spiralis under the experimental conditions detailed here. The source of Il-1 $\beta$ (although it probably primarily derived from activated macrophages) is of secondary importance. What is of importance is the quantity of IL- $1 \beta$ secreted and the timing of the secretions during the course of the infection.

My observations have been confirmed by other researchers. Interleukin- $1 \beta$ and TNF are produced at high levels throughout the course of the infection but drop off markedly during convalescence (Kavelaars, et al 1997; Ramaswasmy, et al 1996; Ishikawa, et al 1998; Lawrence, et al 1998; Faulkner, et al 1998). High levels of IL-1 $\beta$ and other cytokines like INF- $\gamma$ and TNF may stimulate the release of cortisol through the HPA axis. This, however, cannot be directly correlated with the substantially higher numbers of responding leukocytes in the peripheral blood of T. pseudospiralis infected animals. It must be noted that IL-1 $\beta$ levels were higher in $T$. spiralis infected mice and, thus, IL-1 $\beta$ levels do not directly correspond to high cortisol levels under the experimental conditions detailed here. The mechanisms responsible for generating a four-fold difference in cortisol levels in T. pseudospiralis-infected mice remain elusive.

It is interesting that my data shows that, despite less damage to the muscle and higher cortisol levels, T. pseudospiralis elicits a more massive immune cell response 
from the host as measured in peripheral blood but not in tissues. In contrast, T. spiralis stimulates a substantially greater intracellular and tissue leukocyte response than does T. pseudospiralis suggesting again that the two species of worm elicit very different protective mechanisms from the host.

The higher cortisol levels in T. pseudospiralis-infected animals may be the result of an unidentified cytokine-generated host response. The response of peripheral blood macrophages is similar between $T$. spiralis and $T$. pseudospiralis and they are present in much higher numbers than in uninfected control mice. This macrophage response is true in blood but not in tissues as discussed previously. Macrophages are the primary source of IL-1 $\beta$ but other cell types including neutrophils, epithelial cells and $\mathrm{T}$ cells may secrete this and other cytokines during an inflammatory reaction.

The neutrophil and lymphocyte counts in the peripheral blood are higher in $T$. pseudospiralis infected mice than in T. spiralis or controls. These observations tend to lend further support to my assertion that the host inflammatory and immune response differs significantly depending on the species of Trichinella that is infecting. And, although IL-1 $\beta$ may play an important role in initiating an inflammatory reaction, it may be IFN- $\gamma$ and TNF or some other cytokine that sustain the inflammatory response once it has started as has been suggested by Stadnyk and Kearsey (1996) and that, following an initial common innate response, the host expresses a dichotomous reaction that is dependent on a number of factors including differences in the wound healing cascade. 
It has been shown that IFN- $\gamma$ can activate the HPA axis without IL- $1 \beta$ in humans (Ohno, et al 1998). IFN- $\gamma$ is derived from macrophages and, to a lesser extent, other cells during inflammation. In mice infected with Trichinella, IL-4 and IL-6 also play a role in mediating the inflammatory response to the intestinal phase (Frydas, et al 1996). Among other functions, interleukin- 4 generates a Th2 response whereas Il-6 activates the acute-phase response by hepatocytes. I suggest that cytokine production and $\mathrm{T}$ helper response changes as the host moves from the intestinal to the muscle phase of the infection and that this switch is dependent on the species of Trichinella infecting. Evidence of this switch may be presenting itself experimentally in NO and PGE2 production in infected host mice although it seems certain that the biochemical and cellular interplay is far more elaborate than that demonstrated here.

It has been well established that there is an immunosuppressive role for cortisol on the synthesis and actions of IL-1 $\beta$ and other cytokines like IFN- $\gamma$ during inflammatory events (Curti, et al 1996). It may be the high cortisol levels that have a role in lowering IL-1 $\beta$ levels in $T$. pseudospiralis-infected mice when compared to $T$. spiralis-infected mice as I have demonstrated here. This immunosuppressive activity may extend to other cytokines as well including IL-6 and TNF. This suppression also applies to cells stimulated by LPS (P'aez, et al 1996). I found that, despite high cortisol levels, the peripheral blood inflammatory responses to $T$. pseudospiralis are pronounced and that IL-1 $\beta$ levels are elevated and follow a pattern similar to that seen in T. spiralis infected animals but at a substantially decreased level. 
The reasons for the hyperstimulation of the HPA axis in $T$. pseudospiralis infected animals remain unclear. As discussed above, I suspect that there may be other cytokines involved that stimulate the HPA axis in $T$. pseudospiralis infected mice. It seems likely that the two species of worm generate alternative $T$ helper responses with the corresponding differences in cytokine production. This assertion is supported by Capo, et al (1998). These cytokines are probably derived from immune cells in the blood where significant differences are observed in peripheral blood cell counts between mice infected with $T$. spiralis or T. pseudospiralis.

In addition, it has been found that $T$. spiralis and other nematodes release an orthologue of macrophage inhibition factor (MIF or MIP-1 $\beta$ ) thereby inactivating a key subclass $\mathrm{CC}$ chemokine in the activation of $\mathrm{T}$ lymphocyte-dependent adaptive immunity (Pennock, et al 1998). The production of such molecules by $T$. pseudospiralis has not been demonstrated.

It is also noteworthy that I have observed that $T$. spiralis infected mice show a massive infiltrate of macrophages both inside and outside the nurse cell by day 21 of infection. It is possible that IL-1 $\beta$ produced by macrophages inside the collagen cyst does not activate the HPA axis in a manner similar to that seen in $T$. pseudospiralis. It is also reasonable to posit that the very high peripheral blood leukocyte response stimulated by T. pseudospiralis generates a greater response by the HPA axis than does the encysted T. spiralis. And, finally, it is possible that, in Trichinella infected mice, cortisol may not prevent the proliferation of peripheral blood leukocytes but may act to 
prevent activation of these leukocytes through mechanisms that have yet to be elucidated.

In summary, I believe that I am observing a different inflammatory and immune response that is dependent on the species of infecting worm. It is reasonable, therefore, to postulate other, as yet unidentified, factors mediating the host response. A Th1 response would generate a different set of cellular phenomena than would a Th2 response. The subsequent differences in cytokine production generating different cellular responses could help explain my observations. It should also be remembered that Th1 cells have iNOS and Th2 cells do not. Because NO is much more pronounced in T. pseudospiralis infected mice (see Chapter 2), this suggests a primary Th1 response in $T$. pseudospiralis infection in the muscle phase. This could account for variations in cytokine production if $T$. spiralis is generating a primary $\mathrm{Th} 2$ response. Conversely, although I am aware of no data that assigns a role for PGE2 (or any lipidderived mediator) in the transition of naïve T cells to mature Th1 or Th2 lymphocytes, it is possible that the high levels of PGE2 may have a role in determining which type of T helper response dominates the muscle phase in Trichinella infections.

Cortisol does not appear to play a role in either angiogenesis or collagen deposition for either species of worm. Cortisol, however, appears to have a role in larval survival for T. pseudospiralis. Tissue and blood leukocyte responses in host mice infected with one of the two species' of Trichinella are very different in both numbers and in cell type. Once again, interleukin-1 $\beta$, cortisol and PGE2 appear to be key molecules in mediating the host immune reactions to the two species of worm. 
The biochemical and cellular interactions between a eukaryotic parasite and its eukaryotic host are exceedingly complex. Therefore, because $T$. spiralis and $T$. pseudospiralis may generate a different immune profile (including possible differences in the Th1 and Th2 responses), the following chapter addresses the up-regulation and down-regulation of leukocyte surface molecules using flow cytometric analysis in an attempt to further identify the precise mechanisms involved in the host response to Trichinella infections in mice. 


\title{
CHAPTER FOUR
}

\author{
FLOW CYTOMETRIC ANALYSIS \\ OF CELL SURFACE ANTIGENS \\ IN MICE INFECTED WITH TRICHINELLA
}

\section{INTRODUCTION}

\section{FLOW CYTOMETRY}

Chapter Four is directed toward the study of the leukocytes in the spleens of BALB/c mice infected with Trichinella spiralis or Trichinella pseudospiralis during the muscle phase of the parasite life cycle. Most of the Trichinella antigens from the intestinal phase would have been carried to the intestinal lymph nodes and Peyer's patches. Some antigens would have been transported to the liver and spleen. However, most of the cells involved in the adaptive response in the spleen are carried by the blood. During the collection period for spleen cells at designated time points, the immune cells collected are most likely to be reacting to the antigens of the migratory L1 larvae, muscle penetrating L1 larvae and to cells involved in the innate immune response.

In all animals that demonstrate inflammatory responses, the progress of the immune and inflammatory reactions to infectious agents like viruses, bacteria, protozoa and helminths can be ascertained by assaying for the up-regulation and down-regulation 
of various leukocyte surface clusters of differentiation (CD) molecules. As a group of molecules, they serve a variety of biological functions for the cell on which they reside; including adhesion, recognition, binding of specific ligands, communication, differentiation and homing. As secondary lymphoid tissue, the spleen provides an easily accessible organ for the study of the up-regulation and down-regulation of CD markers during inflammatory events in vivo using an assay method known as flow cytometry.

Mature myeloid and lymphoid cells of the immune system respond to inflammatory stimuli in a number of different ways. These responses include the production of cytokines, chemokines, the clonal expansion of certain leukocyte subsets and the up- or down-regulation of various cell surface molecules. The up- or downregulation of these surface molecules may vary depending on the type of invading organism. The inflammatory response of leukocytes in peripheral blood, lymph nodes or spleen can be monitored and quantitated using a number of different assay methods including immunochemistry, immunohistochemistry and flow cytometry.

The flow cytometer or florescence-activated cell sorter (FACS) analyzes cells based on size, granularity and/or the presence of florescent-tagged monoclonal antibodies to selected cell surface markers. Generally, a flow cytometer is able to analyze up to five different markers on the same cell. The cytometer then assigns each cell type to a specific quadrant on a dot plot based on the above parameters. These quadrants are subsequently analyzed by the cytometer's built in analytical software.

This type of analysis makes it possible, for example, to differentiate B cells from all other leukocytes in a sample by first tagging all leukocytes with a pan-leukocyte 
phycoerythrin (PE)-labeled monoclonal antibody against CD45. A fluoresceinisothiocyanate (FITC) labeled anti-CD19 monoclonal antibody would then be added to distinguish all B-cells within this group of CD45-tagged leukocytes. This data allows a quantification of subsets of cells within a larger population of leukocytes. At the same time, it would be possible, for example, to distinguish between and quantify $T$ helper versus $T$ cytotoxic lymphocytes based on florescent tags to differentiate between the CD4 and CD8 markers respectively. Another useful function of flow cytometry is the analysis of activation of molecules on cell surfaces.

The flow cytometer, as used in this study, was used to delineate the up-regulation or down-regulation of selected cell surface antigens in mice infected with one of two species of Trichinella. This data provides a better understanding of the timing and progress of the inflammatory and immune reactions to $T$. spiralis infected mice as compared to T. pseudospiralis infections. 


\section{CELL SURFACE ANTIGENS}

\section{ASSAYED IN THIS STUDY}

Thymocytes and mature T lymphocytes in mice express CD3 (Leo, et al 1987). The cytoplasmic domain of the CD3 molecule participates in signal transduction events and the activation of biochemical pathways following antigen recognition (Isakov, et al 1995; Nakano, et al 1996). The CD3 molecule consists of seven integral membrane proteins that are non-covalently associated with each other and with the $\mathrm{T}$ cell receptor (TCR) $\alpha / \beta$ or $\gamma / \delta$ heterodimers. During T cell activation, CD3 (as a coreceptor with the CD4 or CD8 TCR) is associated with binding the major histocompatibility complex (MHC) of antigen presenting cells (APC) and acts in signal transduction (Kruisbeek and Shevach, 1991). The molecule CD3 was used in this study to identify and quantify all mature $\mathrm{T}$ cells in the spleen of Trichinella-infected BALB/c mice.

The CD4 molecule is a $55 \mathrm{kDa}$ transmembrane glycoprotein of the immunoglobin (Ig) superfamily expressed on thymocytes, macrophages and on a sub-population of $\alpha \beta$-or $\gamma / \delta$-positive MHC class II-restricted T cells (T helper cells). It is also present in low density on myeloid and intrathymic precursor cells and on pluripotent hematopoietic cells (Fredrickson and Bosch, 1989; Wineman, et al, 1992; Wu, et al 1991a; Wu et al 1991b; Godfrey, et al 1994). The CD4 molecule serves as a cell-cell adhesion molecule with invariant affinity for the class II MHC. It is presumed to bind the nonpolymorphic part of the class II MHC molecule in the immunoglobin-like $\alpha 2$ or $\beta 2$ domains where there is an interaction of $\mathrm{MHC}$ restricted $\mathrm{T}$ cells with APC. The 
CD4 molecule has a signal transducing function. The molecule is associated with $\mathrm{T}$ cell activation and is allied with a lymphocyte-specific protein tyrosine kinase $\mathrm{p} 55^{1 \mathrm{ck}}$. In this application, CD4 will be used to identify and quantify a subset of T cells, specifically the T helper lymphocyte in Trichinella-infected BALB/c mice.

The CD8 $\alpha$ molecule is composed of either a $34 \mathrm{kDa}$ homodimer or associated with the $34 \mathrm{kDa} \mathrm{CD} 8 \beta$ in a multimeric or dimeric complex. CD8 is expressed on most thymocytes and on a sub-population of MHC class I restricted T cells (cytotoxic T lymphocytes [CTL]) and T suppressor cells (Abbas, et al 1991; Macdonald, et al 1990a; LeFrancois, 1991; Wang and Klein, 1994; Wu, et al 1995; Suss and Shortman, 1996). The CD8 molecule is an antigen co-receptor and reacts with the nonpolymorphic immunoglobin-like $\alpha 3$ domains of class I MHC on APC. Like CD4, CD8 works with the protein tyrosine kinase $\mathrm{p} 55^{\text {1ck }}$ (Janeway, 1992), thus participating in $\mathrm{T}$ cell activation. The CD8 molecule may transduce signals itself or it may facilitate TCR/CD3-mediated signal transduction after binding class I MHC. Also, like CD4, it is uncertain if CD8-mediated signals are activating, inhibitory or if these signals are essential for the $\mathrm{T}$ cell response to antigen and MHC (Abbas, et al 1991). As used in the present study, CD8 will be used to determine the response of this subset of T lymphocytes to the presence of Trichinella in BALB/c mice.

The common leukocyte antigen is designated CD45 and is found on all cells of the hematopoietic system except erythrocytes and platelets (Ledbetter and Herzenberg, 1979; Van Ewijk, et al 1981). The CD45 molecule is a group of integral membrane proteins that range from 180 to $220 \mathrm{kDa}$ and, in mice, are all products of a single gene 
complex on chromosome 1. Alternative splicing of mRNA results in the production of several polyfunctional isoforms that include CD45RO, CD45RA and CD45RB. The CD45 molecule is a member of the protein tyrosine phosphatase (PTP) family. The intracellular portion consists of two PTP catalytic domains while the extracellular portion is highly variable (Johnson, et al 1997). The CD45 molecule is involved in signal transduction and in modifying signals from other surface markers. It is, therefore, involved in $\mathrm{T}$ cell recognition and in the regulation of various activation pathways through a tyrosine kinase. As used in this study, CD45 will mark all leukocytes in a sample. Secondary florescent markers will identify subsets of leukocytes within this group in Trichinella-infected BALB/c mice.

The molecule $\mathrm{CD} 11 \mathrm{~b} / \mathrm{CD} 18$ (Mac-1) is a significant surface antigen and a heterodimeric member of the integrin family of leukocyte surface molecules. Mac-1 functions as a complement receptor for $\mathrm{iC} 3 \mathrm{~b}$, a fragment in the complement cascade, and as an adhesion molecule whose ligand is the intracellular adhesion molecule-1 (ICAM-1) (Springer, et al 1978; Springer, et al 1979; Lub, et al 1996). Mac-1 is expressed on granulocytes, macrophages, dendritic cells, and NK cells. Mac-1 is rapidly up-regulated on neutrophils following activation (Vremec, et al 1992; Leenen, et al 1994). As a complement receptor of $\mathrm{iC} 3 \mathrm{~b}$, Mac-1 stimulates the phagocytosis of $\mathrm{iC} 3 \mathrm{~b}$ opsonized particles. The molecule $\mathrm{CD} 11 \mathrm{~b} / \mathrm{CD} 18$ will be used in this study to monitor the activation of cells of myeloid lineage (especially macrophages and neutrophils) in response to the presence of Trichinella in BALB/c mice. 
The transmembrane glycoprotein CD19 is a $90 \mathrm{kDa}$ protein differentiation antigen specific for B cells (Krop, et al 1996a). The CD19 molecule is present throughout B cell differentiation but is shed when cells become terminally differentiated plasma cells (Krop, et al 1996b; Fearon, 1993). The CD19 antigen associates with surface B cell Ig, CR-1 and TAPA-1 to promote cellular activation (Krop, et al 1996b). The CD19 molecule may be involved in the clonal expansion of B cells, maturation of memory B cells and B cell activation via T cell dependent antigens (Rickert, et al 1995; Engle, et al 1995). In the present study, CD19 will used to quantitate the clonal expansion of B cells during the specific humoral immune response to Trichinella in BALB/c mice.

The surface antigen CD44 is a sulfated acidic integral membrane protein of 80 to $200 \mathrm{kD}$. The molecular weight depends both on the addition of chondroitin sulfate and on the degree of glycosylation (Leslie and Trowbridge, 1982; Schmits, et al 1997; Kahtoh, et al 1994). The CD44 molecule is expressed on the surface of $T$ cells, thymocytes, B cells, granulocytes, macrophages and on a variety of non-immune cells such as neural cells, erythrocytes epithelial cells, myocytes and fibroblasts (Leslie and Trowbridge, 1982). The antigen is heavily expressed on the surfaces of cells in certain mouse strains including BALB/c (Lynch and Ceredig, 1989). The amino terminal of CD44 is expressed on thymus-derived progenitor or bone marrow cells. It is also expressed in peripheral blood on activated $\mathrm{B}$ cells, $\mathrm{CD} 4^{+} \mathrm{T}$ cells and on memory cells (Spangrude, et al 1989; MacDonald, et al 1990b; Sprent and Tough, 1994; Budd, et al 1987). The CD44 antigen may also play a role in extravasation, acting as a homing receptor that binds to molecules in high endothelial venules (HEV). Binding to HEV is 
a prerequisite for the extravasation of leukocytes from blood to lymphoid tissues such as the spleen and lymph nodes (Hyman, et al 1986). The ligands for CD44 include collagen, fibrinectin hyaluronate and HEV addressin. The molecule CD44 mediates adhesion of leukocytes and, as used in this study, will serve as an additional indicator of an activation response as measured by splenic leukocytes of BALB/c mice infected with Trichinella.

The adhesion molecule CD54 (ICAM-1) is a $95 \mathrm{kDa}$ Ig superfamily member expressed on lymphocytes, HEV, macrophages and dendritic cells (Scheynius, et al 1993). Up-regulation of ICAM-1 occurs in response to inflammatory mediators such as cytokines, chemokines and LPS. It is also the ligand for both leukocyte-functioning antigen (LFA-1)(CD11aCD18) and Mac-1 (CD11b/CD18) (Springer, 1990; Springer, 1994). The adhesion molecule CD54 participates in general inflammatory reactions and in antigen-specific immune reactions. ICAM-1 also participates in rolling (margination) interactions with the endothelium prior to extravasation. (Scheynius, et al 1996; Isobe, et al 1992; Xu, et al 1994). Like CD 44, CD54 will be used to monitor the inflammatory response to Trichinella by splenic leukocytes in BALB/c mice.

Surface antigen CD62L (L-selectin) is a 90kD receptor with lectin-like domains that bind siaylated oligosaccharide determinates on HEV in peripheral lymph nodes (Gallatin, et al 1983; Siegelman, et al 1990). In mice, L-selectin is expressed on most immunocompetent thymocytes, T cells, B cells, neutrophils, eosinophils and monocytes (Reichert, et al 1986a; Reichert, et al 1986b; Reichert, et al 1986c; Iwabuchi, et al 1991; Lewinsohn, et al 1987). This selectin appears to be required for neutrophil 
immigration in response to inflammation and lymphocyte homing to peripheral lymph nodes (Pizcueta and Luscinskas, 1994; Ley, et al 1995). L-selectin is rapidly shed from cell surfaces upon activation. Thus, the levels of CD62L may be used to differentiate mature memory/effector cells from naïve cells (Jung, et al 1988; Kishimoto, et al 1989; Mobley and Dailey, 1992). As used in this study, the loss of CD62L from cells surfaces during Trichinella infection will act as an indicator of the severity of the immune reaction to the presence of the worm in $\mathrm{BALB} / \mathrm{c}$ mice because there is a direct correlation between CD62L loss and the vigorousness of the inflammatory reaction.

The molecule $\mathrm{CD} 69$ (very early activation antigen) is a $28-34 \mathrm{kDa}$ homodimer that is disulfide-linked and composed of differentially-glycosylated subunits (Yokoyama, et al 1988; 1989). The expression of CD69 is induced very rapidly upon the activation of macrophages, T cells, B cells and NK cells in response to inflammatory mediators such as the cytokines IL-1, TNF and IFN- $\gamma$ and to exogenous priming agents like LPS (Ziegler, et al 1994; Brandle, et al 1994). The surface molecule CD69 will be used to monitor the activation of lymphocytes in the presence of Trichinella in BALB/c mice. 


\section{MATERIALS AND METHODS}

Eight female three-month old BALB/c mice were infected with 250 Trichinella larvae from previously infected mice. Four of the mice received T. spiralis and the other four received $T$. pseudospiralis. These eight mice are called the infected group. In addition to the infected group, a separate group of four mice were injected IP with either $100 \mu \mathrm{g}, 200 \mu \mathrm{g}$ or $300 \mu \mathrm{g}$ of LPS dissolved in sterile normal saline or with normal saline without LPS. The priming agent LPS was used to determine the CD response to a known activator of the inflammatory reaction in mammals. Four untreated and uninfected control mice were female BALB/c mice of the same age as the infected and LPS groups and were maintained in an identical manner as the infected and LPS groups according to Oregon law for the care of research animals. Food and water were supplied ad libitum.

Beginning day 7 post-infection, two mice from the infected group, one infected with $T$. spiralis and one infected with $T$. pseudospiralis, and one uninfected control mouse were sacrificed by cervical separation. The spleens were removed, placed in sterile saline and placed at $4^{\circ} \mathrm{C}$. The spleen was washed twice in sterile normal saline, placed in Isoflow sheath fluid (Coulter) and manually minced. Minced spleen was filtered through a $750 \mu \mathrm{m}$ metal grid and the filtered cells were placed in new sterile polypropylene tubes and placed at $4^{\circ} \mathrm{C}$. One milliliter of erythrocyte-lysing reagent (Tris- $\mathrm{Cl}$ buffered $\mathrm{NH}_{4} \mathrm{Cl}$ [pH 7.2]) was added and the cells were held for 10 minutes at $4^{\circ} \mathrm{C}$. The remaining unlysed leukocytes were fixed with $100 \mu \mathrm{l}$ of $10 \%$ 
paraformaldehyde added to the lysing mixture. The fixed leukocytes were allowed to stand at $4^{\circ} \mathrm{C}$ for 10 minutes. One hundred microliters of each leukocyte suspension was removed to a fresh microfuge tube and $900 \mu$ l of Isoflow sheath fluid was added to each tube. This exact procedure was repeated using the remaining mice at days 14, 21 and 28 post-infection.

Mice injected with LPS or saline were sacrificed by cervical dislocation at 6 hours post-injection and the spleens were harvested and treated in a manner identical to the infected and control mice. The leukocytes from the infected group, the uninfected control group and the LPS treated mice were then exposed to specific monoclonal antibodies as detailed below.

As a pan-T cell marker, phycoerythrin (PE)-labeled Armenian hamster antimouse CD3 monoclonal antibody (Sigma) diluted 1:100 in sterile PBS (pH 7.2) containing $0.075 \mathrm{mg} / \mathrm{ml}$ sodium azide was added to selected tubes of spleen cells. Alternatively, as a pan-leukocyte marker, PE-labeled rat antimouse CD45 monoclonal antibody (Sigma) diluted as above was added to other selected tubes of spleen cells. All PE-labeled antibodies used in these experiments were added at a final concentration of $1 \mu \mathrm{g}$ of antibody to $500 \mu l$ spleen cells.

Following addition of the pan-leukocyte or $\mathrm{T}$ cell markers, one of the following was added to select tubes of spleen cells: Fluoroscein-isothiocyante (FITC)-labeled rat antimouse CD4, FITC-labeled rat antimouse CD8, FITC-labeled rat antimouse CD19, FITC-labeled rat antimouse CD44, FITC-labeled Armenian hamster antimouse CD54, 
FITC-labeled rat antimouse CD62L, FITC-labeled rat antimouse CD11b or FITClabeled Armenian hamster antimouse CD69.

All FITC-labeled antibodies used in these experiments were supplied by Pharmingen. The antibodies were diluted in sterile PBS ( $\mathrm{pH}$ 7.2) and added at a final concentration of $1 \mu \mathrm{g}$ of antibody to $500 \mu \mathrm{l}$ of spleen filtrate.

The antibody/spleen cell mixture was held at room temperature for 30 minutes. Cells were then centrifuged at $500 \mathrm{xG}$ for 10 minutes at room temperature. Cells were washed in sterile PBS (pH 7.2) and centrifuged at $500 \mathrm{xG}$ at room temperature for 10 minutes. The wash was removed from the cells with suction and the cells were resuspended in $1 \mathrm{ml}$ of Isoflow sheath fluid. A FACScan flow cytometer (BectonDickinson) or an Epics XL cell sorter (Coulter) was used to determine the relative proportions of various cells types and/or cell surface antigens using FACScan or Epics $\mathrm{XL}$ analytical software.

These experiments were repeated four times using identical protocols $(n=32)$. The results are the averages of pooled data sets. The LPS experiment was repeated once $(n=8)$. 


\section{RESULTS}

Interpretation of the number of cells distributed in appropriate quadrants of the dot plot showed that cells bearing the CD19 antigen increased in mice infected with Trichinella when compared to controls (Figures 4.1 through 4.4). Of total lymphocytes counted, CD19 ${ }^{+}$cells averaged $23.5,25.6,28.9$, and 25.7 percent of lymphocytes on days $7,14,21$, and 28 days post-infection in $T$. spiralis infected mice (+/- 2\%). In $T$. pseudospiralis infected mice $\mathrm{CD} 19^{+}$cells averaged $17.5,21.3,20.9$, and 20.5 at the same time points $(+/-1.5 \%)$. This compares to $16.1,15.7,15.1$, and 16.2 percent of cells in uninfected controls $(+/-2 \%)$. Thus, it appears that $T$. spiralis infected mice have a substantially larger CD19 B cell response in spleen than T. pseudospiralis infected mice and that Trichinella appears to stimulate a significant B cell response in mice when infected mice are compared to uninfected controls.

Cells characterized by CD11b surface molecules in control mice averaged 48.9, $51.2,50.3$, and 49.9 percent of total leukocytes on days $7,14,21$, and 28 respectively (+/- 1\%). In T. spiralis infected mice, the percentages rose to $65.7,78.1,86.3$, and $54.9(+/-3 \%)$. This compares with averages in T. pseudospiralis of $58.8,69.2,84.5$ and $54.4(+/-4 \%)$ on days $7,14,21$, and 28 post-infection respectively as can be seen in Figures 4.5 through 4.8). Infected mice showed significant increases in CD11b when compared to controls.

Cells marked with CD62L in T. spiralis infected mice averaged 9.7, 9.2, 7.8 and $7.9(+/-2.5 \%)$ percent of lymphocytes on days $7,14,21$ and 28 post-infection. $T$ 
pseudospiralis infected mice averaged $11.1,9.9,8.5$ and 8.9 percent $(+/-2 \%)$ of lymphocytes at these time points. Control mice averaged 14.6, 16.2, 15.9 and 14.8 percent $(+/-1.5 \%)$ on days $7,14,21$, and 28 respectively (Figures 4.9 through 4.12 ). Thus, CD62L showed significant decreases in infected mice when compared to controls.

Cells marked with CD69 rose from levels of $2.1,2.3,1.9$ and 2.1 percent $(+/-$ $0.3 \%$ ) of total lymphocytes on days $7,14,21$, and 28 respectively. This is compared to 13.6, 21.1, 19.3, and $10.4(+/-1.5 \%)$ in $T$. spiralis infected mice and $11.8,18.7,19.7$ and 6.9 percent $(+/-1.0 \%)$ in T. pseudospiralis infected mice on days $7,14,21$ and 28 respectively (Figures 4.13 through 4.16). The molecule CD69 was significantly increased in mice infected with Trichinella when compared to uninfected controls.

Cells bearing the CD8 surface antigen that are primarily MHC class I-restricted T lymphocytes (cytotoxic $\mathrm{T}$ lymphocytes) demonstrated substantial increases in the spleen. In uninfected control mice, cells marked with CD8 averaged 3.01, 3.3, 3.1 and 3.3 percent $(+/-0.3 \%)$ of total lymphocytes on days $7,14,21$ and 28 respectively. In $T$. spiralis infected mice, CD8 cells rose to an average of 5.1, 8.3, 9.4 and 7.2 percent $(+/-$ 0.8\%). T. pseudospiralis-infected mice averaged $6.4,7.6,13.7$ and 13.2 percent $(+/-$ $1.2 \%$ ) of lymphocytes on days 7, 14, 21 and 28 post-infection respectively (Figures 4.17 through 4.20)). Cells marked with CD8 remained significantly elevated in $T$. pseudospiralis infected mice at day 28 post-infection even as CD8 began to drop in $T$. spiralis -infected animals. 
The results of the injections of LPS at $100 \mu \mathrm{g}, 200 \mu \mathrm{g}$ or $300 \mu \mathrm{g}$ per mouse are presented in Figure 4.21. Briefly, the surface antigens CD69, CD11b and CD54 responded by increasing in a dose-related manner. Cells with the antigen CD69 increased from $1.56 \%$ to $3.98 \%$. Cells with the antigen CD11b increased from $67.8 \%$ to $86.6 \%$. Cells with the CD54 antigen increased from $8.3 \%$ to $22.5 \%$. The antigen CD62L dropped from $10.4 \%$ to $6.7 \%$.

The cellular markers CD44 and CD54 and CD4 were elevated in infected animals when compared to controls (data not shown). However, the differences in the upregulation of these two molecules in the spleen of animals infected with either $T$. spiralis or T. pseudospiralis were insignificant when compared with each other. 


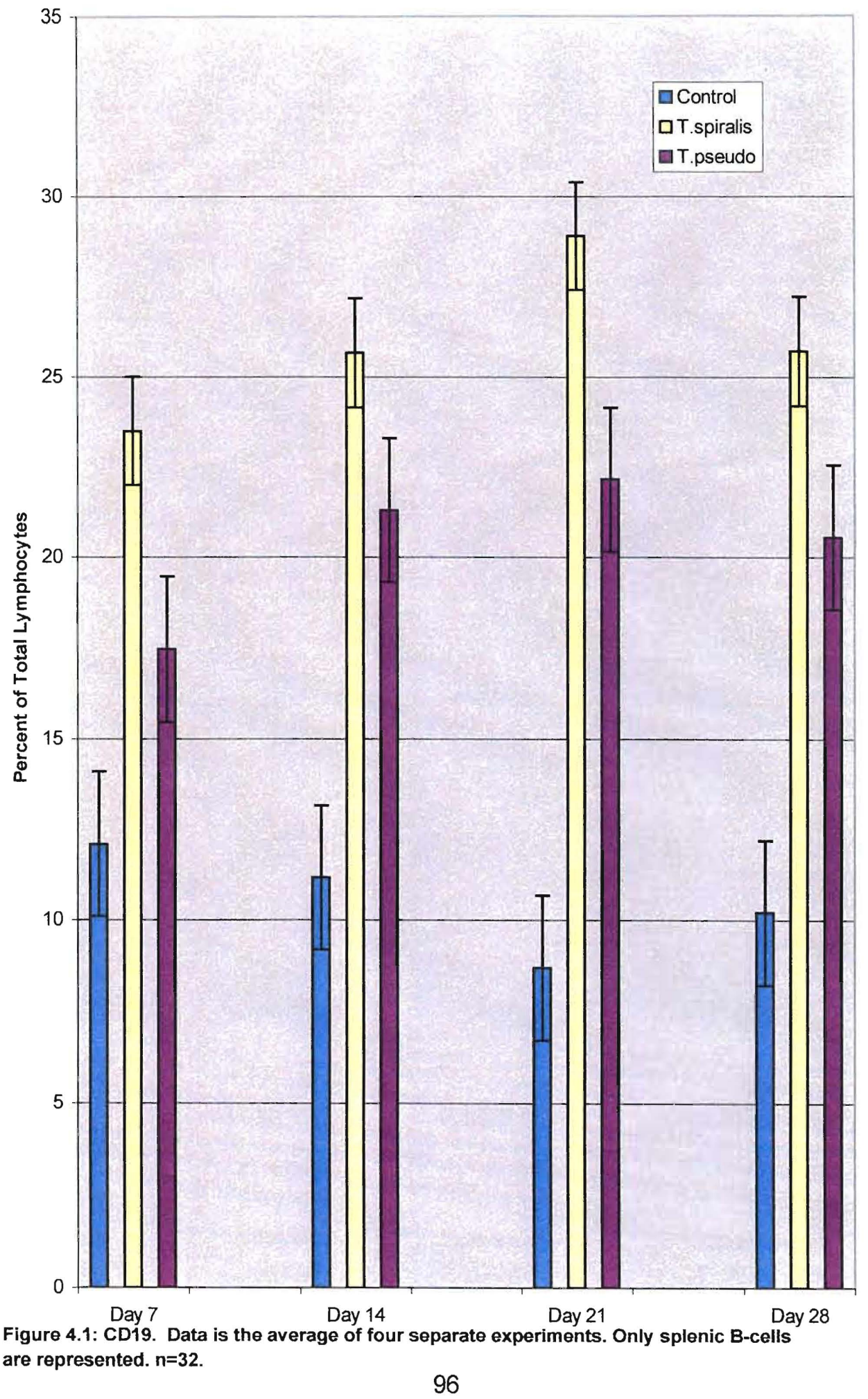




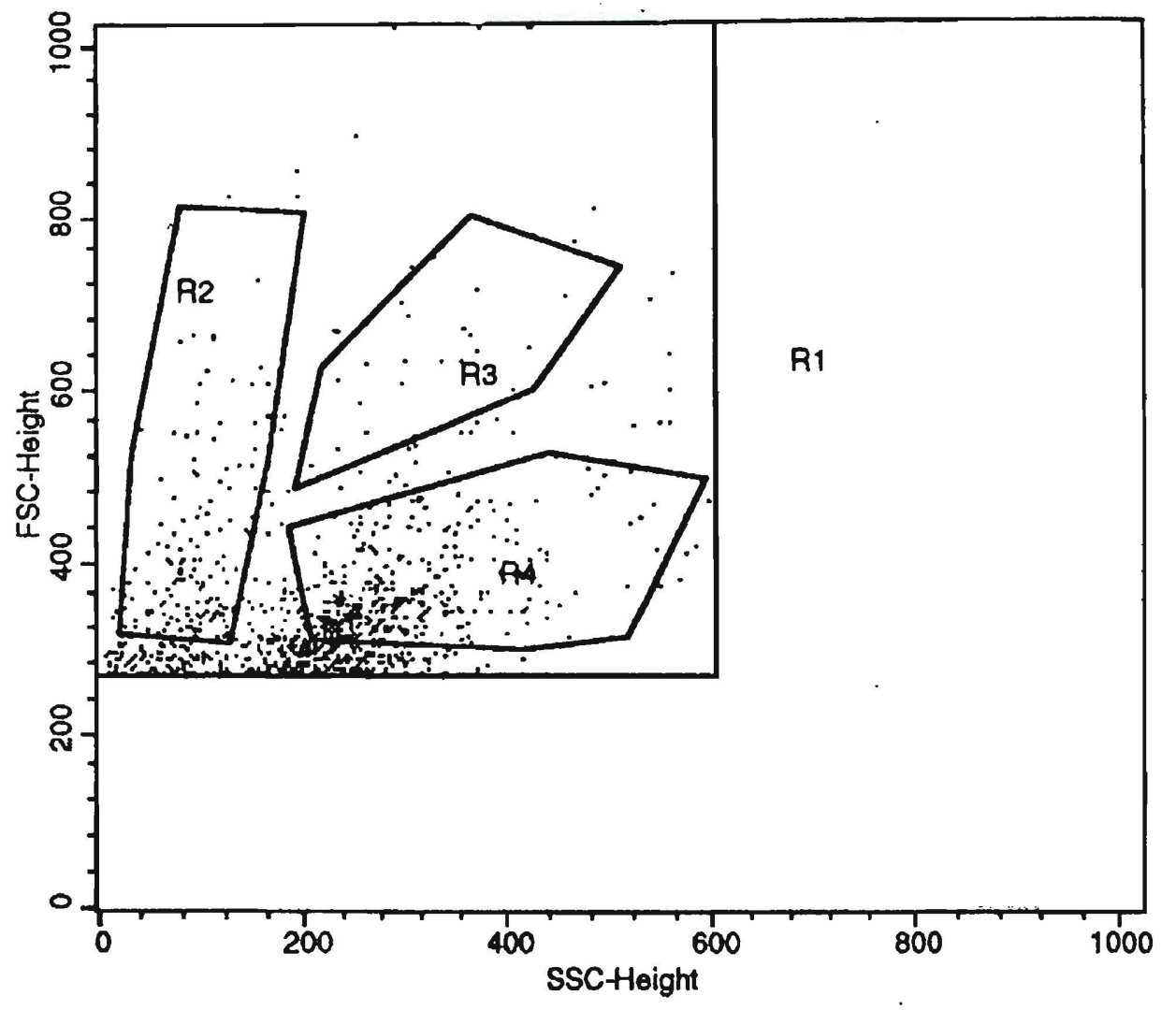

Figure 4.2a: CD45/19. Uninfected control. Total cell acquisition plot. Percent gated: $\mathrm{R} 1=100.00 ; \mathrm{R} 2=16.16 \mathrm{R} 3=1.75 ; \mathrm{R} 4=35.33$. 


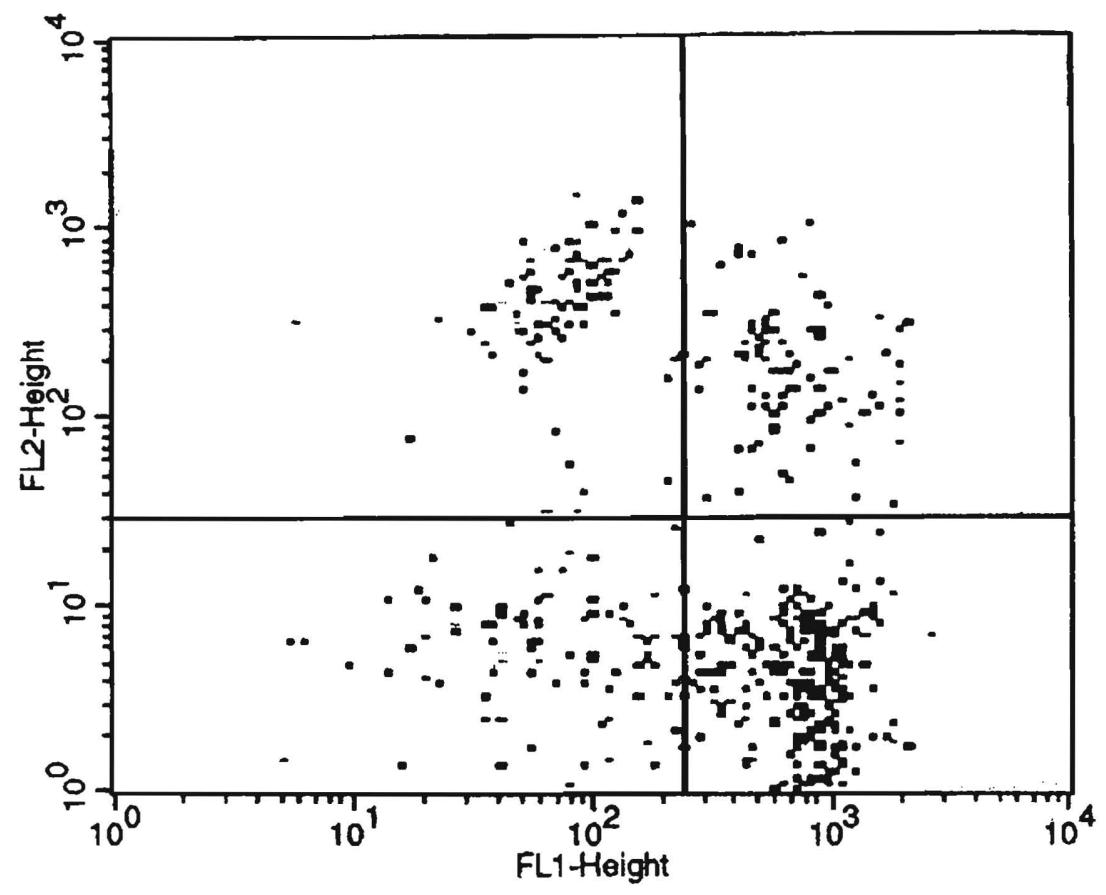

Figure 4.2b: CD45/19. Uninfected control. Quadrant R2 acquisition plot. Percent gated: $\mathrm{UL}=16.01 ; \mathrm{UR}=16.21 ; \mathrm{LL}=17.68 ; \mathrm{LR}=50.09$. 


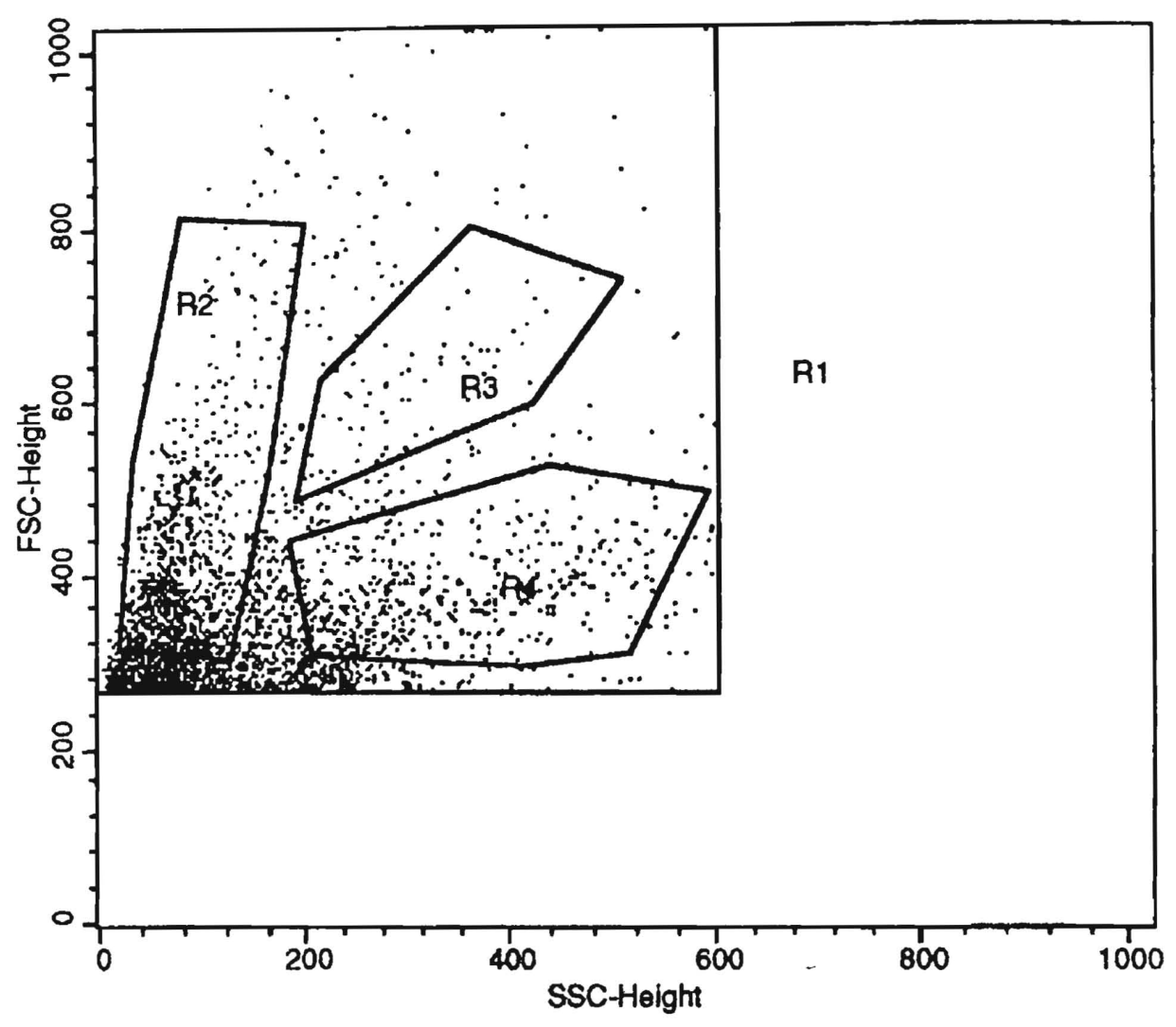

Figure 4.3a: CD45/19. T. pseudospiralis-infected mouse. Total cell acquisition plot. Percent gated: $\mathrm{R} 1=100.00 ; \mathrm{R} 2=34.06 ; \mathrm{R} 3=2.54 ; \mathrm{R} 4=15.96$. 


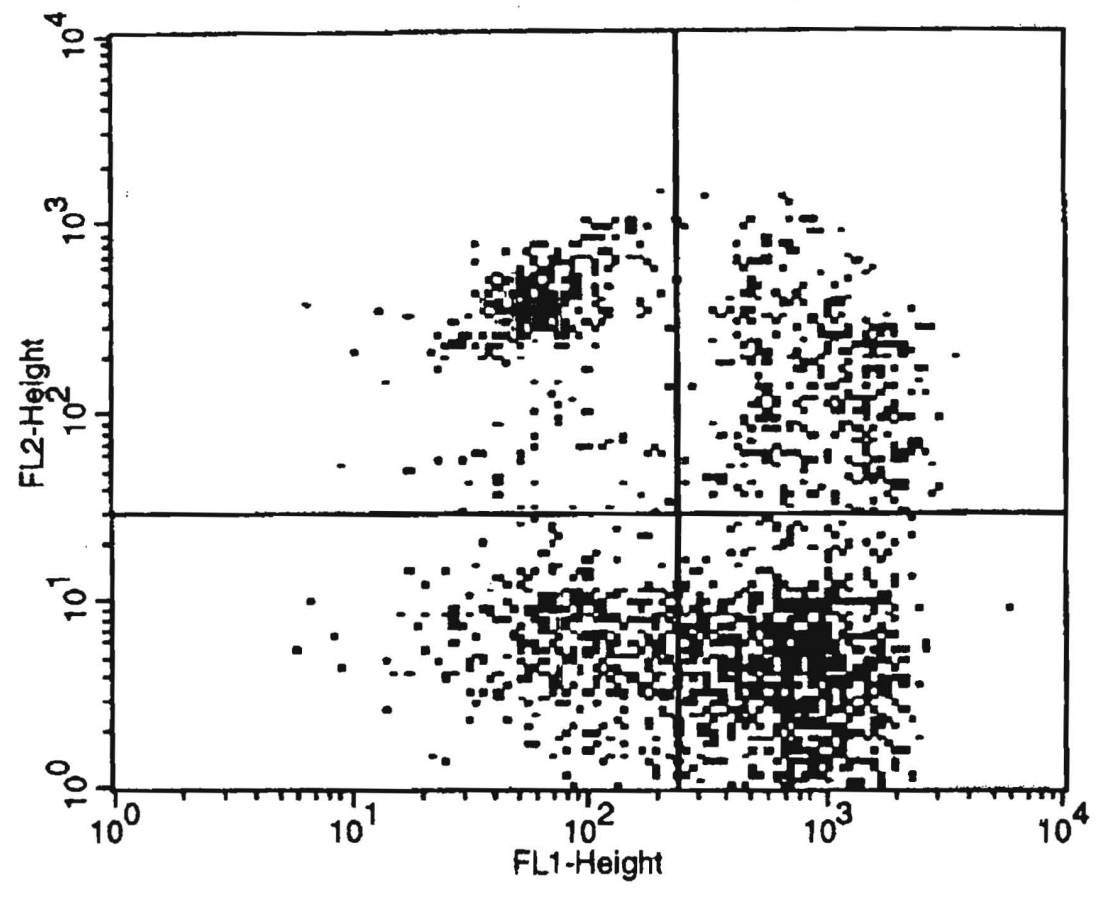

Figure 4.3b: CD45/19. T. pseudospiralis-infected mouse. R2 quandrant acquisition plot. Percent gated: $U L=17.25 ; \mathrm{UR}=17.45 ; \mathrm{LL}=19.70 ; \mathrm{LR}=45.60$. 


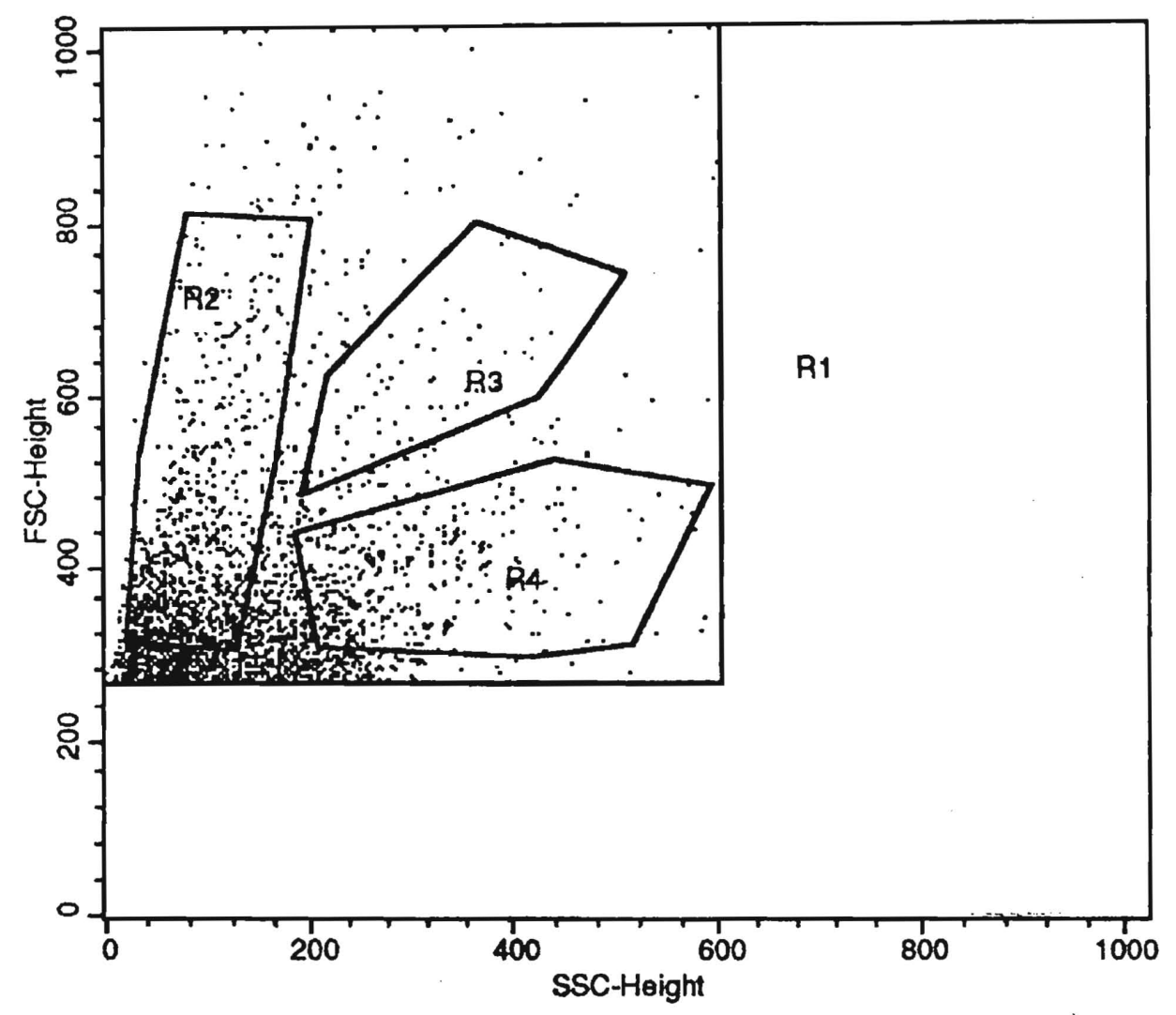

Figure 4.4a: CD45/19. T. spiralis-infected mouse. Total cell acquisition plot. Percent gated: $\mathrm{R} 1=100.00 ; \mathrm{R} 2=36.51 ; \mathrm{R} 3=2.03 ; \mathrm{R} 4=13.44$. 


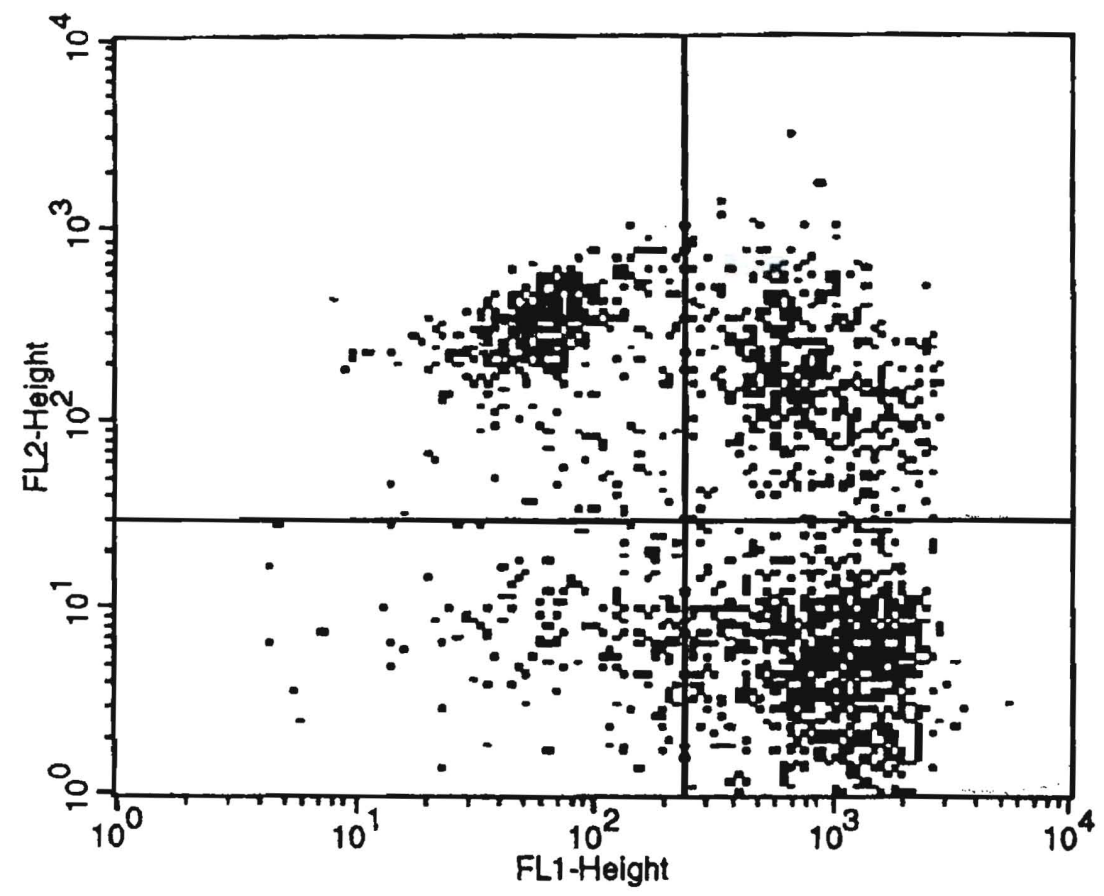

Figure 4.4b: CD45/19. T. spiralis-infected mouse. R2 quadrant acquisition plot. Percent gated: $\mathrm{UL}=21.75 ; \mathrm{UR}=23.50 ; \mathrm{LL}=8.85 ; \mathrm{LR}=45.90$. 


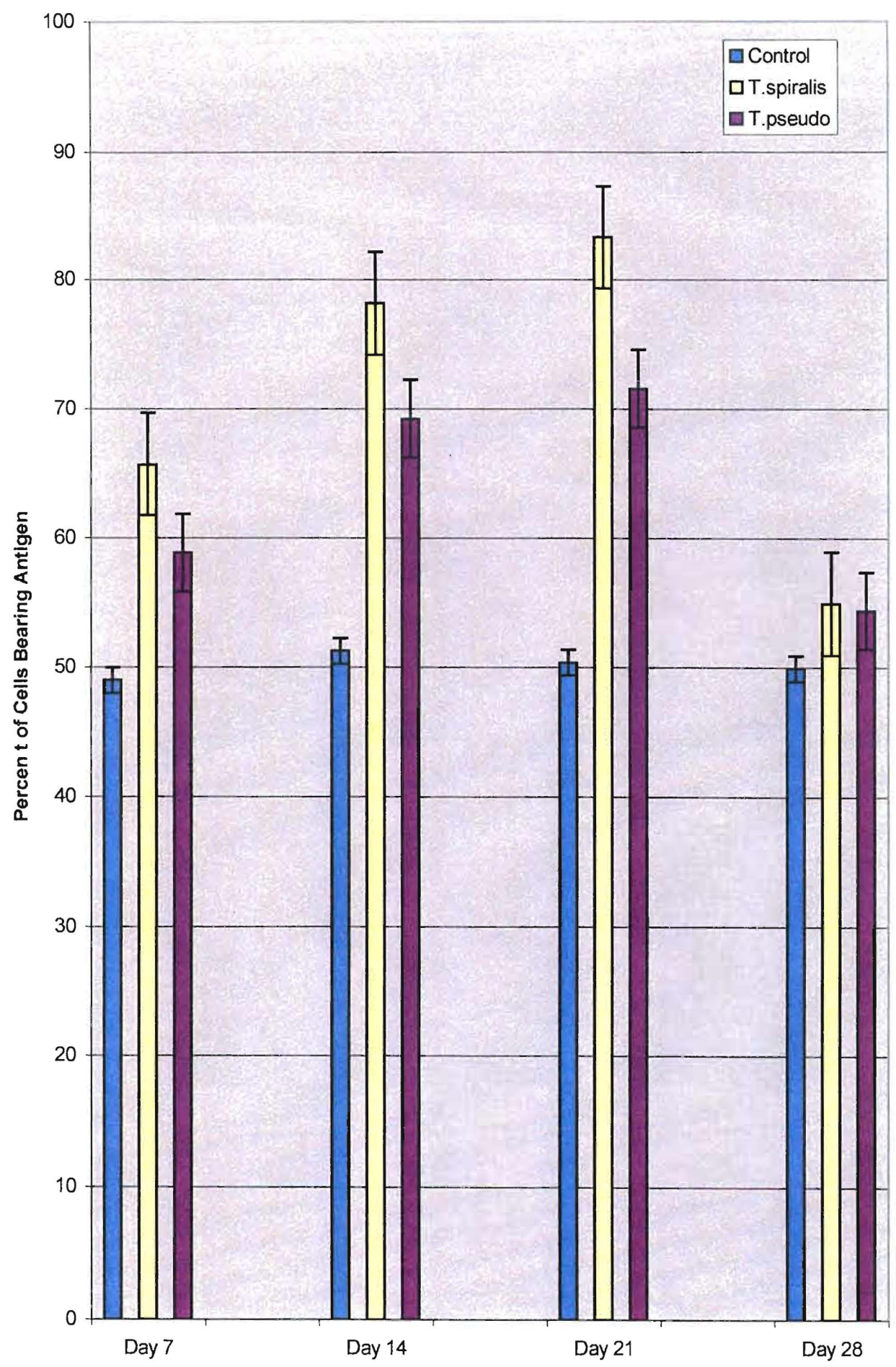

Figure 4.5: CD11b/MAC-1. Data represents the average of four experiments. $n=32$. 


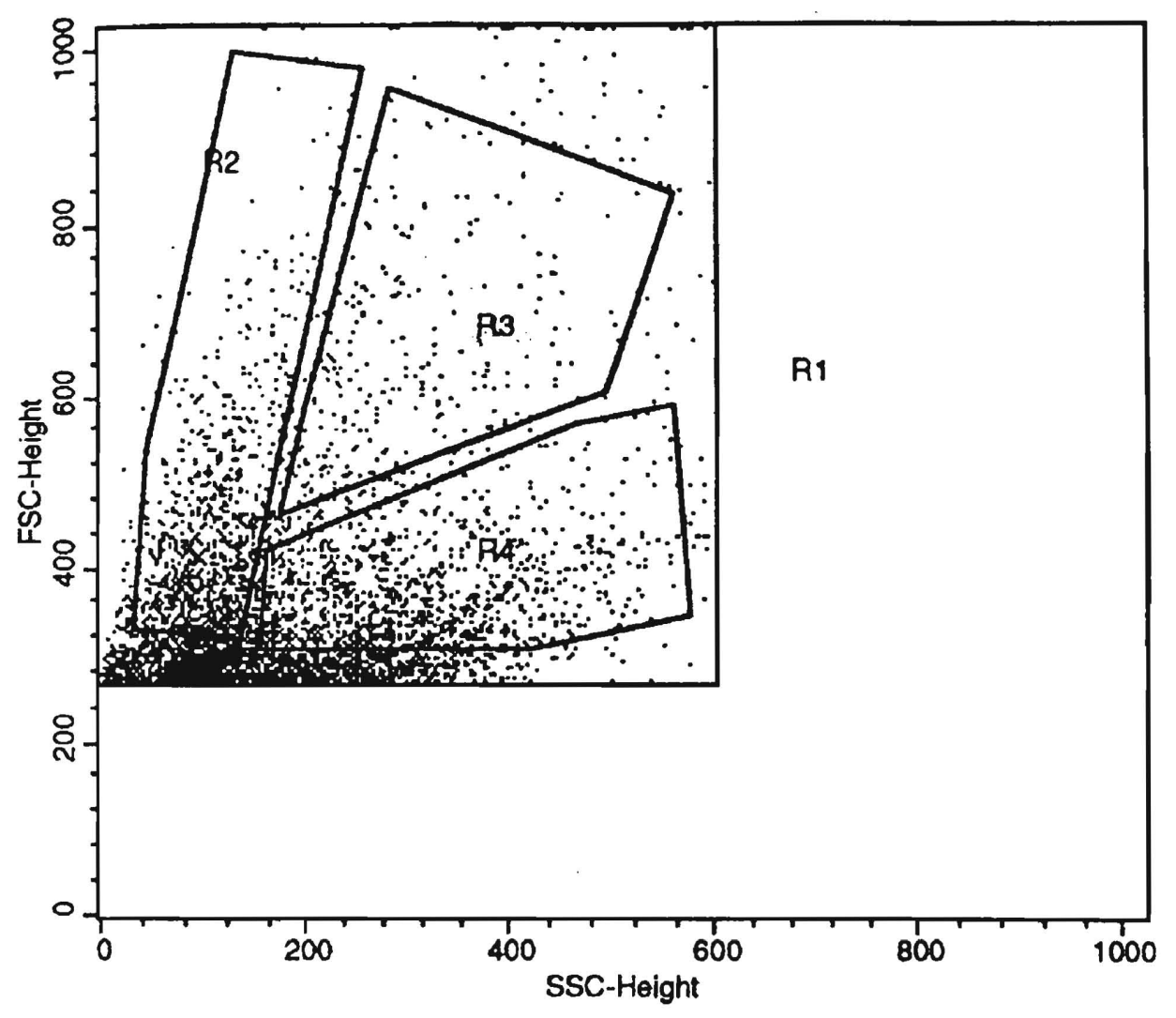

Figure 4.6a: CD45/11b. Uninfected control. Total cell acquisition plot. Percent gated: $\mathrm{R} 1=100.00 ; \mathrm{R} 2=20.34 ; \mathrm{R} 3=5.05 ; \mathrm{R} 4=22.57$. 


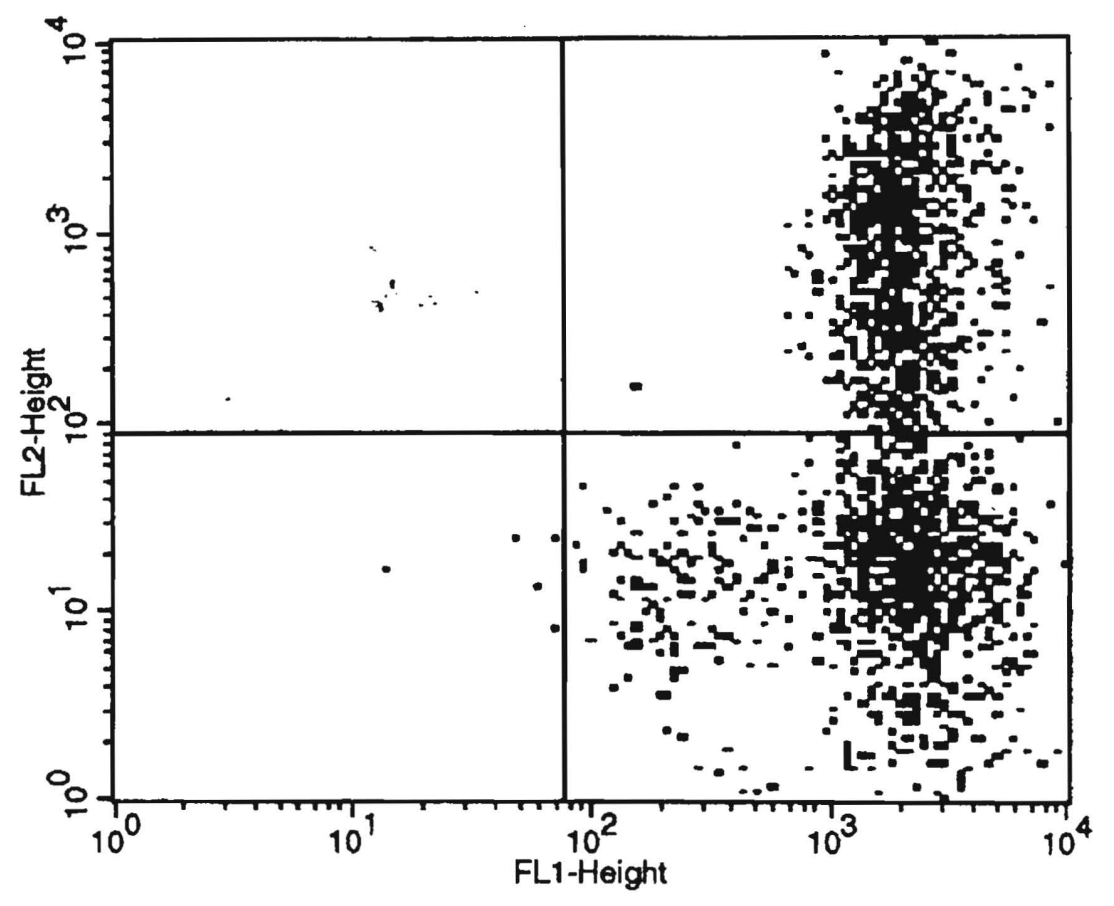

Figure 4.6b: CD45/11b. Uninfected control. R3/4 quadrant acquisition plot. Percent gated: $\mathrm{UL}=0.00 ; \mathrm{UR}=48.15 ; \mathrm{LL}=0.25 ; \mathrm{LR}=51.60$. 


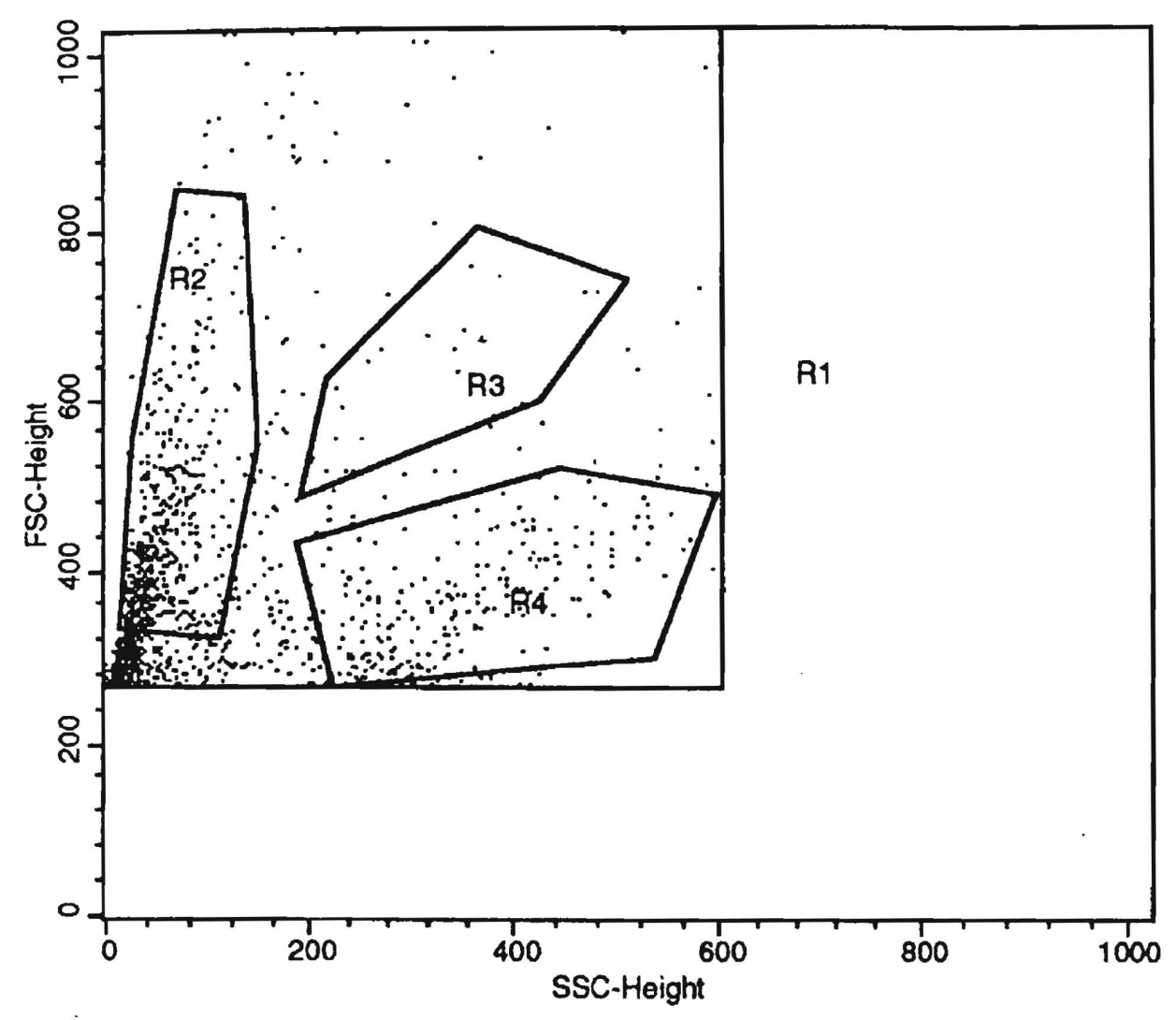

Figure 4.7a: CD45/11b. T. pseudospiralis-infected mouse. Total cell acquisition plot. Percent gated: $\mathrm{R} 1=100.00 ; \mathrm{R} 2=37.02 ; \mathrm{R} 3=1.55 ; \mathrm{R} 4=15.36$. 


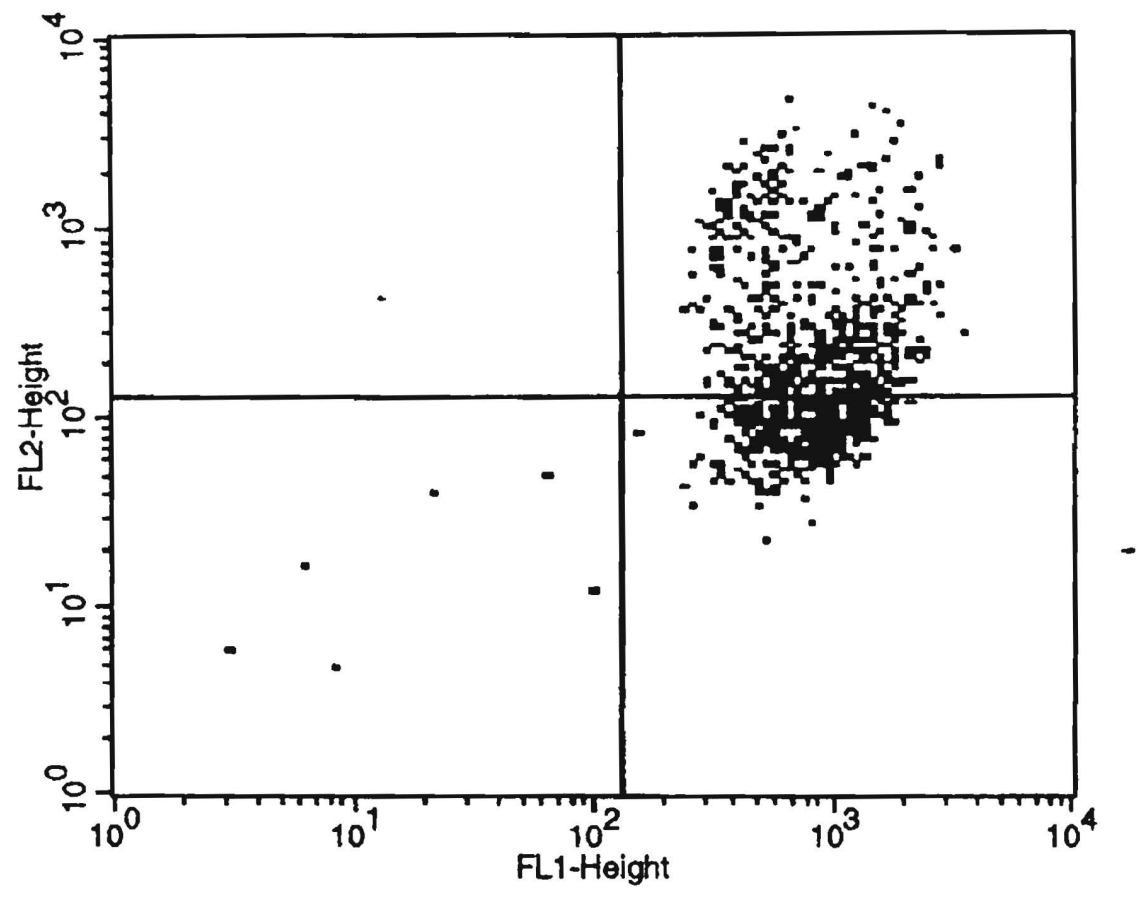

Figure 4.7b: CD45/11b. T. pseudospiralis-infected mouse. R3/4 quadrant acquisition plot. Percent gated: $\mathrm{UL}=0.00 ; \mathrm{UR}=54.60 ; \mathrm{LL}=0.60 ; \mathrm{LR}=44.80$. 


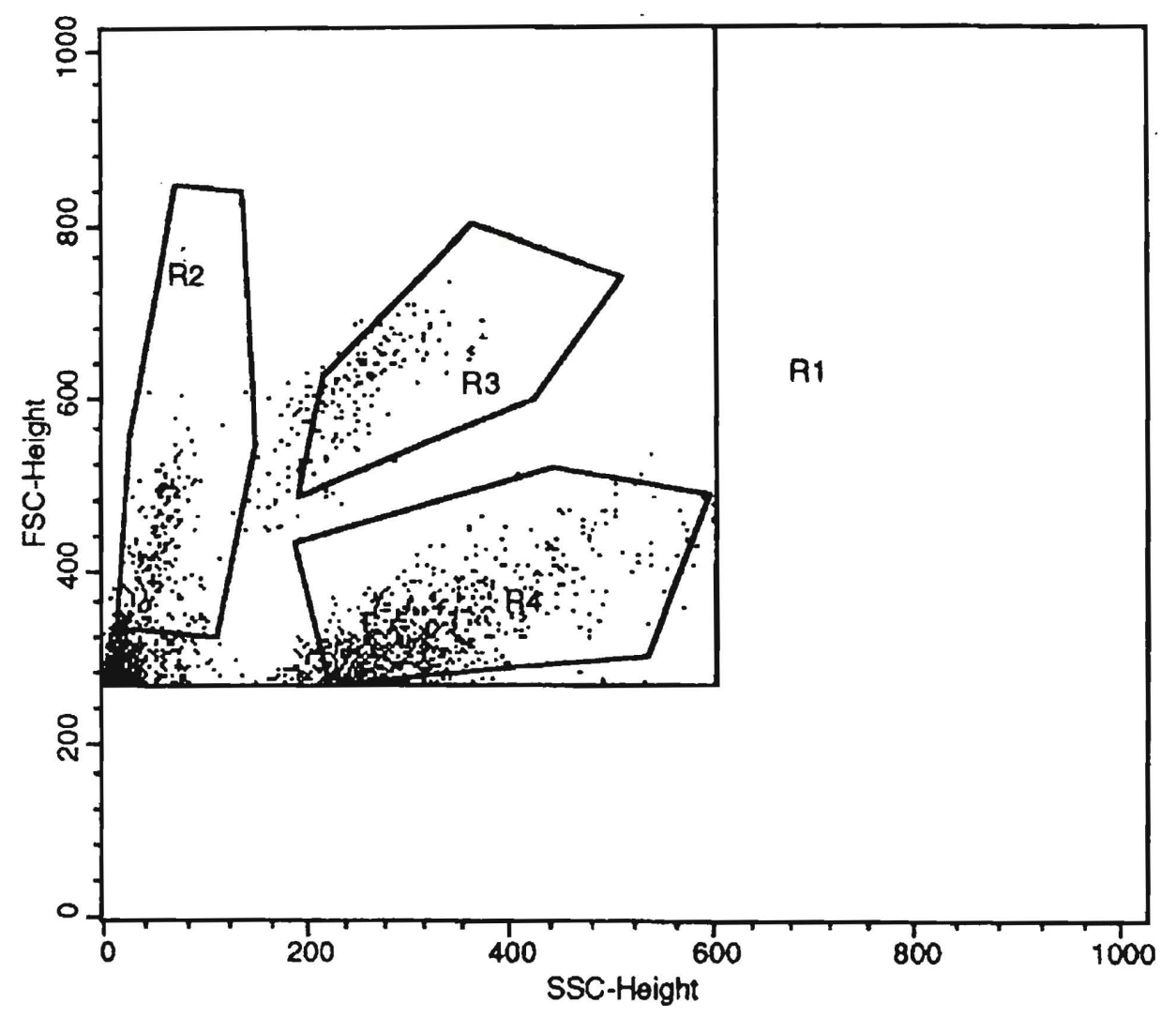

Figure 4.8a: CD45/11b. T. spiralis-infected mouse. Total cell acquisition plot. Percent gated: $\mathrm{R} 1=100.00 ; \mathrm{R} 2=12.91 ; \mathrm{R} 3=7.15 ; \mathrm{R} 4=37.12$. 


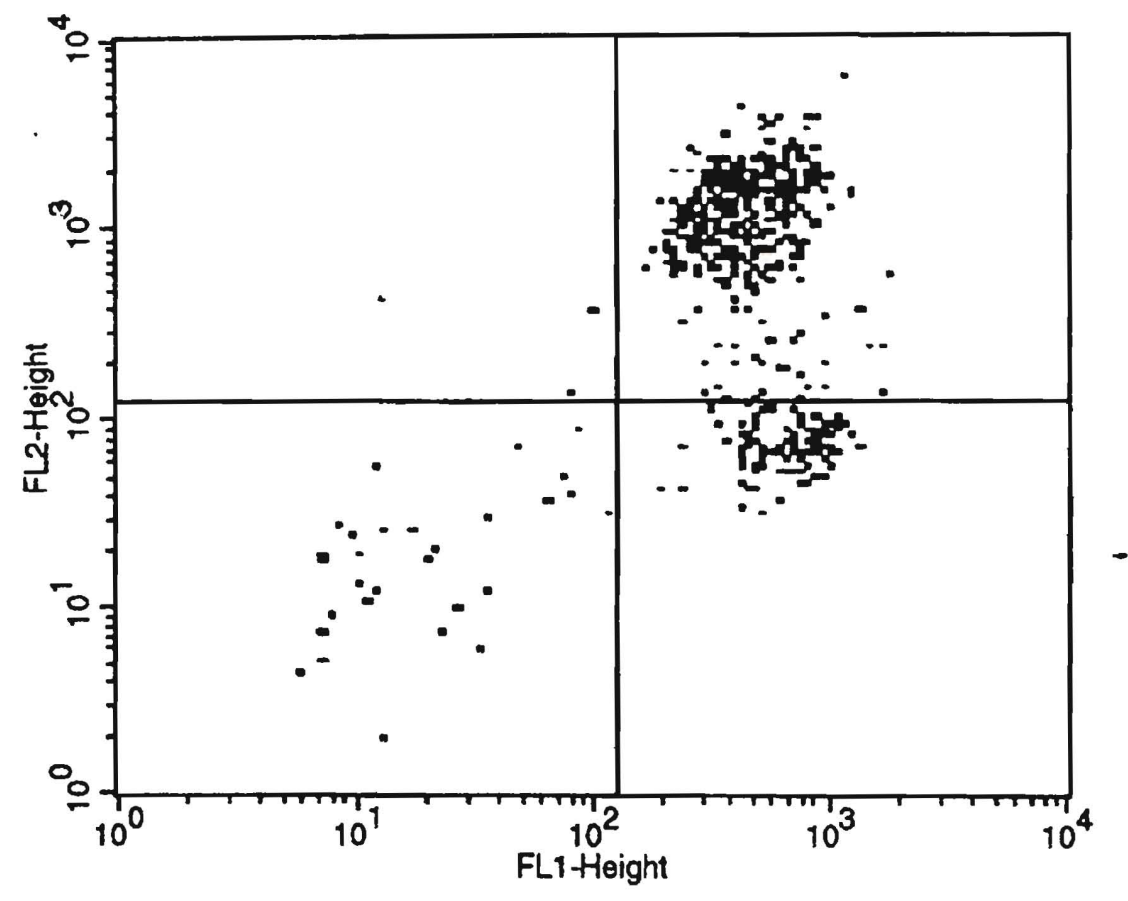

Figure 4.8b: CD45/11b. T spiralis-infected mouse. R3/4 quadrant acquisition plot. Percent gated: $\mathrm{UL}=0.40 ; \mathrm{UR}=72.80 ; \mathrm{LL}=5.80 ; \mathrm{LR}=21.00$. 


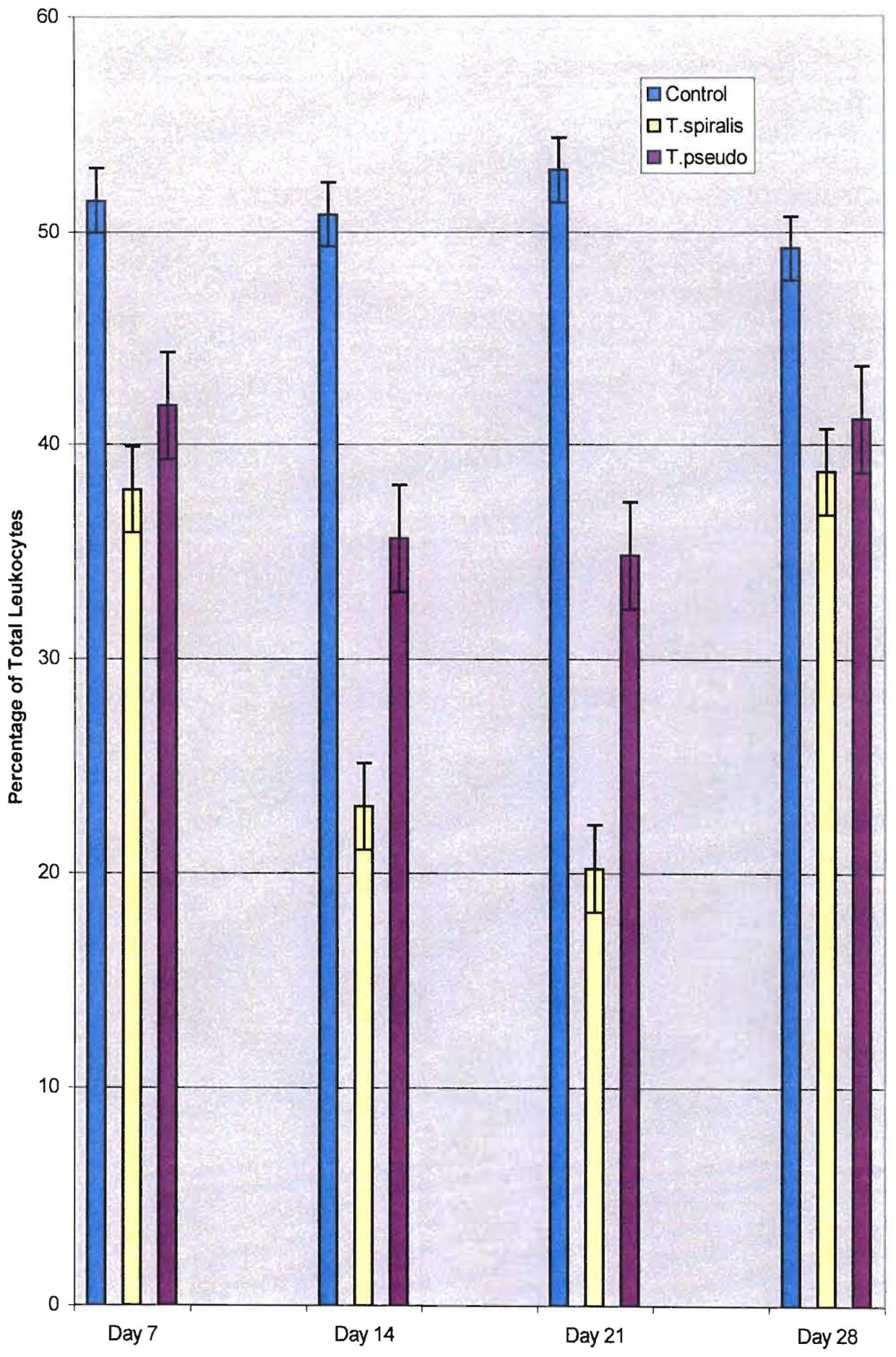

Figure 4.9: CD 62L. Data is the average of four separate experiments. $n=32$ 


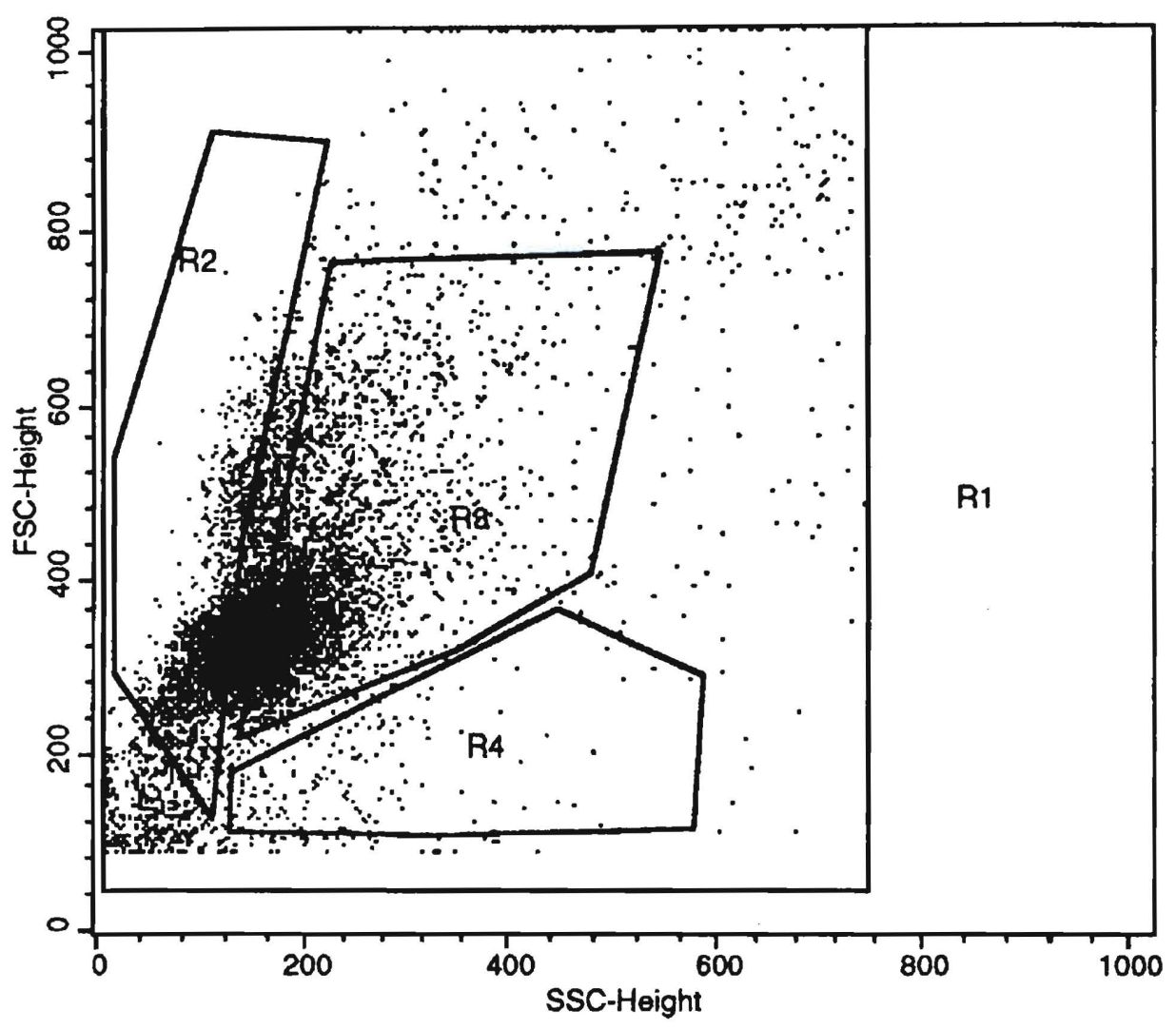

Figure 4.10a: CD45/62L. Uninfected control. Total cell acquisition plot. Percent gated: $\mathrm{R} 1=100.00 ; \mathrm{R} 2=22.24 ; \mathrm{R} 3=45.52 ; \mathrm{R} 4=1.43$. 


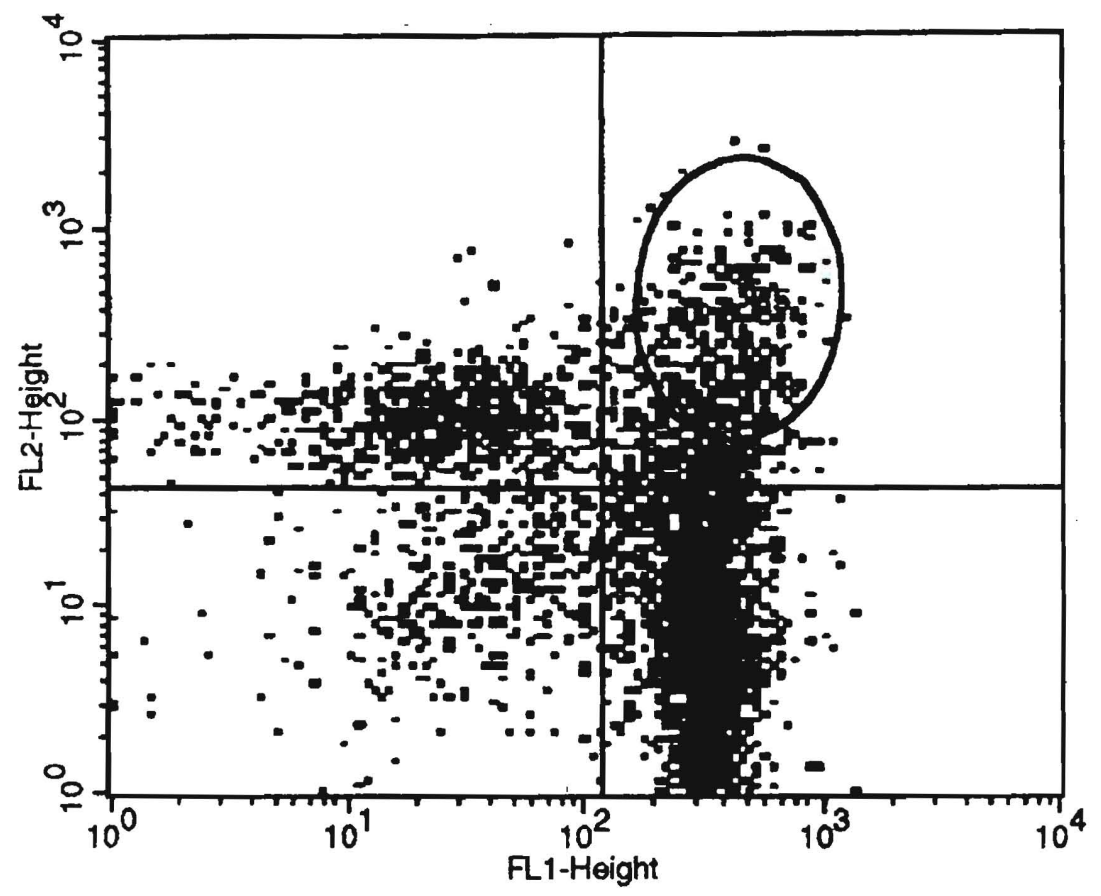

Figure 4.10b: CD45/62L. Uninfected control. R2 quadrant acquisition plot. Percent gated: $\mathrm{UL}=17.17 ; \mathrm{UR}=20.12 ; \mathrm{LL}=8.96 ; \mathrm{LR}=53.75$. 


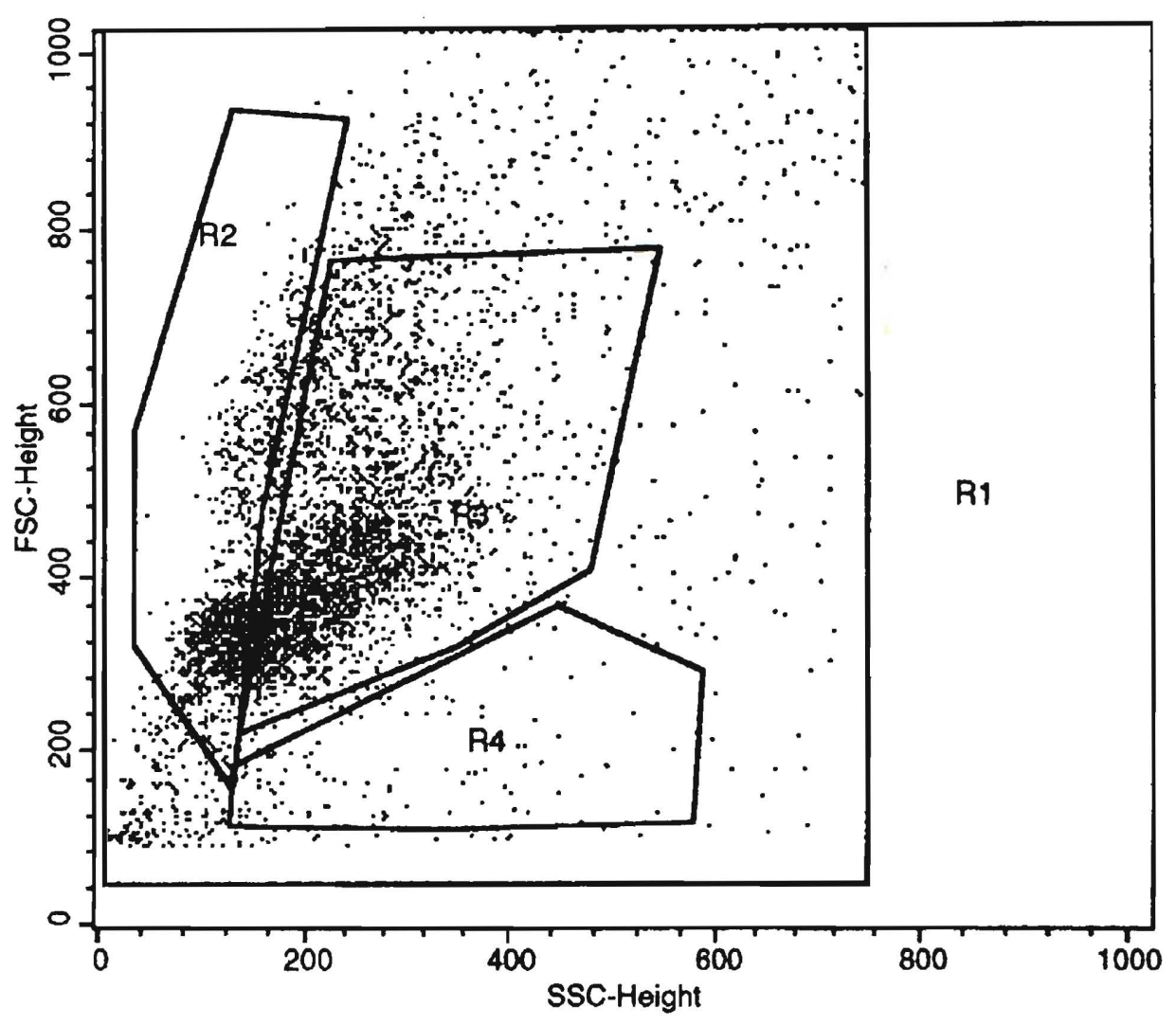

Figure 4.11a: CD45/62L. T pseudospiralis-infected mouse. Total cell acquisition plot. Percent gated: $\mathrm{R} 1=100.00 ; \mathrm{R} 2=21.44 ; \mathrm{R} 3=57.07 ; \mathrm{R} 4=2.03$. 


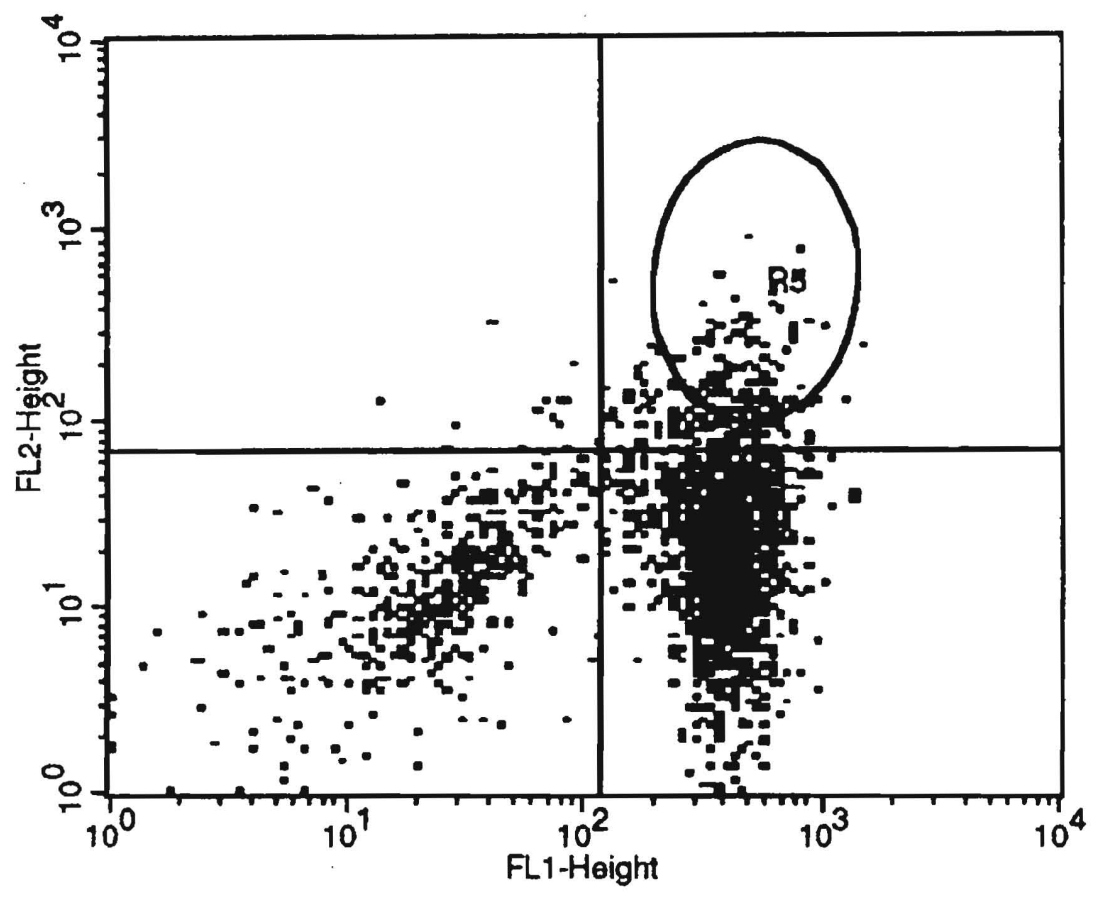

Figure 4.11b: CD45/62L. T. pseudospiralis-infected mouse. R2 quadrant acquisition plot. Percent gated: $\mathrm{UL}=0.68 ; \mathrm{UR}=12.81 ; \mathrm{LL}=19.74 ; \mathrm{LR}=66.77$. 


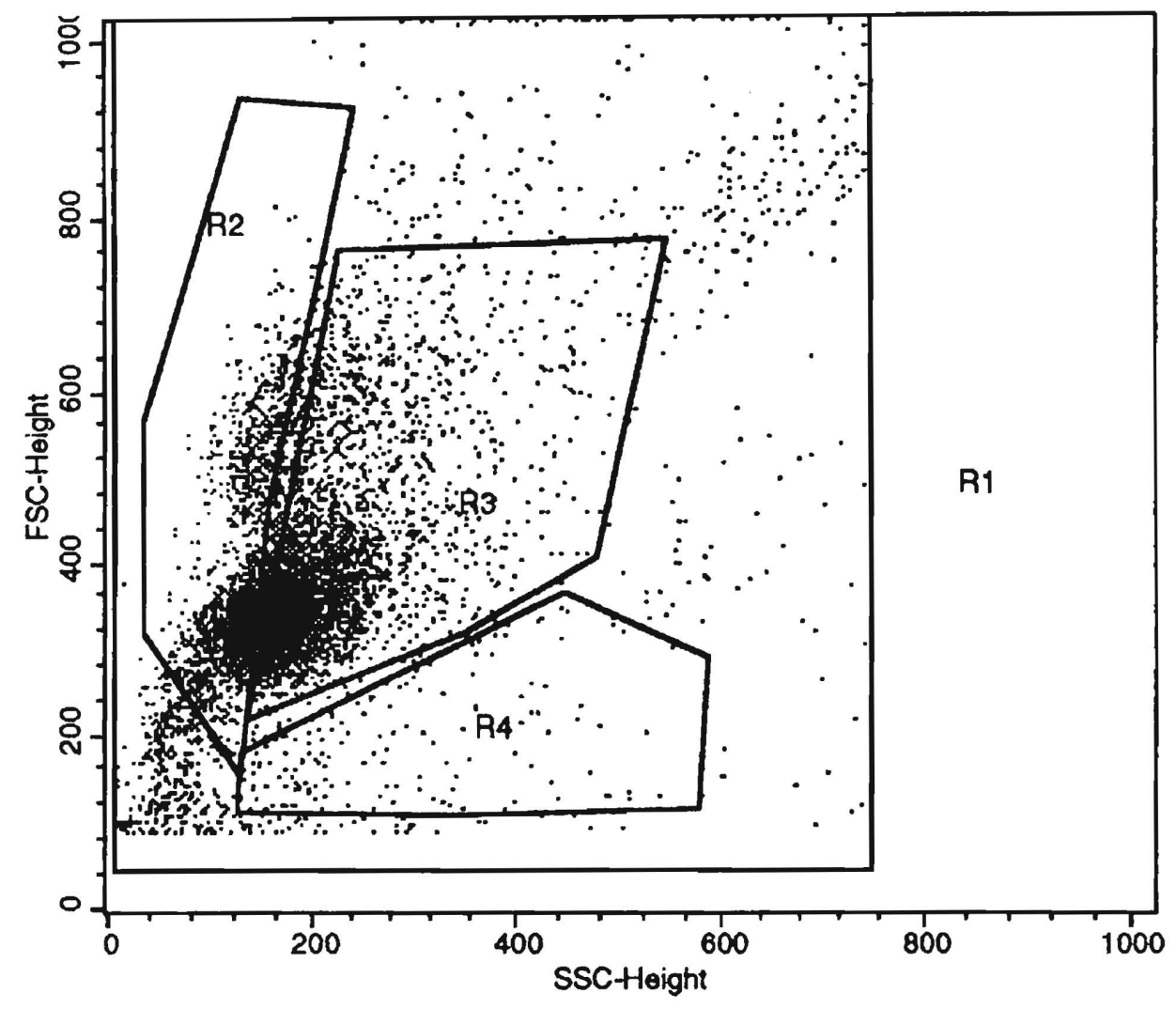

Figure 4.12a: CD45/62L. T. spiralis-infected mouse Total cell acquisition plot. Percent gated: $\mathrm{R} 1=100.00 ; \mathrm{R} 2=25.75 . \mathrm{R} 3=54.08 ; \mathrm{R} 4=1.95$. 


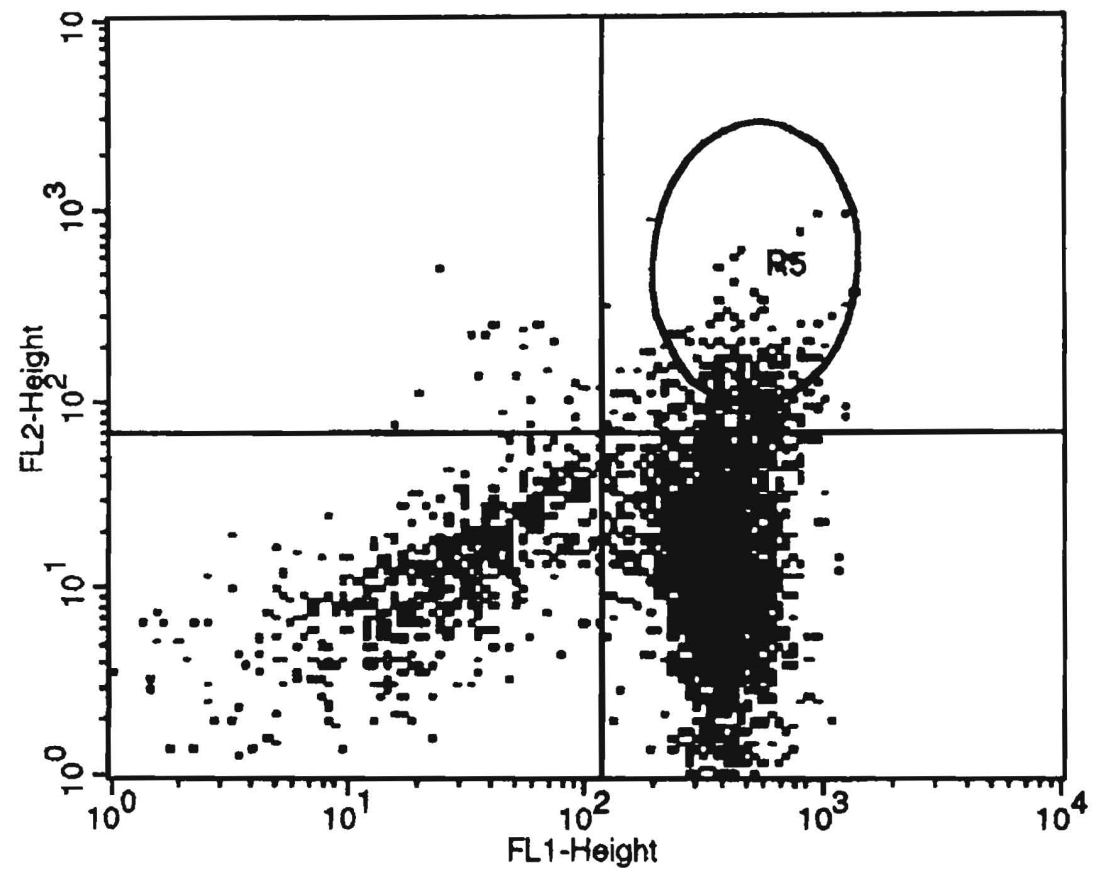

Figure 4.12b: CD45/62L. T. spiralis-infected mouse. R2 quadrant acquisition plot. Percent gated: $\mathrm{UL}=0.56 . \mathrm{UR}=9.36 ; \mathrm{LL}=16.35 ; \mathrm{LR}=73.73$. 


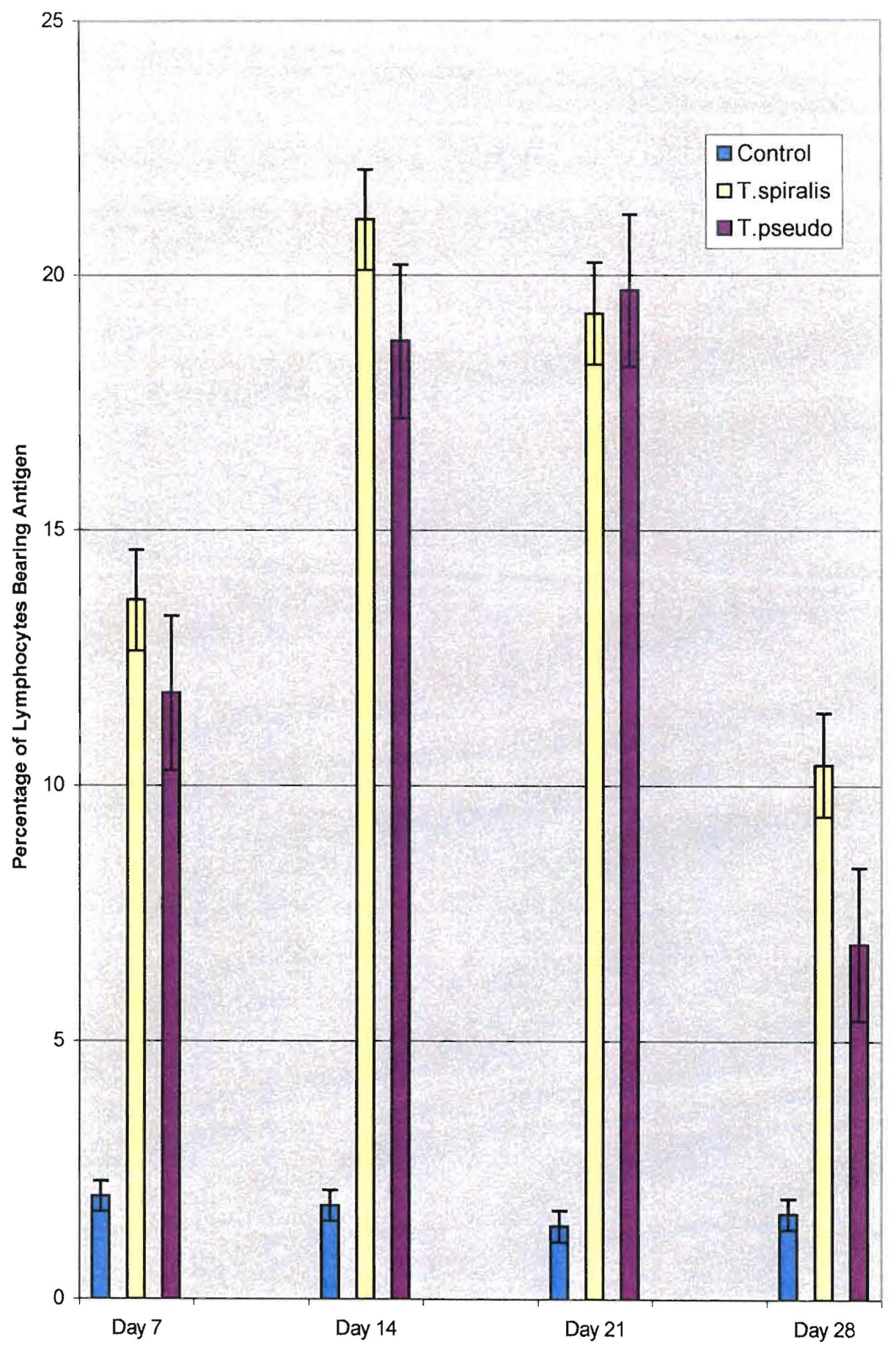

Figure 4.13: CD69/Early Activation Antigen. Data is the average of four separate experiments. $n=32$ 


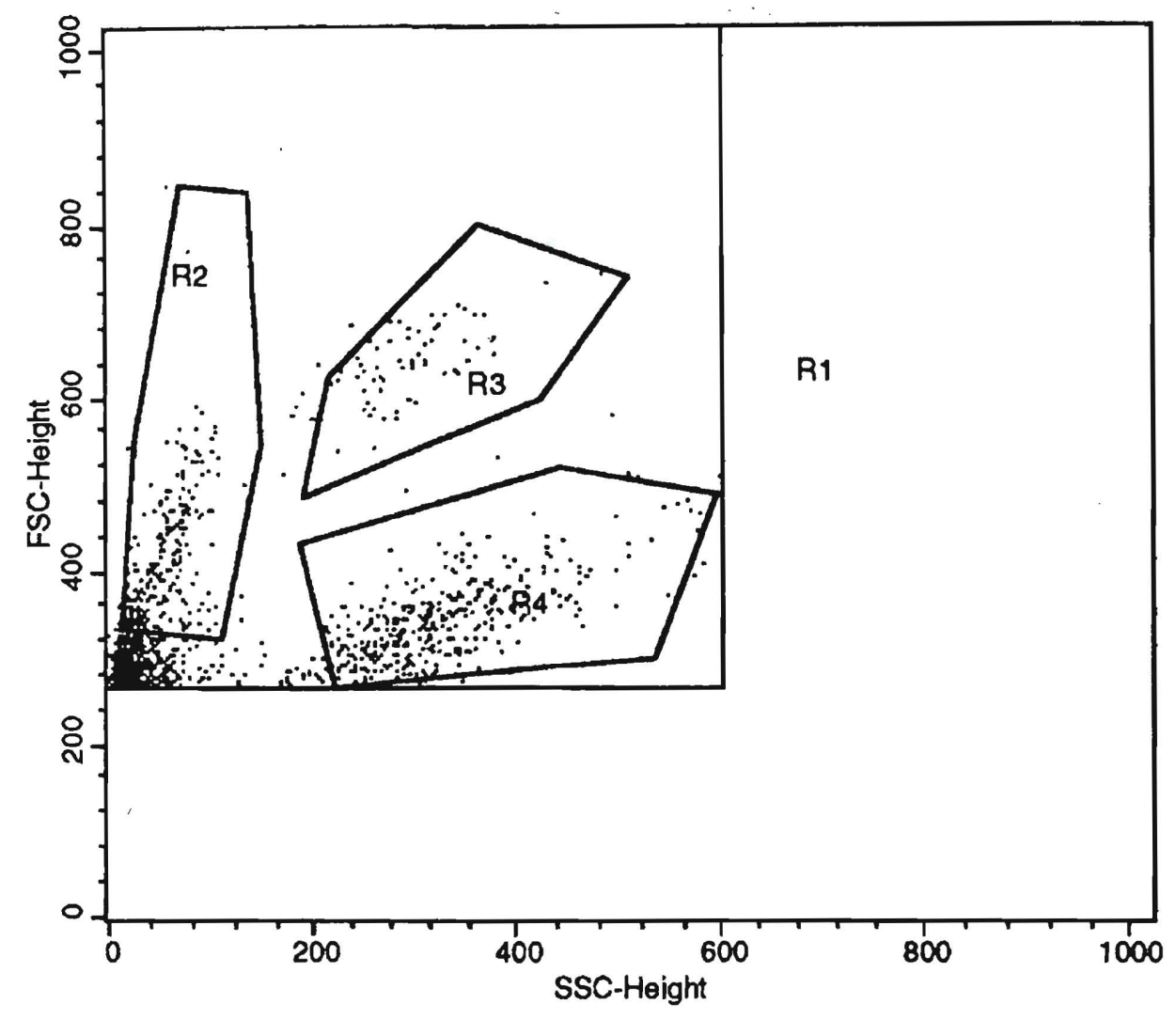

Figure 4.14a: CD45/69. Uninfected control. Total cell acquisition plot. Percent gated: $\mathrm{R} 1=100.00 ; \mathrm{R} 2=17.81 ; \mathrm{R} 3=5.06 ; \mathrm{R} 4=24.32$. 


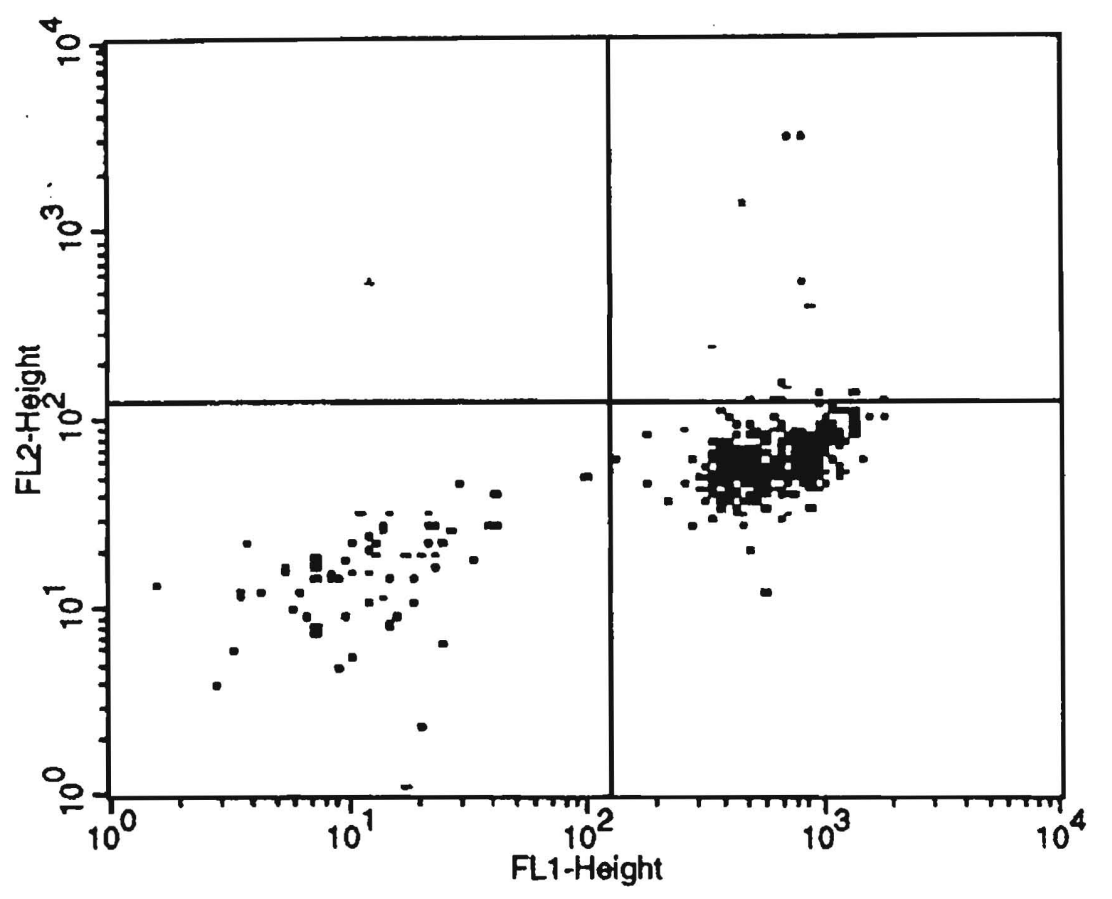

Figure 4.14b: CD45/69. Uninfected control. R2 quadrant acquisition plot. Percent gated: $\mathrm{UL}=0.00 ; \mathrm{UR}=2.80 ; \mathrm{LL}=13.80 ; \mathrm{LR}=83.40$. 


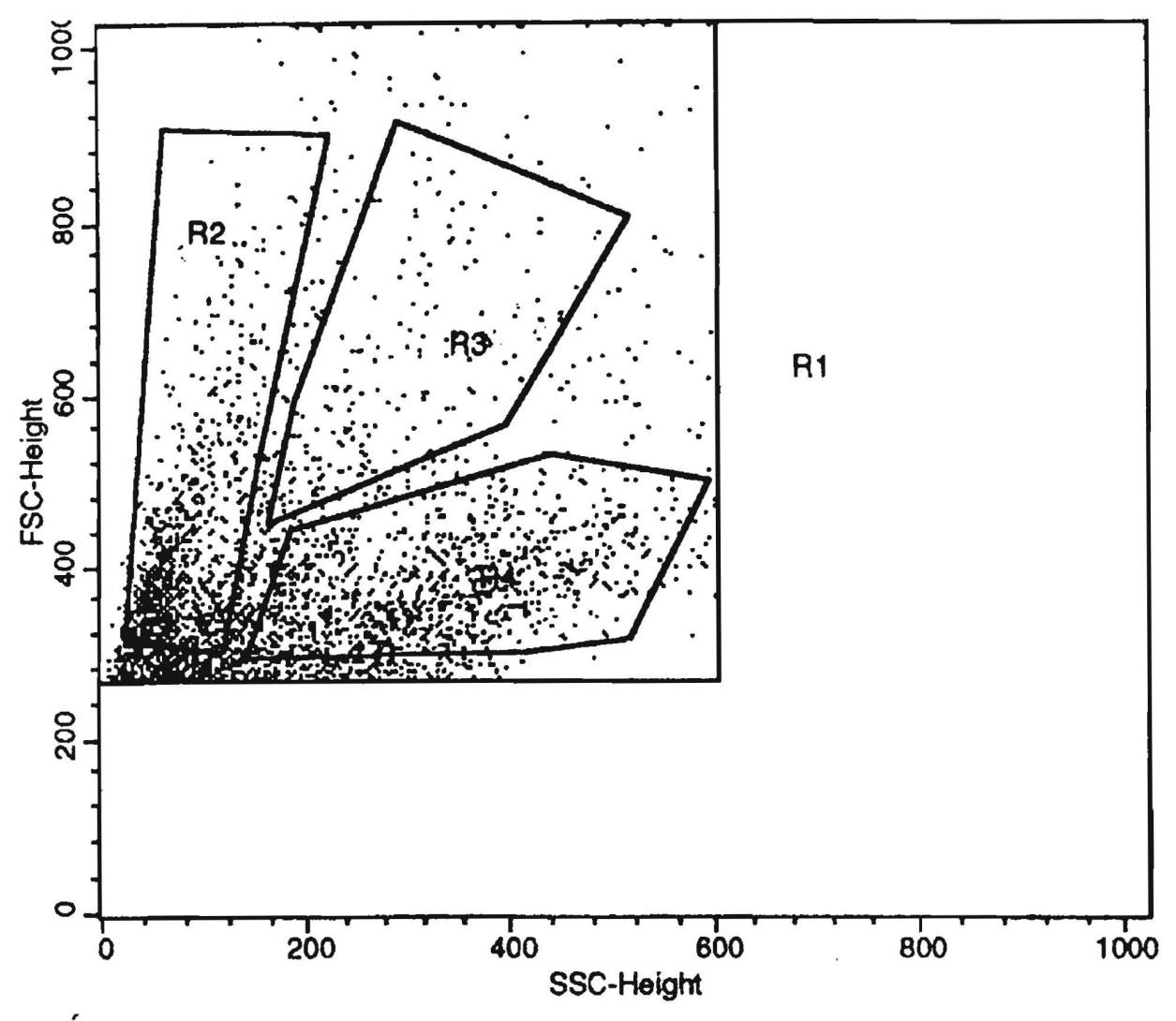

Figure 4.15a: CD45/69. T. pseudospiralis-infected mouse. Total cell acquisition plot. Percent gated: $\mathrm{R} 1=100.00 ; \mathrm{R} 2=31.11 ; \mathrm{R} 3=5.40 ; \mathrm{R} 4=31.02$. 


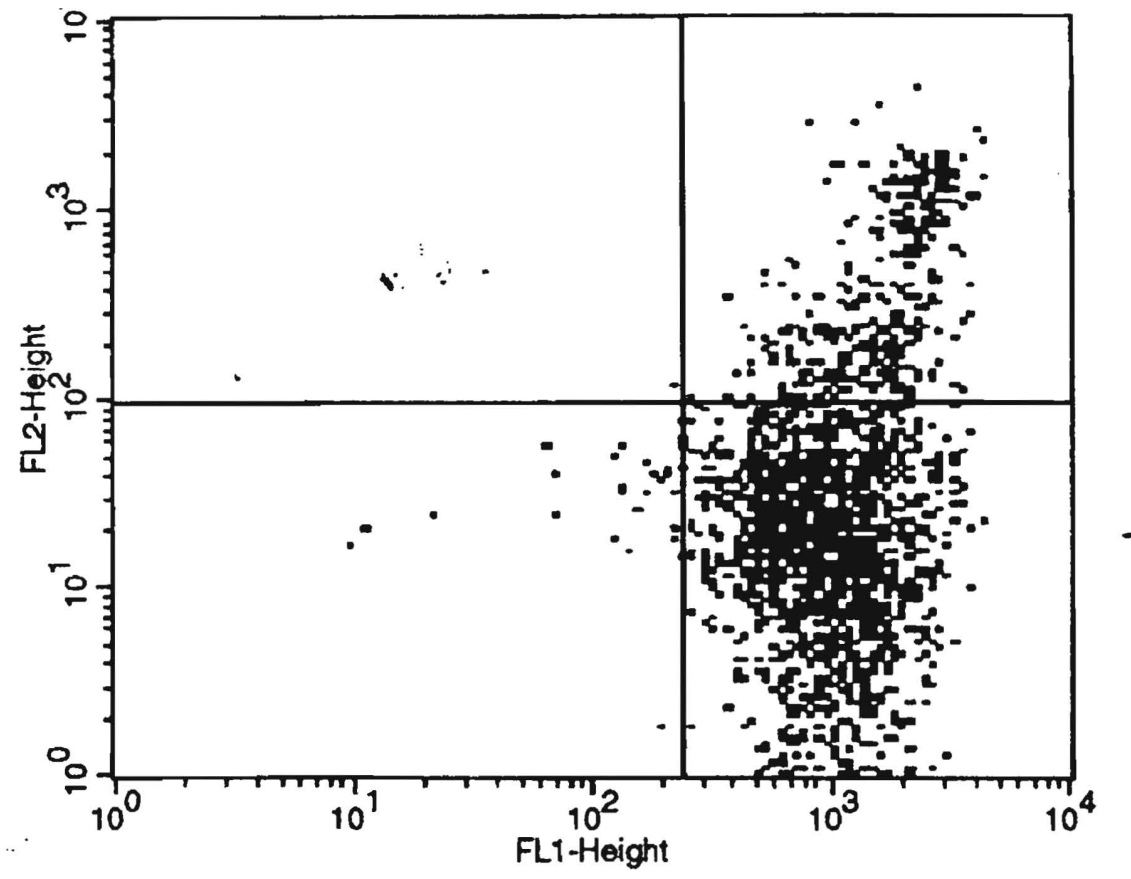

Figure 4.15b: CD45/69. T. pseudospiralis-infected mouse. R2 quadrant acquisition Plot. Percent gated: $\mathrm{UL}=0.05 ; \mathrm{UR}=18.70 ; \mathrm{LL}=1.70 ; \mathrm{LR}=79.55$. 


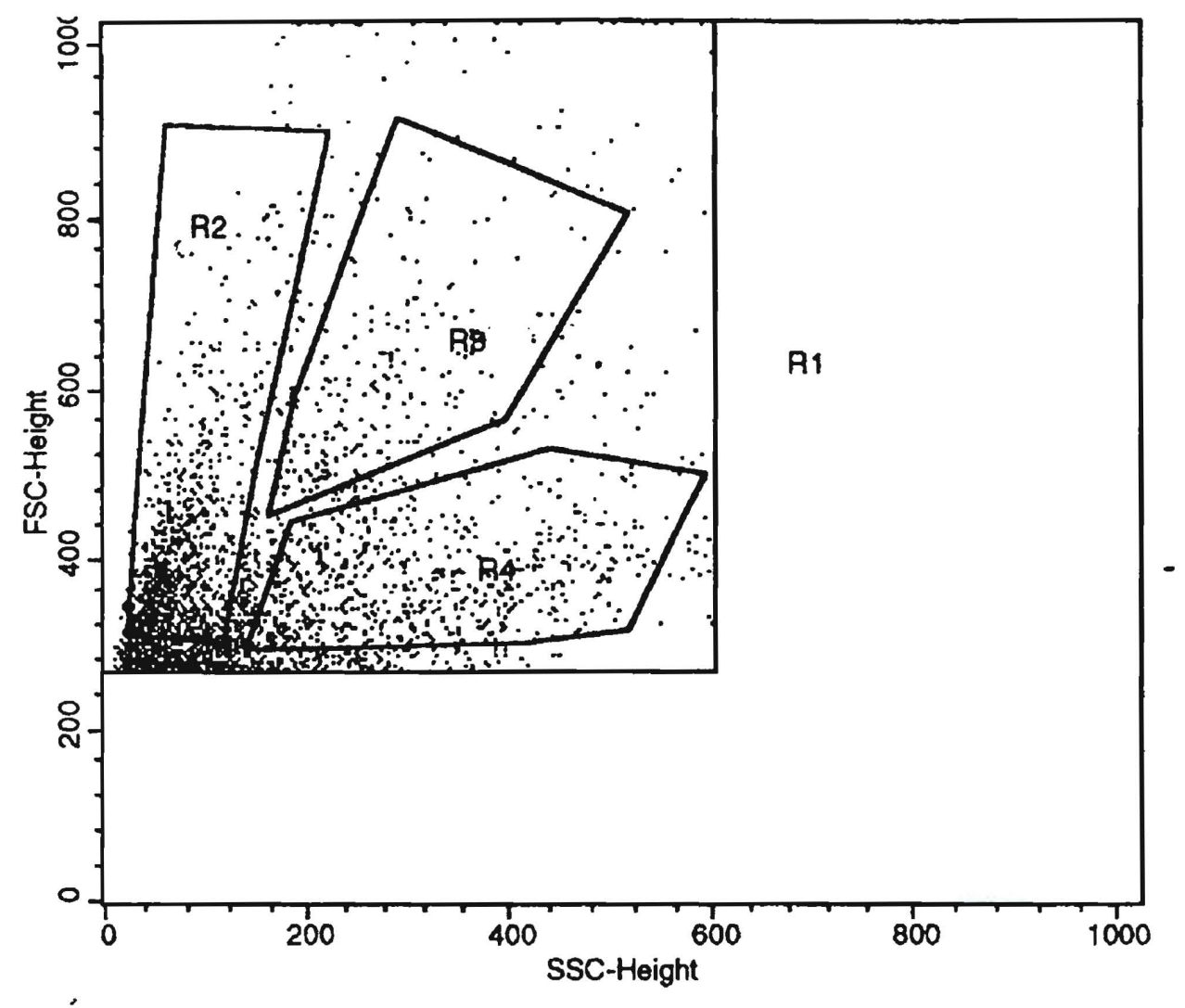

Figure 4.16a: CD45/69. T. spiralis-infected mouse. Total cell acquisition plot. Percent gated: $\mathrm{R} 1=100.00 ; \mathrm{R} 2=35.41 ; \mathrm{R} 3=6.73 ; \mathrm{R} 4=22.24$. 


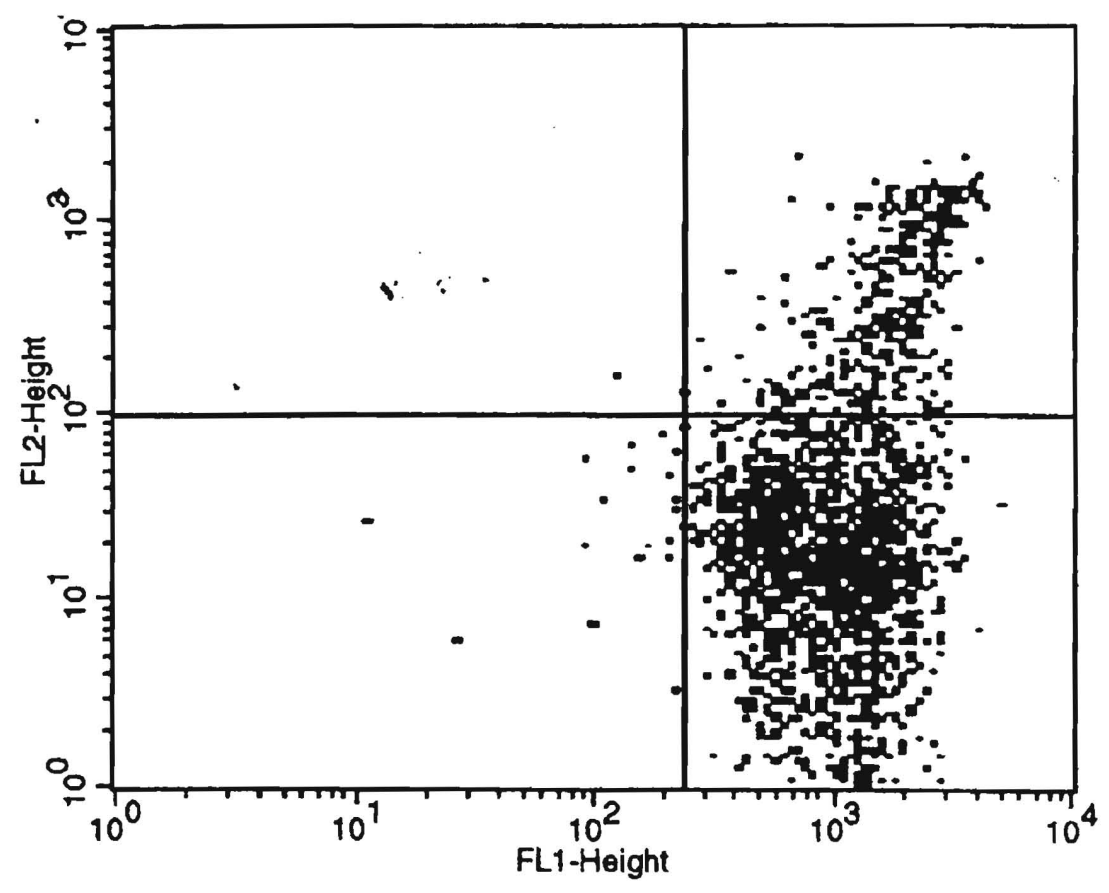

Figure 4.16b: CD45/69. T. spiralis-infected mouse. R2 quadrant acquisition plot. Percent gated: $\mathrm{UL}=0.10 ; \mathrm{UR}=19.25 ; \mathrm{LL}=1.10 ; \mathrm{LR}=79.55$. 


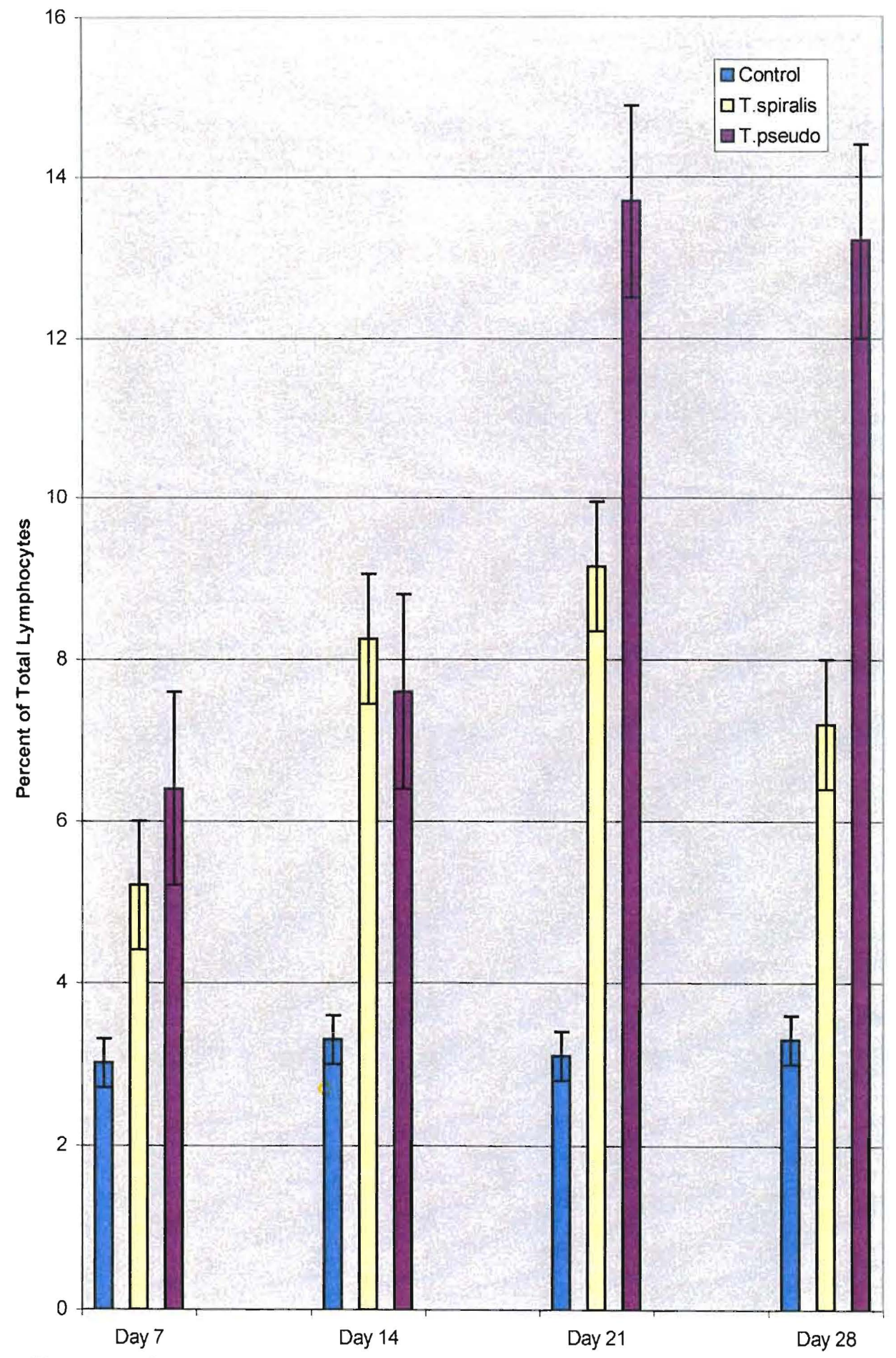

Flgure 4.17: CD8 Possitive cells. Data is the average of four experiments. Only splenic cytotoxic $\mathrm{T}$-cells are represented. $\mathrm{n}=\mathbf{3 2}$. 


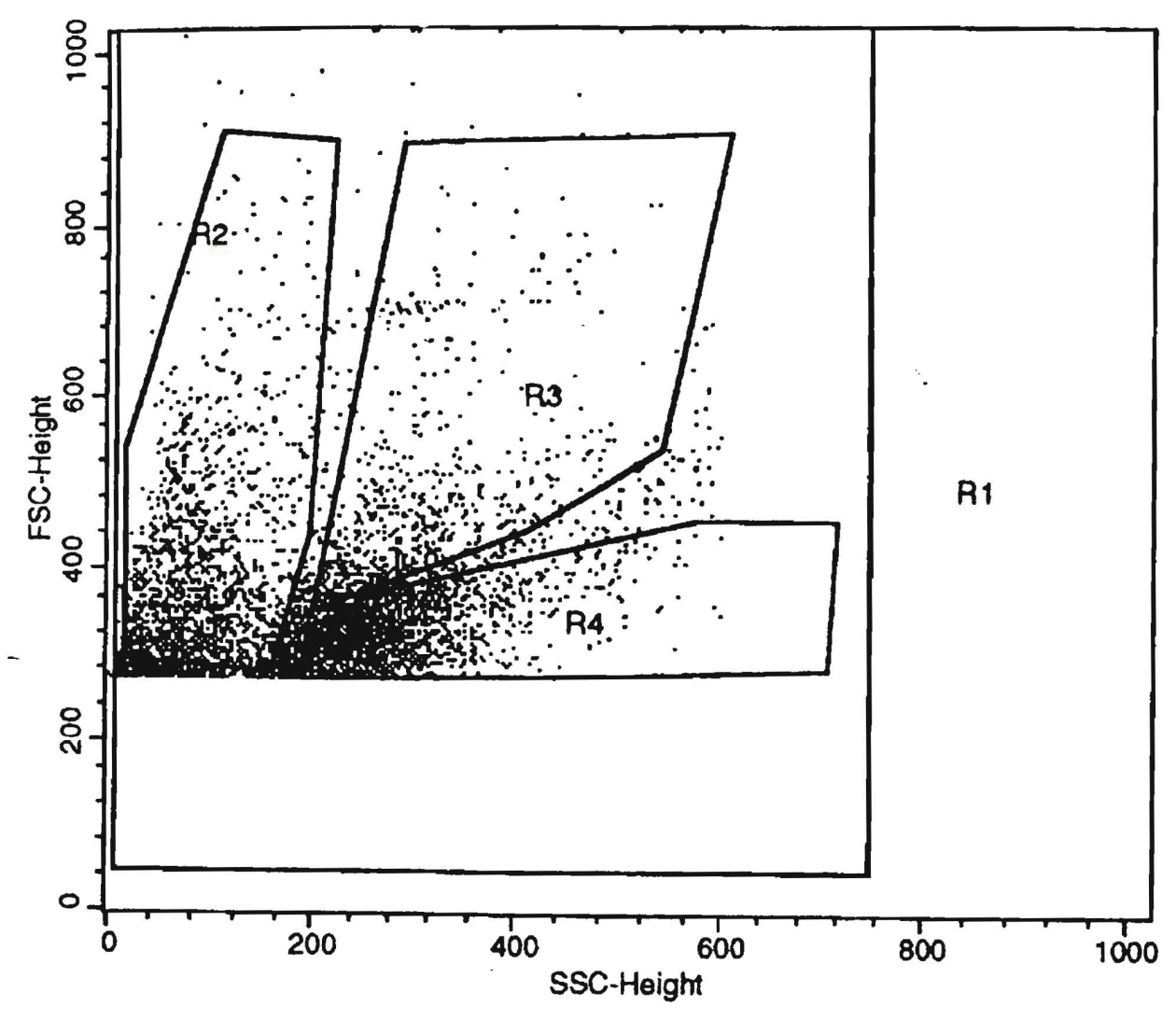

Figure 4.18a: CD45/8. Uninfected control. Total cell acquisition plot. Percent gated: $\mathrm{R} 1=100.00 ; \mathrm{R} 2=28.30 ; \mathrm{R} 3=12.23 ; \mathrm{R} 4=34.24$. 


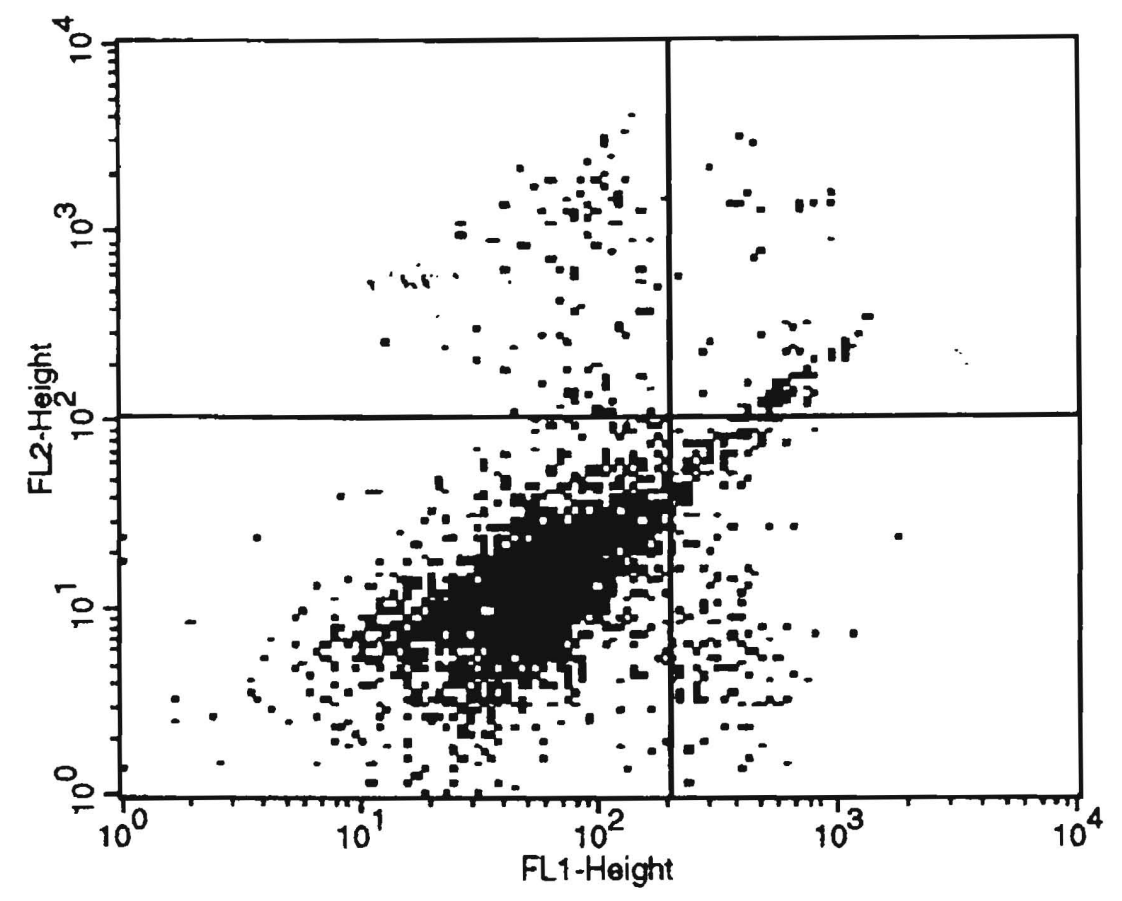

Figure 4.18b: CD45/8. Uninfected control. R2 quadrant acquisition plot. Percent gated: $\mathrm{UL}=3.01 ; \mathrm{UR}=2.85 ; \mathrm{LL}=88.72 ; \mathrm{LR}=5.42$. 


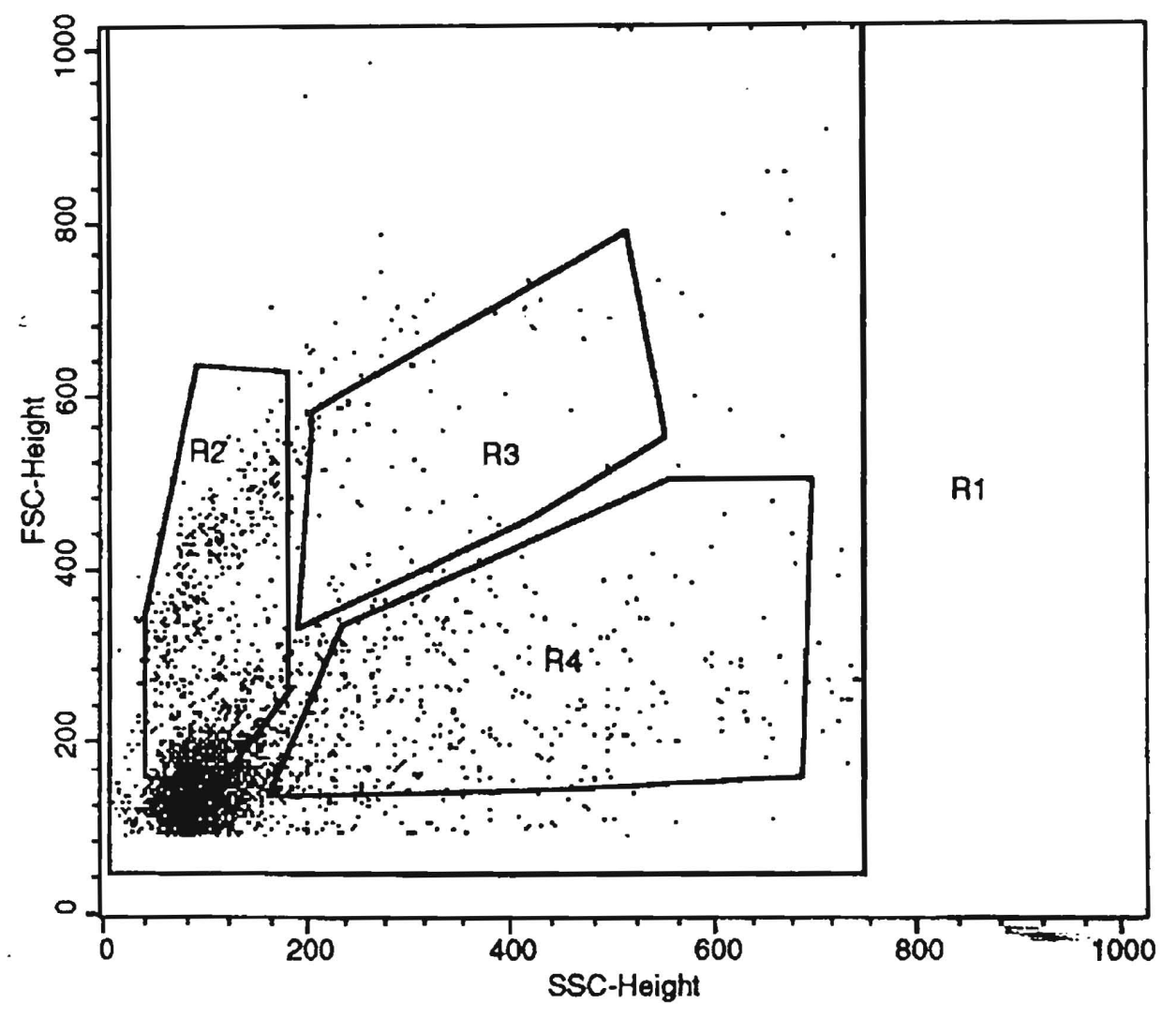

Figure 4.19a: CD45/8. T. pseudospiralis-infected mouse. Total cell acquisition plot. Percent gated: $\mathrm{R} 1=100.00 ; \mathrm{R} 2=31.79 ; \mathrm{R} 3=1.95 ; \mathrm{R} 4=10.92$. 


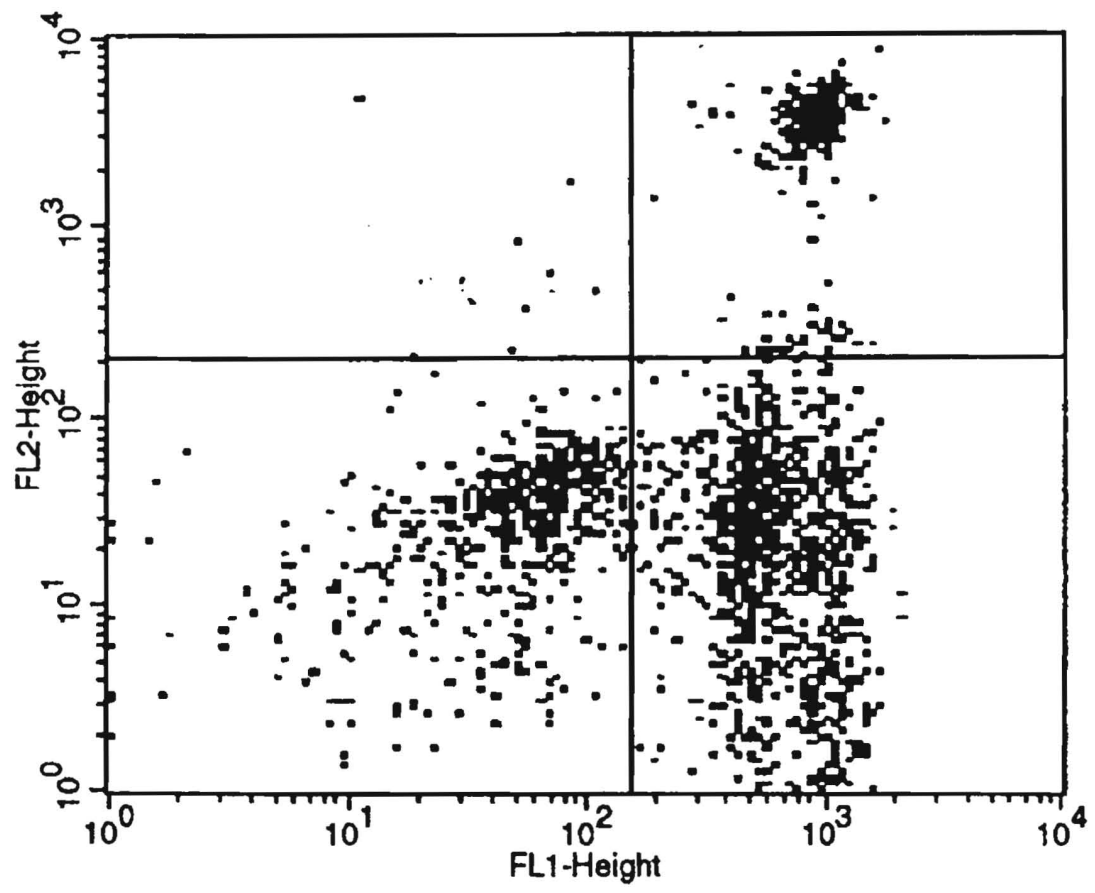

Figure 4.19b: CD45/8. T. pseudospiralis-infected mouse. R2 quadrant acquisition plot. $\mathrm{UL}=0.40 ; \mathrm{UR}=13.70 ; \mathrm{LL}=30.05 ; \mathrm{LR}=55.85$. 


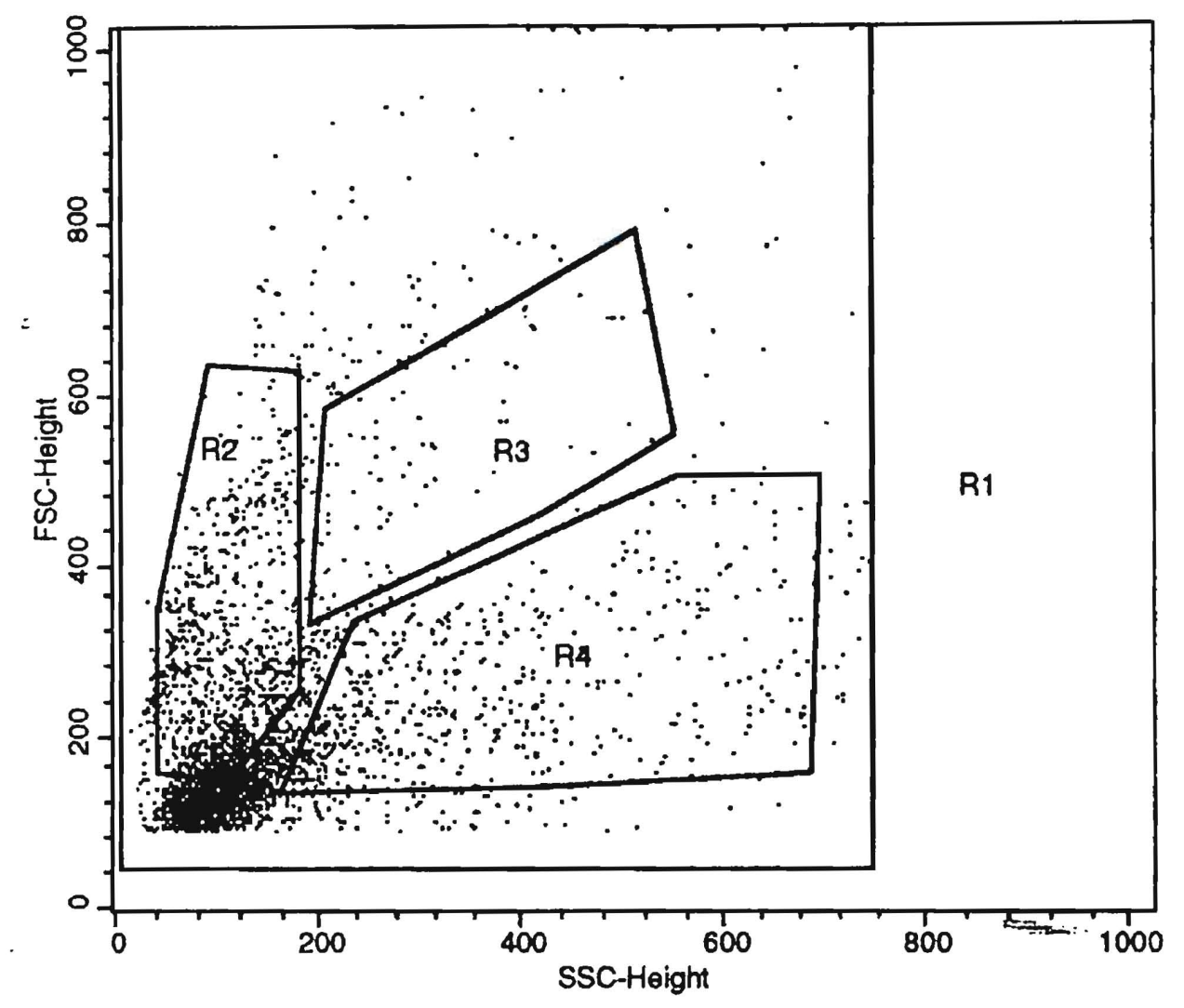

Figure 4.20a: CD45/8. T. spiralis-infected mouse. Total cell acquisition plot. Percent gated: $\mathrm{R} 1=100.00 ; \mathrm{R} 2=28.47 ; \mathrm{R} 3=2.31 ; \mathrm{R} 4=14.70$. 


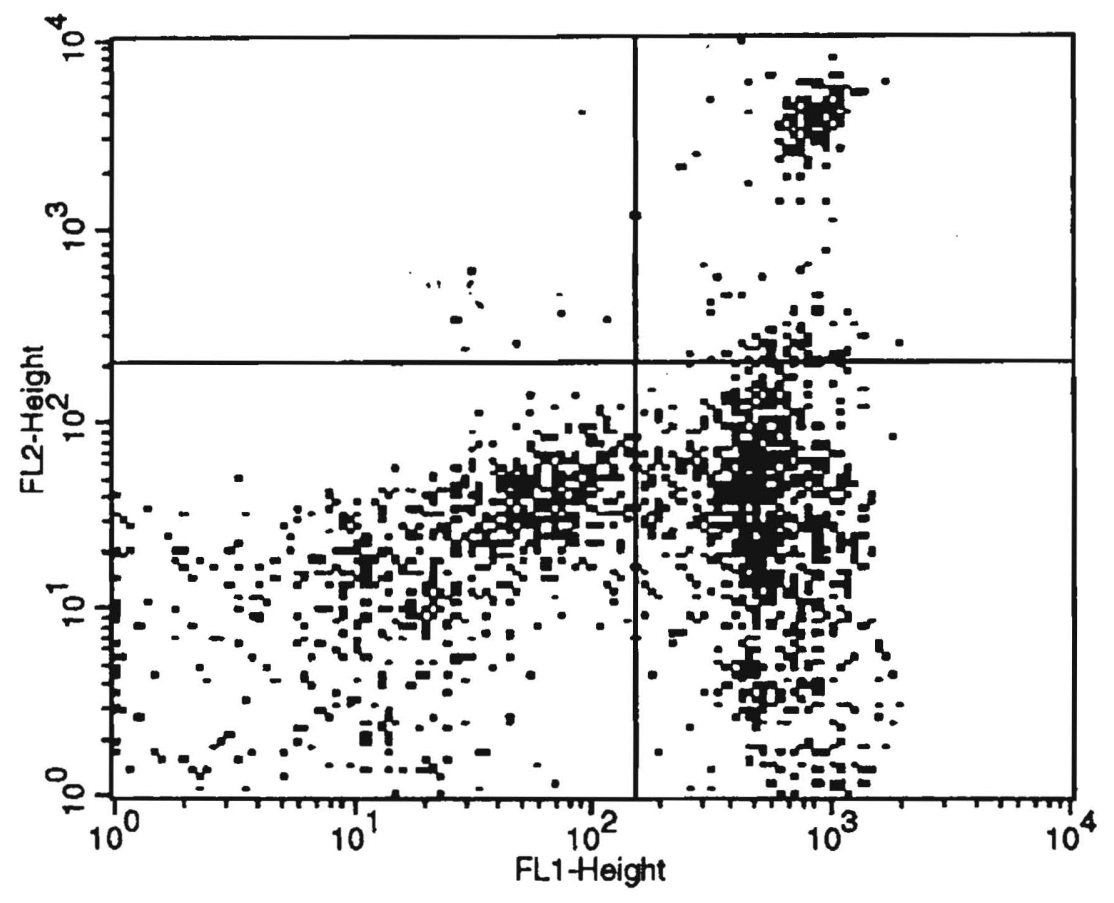

Figure 4.20b: CD45/8. T. spiralis-infected mouse. R2 quadrant acquisition plot. Percent gated: $\mathrm{UL}=0.40 ; \mathrm{UR}=9.15 ; \mathrm{LL}=38.50 ; \mathrm{LR}=51.95$. 


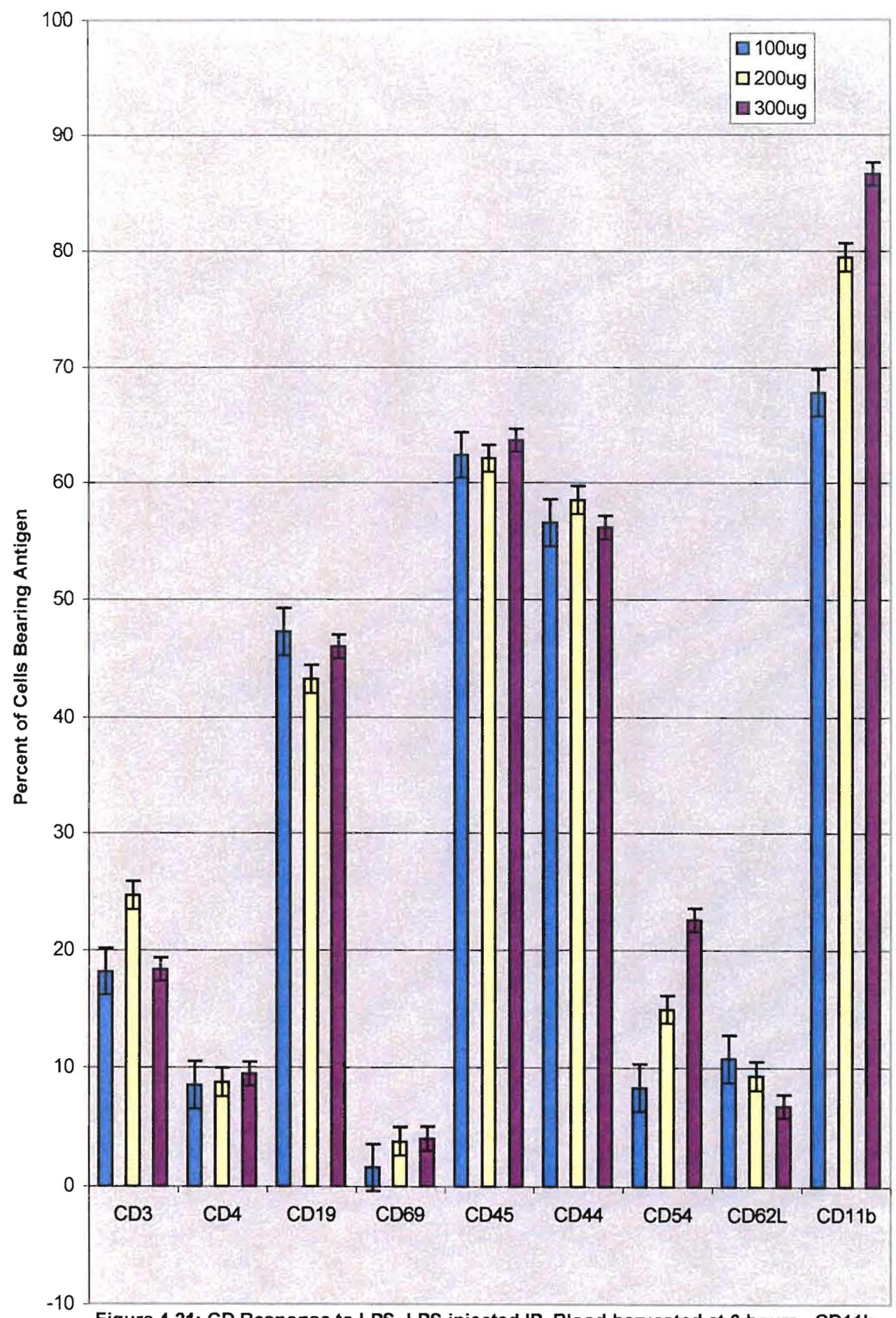

Figure 4.21: CD Response to LPS. LPS injected IP. Blood harvested at 6 hours. CD11b, CD69, CD54, CD19 and CD62L show dosage dependent changes. $n=8$. 


\section{DISCUSSION}

\section{The Antigen CD11b}

Cells with the surface markers $\mathrm{CD} 11 \mathrm{~b} / \mathrm{CD} 18$ showed considerable increases in mice infected with T. spiralis or T. pseudospiralis when compared to uninfected controls and showed important differences when compared to each other. CD11b is the $\alpha_{m}$ chain of this $\beta 2$ family of integrins. The CD11b subunit $\alpha_{m}$ binds CD54, complement component $\mathrm{iC} 3 \mathrm{~b}$ and extracellular matrix proteins. The $\beta$ chain is synonymous with $\mathrm{CD} 18$ that associates with $\mathrm{CD} 11 \mathrm{a}, \mathrm{b}, \mathrm{c}$ or $\mathrm{d}$. The molecule CD11b is a leukocyte adhesion receptor and mediates the adhesion of neutrophils and monocytes to endothelium during extravasation. The molecule also participates in the phagocytosis of complement-opsonized molecules (Lee, et al 1999).

Elevation of $\mathrm{CD} 11 \mathrm{~b}$, as a surface antigen on granulocytes, monocytes and macrophages is a well-known indicator of infection in human beings and may be used to prognosticate outcomes for patients with viral or bacterial disease (Weirich, et al 1998). Workers have found a correlation between elevated CD11b levels and progression of HIV infection (Benito, et al 1997). In cattle infected with the parasite Theileria annulata, cells showing increased expression of $\mathrm{CD} 11 \mathrm{~b}$ have been found in thymus, spleen and lymph nodes. This was especially evident in nodes draining the site of infection (Forsyth, et al 1997). It has also been noted, however, that up-regulation of CD11b may not be sufficient to sustain phagocytosis in infected animals (Dosgone, et 
al 1997). Nevertheless, up-regulated CD11b may be involved in the activation of NK cells in vivo in cooperation with LFA-1, CD54 and other cytokines (Ito, et al 1996).

It is noteworthy that $\mathrm{CD} 11 \mathrm{~b}$ up-regulation in mice infected with $T$. spiralis averaged a $26 \%$ increase on day 7 post-infection compared with controls. This compares with mice infected with $T$. pseudospiralis averaging a $17 \%$ increase in $\mathrm{CD} 11 \mathrm{~b}$ at the same time point, when compared to controls. This suggests either an ongoing inflammatory response to the adult worms in the intestinal phase and/or the beginning of the systemic inflammatory reaction to the L1 larvae that are present in the skeletal muscle at this time. I believe that, at 7 days post-infection, it is both. At this point in time, however, there is no way to discriminate between the responses to the intestinal phase and the muscle phase. As stated in Chapter 3 however, I noted that the two species of worm appear to elicit different sets of immune phenomena in the host. I suggest that the immune response to the newborn larvae in muscle may also elicit different responses from the host depending on the species of worm infecting when compared to the host response to the intestinal phase. These differences might be expected to present themselves as quantifiable differences in the $\mathrm{CD}$ responses on various types of responding leukocyte subsets that are measurable by flow cytometric analysis.

At days 14 and 21 post-infection, an increase of $35 \%$ and $41 \%$ respectively was noted in CD11b in T. spiralis infected mice over uninfected controls. For mice infected with $T$. pseudospiralis, the percentages were considerably lower averaging $26 \%$ and $30 \%$ at these same time points as compared to uninfected controls. These results 
suggest that adhesion molecules like CD11b may be up-regulated to allow extravasation of neutrophils and other responder cells to the site of inflammation as has been previously noted by Wang, et al 1998 and Benton, et al 1996). The major sites of inflammation at these time points might now be expected to be in striated muscle as the adult worms are expelled from the intestine and intestinal inflammation subsides. The expression of $\mathrm{CD} 11 \mathrm{~b}$ in splenic leukocytes returns to near normal levels by day 28 post-infection although its remains slightly elevated when compared to uninfected control animals.

Up-regulation of CD11b is also linked to ischemia-induced tissue injury and the production of certain cytokines like TNF and INF- $\gamma$. After cytokines return to preinfection levels, CD11b is shed from cell surfaces and returns to levels approximating those seen before infection (Lin, et al 1996). This information supports my findings and suggests that, in Trichinella infections, the insertion of the larvae into the intracellular niche allows the animal to return to homeostasis. It is also recognized that leukocyte activation as measured by $\mathrm{CD} 11 \mathrm{~b}$ may remain slightly elevated for varying periods of time following infection/injury events in both human beings and in mice (Engervall and Lundahl, 1998; Paugam, et al 1997).

As stated above, in Trichinella infection the adults have generally been expelled by day 14 post-infection and my data suggests that the surviving L1 larvae are still eliciting a full inflammatory response at day 21 post-infection. This response appears to be diminished to near-normal levels by day 28 . However, my investigation of responder cells in peripheral blood after day 28 indicates an ongoing generalized leukocytosis that 
is evident for as long as day 75 post-infection (data not shown). This is particularly notable in T. pseudospiralis infected mice. This data supports the general observation that helminthic infections tend to be chronic and that low level inflammatory reactions continue into the convalescent period.

\section{The Antigen CD62L}

The selectin CD62L is found on a subpopulation of $\mathrm{T}$ and $\mathrm{B}$ lymphocytes, monocytes, neutrophils and other leukocytes and functions in rolling interactions and as a homing receptor for lymphocytes. The molecule also mediates leukocyte traffic using glycosylation-dependent cell adhesion molecule-1 (Gly-CAM-1) as its ligand along with CD34 in high endothelial venules (HEV) (Siegelman, et al 1990; Carlos and Harlan, 1994; Lawrence and Springer, 1991). The selectin CD62L is also involved in the activation of platelets (Kiuchi, et al 1998).

As one of the selectin family that includes E-selectin (CD62E) and P-selectin (CD62P), CD62L is involved in inflammatory responses to infection and/or injury events in mammals. Unlike the P-and E-selectins, CD62L is shed from cells following inflammatory activation and is not generally present on endothelial cells. During inflammatory events, CD62L is down-regulated on leukocytes but up-regulated on platelets. My protocol for the flow cytometric analysis of CD62L eliminated platelets and erythrocytes from consideration and included only those lymphocytes that expressed CD62L.

Cells with the CD62L molecule's expression on the cell surface was markedly lower in T. spiralis infected mice than in controls at all time points examined. And, 
although T. pseudospiralis infected mice also showed a loss of CD62L from lymphocyte surfaces, it was retained in considerably higher amounts on these lymphocytes than on those of $T$. spiralis infected mice. The down-regulation of CD62L in Trichinella infected mice suggests an ongoing systemic inflammatory response that peaks at approximately day 21 and subsides by about day 28 post-infection. These observations are in agreement with the work of other investigators who have found that down-regulation of CD62L occurs concomitantly with the up-regulation of other cell surface molecules including CD44, CD54 and CD11b (Aziz, et al 1996; Condliffe, et al 1996). In addition, Fanelli, et al (1997) have suggested that there may be a direct correlation between the degree of shedding of CD62L from leukocyte membranes and the up-regulation of both CD62L and CD63 on platelets. These observations may be correlated with the severity of the inflammatory response to both injury and certain haemostatic disorders such as antiphospholipid syndrome.

The treatment of $\mathrm{BALB} / \mathrm{c}$ mice with increasing doses of the priming agent lipopolysaccharide (LPS) resulted in the down-regulation of CD62L in a dosedependent manner. This corresponded to an up-regulation of CD11b in a dose dependent manner as can be seen in Figure 4.21. Condliffe, et al (1996) also noted that the use of the priming agent LPS caused a detectable loss of CD62L from the surface of neutrophils. This same researcher noted a correlation between CD62L downregulation and increases in the presence of inflammatory cytokines like TNF and platelet activating factor (PAF) following injury. However, no correlation was found between PAF and CD11b up-regulation and CD62L loss but a correlation was found 
between TNF, CD11b up-regulation and CD62L loss. In other words, platelet activation during an inflammatory event is concomitant with, but not dependent on, neutrophil activation events that are signaled by the loss of CD62L from leukocyte surfaces. Condliffe, et al (1996) suggests, therefore, that neutrophil activation and recruitment to the sites of injury is dependent on a number of factors including the coordinated regulation of adhesion and activation molecules.

In parasitic infections, adhesion molecules such as CD62L have a role in antibodydependent cell-mediated cytotoxicity (ADCC). Trottein, et al (1997) has found that the carbohydrate determinate sialyl Lewis(x) (CD15), CD11b (Mac-1) and Cd62L are required for activation of macrophage effector function against Schistosoma targets in vivo. The sialylated form of CD15 Lewis $(\mathrm{x})\left(\mathrm{sLe}^{\mathrm{x}}\right)$ is the ligand for P-, E- and probably L- selectins (CD62P, CD62E and CD62L) in vivo.

My data shows that CD62L as measured by flow cytometry in lymphocyte populations follows a predictable pattern of down-regulation in mice infected with either T. spiralis or T. pseudospiralis. From the literature and my results, I suggest that the observed patterns of CD62L down-regulation in infected mice may be the result of the presence of collagen related peptides at the site of injury. Kehrel, et al (1998) found that CD62L and CD63 recognize the collagen sequence glycine-proline-hydroxyproline (gly-pro-hyp) leading to up-regulation on platelets and down-regulation on leukocytes. I suggest that the presence of extracellular matrix (ECM) proteins such as collagen fragments have a role in the down regulation of CD62L in Trichinella infections in mice and in the subsequent activation and adhesion of phagocytic cells to endothelium. 
These ECM components may be present in higher amounts in $T$. spiralis infected animals as compared to $T$. pseudospiralis due to the increased muscle damage in $T$. spiralis infections as measured previously by creatine phosphokinase (CPK) assays (refer to Chapter 2). This further demonstrates that $T$. spiralis is significantly more damaging to the myofiber than is $T$. pseudospiralis and that this damage and subsequent inflammatory response results in measurably different cellular phenomena. These differences are of both type and strength. The possible role for cortisol and/or PGE2 in these events is unknown at this time.

I have also shown that down-regulation of CD62L is a measurable event by flow cytometric analysis. This down-regulation may correlate with the severity of the infection and with the corresponding severity of the muscle damage in Trichinella infected mice. Analysis of CD62L, therefore, is efficacious in comparing the pathological consequences of T. spiralis and T. pseudospiralis infections in mice.

\section{The Antigen CD69}

The surface antigen CD69 was much higher in Trichinella infected mice than in controls but the differences between the two species of Trichinella were not significantly different. This suggests that lymphocyte activation as measured by CD69 is approximately the same for both species of worm.

The surface antigen CD69 is expressed constitutively on platelets, neutrophils and eosinophils but can be induced transiently on T, B and NK cells following activation (Testi, et al 1994) and serves as the earliest inducible and detectable glycoprotein at the cell surface in these cell lines. The molecule CD69 is a type II membrane protein that is 
characterized by having the $-\mathrm{NH}_{2}$ terminal inside the cell and the $-\mathrm{COOH}$ terminal outside. The antigen contains a C-lectin domain that has been associated with glycoprotein endocytosis and is probably involved in binding surface residues on parasites such as Trichinella and certain bacteria (Lee, et al 1999).

Cross-linking of CD69 following the binding of its ligand initiates $\mathrm{Ca}^{++}$influx and subsequent activation of phospholipase A2. Therefore, it may be active in arachodonic acid hydrolysis and in IL-2 activated NK cell target lysis and platelet activation (Testi, et al 1994). It should be remembered here that arachodonate hydrolysis is a seminal biochemical event in the production and secretion of a number of inflammatory lipid mediators including the prostaglandins (through cyclooxygenase), the leukotrienes (through 5-lipooxygenase) and PAF (through an acetyl transferase). Activation of CD69 on T cells can be induced and measured both in vitro and in vivo within hours of stimulation by intracellular parasites like HIV using flow cytometry (Perfetto, et al 1997). With this information in mind, I suggest that the high PGE2 levels seen in $T$. spiralis-infected mice but not in T. pseudospiralis-infected animals are due to factors other than CD69. These purported other factors remain to be elucidated.

Because CD69 is expressed constitutively on neutrophils, eosinophils and platelets, all measurements focused on those quadrants of the flow cytometric dot plots that indicated lymphocytes. My data shows that Trichinella does induce an early activation of CD69 on T and/or B lymphocytes or NK cells in vivo as there are important differences between Trichinella-infected animals and uninfected controls. My data also 
shows that CD69 is expressed at low levels even in non-infected control animals but at basal levels that never exceeded $2.5 \%$ of lymphocytes as determined by flow cytometry.

Trichinella infected animals showed a substantial (more than six-fold) rise in lymphocytes marked with CD69 when contrasted with uninfected controls although my data indicate no appreciable differences in the host response to the two species of worm as measured by CD69 up-regulation. Prince and Lape-Nixon (1997) found that CD69 is an excellent tool for measuring the mitogenic response of lymphocytes to stimulation. These same researchers and Nielson, et al (1998) suggested that the pathogenesis and clinical outcome for certain parasitic diseases like HIV may be predicted using a CD69 assay. The crucial role for CD69 in T cell activation was demonstrated by Krowka, et al in1996. These researchers blocked the up-regulation of CD69 using the HIV-derived protein GP120 causing a significantly reduced $\mathrm{T}$ cell activation in vitro even when $\mathrm{T}$ cells were stimulated with the priming agent and mitogen phytohemagglutin.

The predictability of the pathogenesis and sequelae of inflammatory events using CD69 is meaningful to my research on Trichinella. I support this statement with the data from the LPS injection experiments that showed a large dose-dependent upward shift in CD69. Based on these observations, T cell and/or B cell activation as measured by CD69 appears to be approximately equal in mice infected with $T$. spiralis or $T$. pseudospiralis. Other (non-lymphocyte) cell responses may also be predicted using CD69 as has been demonstrated by Neilson, et al (1998) who showed that activation of 
peripheral blood mononuclear cells (PBMC) may be predicted accurately both in vitro and in vivo in individuals infected with HIV.

Lim, et al (1998) found that activation of both $\mathrm{CD}^{+}$and $\mathrm{CD}^{+} \mathrm{T}$ lymphocytes could be reliably predicted by assessing the percent of cells gaining the CD69 marker in human beings infected with HIV. They also demonstrated that $\mathrm{CD}^{+} 9^{+}$cells were $51 \%$ (+/-3\%) higher in HIV infected individuals than in uninfected controls. I have also shown that CD69 is significantly elevated in mice that are infected with either $T$. spiralis or T. pseudospiralis. However, CD69 is much more markedly elevated in my studies than was found in humans infected with HIV. This may be due to the high level of acute tissue injury seen in Trichinella infections as measured by CPK assay. Therefore, it is reasonable to suggest that CD69 up-regulation is positively correlated with the degree of inflammation resulting from a Trichinella infection/injury event in vivo.

Although CD69 is constitutively expressed on human monocytes, it may be inducible on murine bone-derived macrophages in the presence of IFN- $\gamma$ plus LPS or in the presence of TNF (Marzio, et al 1997). In support of my findings, these same researchers also found that LPS alone was sufficient to induce expression of CD69 on murine leukocytes. In addition, they found that nitric oxide production is stimulated in the presence of INF- $\gamma$ and by anti-CD69 monoclonal antibody suggesting a possible role for CD69 as a signaling receptor for an uncharacterized ligand. Lahn, et al (1998) found that CD69 activation may be an indicator of the type of $\mathrm{T}$ cell response. Other researchers found that TNF may be a key mediator in activating either an $\alpha / \beta$ or $\gamma / \delta$ 
response in T lymphocytes in response to bacterial (Terres and Pajares, 1998), parasitic (Candida) or LPS induced inflammation (Angulo and Fulcher, 1998).

\section{The Antigen CD19}

The constitutive surface antigen CD19 is found on B lymphocytes and changes during the course of an infection. This change can be quantified using flow cytometry (Ginaldi, et al 1998; Cheek, et al 1997). Tomazic, et al (1997) have found substantial increases in the percentages of CD19 lymphocytes in human beings with neuroborreliosis or tick-born encephalitis; thus, flow cytometry may be used to characterize this lymphocyte subset during infection. Conversely, blocking CD19 results in marked abnormalities in cytokine production (Mistchenko, et al 1998). However, there is not always a correlation between CD19 and infection. Sabatier, et al (1997) have found that CD19 levels vary depending on the type of infectious agent and, in some cases, may be even lower than in uninfected controls.

I have shown that there is an increase in most types of peripheral blood leukocytes (PBL) in Trichinella infected animals (see Chapter 3). There are also significant increases of $\mathrm{CD}_{1} 9^{+}$lymphocytes in the spleen of infected animals when compared to uninfected controls as demonstrated by flow cytometry. Although $T$. spiralis infected animals have fewer PBL than do those infected with $T$. pseudospiralis (refer to Table 3.2), splenic $\mathrm{CD}^{+} 9^{+}$cells are notably higher in $T$. spiralis infected mice. The compartmentalization of immune cells has been demonstrated by other researchers. Rosenmann, et al (1998) maintains that lymphocyte subsets may evolve independently in peripheral lymphoid organs from those in peripheral blood. I have shown that CD19 ${ }^{+}$ 
lymphocytes are present in the spleens of $\mathrm{BALB} / \mathrm{c}$ mice at percentages that approximate those found in healthy human beings. These $\mathrm{CD}_{1} 9^{+}$cells average approximately $12.4 \%$ of lymphocytes but rise dramatically during parasitic infections like those caused by the Hepatitis B virus (Choong, et al 1996). It is also noteworthy that CD19 remains on activated B lymphocytes during clonal expansion but is not expressed on terminally differentiated plasmacytes (Fehr, et al 1998). These same researchers suggest that $\mathrm{CD} 19$, which contains nine tyrosine residues as possible phosphorylation sites, acts as a signal-transducing element for complement receptor 2 (CR2) and that circulating memory B cells are fully dependent on CD19. This correlates with my data that shows an increase in cells bearing CD19 in the spleen in Trichinella infected mice and that the cells marked with CD19 remain higher than controls in the spleen during convalescence (data not shown). I have noted that this number gradually declines after the intracellular niche is established and the host returns to homeostasis.

Once again, it must be noted that $T$. spiralis is eliciting a larger B-cell response than is $T$ pseudospiralis. As stated in the introduction, it has been noted that the types of IgG secreted by plasma cells during Trichinella infections also varies. It is not possible at this juncture to determine how much of the B cell response at day 7 postinfection is due to the host response to the intestinal phase, however B cell clonal expansion continues to rise though day 21 post-infection before beginning to decline slowly. It should also be remembered that CD19 is not expressed on terminally differentiated plasmacytes which means that the actual number of cells present of $B$ cell 
lineage is actually much higher than is indicted by the flow cytometric percentages analyzed using CD19. Therefore, flow cytometric CD19 analysis in Trichinella-infected mice indicates increasing clonal expansion of B cells and, by extrapolation, continued expansion of antibody-secreting plasmacytes

Interleukin-4 (IL-4) plays a primary role in the dichotomous activation of Th1 or Th2 subsets in vivo and plays a role in activating $\mathrm{CD} 19^{+}$cells during an infectionstimulated inflammatory activation (Collins, et al 1998). In addition, IL-1 $\beta$ is expressed intracytoplasmically in $\mathrm{CD}_{1} 9^{+}$cells in vivo in infected human beings (Gray, et al 1996). Other cytokines expressed by $\mathrm{CD} 19^{+}$cells during activation include IL-6, IL-10 and TNF.

\section{The Antigen CD8}

The expression of CD8 on cytotoxic T lymphocytes (CTL) is of particular importance in parasitic infections such as those caused by Toxoplasma gondii and Trypanosoma brucei brucei (Purner, et al 1996; Bakheit, et al 1996). As part of the cell-mediated immune response, CTL play a vital role in eliminating intracellular parasites. However, $\mathrm{CD} 4^{+}$cells act in a cooperative manner with $\mathrm{CD} 8^{+}$cells in animals infected with both intra- and extracellular parasites. Trichinella is both intra- and extracellular during its life cycle within the host and, therefore, may elicit a complex and overlapping inflammatory and adaptive immune reaction.

I have shown that there are significant increases in $\mathrm{CD}^{+}$cells in mice infected with either T. spiralis or T. pseudospiralis when compared to uninfected controls. There is a gradual increase in $\mathrm{CD}^{+}$cells beginning at approximately day 7 post- 
infection and peaking at about day 21 post-infection. After day 21 , there is a decline in $\mathrm{CD}^{+}$marked cells in the spleens of mice infected with Trichinella. This may be due, in part, to the resolution of the intestinal phase and/or the establishment of the L1 larvae in the intracellular niche. Cells marked with CD8 in uninfected control mice remain at $3 \%$ of lymphocytes. These results are supported by Scheller, et al (1997) who found that, in animals infected with the intracellular parasite Plasmodium berghei, $\mathrm{CD}^{+}$(and $\mathrm{CD}^{+}$) cells increased up to six-fold and that CTL are essential for parasite clearance from infected animals. These same researchers have suggested that, at least for animals infected with Plasmodium, NO production is regulated by both $\mathrm{CD}^{+}$and $\mathrm{CD}^{+} \mathrm{T}$ lymphocytes. As can be seen in Figures 4.17-4.20b, T. pseudospiralis elicits a significantly higher $\mathrm{CD}^{+}$response in $\mathrm{BALB} / \mathrm{c}$ host mice than does $T$. spiralis. This difference in the numbers of CTL present in the spleen could help explain (in part) the very substantial differences measured in the host production of NO in infected mice. Kumar and Tarleton (1998) have also discussed the primary importance of the cellmediated immune response in parasitic infections but also confirmed that the humoral response is essential for parasite elimination.

Circulating and splenic CTL are seen to increase dramatically initially but decline slowly during the convalescent period in animals infected with Loa loa (Dennis, et al 1997) or Trichostrongylus axei (Pernthaner, et al 1996). This supports my findings that splenic $\mathrm{CD}^{+}$cells, although beginning to decline, remain at approximately two and four times the control levels in T. spiralis and T. pseudospiralis infected mice at day 28 post-infection respectively. The importance of CTL in parasitic infections was 
demonstrated by Russo, et al (1996) who showed that the blocking of CD8 with monoclonal antibody caused a 200 -fold increase in parasite burden in mice infected with Trypanosoma cruzi. Interestingly, these same workers found that the increase in parasite burden was organ specific, suggesting again that immune cell activation and surface marker up-regulation may be compartmentalized in vivo.

As mentioned above, that since Trichinella is present both intra- and extracellularly in infected animals, it is, therefore, reasonable to predict a complex mix of inflammatory and immune responses to this particular nematode. Large extracellular parasites like Schistosoma mansoni elicit a primary Th1 $\mathrm{CD}^{+}$response and it has been postulated that $\mathrm{Th} 2 \mathrm{CD}^{+}$cells function to regulate Th1 (Pearce and PedrasVasconcelos, 1997). In addition, adoptive transfer of $\mathrm{CD}^{+}$splenocytes from mice infected with Toxoplasma to naïve mice gave protection against a lethal challenge of $T$. gondii. The intracellular T. gondii, Plasmodium and Leishmania also elicit a primary $\mathrm{CD}^{+} / \mathrm{CD}^{+} \mathrm{Th} 2$ response and a pulse with parasite antigen forces secretion of large quantities of INF- $\gamma$, a prime activator of macrophages in vivo (Kasper and Kahn, 1998). Despite this, my NO data indicates a primary Th1 response in T. pseudospiralis infected mice. This may be due to the fact that T. pseudospiralis is unencapsulated and, therefore, more susceptible to the MHC class 1 -restricted $\mathrm{CD}^{+} \mathrm{T}$ cell.

My data suggests a primary role for a CTL-mediated response to Trichinella in mice. This is in addition to a pronounced humoral response. Again, T. pseudospiralis shows a CD8 response more than 50\% higher at peak than does $T$. spiralis. I suggest again that this may be due to the exposure of the unencapsulated L1 worm and L1 
worm antigens to phagocytes (especially macrophages) and the subsequent presentation of these antigens to $\mathrm{T}$ cells. In addition, the excretory/secretory antigens in the saliva of $T$. pseudospiralis may be more readily presented to MHC I-restricted CTL than those secreted by the encapsulated $T$. spiralis. 


\section{SUMMARY AND}

\section{CONCLUSIONS}

In conclusion, I will summarize my findings and attempt to answer the questions posed at the beginning of this research. Based on the data presented, it was shown that there are considerable differences in the infectious strategies when one examines $T$. spiralis and T. pseudospiralis infections in mice. These differences are of both kind and degree. The two species of this nematode generate a different immune, physiological and inflammatory response from the mouse host. Cortisol is obviously a component in the ability of $T$. pseudospiralis to establish an intracellular skeletal muscular niche. To a much lesser extent, cortisol may play a role in the survival of $T$. spiralis. Cortisol appears to have no bearing on the deposition of collagen or on the initiation of angiogenesis in either T. spiralis or T. pseudospiralis infected mice. It is also apparent that there may be two very different immune defensive mechanisms at work depending on which species of worm is infecting the host.

There are noteworthy differences in the type, location and numbers of responding immune cells to the two species of worm. T. pseudospiralis generates an extensive peripheral blood response that is generally larger than that seen in T. spiralis. Trichinella spiralis, while also eliciting a large peripheral blood response, generates a much more pronounced tissue infiltrate of immune cells than does T. pseudospiralis. Based on the quantitative assays of cells in peripheral blood, it is reasonable to assume that there is a more important role for eosinophils and macrophages in T. spiralis - 
infected animals. Conversely, T. pseudospiralis-infected mice have a more pronounced neutrophilia and higher numbers of peripheral blood lymphocytes than do $T$. spiralisinfected mice. As demonstrated by flow cytometry, splenic lymphocytes are markedly elevated in Trichinella infections in mice. Cytotoxic $\mathrm{T}$ lymphocytes are more pronounced in the spleen of $T$. pseudospiralis-infected animals and B cells are more abundant in $T$. spiralis-infected mice. This suggests that the humoral response may be playing a larger role in $T$. spiralis infections and that the cellular response may be more important in the host defense against T. pseudospiralis.

The flow cytometric analysis, as demonstrated by the dot plots, shows that there are substantial differences in the up-regulation or down-regulation of certain cell surface antigens when the two species of infecting worm are compared to each other and to uninfected controls mice. Levels of CD19 and CD8 both rose significantly in Trichinella-infected animals. As stated previously, the humoral response as measured by CD19 is markedly higher in T. spiralis-infected animals whereas the cell-mediated response as measured by the $\mathrm{CD}^{+}$population is much more prominent in $T$. pseudospiralis-infected mice. The surface antigens CD11b and CD69 rose to notably higher levels in infected animals when compared to uninfected controls. On average $T$. spiralis generated higher number of CD11b and CD69 surface antigens than did $T$. pseudospiralis. Whether or not this difference is related to cortisol is unknown. The decrease in CD62L was also more conspicuous in T. spiralis-infected animals and was lower on day 7 post-infection suggesting that the inflammatory response to the ongoing intestinal phase is also more pronounced in $T$. spiralis-infected animals. The differences 
between the two species of worm with regard to CD44 and CD54 up-regulation were insignificant and unremarkable although both antigens were present in much higher levels in infected animals than in uninfected controls. This finding may be explained in part by the fact that CD44 is expressed heavily on many cells types and is essential for the extravasation of these cells in the spleen. The molecule CD54 or ICAM-1 is also necessary for leukocyte binding and is up-regulated in inflammatory reactions. Because CD44 and CD54 were up-regulated in a very similar manner in mice infected with either species of Trichinella, my findings suggest that CD44 and CD54 have equally important functions in Trichinella infections regardless of the species of worm infecting.

From the analysis of creatine phosphokinase in infected animals, I have shown that $T$. spiralis inflicts substantially more damage to the host myocyte than does $T$. pseudospiralis. This difference in myofiber damage (including ischemia) and in the type and degree of the ensuing inflammatory reactions, cellular infiltration and wound healing mechanisms may have important consequences for the subsequent differences seen in the angiogenic and collagen deposition responses seen in T. spiralis and not in T. pseudospiralis-infected animals. Indeed, based on these observations, one might speculate that it is the damage to the extracellular matrix and the subsequent invasion by macrophages that stimulate the cascade of extracellular and sub-cellular events leading to both neovascularization and collagen synthesis in $T$. spiralis-infected animals. 
The investigations of collagen deposition, nurse cell formation and angiogenesis have shown that there are major differences in the strategy of the two species of Trichinella in the intracellular niche. These differences appear to be specific to the species of nematode that is infecting. Cortisol does not appear to play any appreciable role in either the deposition of collagen to form the nurse cell or in the subsequent neovascularization of the nurse cell in T. spiralis-infected mice. In addition, cortisol has no discernible role in mice infected with $T$. pseudospiralis except in its effect on larval survival. My results indicate that $T$. pseudospiralis is dependent on cortisol for the survival of both adults and larvae in the infected host. The mechanisms leading to the very high levels of cortisol in T. pseudospiralis-infected mice remain elusive. Using a developing method for flow cytometric study of intracellular cytokine generation in Trichinella infections may shed light on the phenomena. However, I suspect that PGE2 may have a role in down-regulating cortisol and NO in animals infected with $T$. spiralis. Indeed, PGE2 inhibits NO production as previously discussed. In addition, because Th1 cells secrete NO and Th2 cells do not, PGE2 is probably acting to suppress Th1 cell-production of NO in T. spiralis-infected BALB/c mice.

Nitric oxide appears to be an important mediator of parasite killing in vivo in Trichinella-infected mice. Interference with NO production using aminoguanidine (data not shown) resulted in considerably larger or lethal parasite burden in both $T$. spiralis and T. pseudospiralis-infected mice. I have shown that NO production is not related to muscle damage. If there were a relationship between muscle damage as measured by CPK and NO production, NO production in T. spiralis-infected animals would have 
been much higher than in $T$. pseudospiralis-infected mice. Again, I seem to be observing a different response by the host animal that is dependent on the species of infecting worm. It should be remembered that natural killer cells and Th1 cells both express type II iNOS but Th2 cells do not. I have shown that, during the muscle phase, both species of Trichinella induce NO production indicating the activation of a primary Th1 response. It also suggests that $T$. pseudospiralis induces a more vigorous Th1 cellmediated response than does T. spiralis. However, only further investigation will identify these details of the host response.

In conclusion, I have shown that $T$. pseudospiralis generates a very different immune and inflammatory response in the host than does $T$. spiralis. These differences are of both kind and degree. I have demonstrated the efficacy of flow cytometry in the evaluation of the response of mice to specific infectious or inflammatory agents in vivo. I have shown that there are significant differences in the up-regulation and/or downregulation of most of the cell surface antigens examined. I have shown that there are important variations in the response of leukocytes in the peripheral blood of infected animals. I have clearly demonstrated that $T$. spiralis is more damaging to the host than is $T$. pseudospiralis as measured by creatine phosphokinase. I have shown that, in $T$. spiralis-infected mice, cortisol has no evident role in the formation of the nurse cell or in the subsequent neovascularization of the intracellular niche. I have also shown, however, that cortisol does play a major role in larval survival in T. pseudospiralis infected mice and, to a lesser extent, in T. spiralis-infected animals. I have clearly established that there is a vital role for nitric oxide in the killing of Trichinella larvae in 
vivo. I have suggested that the presence of extracellular matrix components and the very pronounced recruitment of macrophages to the site of injury may be crucial in establishment of the intracellular niche in T. spiralis-infected mice. And, finally, although I have elucidated some of the mechanisms responsible for the pathogenesis and sequelae of trichinellosis in mice, it is obvious that a great deal more work remains to be done on Trichinella and its parasitic relationship with animals. 


\section{LITERATURE CITED}

Abbas A.K., A. Lichtman and J. Pober. 1991. Cellular and Molecular Immunology. W.B. Saunders Co.London, U.K..

Aikawa T., T. Hirose, I. Matsumoto, T. Shimada, Y. Tsujimoto and Y. Tsuji. 1991. Effect of platelet-activating factor on cortisol and corticosterone secretion by perfused dog adrenal. Lipids. 26(12):1108-11.

Akiyama S.K., K. Olden and K.M.Yamada. 1995. Fibronectin and integrins in invasion and metastasis. Cancer and Metastasis Reviews. 14(3): 173-89.

Alford K., D.L. Obendorf, T.M. Fredeking, E. Haehling and G.L. Stewart. 1998. Comparison of the inflammatory responses of mice infected with American and Australian Trichinella spiralis or Trichinella pseudospiralis. International Journal for Parasitology. 28(2): 343-8.

Allen P.C. 1997. Nitric oxide production during Eimeria tenella infections in chickens. Poultry Science. 76(6):810-13.

Angioni S., F. Petraglia , A. Galinelli, A. Cossarizza, C. Franceschi, M. Muscettola, A.D. Genazzani, N. Surico and A.R. Genazzani. 1993. Corticotropin-releasing hormone modulates cytokine release in cultured human peripheral blood mononuclear cells. Life Sciences. 53(23):1735-42.

Angulo R. and D.A. Fulcher. 1998. Measurement of Candida-specific blastogenesis: comparison of carboxyfluorescein succinimidyl etser labeling of T cells, thymidine incorporation and CD69 expression. Cytometry. 34(3):143-51.

Arai K.I., F. Lee, A. Miyajima, S. Miyatake, N. Arai and T. Yokota. 1990. Cytokines: coordinators of immune and inflammatory responses. Annual Review of Biochemistry. 59:783-836.

Atlas R.. 1997. Principles of Microbiology. Wm C. Brown, Publishers Dubuque, IA, USA.

Augusto O., E. Linares and S. Giorgio. 1996. Possible roles of nitric oxide and peroxynitrite in murine leishmaniasis. Brazilian Journal of Medical and Biological Research. 29(7):853-62. 
Aziz K.E., P.J. McCluskey and D. Wakefield. 1996. Expression of Selectins (CD62 $\mathrm{E}, \mathrm{L}, \mathrm{P})$ and cellular adhesion molecules in primary Sjogren's syndrome: questions to immunoregulation. Clinical Immunology and Immunopathology. 80(1):55-66.

Bakheit M., T. Olsson, A. Ljungdahl, P. Van Der Meide and K. Kristensson. 1996. Induction of interferon-gamma, transforming growth factor-beta and interleukin-4 in mouse strains with different susceptibilities to Trypanosoma brucei brucei. Journal of Interferon and Cytokine Research. 16(6):427-33.

Banda M.J., D.R. Knighton, T.K. Hunt and Z. Werb. 1982. Isolation of non-mitogenic angiogenesis factor from wound fluid. Proceedings of the National Academy of Sciences (USA). 79(24):7773-7.

Barnes P.J. and F.W. Liew. 1995. Nitric oxide and asthmatic inflammation. Immunology Today. 16(3):128-30.

Baruch A.M. and D.D. Despommier. 1991. Blood vessels in Trichinella spiralis infections: a study using vascular casts. Journal of Parasitology. 77(1):99-103.

Beatty P.R., S.M. Krams and O.M. Martinez. 1997. Involvement of IL-10 in the autonomous growth of EBV-transformed B cell lines. Journal of Immunology. 158(9):4045-51.

Benito J.M., J.M. Zabay, J. Gil, M. Bermejo, A. Escudero, E. Sanchez and E Fernadez-Cruz. 1997. Quantitative alterations of the functionally distinct subsets of CD4 and CD8 T lymphocytes in asymptomatic HIV infection: changes in theexpression of CD45RO, CD45RA, CD11b, CD38, HLA-DR and CD25 antigens. JAIDS: Journal of Acquired Immune Deficiency Syndrome. $14(2): 128-35$.

Bogden A.E., J.P. Moreau and P.A. Eden. 1997. Proliferative response of human and animal tumors to surgical wounding of normal tissues: onset, duration and inhibition. British Journal of Cancer. 75(7):1021-7.

Bolton C.E..1996. Sepsis and the systemic inflammatory response syndrome: neuromuscular manifestations. Critical Care Medicine. 24(8):1408-16.

Boros D.L.. 1994. The role of cytokines in the formation of the shistosome egg granuloma. Immunobiology. 191(4-5):441-50.

Boulos L.M., I.H. Hegazy, M. Abou-Seif and M. Abdel-Kader. 1993. Modulation of the host response during infection with Trichinella pseudospiralis using an immunostimulant drug. Journal of the Egyptian Society of Parasitology. 23(1):1-8. 
Brandle D., S. Muller, C. Muller, H. Hengartner and H. Pircher. 1994. Regulation of RAG-1 and CD69 expression in the thymus during positive and negative selection. European Journal of Immunology. 24(1): 145-51.

Bredt D.S., P.M. Hwang and S.H. Snyder. 1990. Localization of nitric oxide synthase indicating a neural role for nitric oxide. Nature. 347(6295):768-70.

Buckingham J.C., H.D. Lozley, A.D. Taylor and R.J. Flower. 1994. Cytokines, glucocorticoids and neuroendocrine function. Pharmacological Research. 30(1):35-42.

Budd R.C., J.C. Cerottini, C. Horvath, C. Bron, T. Pedrazzini, R.C. Howe and H.R. MacDonald. 1987. Distinction of virgin and memory T lymphocytes. Stable acquisition of the Pgp-1 glycoprotein concomitant with antigenic stimulation. Journal of Immunology. 138(10): 3220-9.

Burgner D., K. Rockett and D. Kwiatkowski. 1999. Nitric oxide and infectious diseases. Archives of Diseases in Childhood. 81(2):185-8.

Burton J.L., M.E. Kehrli, S. Kapil and R.L. Horst. 1995. Regulation of L-selectin and CD18 on bovine neutrophils by glucocorticoids: effects of cortisol and dexamethasone. Journal of Leukocyte Biology. 57(2):317-25.

Calcalano G., J. Lee, K. Kikly, A.M. Ryan, S. Pitts-Meek, B. Hultgren, W.I. Wood and M.W. Moore. 1994. Neutrophil and B cell expansion in mice that lack the Il-8 receptor homologue. Science. 265(5172):682-4.

Capo V.A., D.D. Despommier and R.I. Polvere. 1998. Trichinella spiralis: vascular endothelial growth factor is up-regulated within the nurse cell during the early phase of its formation. Journal of Parasitology. 84(2):209-14.

Carłos T.M. and J.M. Harlan. 1994. Leukocyte-endothelial adhesion molecules. Blood. 84(7):2068-101.

Carter W.O., C. Bull, E. Bortolon, L. Yang, G.J. Jesmok and R.H. Gundel. 1998. A murine skeletal muscle eschemia-reperfusion injury model: differential pathology in BALB/c and DBA/2N mice. Journal of Applied Physiology. 85(5):1676-83.

Casini-Raggi V., L. Monsacchi, K. Vaosbeck, C.C. Nast, T.T. Pizarro and F. Cominelli. 1995. Anti-inflammatory effects of CGP 47969A, a novel inhibitor of proinflammatory cytokine synthesis in rabbit immune colitis.

Gastroenterology. 109(3):812-18. 
Cheek R.F., I. Olszak, S.S. Madoff and F.I Preffer. 1997. In vitro detection of Mycoplasma fermentans binding to B lymphocytes in fresh peripheral blood using flow cytometry. Cytometry. 28(1):90-5.

Chen M., H. Hashizume, C.Y. Xiao, A. Hara and Y. Abiko. 1997.

Lysophophatidylcholine induces $\mathrm{Ca} 2+$-independent cellular injury attenuated by d-propranolol in ray cardiomyocytes. Life Sciences. 60(30:PL57-62).

Chikanza I.C., P. Petrou, G. Kingsley, G. Chrousos and G.S. Panayi. 1992. Defective hypothalamic response to immune and inflammatory stimuli in patients with rheumatoid arthritis. Arthritis and Rheumatism. 35(11):1281-8.

Choong M.L., S.H. Ton and S.K. Cheong. 1996. The cellular immune status of HBsAg positive carriers in Malaysia. Asian Pacific Journal of Allergy and Immunology. 14(1):19-24.

Cochran, P.. 1999. Personal Communication.

Collins H.L., U.E. Schaible and S.H. Kaufmann. 1998. Early IL-4 induction in bone marrow lymphoid precursor cells by mycobacterial lipoarabinomannan. Journal of Immunology, 161(10):5546-54.

Condliffe A.M., E.R. Chilvers, C. Haslett and I. Dransfield. 1996. Priming differentially regulates neutrophil adhesion molecule expression/function. Immunology. 89(1):105-11.

Crofford L.J., K.T. Kalogeras, G. Masorakos, M.A. Magiaou, J. Wells, K.S. Kanik, P.W. Gold, G.P. Chrousos and R.L. Wilder. 1997. Circadian relationships between interleukin- 6 and hypothalamic-pituitary-adrenal axis hormones: failure of IL-6 to cause sustained hypercortisolism in patients with early untreated rheumatoid arthritis. Journal of Clinical Endocrinology and Metabolism. 82(4):1279-83.

Cuono C.B., R. Marquetand, M.B. Klein and I. Armitage. 1998. Critcal role of phosphagens in the energy cascade of cutaneous ischemia and protective action of phosphocreatine analogues in skin flap survival. Plastic and Reconstructive Surgery. 101(6):1597-603. 
Curti B.D., W.J. Urba, D.L. Longo, J.E. Janik, W.H. Sharfman, L.L. Miller, G. Cizza, M. Shimizu, J.J. Oppenheim, W.G. Alvord, and J.W. Smith. 1996. Endocrine effects of IL-1 alpha and beta administered in a phase one trial to patients with advanced cancer. Journal of Immonotherapy with Emphasis on Tumor Immunology. 19(2):142-8.

DaCosta M.L., M.C. Reagan, M. al Sader, M. Leader and D. Bouchier-Hayes. 1998. Diphenylhydantoin sodium promotes early and marked angiogenesis and results in increased collagen deposition and tensile strength in healing wounds. Surgery. 123(3):287-93.

Davis T.M., T.A. Li, Q.B. Tran, K. Robertson, J.R. Dyer, T.D. Phan, D. Meyer, M.H. Beaman and K.A. Trinh. 1997. The hypothalamic-pituitary-adrenalcortical axis in severe falciparum malaria: effects of cytokines. Journal of Clinical Endocrinologyand Metabolism. 82(9):3029-33.

Del Prete G.. 1992. Human Th1 and Th2 lymphocytes: their role in the pathophysiology of atopy. Allergy. 47(5):450-5.

De Winter R.J., R.W. Koster and G.T. Sanders. 1998. Early exclusion of ischemic myocardial damage by new biochemical cardiac markers. Nederlands Tijdschrift voor Geneeskunde. 142(17):940-4.

Delaney A.M., B.Y. Gabbitas and E. Canalis. 1995. Cortisol down-regulates osteoblast alpha 1 procollagen mRNA by transcriptional and post transcriptional mechanisms. Journal of Cellular Biochemistry. 57(3):488-94.

Dennis V.A., G. Osae-Addo and R.C. Lowrie Jr.. 1997. Blastogenic responses, interleukin-2 production and interleukin-2 receptor expression on CD4 and CD8 lymphocytes in rhesus monkeys experimentally inoculated with Loa loa. Parasite Immunology. 19(7):301-8.

Deroanne C.F., A.C. Colige, B.V. Nusgens and C.M. Laspiere. 1996. Modulation of expression and assembly of vinculin during in vitro fibrillar collagen-induced angiogenesis and its reversal. Experimental Cell Research. 224(2):215-23.

Despommier D.D.. 1993. Trichinella spiralis and the concept of niche. Journal of Parasitology. 79(4):472-82.

Despommier D.. 1975. Adaptive changes in muscle fibers infected with Trichinella spiralis. American Journal of Pathology. 78(3):477-96. 
Despommier D.D., A.M. Gold, S.W. Buck, V. Capo and D. Silberstien. 1990.

Trichinella spiralis: secreted antigen of the infective L1 larvae localizes to the cytoplasm and nucleoplasm of the infected host cells. Experimental Parasitology. 71(1):27-38.

Despommier D., W.F. Symmans, and R. Dell. 1991. Changes in the nurse cell nuclei during synchronous infection with Trichinella spiralis. Journal of Parasitology. 77(2):290-5.

Despommier D.D., M. Sukhedo and E. Meerovitch. 1978. Trichinella spiralis: site selection by the larva during the enteral phase of infection in mice. Experimental Parasitology. 44(2):209-15.

Dick T.A.. 1983. In: Trichinella and Trichinosis. William C. Campbell, Editor. Plenum Press. New York, N.Y..

Diefenbach A., H. Schindler, N. Donhauser, E. Lorenz, T. Laskay, J. MacMicking, M. Rollinghoff, I. Gresser and C. Bogdan. 1998. Type 1 interferon alpha and beta and nitric oxide synthase regulate the innate immune response to a protozoan parasite. Immunity. 8(1):77-87.

Dosgone H., C. Burvenich, T. van Werven, E. Roets, E.N. Noordhuizen-Stassen and B. Goddeeris. 1997. Increased surface expression of CD11b receptors on polymorphnuclear leukocytes is not sufficient to sustain phagocytosis during E. coli mastitis in early postpartum dairy cows. Veterinary Immunology and Immunopathology. 60(1-2):47-59.

Drenth J.P., J. Goertz, M.R. Daha and J.W. van der Meer. 1996. Immunoglobin D enhances the release of TNF-alpha and IL-1 beta as well as IL-1 receptor antagonist from human mononuclear cells. Immunology. 88(3):355-62.

Edwards S.W.. 1994 Biology and Physiology of the Neutrophil. Cambridge Press. New York, N.Y..

Ellis G., I. Adatia, M. Yazdanpanah and S.K. Maleka. 1998. Nitrite and nitrate analyses: a clinical biochemistry perspective. Clinical Biochemistry. 31(4):195-220.

Engel P., L.J. Zhou, D.C. Ord, S. Sato, B. Koller and T.F. Tedder. 1995. Abnormal lymphocyte development, activation and differentiation in mice that lack or over express the CD19 signal transduction molecule. Immunity. 3(1):39-50.

Engervall P. and J. Lundahl. 1998. Alterations in adhesion molecule (CD11b/CD18 and CD62L) expression on granulocytes after chemotherapy. European Journal of Clinical Investigation. 28(11):924-9. 
Eskay R.L., M. Grino and H.T. Chen. 1990. Interleukins, signal transduction and the immune system-mediated stress response. Advances in Experimental Medicine and Biology. 274:331-43.

Fanelli A., C. Bergamini, S. Rapi, A. Caldini, A. Spinelli, A. Buggiani and L. Emmi. 1997. Flow cytometric detection of circulating activated platelets in primary antiphospholipid syndrome: correlation with thrombocytopenia and anticardiolipin antibodies. Lupus. 6(3):261-7.

Faulkner H., J.C. Reynauld, J. Van Snick and R.K. Grencis. 1998. Interleukin-9 enhances resistance to the intestinal nematode Trichuris muris. Infection and Immunity. 66(8):3832-40.

Fearon D.T.. 1993. The CD19-CR2-TAPA-1 complex, CD45 and signaling by the antigen receptor of B lymphocytes. Current Opinion in Immunology. 5(3):34148.

Fehr T., R.C. Rickert, B. Odermatt, J. Roes, K. Rajewsky, H. Hengartner and R.M. Zinkernagel. 1998. Antiviral protection and germinal center formation but impaired B cell memory in the absence of CD19. Journal of Experimental Medicine. 188(1):145 55.

Felice K.J. and W.A. North. 1998. Creatine kinase values in amytrophic lateral sclerosis. Journal of Neurological Sciences. 160 Supp. 1:S30-2.

Folkman J. and M. Klagsbrun. 1987. Vascular physiology: a family of antigenic peptides. Nature 329(6141):671-2.

Forsyth L.M., L.A. Jackson, G. Wilke, A. Sanderson, G.G. Brown and P.M. Prerston. 1997. Bovine cells infected in vivo with Theileria annulata express CD11b, the C3bi complement receptor. Veterinary Research Communications. 21(4):24963.

Frederickson G.G. and R. S. Bosch. 1989. L3T4 antigen expression by hemopoietic cells. Journal of Experimental Medicine. 169(4):1473-8.

Frisbie D.D. and A.J. Nixon. 1997. Insulin-like growth factor 1 and corticosteroid modulation of chondrocyte metabolic and mitogenic activities in IL-1 conditioned equine cartilage. American Journal of Veterinary Research. 58(5):524-30. 
Frydas S., E. Karagouni, E. Dotsika, M. Reale, R.C. Barbacane, I. Vlemmas, G. Anogianakis, A. Trakatellis and P. Conti. 1996. Generation of TNF-alpha, IFN gamma, IL-6, and IL-10 in mouse serum from trichinellosis: effect of the anti inflammatory compound 4-deoxypyridoxine. Immunology Letters. 49(3):179 84.

Fukuuchi F., N. LeFrancois, F. Chapuis, L. Gebuhrer, S. Bosshard, J.M. Dubernard and J.L. Touraine. 1996. Comparative efficacy of prophylactic monoclonal (OKT3) and polyclonal antibodies (ATG) in immunologic high-risk renal transplant recipients. Transplant Proceedings. 28(5):2808-9.

Gallatin W.M., I.L. Weisman and E.C. Butcher. 1983. A cell surface molecule involved in organ-specific homing of lymphocytes. Nature. 304(5921):30-4.

Geboes K.. 1994. From inflammation to lesion. Acta Gastroenterlogica Belgica. 57(56):273-84.

Gerencer M., A. Marinculic, D. Rapic, M. Frankovic and I. Valpotic. 1992.Immunosuppression of in vivo and in vitro lymphocyte responses in swine nduced by Trichinella spiralis or excretory-secretory antigens of the parasite. Veterinary Parasitology. 44(3-4):263-73.

Ghosh S., D. Wolan, S. Adak, B.R. Crane, N.S. Kwon, J.A. Tainer, E.D. Getzoff and D.J. Stuehr. 1999. Mutational analysis of the tetrahydrobiopterin-binding site in inducible nitric oxide synthase. Journal of Biological Chemistry. 274(34):24100-12.

Giltay E.J., D. van Schaardenburg, L.J. Gooren, P.J. Kostense and B.A. Dijkmans.1999. Decreased serum biochemical markers of muscle origin in patients with ankylosing spondylitis. Annals of Rheumatic Diseases. 58(9):541-5.

Ginaldi L., M. DeMartinis, A. D’Ostilio, and L. Marini-Quaglino. 1998. Changes in antigen expression on B lymphocytes during HIV infection. Pathobiology. 66(1):17-23.

Goddard P.J., G. Keay and P.N. Grigor. 1997. Lactate dehydrogenase quantification and isoenzyme distribution in physiological response to stress in red deer (Cervus elaphus). Research in Veterinary Science. 63(2):119-22.

Godfrey D.I., J. Kennedy, P. Mombaerts, S. Tonegawa and A. Zlotnik. 1994. Onset of TCR beta gene rearrangement and role of TCR beta expression during CD3, CD4, CD8 thymocyte differentiation. Journal of Immunology. 152(10):478392. 
Good M.F.and D.L. Doolan. 1999. Immune effector mechanisms in malaria. Current Opinion in Immunology. 11(4):412-19.

Grad S., W. Ertel, M. Keel, M., Infanger M. Vonderschmitt and F.E. Maly. 1998. Strongly enhanced serum levels of vascular endothelial growth factor (VEGF) after polytrauma and burn. Clinical Chemistry and Laboratory Medicine. 36(6):379-83.

Graham M.F., A. Willey, Y.N. Zhu, D.R. Yager H.J., Sugerman and R.F. Diegelmann. 1997. Corticosteroids repress the IL-1-beta-induced secretion of collagenase in human intestinal smooth muscle cells. Gastroenterology. 113(6):1924-9.

Grant D.S., H.K. Kleinman, and G.R. Martin. 1990. The role of basement membranes in vascular development. Annals of the New York Academy of Sciences. 588:61-72.

Gray C.M., L. Morris, J. Murray, J. Keeton, S. Shalekoff, S.F. Lyons, P. Sonnenberg and D.J. Martin. 1996. Identification of cell subsets expressing intracytoplasmic cytokines within HIV-1-infected lymph nodes. AIDS. 10(13):1467-75.

Gregor M., J. Mejsnar, A. Janovska, J. Zurmanova, O. Benada and B. Mejsnarova. 1999. Creatine kinase reaction in skinned rat psoas muscle fibers and their myofibrils. Physiological Research. 48(1):2-35.

Griffin J.E.and S.R. Ojeda. 1992. Textbook of Endocrine Physiology. Oxford University Press. London, U.K..

Guller S., L. Kwong, R. Wozniak and C.J. Lockwood. 1995. Reduction of extracellular matrix protein expression in human amnion epithelial cells by glucocorticoids: a potential role in preterm rupture of the fetal membranes. Journal of Clinical Immunology and Metabolism. 80(7):2244-50.

Guthrie S.. 1991. The impact of dexamethasone pharmacokinetics on the DST: a review. Psychopharmacology Bulletin. 27(4):565-76.

Haapasaari K.M., J. Risteli, V. Koivukangas and A. Oikarinen. 1995. Comparison of the effect of hydrocortisone-17 butyrate and betamethasone on collagen synthesis in human skin in vivo. Acta Dermato-Venereologica. 75(4):269-71.

Haas T.L., S.J. Davis and J.A. Madri. 1998. Three dimensional type I collagen lattices induce coordinate expression of matrix metalloproteases MT-1, MMP and MMP-2 in microvascular endothelial cells. Journal of Biological Chemistry. 273(6):3604-10. 
Haehling E., J.Y. Neiderkorn and G.L. Stewart. 1995. Trichinella spiralis and Trichinella pseudospiralis induce collagen synthesis by host fibroblasts in vitro. International Journal for Parasitology. 25(12):1393-400.

Hagan P., S. Poole and A.F. Bristow. 1992. Immunosuppressive activity of corticotropin releasing factor: inhibition of IL-1 and IL-6 production by human mononuclear cells. Biochemical Journal. 281 (Pt 1): 251-4.

Hansen-Smith F.M., L. Watson, D.Y. Lu and I. Goldstein. 1998. Griffonia simplicifolia I: a fluorescent tracer for microcirculatory vessels in non-perfused thin muscles and sectioned muscle. Microvascular Research. 36(3):199-215.

Hansen-Smith F.M., L.H. Blackwell and G.R. Joswiak. 1992a. Expression of muscle capillary alkaline phosphatase is affected by hypoxia. Journal of Applied Physiology. 73(2):7760-80.

Hansen-Smith F.M., K. Banker, L. Morris and G. Joswiak. 1992b. Alternative histochemical markers for skeletal muscle capillaries: a statistical comparison among three muscles. Microvascular Research. 44(1):112-16.

Haroun E.M., O.M. Mahmoud, M. Magzoub, Y. Addel Hamid and O.H. Omer. 1996. The haematological and biochemical effects of the gastrointestinal nematodes prevalent in camels (Camelus dromedarius) in central Saudi Arabia. Veterinary Research Communications. 20(3):255-64.

Haveman J.W., A.C. Muller Kobold, J.W. Tervaert, A.P. van den Berg, J.E. Tulleken, C.G. Kallenberg and T.H. The. 1999. The central role of monocytes in the pathogenesis of sepsis: consequences for immunomonitoring and treatment. Netherlands Journal of Medicine. 55(3):132-41.

Hayashi S., C.C. Chan, R. Gazzinelli and F.G. Roberge. 1996. Contribution of nitric oxide to the host parasite equilibrium in toxoplasmosis. Journal of Immunology. 156(4):1476-81.

Hegazy I.H.and L.M. Boulos. 1993. Scanning electron microscopic study of Trichinella pseudospiralis muscle phase after modulation of the host using an immunostimulant drug. Journal of the Egyptian Society of Parasitology. 23(2):501-5.

Hermanek J., P.K. Goyal and D. Wakelin. 1994. Lymphocyte, antibody and cytokine responses during concurrent infections between helminths that selectively promote T helper-1 or T helper-2 activity. Parasite Immunology. 16(2):111-17. 
Hiraizumi Y., E. Fujimaki, E.E. Transfeldt, N. Kawahara, V.D. Fiegel, D. Knighton and J.H. Sung. 1996. The effect of platelet-derived wound healing formula and the nerve growth factor on the experimentally injured spinal cord. Spinal Cord. 34(7):394-402.

Hirji N., T.J. Lin, E. Bissonnette, M. Belosevic and A.D. Befus. 1998. Mechanisms of macrophage stimulation through CD8: macrophage CD8-alpha and CD8-beta induce nitric oxide production and associated killing of the parasite Leishmania major. Journal of Immunology. 160(12):6004-11.

Holland E.G.and A.T. Taylor. 1991. Glucocorticoids in clinical practice. Journal of Family Practice. 32(5):512-19.

Hong, Y., C.W. Kim and B. Ghebrehiwet. 1992. Trichinella spiralis: activation of complement by infective larvae, adults and newborn larvae. Experimental Parasitology. 74(3):290-9.

Hoppmann, B.. 1999. Personal Communication.

Hrabak A., H. Sefrioui, V. Vercruysse, A. Temesi, T. Bajor and B. Vray. 1998. Action of chloroquine on nitric oxide production and parasite killing by macrophages. European Journal of Pharmacology. 354(1):83-90.

Hughes W.L. and J.P. Harley. 1977. Trichinella spiralis: taxes of first stage migratory larvae. Experimental Parasitology. 42(2):363-73.

Hyman R., J. Lesley, R. Schulte and J. Trotter. 1986. Progenitor cells in the thymus: most thymus-homing progenitor cells in the adult mouse thymus bear Pgp-1 glycoprotein but not interleukin-2 receptor on their cell surface. Cellular Immunology. 101(2):320-7.

Ilan N., S. Mahooti and J.A. Madri. 1998. Distinct signal transduction pathways are utilized during the tube formation and survival phases of in vitro angiogenesis. Journal of Cell Science. 11(Pt24):3621-31.

Isakov N., R.L. Wange, W.H. Burgess, J.D. Watts, R. Aebersold and L.E. Samelson. 1995. ZAP-70 binding specificity to T cell receptor tyrosine-based activation motifs: the tandem SH2 domains of ZAP-70 bind distinct tyrosine-based activation motifs with varying affinity. Journal of Experimental Medicine. 181(1):375-80.

Ishikawa N., P.K. Goyal, Y.R. Mahida, K.F. Li and D. Wakelin. 1998. Early cytokine responses during intestinal parasitic infections. Immunology. 93(2):257-63. 
Ishikawa N., D. Wakelin and Y.R. Mahida. 1997. Role of T helper 2 cells in intestinal goblet cell hyperplasia in mice infected with Trichinella spiralis. Gastroenterology. 113(2):542-9.

Isobe M., H. Yagita, K. Okumara and A. Ihara. 1992. Specific acceptance of cardiac allograft after treatment with antibodies to ICAM-1 and LFA-1. Science. 255(5048):1125-27.

Ito M., M. Watanabe, H. Kamiya and M. Sakurai. 1996. Role of adhesion molecules in natural killer cell-induced DNA fragmentation of cytomegalovirus-infected fibroblasts. Viral Immunology. 9(4):219-24.

Ivanoska D., K. Cuperlovic and J.K. Lunney. 1990. Peripheral blood mononuclear subsets during Trichinella spiralis infection in pigs. Research in Veterinary Science. 49(1): 92-7.

Iwabuchi K., J. Ohgama, K. Ogasawara, C. Iwabuchi, I. Negishi, R.A. Good and K. Onoe. 1991. Distribution of MEL-14+ cells in various lymphoid tissues. Immunobiology. 182(2):161-73.

Iwagaki H., A. Hizuta, M. Uomoto, Y. Takeuchi, H. Kohoka, T. Okamoto and N. Tanaka. 1997. Clinical value of cytokine antagonists in infectious complications. Research Communications in Molecular Pathology and Pharmacology. 96(1):25-34.

Iwasaka, C., K. Tanaka, M. Abe and Y. Sato. 1996. Ets-1 regulates angiogenesis by inducing expression of urokinase-type plasminogen activator and matrix metalloproteinase- 1 and the migration of vascular endothelial cells. Journal of Cellular Physiology. 169(3):522-31.

Jacobs P., D. Radzioch and M.M. Stevenson. 1995. Nitric Oxide expression in spleen, but not in liver correlates with resistance to blood-stage malaria in mice. Journal of Immunology. 155(11):5306-13.

Jaggers D.C., W.P. Collins and S.R. Milligan. 1996. Potent inhibitory effects of steroids in an in vitro model of angiogenesis. Journal of Endocrinology. 150(3):457-64.

James S.L.. 1995. Role of nitric oxide in parasitic infections. Microbiological Reviews. 59(4):533-47.

Janeway C.A. Jr.. 1992. The T cell receptor as a multicomponent signaling machine: CD4/CD8 coreceptors and CD45 in T cell activation. Annual Review of Immunology. 10:645-74.

Jasmer D.P.. 1990. Trichinella spiralis: altered expression of muscle protein in trichinosis. Experimental Parasitology. 70(4):452-65. 
Jasmer D.P.. 1993. Trichinella spiralis-infected skeletal muscle cells arrest in G2/M and cease muscle gene expression. Journal of Cell Biology. 121(4):785-93.

Jasmer D.P. and S.M. Neary. 1994. Trichinella spiralis: inhibition of muscle larval growth and development is associated with a delay in expression of infected skeletal muscle characteristics. Experimental Parasitology. 78(3).317-25.

Jongwutiwes S., N. Chantachum, P. Kraivichian, P. Siriyasatien, C. Putaporntip, A. Tamburruni, G. La Rosa, C. Sreesunpasirikul, P. Yingyourd and E. Pozio. 1998. First outbreak of human trichinellosis caused by Trichinella pseudospiralis. Clinical Infectious Diseases. 26(1):11-15.

Johnson P.. 1997. In: Weir's Handbook of Experimental Immunology. L.A. Herzenberg, Editor. Blackwell Science. Cambridge, MA..

Jorgensen C. and J. Sany. 1994. Modulation of the immune response by the neuroendocrine axis in rheumatoid arthritis. Clinical \& Experimental Immunology. 12(4):435-41.

Jung T.M., W.M. Gallatin, I.L. Wiesmann and M.O. Dailey. 1988. Down-regulation of homing receptors after $\mathrm{T}$ cell activation. Journal of Immunology. 141(12):4110-17.

Kahtoh S., J.B. McCarthy and P.W. Kincade. 1994. Characterization of soluble CD44 in the circulation of mice. Levels are affected by immune activity and tumor growth. Journal of Immunology. 153(8):3440-9.

Kanazawa T., H. Asahi, H. Kata, K. Mochida, N. Kagei and M.J. Stadecker. 1993. Arginine-dependent generation of reactive nitrogen intermediates is instrumental in the in vitro killing of protoscoleces of Eichinococcus multilocularis by activated macrophages. Parasite Immunology. 15(11):61923.

Kannon C.R.. 1986. Essential Endocrinology. Plenum Press. New York, NY.

Kaspar L.H.and I.A. Khan. 1998. Antigen-specific CD8+ T cells protect against lethal toxoplasmosis in mice infected with Neospora caninum. Infection and Immunity. 66(4):1554-60.

Kavelaars A., C.J. Heijnen, B. Ellenbroek, H. Van Loveren and A. Cools. 1997. Apomorphine-susceptible and apomorphine-unsusceptible Wistar rats differ in their susceptibility to inflammatory and infectious diseases: a study on rats. Journal of Neuroscience. 17(7):2580-4.

Kawaguchi Y., H. Matsui and H. Tsuji. 1997. Changes in serum creatine phosphokinase MM isoenzyme after lumbar spine surgery. Spine. 22(9):101823. 
Kehrel B., S. Wierwille, K.J. Clemetson, O. Anders, M. Steiner, C.G. Knight, R.W. Farndale, M. Okuma and M.J. Barnes. 1998. Glycoprotein VI is a major collagen receptor for platelet activation: it recognizes the platelet activating quaternary structure of collagen, whereas CD36, glycoprotein IIb/IIIa and von Willenbrand factor do not. Blood. 91(2):491-9.

Kemp G.J., D.N. Manners, J.F. Clark, M.E. Bastin and G.K. Radda. 1998. Theoretical modeling of some temporal and spatial aspects of the mitochondrion/creatine kinase/myofibril system in muscle. Molecular and Cellular Biochemistry. 184 (12):249-89.

Kilcullen J.K., Q.P. Ly, T.H. Chang, S.M. Levenson and J.J. Steinberg. 1998. Nonviable Staphylococcus aureus and its peptidoglycan stimulate macrophage recruitment, angiogenesis, fibroplasia and collagen accumulation in wounded rats. Wound Repair Regeneration. 6(2):149-56.

Kishimoto T.K., M.A. Jutila, E.L. Berg and E.C. Butcher. 1989. Neutrophil Mac-1 and MEL-1 4 adhesion proteins inversely regulated by chemotactic factors. Science. 245(4923):1238-41.

Kiuchi T., K.J. Oldhafer, H.J. Schlitt, B. Nashan, A. Deiwick, K. Wonigeit, B. Ringe, K. Tanaka, Y. Yamaoka and R. Pichlmayr. 1998. Background and prognostic implications of perireperfusion tissue injuries in human liver transplants: a panel histochemical study. Transplantation. 66(6):737-47.

Klemm P., C. Thiemermann, G. Winklmaier, P.A. Martorana and R. Hennign. 1995. Effects of nitric oxide synthase inhibition combined with nitric oxide inhalation in a porcine model of endotoxin shock. British Journal of Pharmacology. 114(2):363-68.

Knipper P., D. Maladry and V. Mitz. 1996. In situ thrombolysis. Correlation between creatine phosphokinase increase and local thrombolysis: an experimental study in the rat. Annales de Chirurgie Plastique et Esthetique. 41(4):367-75.

Ko R.C., L. Fan, D.L. Lee and H. Compton. 1994. Changes in host muscles induced by excretory/secretory products of larval Trichinella spiralis and Trichinella pseudospiralis. Parasitology. 108(Pt 2):195-205.

Kramer R.M.and J.D. Sharp. 1995. Recent insights into the structure, function and biology of cPLA2. Agents and Actions-Supplements. 46:65-76.

Kroncke K.D., K. Fehsel and V. Kolb-Bachofen. 1995. Inducible nitric oxide synthase and its product nitric oxide, a small molecule with complex biological activities. Biological Chemistry Hoppe-Seyler. 376(6):327-43. 
Krop I., A.L. Shaffer, D.T. Fearon and M.S. Schlissel. 1996a. The signaling activity of murine CD19 is regulated during cell development. Journal of Immunology. $157(1): 48-56$.

Krop I., A.R. de Fougerolles, R.R. Hardy, M. Allison, M.S. Schlissel and D.T. Fearon. 1996b. Self-renewal of B-1 lymphocytes is dependent on CD19. European Journal of Immunology. 26(1):238-42.

Krowka J.F., B. Cuevas, D.C. Maron, K.S. Steimer, M.S. Ascher and H.W. Sheppard. 1996. Expression of CD69 after in vitro stimulation: a rapid method for quantitating impaired lymphocyte responses in HIV infected individuals. JAIDS: Journal of Acquired Immune Deficiency Syndromes. 11(1):95-104.

Kruisbeek A.M.and E.M. Shevach. 1991. In: Current protocols in Immunology. S. Colligan, Editor. John Wiley and Sons. New York, N.Y..

Kuby J.. 1994. Immunology. $3^{\text {rd }}$ Edition. W.H. Freeman \& Co. New York, N.Y..

Kumar S.and R.L. Tarleton. 1998. The relative contribution of antibody production and CD8+ T cell function to immune control of Trypanosoma cruzi. Parasite Immunology. 20(5):207-16.

Kunz D., G. Walker, W. Eberhardt and J. Pfeilschifter. 1996. Molecular mechanisms of dexamethasone inhibition of nitric oxide synthase expression in IL-1 $\beta$ stimulated mesangial cells: evidence for the involvement of transcriptional and post-transcriptional regulation. Proceedings of the National Academy of Sciences (USA). 93(1):255-9.

Kurdy N.M., J.B. Weiss and A. Bate. 1996. Endothelial stimulating angiogenic factor in early fracture healing. Injury. 27(2):143-5.

Kusano K., C. Miyaura, M. Inada, T. Tamura, A Ito, H. Nagase, K. Kamoi and T. Suda. 1998. Regulation of matrix metalloproteinases (MMP-2,-3,-9, and 13) by interleukin -1 and interleukin -6 in mouse calvaria: association of MMP induction with bone resorption. Endocrinology. 139(3):1338-45.

Kuzuya M., S. Satake, S. Ai, T. Asai, S. Kanda, M.A. Ramos, H. Miura, M. Ueda and A. Iguchi. 1998. Inhibition of angiogenesis on glycolated collagen lattices. Diabetologia. 41(5):491-9.

Laemmli U.K.. 1970. Cleavage of structural proteins during the assembly of the head of bacteriophage T4. Nature. 227(259):680-5. 
Lahn M., H. Kalataradi, P. Mittelstadt, E. Pflum, M. Vollmer, C. Cady, A. Mukasa, A.T. Vella, D. Ikle, R. Harbeck, R. O'Brien and W. Born. 1998. Early preferential stimulation of gamma/delta $\mathrm{T}$ cells by TNF-alpha. Journal of Immunology. 160(11):5221-30.

Lane P.J., P. Lees, and J. Fink-Gremmels. 1990. Action of dexamethasone in an equine model of acute non-immune inflammation. Research in Veterinary Science. 48(1):87-95.

La Rosa G., E. Pozio, P. Rossi and K.D. Murrell. 1992. Allozyme analysis of Trichinella isolates from various host species and geographical regions. Journal of Parasitology. 78(4):641-6.

Larson E., G.L. Stewart and J.Y. Niederkorn. 1991. Trichinella pseudospiralis overcomes innate resistance of the Chinese hamster to Trichinella spiralis. Parasitology. 103 (Pt. 3):465-70.

Lawrence M.B.and T.A. Springer. 1991. Leukocytes roll on a selectin at physiological flow rates: distinction from and prerequisite for adhesion through integrins. Cell. 65(5):859-73.

Lawrence C.E., J.C. Patterson, L.M. Higgins, T.T. MacDonald, M.W. Kennedy and P. Garside. 1998. IL-4 regulated enteropathy in an intestinal nematode infection. European Journal of Immunology. 28(9):2672-84.

Ledbetter J.A.and L.A. Herzenberg. 1979. Xenogenic monoclonal antibodies to mouse lymphoid differentiation antigens. Immunological Reviews. 47:63-90.

Lee G.R.. 1999. Wintrobe's Clinical Hematology. $10^{\text {th }}$ Edition. Williams and Wilkins, Publishers. Baltimore, Maryland. USA.

Lee W.S., M.K. Jain, B.M. Arkonak, D. Zhang, S.Y. Shaw, S. Kashiki, K. Maemura, S.L. Lee, N.K. Hollenberg, M.E. Lee and E. Haber. 1998. Thy-1, a novel marker for angiogenesis up-regulated by inflammatory cytokines. Circulation Research. 82(8):845-51.

Leenen P.J., M.F. de Bruijn, J.S. Voerman, P.A. Campbell and W. Van Ewijk. 1994. Markers of mouse macrophage development by monoclonal antibodies. Journal of Immunological Methods. 174(1-2):5-19.

Lefebvre H.P., V. Laroute, J.P. Braun, V. Lassourd and P.L. Toutain. 1996. Noninvasive and quantitative evaluation of post-injection muscle damage by pharmacological analysis of creatine kinase. Veterinary Research. 27(4-5):34361. 
LeFrancois L..1991. Extrathymic differentiation of intraepithelial lymphocytes: a generation of a separate and unequal $\mathrm{T}$ cell repertoire? Immunology Today. 12(12):436-38.

Leibovich S.J., P.J. Polverini, H.M. Shepard, D.M. Wiseman, V. Shively and N. Nusier. 1987. Macrophage-induced angiogenesis is mediated by tumor necrosis factor alpha. Nature. 329(6140):630-2.

Leo O., M. Foo, D.H. Sachs, L.E. Samelson and J.A. Bluestone. 1987. Identification of a monoclonal antibody specific for murine T3 peptide. Proceedings of the National Academy of Sciences (USA). 84(5):1374-8.

Lertchirakarn V., R. Birner and H.H. Messer. 1998. Effects of interleukin-1 beta on human pulpal fibroblast proliferation and collagen synthesis. Journal of Endodontics. 24(6):409-13.

Lesch K.P.and B. Lerer. 1991. 5-HT receptor/G-protein/effector system complex in depression: Effect of glucocorticoids. Journal of Neural Transmission. General Section. 84(1-2):3-18.

Lesley J.and I.S. Trowbridge. 1982. Genetic characterization of a polymorphic murine cell surface glycoprotein. Immunogenetics. 15(3):313-20.

Lesley J., R. Hyman and P.W. Kincade. 1993. CD44 and its interaction with extracellular matrix. Advances in Immunology. 54:271-335.

Lewinsohn D.M., R.F. Bargatze and E.C. Butcher. 1987. Leukocyte-endothelial cell recognition: evidence of a common molecular mechanism shared by neutrophils, lymphocytes and other leukocytes. Journal of Immunology. 138(12):4313-21.

Levine S., F. Berkenbosch, D. Suchecki and F.J. Tolders. 1994. Pituitary-adrenal and interleukin-6 responses to recombinant interleukin-1 in neonatal rats. Psychoneuroendocrinology. 19(2):143-53.

Ley K., D.C. Bullard, M.L. Arbones, R. Bosse, D. Vestwebber and T.F. Tedder. 1995. Sequential contribution of L- and P-selectin to leukocyte rolling in vivo. Journal of Experimental Medicine. 181(2):669-75.

Liew F.Y., X.Q. Wei and L. Proudfoot. 1997. Cytokines and nitric oxide as effector molecules against parasitic infections. Philosophical Transactions of the Royal Society of London-Series B: Biological Sciences. 352(1359):1311-5.

Liew F.Y., D. Xu and W.L. Chan. 1999. Immune effector mechanisms in parasitic infections. Immunology Letters. 65(1-2):101-4. 
Lim L.C., M.N. Fiordalisi, J.L. Mantell, J.L. Schmitz and J.D. Folds. 1998. A whole blood assay for qualitative and semi-quantitative measurements of CD 69 surface expression on CD4 and CD8 T lymphocytes using flow cytometry. Clinical and Diagnostic Laboratory Immunology. 5(3):392-8.

Lin R.Y., D.C. Saha, C.J. Berstein, M.E. Astiz and E.C. Racjow. 1996. The pattern of inflammation in rat sepsis due to enterotoxin-producing Staphylococcus aureus: a comparison with ischemia-reperfusion injury. Journal of Medicine. 27(5-6):303-17.

Lincoln J.. 1997. Nitric Oxide in Health and Disease. Cambridge University Press. London, U.K..

Lub M., Y. van Kooyk and C.G. Figdor. 1996. Competition between lymphocyte function associated antigen 1 (CD11a/CD18) and Mac-1 (CD11b/CD18) for binding intracellular adhesion molecule -1 CD54). Journal of Leukocyte Biology. 59(5):648-55.

Lynch F.and R. Ceredig. 1989. Mouse strain variation in Ly-24 (Pgp-1) expression by peripheral $\mathrm{T}$ cells and thymocytes: implications for $\mathrm{T}$ cell differentiation. European Journal of Immunology. 19(2):223-9.

MacDonald H.R., R.C. Budd and J.C. Certottini. 1990a . Pgp-1 (Ly-24) as a marker of T lymphocytes. Current Topics in Microbiology and Immunology. 159:97-109.

MacDonald H.R., M. Schreyer, R.C. Howe and C. Bron. 1990b. Selective expression of CD8 alpha (Ly-2) subunit on activated thymic gamma/delta T cells. European Journal of Immunology. 20(4):927-30.

MacMicking J., Q.W. Xie and C. Nathan. 1997. Nitric oxide and macrophage function. Annual Review of Immunology. 15:323-50.

Maeda H. and T. Akaike. 1998. Nitric oxide and oxygen radicals in infection, inflammation and cancer. Biochemistry (Moscow). 63(7):854-65.

Malekan R., C. Reynolds, N. Narula, S.T. Kelley, Y. Suzuki and C.R. Bridges. 1998. Angiogenesis in transmyocardial laser revascularization. A non-specific response to injury. Circulation. 98(19 Supp.):II62-5:discussion II66.

Martin H., R. Mestril, R. Hilal-Dandan, L.L.Brunton and W.H. Dillmann. 1997. Small heat shock proteins and protection against ischemic injury in cardiac myocytes. Circulation. 96(12):4343-8.

Marzio R., E. Jirillo, A. Ransijn, J. Mauel and S.B. Corradin. 1990. Expression and function of the early activation antigen CD69 in murine macrophages. Journal of Leukocyte Biology. 62(3):349-55. 
Mastorakos G., J.S. Weber, M.A. Magiakau, H. Gunn and G.P. Chrousos. 1994. Hypothalamic-pituitary-adrenal axis activation and stimulation of systemic vasopressin secretion by recombinant interleukin-6 in humans: potential implications for the syndrome of inappropriate vasopressin secretion. Journal of Clinical Endocrinology and Metabolism. 79(4):934-9.

Mauri C., R.O. Williams, M. Walmsley, and M. Feldmann. 1996. Relationship between Th1/Th2 cytokine patterns and the arthritogenic response in collagen induced arthritis. European Journal of Immunology. 26(7):1511-8.

McCann S.M., M. Kimura, S. Karanth, W.H. Yu and V. Rettori. 1997. Nitric oxide controls the hypothalamic-pituitary response to cytokines.

Neuroimmunomodulation. 4(2):98-106.

Mehdizadehkashi Z. 1995. Master's Thesis. Portland Sate University. Portland, Oregon.

Milano S., F. M. Arcoleo, R.D. Dieli, P.D. Augostino, P.G. Augostino, G. E. DeNucci and E. Cillari. 1995. Prostaglandin E2 regulates inducible nitric oxide synthase in the murine macrophage cell line. Prostaglandins. 49(2):105-15.

Mistichenko A.S., E.R. Koch, A.E. Kajon, F. Tibaldi, A.F. Maffey and R.A. Deiz. 1998. Lymphocyte subsets and cytokines in adenoviral infection in children. Acta Paediatrica. 87(9):933-9.

Mizutani M., K. Hirasawa, M. Takeda, K. Doi, M. Yukawa, Y. Matsumoto and T. Onodera. 1996. Variation in serum creatine phosphokinase activity as indicated in two phase EMC-D virus-induced myocarditis. Experimental Animals. 45(4):333-38.

Mobley J.L. and M.O. Dailey. 1992. Regulation of adhesion molecule expression by CD8 T cells in vivo: Differential regulation of gp90MEL-14 (LECAM-1), pgp 1, LFA-1, and VLA-4 alpha during the differentiation of cytotoxic T lymphocytes induced by allografts. Journal of Immunology. 148(8):2348-56.

Moczon T.and M. Wranicz. 1999. Trichinella spiralis: proteinases in the larvae. Parasitology Research. 85(1):47-58. 
Munno I., S. Damiani, R. Scardapane, G. Lacedra, M. Megna, C. Patimo and G.F. Megna. 1998. Evaluation of hypothalamic-pituitary-adrenalcortical hormones and inflammatory cytokines in patients with persistent vegetative state. Immunopharmacology and Immunotoxicology. 20(4):519-29.

Murosaki S., Y. Yoshikai, A. Ishida, T. Nakamura, G. Matsuzaki, H. Takimoto, H. Yuuki and K. Nomoto. 1991. Failure of T cell receptor V beta negative selection in murine intestinal intra-epithelial lymphocytes. International Immunology. 3(10):1005-13.

Murphy S., M.L. Simmons, L. Agullo, A. Garcia, D.L. Feistein, E. Galea, E. Reis, D. Minc-Goloomb and J.P. Schwartz. 1993. Synthesis of nitric oxide in CNS glial cells. Trends in Neurosciences. 16(8):323-8.

Nakano H., T. Yamazaki, S. Miyatake, N. Nozaki, A. Kikuchi, and T. Saito. 1996. Specific interaction of topoisomerase II beta and the CD3 epsilon chain of T cell receptor complex. Journal of Biological Chemistry. 271(11):6483-9.

Nathan N., Y. Denizot, E. Cornu, M.O. Jauberteau, C. Chauvreau and P. Feiss. 1997. Cytokine and lipid mediator blood concentrations after coronary artery surgery. Anesthesia and Analgesia. 85(6):1240-6.

Ng W.F.and K.T. Loo. 1993. Cutaneous cryptococcosis: primary versus secondary disease. Report of two cases with review of literature. American Journal of Dermatopathology. 15(4):372-7.

Nielsen S.D., P. Afzelius, A.K. Ersboll, J.O. Nielsen and J.E. Hansen. 1998. Expression of the activation antigen CD69 predicts the functionality of in vitro expanded peripheral blood mononuclear cells (PBMC) from health donors and HIV-infected patients. Clinical and Experimental Immunology. 114(1):66-72.

Nussler A.K.and T.R. Billiar. 1993. Inflammation, immunoregulation and inducible nitric oxide synthase. Journal of Leukocyte Biology. 54(2):171-8.

O'Gorman E., G. Beutner, T. Wallimann and D. Brdiczka. 1996. Differential effects of creatine depletion on the regulation of enzyme activities and on creatine stimulated mitochondrial respiration in skeletal muscle, heart and brain. Biochimica et Biophysica Acta. 1276(2):161-70.

Ohno Y., M. Fugimoto, A. Mishimura and N. Aoki. 1998. Change of peripheral levels of pituitary hormones and cytokines after injection of interferon beta in patients with chronic hepatitis C. Journal of Clinical Endocrinology and Metabolism. 83(10):3681-7. 
Okada H., J. Woodcock-Mitchell, J. Mitchell, T. Sakamoto, K. Marutsuka, B.E. Sobel and S. Fujii. 1998. Induction of plasminogen activator inhibitor type 1 and type 1 collagen expression in rat cardiac microvascular endothelial cells by interleukin-1 and its dependence on oxygen-centered free radicals. Circulation. 97(21):2175-82.

Oswald I.P., T.A. Wynn, A. Sher and S.L. James. 1994. NO as an effector molecule of parasite killing: modulation of its synthesis by cytokines. Comparative Biochemistry and Physiology, Pharmacology, Toxicology and Endocrinology. 108(1):11-8.

Otsuki T. and M. Oku. 1995. A study on the effect of cortisol and progesterone on cytosolic arachidonic and palmitic acid concentration in cultured myometrial cells. Acta Obstetrica et Gynaecologica Japonica. 47(6):531-8.

Paez-Pereda M., C. Perez-Castro, M. Costas, V.E. Mahmod, G.K. Stalla, F. Holsboer and E. Arzt. 1996. Glucocorticoids inhibit the autoregulatory induction of interleukin-1 in monocytes after endotoxin stimulation.

Neuroimmunomodulation. 3(4):227-32.

Pagel C.N.and T.A. Partridge. 1999. Covert persistence of $\mathrm{mdx}$ mouse myopathy is revealed by acute and chronic effects of irradiation. Journal of the Neurological Sciences. 164(2):103-16.

Panayi G.S.. 1993a. The pathogenesis of rheumatoid arthritis: from molecules to the whole patient. British Journal of Rheumatology. 32(7):533-6.

Panayi G.S.. 1993b. A defect in neuroendocrine axis in rheumatoid arthritis: pathogenic implications. Clinical and Experimental Rheumatology. 11 Supp. 8:S83-5.

Panteghini M., F.S. Apple, R.H. Christenson, F. Dati , J. Mair and A.H. Wu. 1999. Use of biochemical markers in acute coronary syndrome. IFCC Scientific Division, Committee on Standardization of Markers of Cardiac Damage. Clinical Chemistry and Laboratory Medicine. 37(6):687-93.

Parks T.P., A.F. Hoffman, C.A.Homon, A.G. Graham, E.S. Lazer, F.H. Chilton, P. Borgeat, D. Railble, E. Schulman and D.A. Bass. 1995. Inhibition of lipid mediator biosynthesis in human inflammatory cells by BIRM 270. Agents and Actions. Supplements. 46:139-46.

Patel F.A., V.L. Clifton, K. Chwalisz and J.R. Challis. 1999. Steroid regulation of prostaglandin dehydrogenase activity in human term placenta and chorio decidua in relation to labor. Journal of Clinical Endocrinology and Metabolism. 84(1):291-9. 
Paugam C., S. Chollet-Martin, S. M. Dehoux, D. Chatel, N.B. Brient, J.M. Desmonts and I. Philip. 1997. Neutrophil expression of CD11b/CD18 and IL-8 secretion during normothermic cardiopulmonary bypass. Journal of Cardiothoracic and Vascular Anesthesia. 11(5):575-9.

Pearce E.J., and J. Pedras-Vasconcelos. 1997. Schistosoma mansoni infection induces type 1 CD8+ cell response. Behring Institute Mitteilungen. (99):79-84.

Pennock J.L., J.M. Behnke, Q.D. Bickle, E. Devaney, R.K. Grencis, R.E. Isaac, G.W. Joshua, M.E. Selkirk, Y. Zhang and D.J. Meyer. 1998. Rapid purification and characterization of L-dopachrome-methyl ester tautomerase (macrophage migration inhibition factor) from Trichinella spiralis, Trichuris muris and Brugia pahangi. Biochemical Journal. 335(Pt 3):495-8.

Penrith M.L.and E. Van Vollenhoven. 1994. Pulmonary and hepatic lesions associated with suspected ganskweek (Lasiospermum bipinnatum) poisoning in cattle. Journal of the South African Veterinary Association. 65(3):122-4.

Perfetto S.P., T.E. Hickey, P.J. Blair, V.C. Maino, K.F. Wagner, S. Zhou, D.L. Mayers, D. St. Louis, C.H. June and J.N. Siegel. 1997. Measurement of CD69 induction in the assessment of immune function in asymptomatic HIV-infected individuals. Cytometry. 30(1):1-9.

Pernthaner A., M. Stankiewicz, W. Cabaj, A. Pfeffer, R.S. Green and P.J. Douch. 1996. Immune responsiveness of nematode-resistant or susceptible Rhomney line bred sheep to continuous infection with Trichostrongylus axei. Veterinary Immunology and Immunopathology. 51(1-2):137-46.

Philipp M., R.M. Parkhouse, and B.M. Ogilvie. 1980. Changing proteins on the surface of a parasitic nematode. Nature. 287(5782):558-40.

Pizcueta P.and F.W. Luscinskas. 1994. Monoclonal antibody blockade of L-selectin inhibits mononuclear leukocyte recruitment to inflammatory sites in vivo. American Journal of Pathology. 145(2):461-9.

Pollock J.S., U. Forstermann, J.A. Mitchell, T.D. Warner, H.H. Schmidt, M. Nakane and F. Murad. 1991. Purification and characterization of particulate endothelium-derived relaxing factor synthase from cultured and native bovine aortic endothelial cells. Proceedings of the National Academy of Sciences (USA). 88(23):10480-84.

Polvere R.I., C.A. Kabbash, V.A. Capo, I Kadan and D.D. Despommier. 1997. Trichinella spiralis: synthesis of type IV and type VI collagen during nurse cell formation. Experimental Parasitology. 86(3):191-99. 
Pozio E., G. La Rosa, K.D. Murrell and J.R. Lichtenfels. 1992a. Taxonomic revision of the genus Trichinella. Journal of Parasitology. 78(4):654-9.

Pozio E., G. La Rosa, P. Rossi and K.D. Murrell. 1992b. Biological characterization of Trichinella isolates from various host species and geographical regions. Journal of Parasitology. 78(4):647-53.

Pozio E., B. Shaikenov, G. La Rosa and D.L. Obendorf. 1992c. Allozymic and biological characters of Trichinella pseudospiralis isolates from free-ranging animals. Journal of Parasitology. 78(6):1087-90.

Pozio E. and G. La Rosa. 2000. Trichinella murrelli:etiological agent of trichinellosis in temperate areas of North America. Journal of Parasitology. 86(1):134-9.

Prince H.E.and M. Lape-Nixon. 1997. CD69 expression reliably predicts the anti-CD3 induced proliferative response of lymphocytes from human immunodeficiency virus type 1-infected patients. Clinical and Diagnostic Laboratory Immunology. 4(2):217-22.

Pruhiere, D.. 1994. Master's Thesis. Portland State University. Portland, Oregon.

Purner M.B., R.L. Berens, P.B. Nash, A. van Linden, E. Ross, C. Kruse, E.C. Krug and T.J. Curiel. 1996. CD4-mediated and CD8-mediated cytotoxic and proliferative immune responses to Toxoplasma gondii in seropositive patients. Infection and Immunity. 64(10):4330-8.

Qin W., Z. Khuchua, J. Borero, R.M. Payne and A.W. Strauss. 1999. Oxidative myocytes of heart and skeletal muscle express abundant sarcomeric mitochondrial creatine kinase. Histochemical Journal. 31(6):357-65.

Rapala K., J. Heino, J. Peltonen and M. Laato. 1997. The effects of interleukin-1 and prostaglandin E2 on accumulation of collagen and steady-state levels of pro alpha 1 collagen messenger RNA in experimental granulation tissue in rats. Archives of Dematological Research. 289(4):219-23.

Rajan T.V., P. Porte, J.A. Yates, L. Keefer and L.D. Shultz. 1996. Role of nitric oxide in host defense against extracellular metazoan parasite Brugia malayi. Infection and Immunity. 64(8):3351-3.

Ramaswamy K., D. Negrao-Correa and R. Bell. 1996. Local intestinal immune responses to infections with Trichinella spiralis: real time continuous assay of cytokines in the intestinal (afferent) and efferent thoracic duct lymph of rats. Journal of Immunology. 156(11):4328-37. 
Reed M.J., A. Corsa, W. Pendergrass, P. Penn, E.H. Sage and I.B. Abrass. 1998. Neovascularization in aged mice: delayed angiogenesis is coincident with decreased levels of transforming growth factor beta and type I collagen. American Journal of Pathology. 152(1):113-23.

Reeves R. and N.S. Magnuson. 1990. Mechanisms of regulating transient expression of mammalian cytokine genes and cellular oncogenes. Progress in Nucleic Acid Research and Molecular Biology. 38:241-82.

Reyes T.M.and C.L. Coe. 1998. The proinflammatory cytokine network: interactions in the CNS and blood of rhesus monkeys. American Journal of Physiology. 274(1 pt-2):R139-44.

Rickert R.C., K. Rajewsky and J. Roes. 1995. Impairment of T cell dependent B cell responses and B cell development in CD19-deficient mice. Nature. 376(6538):352-55.

Reichert R.A., I.L. Weissman and E.C. Butcher. 1986a. Dual immunofluorescence studies of cortisone-induced thymic involution: evidence for a major cortical component to cortisone-resistant thymocytes. Journal of Immunology. 136(10):3529-34.

Reichert R.A., I.L. Weissman, and E.C. Butcher. 1986b. Phenotypic analysis of thymocytes that express homing receptors for peripheral lymph nodes. Journal of Immunology. 136(10):3521-8.

Reichert R.A., L. Jerabek, W.M. Gallatin, E.C. Butcher and I.L. Weissman. 1986c. Ontogeny of lymphocyte homing receptor expression in mouse thymus. Journal of Immunology. 136(10):3535-42.

Rooney P.and S. Kumar. 1993. Inverse relationship between hyaluronan and collagens in development of angiogenesis. Differentiation. 54(1):1-9.

Rosenmann E., R. Rabinowitz and M. Schlesinger. 1998. Lymphocyte subsets in human tonsils: the effect of age and infection. Pediatric Allergy and Immunology. 9(3):161-7.

Rosenquist J.B., A. Ohlin and U.H. Lerner. 1996. Cytokine-induced inhibition of bone matrix proteins is not mediated by prostaglandins. Inflammation Research. 45(9):457-63.

Ruhl A. and S.M. Collins. 1997. Role of nitric oxide in norepinephrine release from myenteric plexus in vitro and in Trichinella spiralis infected rats. Neurogastroenterology and Motility. 9(1):33-9. 
Ruitenberg E.J., A. Perrudet-Badoux, Y. Boussac-Aron and A. Elgersma. 1980. Trichinella spiralis infection in animals genetically selected for high and low antibody production:studies on intestinal pathology. International Archives of Allergy and Applied Immunology. 62(1):104-10.

Russo M., N. Starobinas, M.C. Marcondes, P. Minoprio and M. HonteyberieJosckowicz. 1996. The influence of T cell subsets on Trypanosoma cruzi multiplication in different organs. Immunology Letters. 49(3):163-8.

Sabatier F., F. Dignat-George, J.L. Mege, C. Brunet, D. Raoult and J. Sampol. 1997. CD4+ T cell lymphopenia in Q-fever endocarditis. Clinical and Diagnostic Laboratory Immunology. 4(1):89-92.

Saito S., M. Kahtoh, M. Masumoto, S. Matsumoto and Y. Masuho. 1998. Involvement of MMP-1 and MMP-3 in collagen degradation induced by IL-1 in rabbit cartilage explant culture. Life Sciences. 62(22):PL 359-65.

Sauer J., M. Castren, U. Hopfner, F. Holsboer, G.K. Stalla and E. Arzt. 1996. Inhibition of lipopolysaccharide-induced monocyte interleukin-1 receptor antagonist synthesis by cortisol: involvement of the mineralcorticoid receptor. Journal of Clinical Immunology and Metabolism. 81(1):73-9.

Schaffer M., and A. Barbul. 1998. Lymphocyte function in wound healing and following injury. British Journal of Surgery. 85(4):444-60.

Scharton-Kersten T.M., G. Yap, J. Magram and A. Sher. 1997. Inducible nitric oxide is essential for host control of persistent but not acute infection with the intracellularpathogen Toxoplasma gondii. Journal of Experimental Medicine. 185(7):1261-73.

Scheller L.F., S.J. Green and A.F. Azad. 1997. Inhibition of nitric oxide interrupts the accumulation of CD8 $+\mathrm{T}$ cells surrounding Plasmodium berghei-infected hepatocytes. Infection and Immunity. 65(9):3882-8.

Scheynius A., R.L. Camp and E. Pure. 1993. Reduced contact sensitivity reactions in mice treated with monoclonal antibodies to leukocyte function-associated molecule-1 and intracellular adhesion molecule-1. Journal of Immunology. 159(2):655-63.

Scheynius A., R.L. Camp and E. Pure. 1996. Unresponsiveness to 2,4-dinitro-1-fluor benzene after treatment with monoclonal antibodies to leukocyte function associated molecule-1 and intracellular adhesion molecule-1 during sensitization. Journal of Immunology. 156(5):1804-9.

Schleimer R.P.. 1993. An overview of glucocorticoid anti-inflammatory actions. European Journal of Clinical Pharmacology. 45 Supp.1 S3-7: dis. S43-4. 
Schmits R., J. Filmus, N. Gerwin, G. Senaldi, F. Kiefer, T. Kundig, A. Wakeham, A. Shahinian, C. Catzavelos, J. Rak, C. Furlonger, A. Zakarian, J.J. Simard, P.S. Ohashi, C.J. Paige, J.C. Gutierez-Ramos and T.W. Mak. 1997. CD44 regulates hematopoietic progenitor distribution, granuloma formation and tumorgenicity. Blood. 90(6):2217-33.

Sephel G.C., R. Kennedy and S. Kudravi. 1996. Expression of capillary basement membrane components during sequential phases of wound angiogenesis. Matrix Biology. 15(4):263-79.

Sharma J.N.and W.W. Buchanan. 1996. Pathogenic responses of bradykinin system in chronic inflammatory rheumatoid disease. Experimental and Toxicological Pathology. 46(6):421-33.

Shintani F., T. Nakaki, S. Kanba, R. Kato, and M. Asai. 1995. Role of Interleukin-1 in stress responses: a putative neurotransmitter. Molecular Neurobiology. 10(1):47-71.

Siegelman M.H., I.C. Cheng, I.L. Weissman and E.K. Wakeland. 1990. The mouse lymph node homing receptor is identical with the lymphocyte cell surface marker Ly-22: role of the EGF domain in endothelial binding. Cell. 61(4):61122.

Skvortsova F.K.and N.L. Veretennikova. 1997. The comparative morphology of Trichinella spiralis and Trichinella pseudospiralis. Meditsinskaia Parazitologiia I Parazitarnye Bolezni. (1):22-27.

Spangrude G.J., J. Klein, S. Heimfeld, Y. Aihara and I.L. Weissman. 1989. Two monoclonal antibodies identify thymic-repopulating cells in mouse bone marrow. Journal of Immunology. 142(2):425-30.

Spivak B., B. Shohat, R. Metser, S. Avraham, I. Gil-Ad, A. Bleich, A. Valevski and A Weizmann. 1997. Elevated levels of serum interleukin-1 beta in combat related post-traumatic stress disorder. Biological Psychiatry. 42(5):345-8.

Sprent J.and D.F. Tough D.F. 1994. Lymphocyte life-span and memory. Science. 265(5177):1395-400.

Springer T., G. Galfre, D.S. Secher and C. Milstein. 1978. Monoclonal xenogeneic antibodies to murine cell surface antigens: identification of novel leukocyte differentiation antigens. European Journal of Immunology. 8(8):539-51.

Springer T., G. Galfre, D.S. Secher and C. Milstein. 1979. Mac-1: a macrophage differentiation antigen identified by monoclonal antibody. European Journal of Immunology. 9(4):301-6. 
Springer T.A., D. Davignon, M.K. Ho, K. Kurzinger, E. Martz and F. Sanchez-Madrid 1982. LFA-1 and Lyt-2,3 molecules associated with T lymphocyte-mediated killing and Mac-1, and LFA-1 homologue associated with complement receptor function. Immunological Reviews. 68:171-95.

Springer T.A.. 1990. Adhesion receptors of the immune system. Nature. 346(6283):425-34.

Springer T.A.. 1994. Traffic signals for lymphocyte recirculation and leukocyte emigration: the multi-step paradigm. Cell. 76(2):301-14.

Stadecker M.J. and P.O. Flores-Villanueva. 1994. Accessory signals regulate Th cell responses: from basic immunology to a model of helminthic disease. Immunology Today. 15(12):571-4.

Stadnyk A.W.and J.A. Kearsey. 1996. Pattern of pro-inflammatory cytokine mRNA expression during Trichinella spiralis infection of the rat. Infection and Immunity. 64(12):5138-43.

Stewart G.L.and L.M. Carniga. 1980. Distribution of Trichinella spiralis in muscles of the mouse. Journal of Parasitology. 66(4):688-9.

Stewart G.L., J.Y. Niederkorn, R.R. Kennedy and E. Mayhew. 1991. Effect of acute versus chronic Trichinella pseudospiralis infections on systemic cell-mediated immunity. International Journal of Parasitology. 21(8):935-40.

Stewart G.L., H. Na, L. Smart and L.L. Seelig. 1999. The temporal relationship among antiparasite immune elements expressed during the early phase of infection of the rat with Trichinella spiralis. Parasitology Research. 85(8-9):672-7.

Stites D.T.and A.I. Terr. 1991. Basic and Clinical Immunology. $7^{\text {th }}$ Edition. Appleton and Lang, Publishers. New York, N.Y..

Stuehr D.J., N.S. Kwon, C.F. Nathan, O.W. Griffith, P.L.Feldman and J. Wiseman. 1991. N-omega-hydroxyl-L-arginine is an intermediate in the biosynthesis of nitric oxide from L-arginine. Journal of Biological Chemistry. 266(10):625963.

Suss G.and K. Shortman. 1996. A subclass of dendritic cells kill CD4 T cells via Fas/Fas ligand-induced apoptosis. Journal of Experimental Medicine. 183(4):1789-96.

Sutton E.C., L.A. Evans, M.T. Rinaldi and K.A. Norton. 1996. Predicting injection site muscle damage: evaluation of extended release parenteral formulations in animal models. Pharmaceutical Research. 13(10):1514-8. 
Swollin-Eide D.and C. Ohlsson. 1998. Effects of cortisol on the expression of IL-6 and IL-1 beta in human osteoblast-like cells. Journal of Endocrinology. 156(1):107-14.

Tang L.and J.W. Eaton. 1995. Inflammatory responses to biomaterials. American Journal of Clinical Pathology. 103(4):466-71.

Taylor-Robinson A.W., A. Severn and R.S. Phillips. 1996. Kinetics of nitric oxide production during infection and reinfection of mice with Plasmodium chabaudi. Parasite Immunology. 18(8):425-30.

Teppema J.S., J.E. Robinson and E.J. Ruitenberg. 1973.Ultrastructural aspects of capsule formation in Trichinella spiralis infection in the rat. Parasitology. 66(2):291-6.

Terres A.M.and J.M. Pajares. 1998. An increased number of follicles containing activated CD69+ helper T cells and proliferating CD71+ B cells are found in H. pylori infected gastric mucosa. American Journal of Gastroenterology. 93(4):579-83.

Testi R., D. D’Ambrosio, R. De Maria and A. Santoni. 1994. The CD69 receptor: a multipurpose cell-surface trigger for hematopoietic cells. Immunology Today. 15(10):479-83.

Thomas G.R., M. McCrossan and M.E. Selkirk. 1997. Cytostatic and cytotoxic effects of activated macrophages and nitric oxide donors on Brugia malayi. Infection and Immunity. 65(7):2732-9.

Thorburn G.D.. 1991. The placenta, prostaglandins and parturition: a review. Reproduction, Fertility and Development. 3(3):277-94.

Thorburn G.D., S.A. Hollingworth and S.B. Hooper. 1991. The trigger for parturition in sheep: fetal hypothalamus or placenta? Journal of Developmental Physiology. 15(2):71-9.

Tilders F.J., R.H. DeRijk, A.M. Van Dam, V.A. Vincent, K. Schotanus and J.H. Persoons. 1994. Activation of the hypothalamus-pituitary-adrenal axis by bacterial endotoxins: routes and intermediate signals.

Psychoneuroendocrinology. 19(2):209-32.

Tomazik J., A. Ihan, F. Strle, J. Stare, M. Maticic and B. Zakotnik. 1997.

Immunological differentiation between tick-born encephalitis with and without concomitant neuroborreliosis. European Journal of Clinical Microbiology and Infectious Diseases. 16(12):920-3. 
Trottein F., S. Nutten, J.P. Papin, C. Leportier, O. Poulain-Godefroy, A. Capron and M. Capron. 1997. Role of adhesion molecules of the selectin-carbohydrate families in antibody-dependent cell-mediated cytotoxicity to schistosome targets. Journal of Immunology. 159(2):804-11.

Vago T., M. Clerici and G. Norbiato. 1994. Glucocorticoids and the immune system in AIDS. Baillieres Clinical Endocrinology and Metabolism. 8(4):789-802.

Van Ewijk W., P.L. van Soest and G.H. van den Engh. 1981. Fluorescence analysis and anatomic distribution of mouse $\mathrm{T}$ lymphocyte subsets defined by monoclonal antibodies to the antigens Thy-1, Lyt-1, Lyt-2 and T-200. Journal of immunology. 127(6):2594-604.

Vassilatis D.K., D. Despommier, D.E. Misek, R.I. Polvere, A.M. Gold and L.H. Van der Ploeg. 1992. Analysis of a 43kDa glycoprotein from the intracellular parasitic nematode Trichinella spiralis. Journal of Biological Chemistry. 267(26):18459-65.

Vassilatis D.K., R.I. Polvere, D.D. Despommier, A.M. Gold and L.H. Van der Ploeg. 1996. Developmental expression of a $43 \mathrm{kD}$ secreted glycoprotein from Trichinella spiralis. Molecular and Biochemical Parasitology. 78(1-2):13-23.

Venturiello S.M., G.H. Giambartolomei and S.N. Costantino. 1993. Immune killing of newborn Trichinella larvae by human leukocytes. Parasite Immunology. 15(10):559-64.

Vermillion D.L., P.B. Ernst and S.M. Collins. 1991. T lymphocyte modulation of intestinal muscle function in the Trichinella-infected rat. Gastroenterology. 101(1):31-8.

Vieira L.Q., M. Goldschmidt, M. Nashleanas, K. Pfeffer, T. Mak and P. Scott. 1996. Mice lacking the TNF receptor $\mathrm{p} 55$ fail to resolve lesions caused by infection with Leishmania major, but control parasite replication. Journal of Immunology. 157(2):827-35.

Vremec D., M. Zorbas, R. Scollay, D.J. Saunders, C.F. Ardavin, L. Wu and K. Shortman. 1992. The surface phenotype of dendritic cells purified from mouse thymus and spleen: investigation of the CD8 expression by a sub-population of dendritic cells. Journal of Experimental Medicine. 176(1):47-58.

Wakelin D., R.K. Grencis, and A.M. Donachie. 1982. Short-lived dividing cells mediate adoptive transfer of immunity to Trichinella spiralis in mice: In vivo characteristics of the cells. Immunology. 46(2):451-7.

Wakelin D., P.K. Goyal, M.S. Dehlawi and J. Hermanek. 1994. Immune responses to Trichinella spiralis and T. pseudospiralis in mice. Immunology. 81(3):475-9. 
Wandurska-Nowak E., and K. Boczon. 1993. Dynamics of rat muscle mitochondria uncoupling in trichinellosis. International Journal of Parasitology. 23(5):58790 .

Wang J.and J.R. Klein. 1994. Thymus-neuroendocrine interactions in extrathymic T cell development. Science. 265(5180):1860-62.

Wang S.Z., P.K. Smith, M. Lovejoy, J.J. Bowdern, J.H. Alpers and K.D. Forsyth. 1998. Shedding of L-selectin and PECAM-1 and up-regulation of Mac-1 and ICAM-1 on neutrophils in RSV bronchiolitis. American Journal of Physiology. 275 (5 pt.1):L983-9.

Weirich E., R.L. Rabin, Y. Maldonado, W. Benitz, S. Modler, and L.A. Herzenberg. 1998. Neutrophil CD11b expression as a diagnostic marker for early-onset neonatal infection. Journal of Pediatrics. $132(3 \mathrm{pt} 1): 445-51$.

Wheeldon E.B., T.A. Dick and T.A. Schulz. 1983. First report of Trichinella spiralis variation pseudospiralis in North America. Journal of Parasitology. 69(4);78182 .

Wineman J.P., G.L. Gilmore, C. Gritzmacher, B.E. Torbett and C.E. Muller-Sieburg. 1992. CD4 is expressed on murine pluripotent hematopoietic stem cells. Blood. 80(7):1717-24.

Wolf H.M., I. Hauber, H. Gulle, A. Samstag, M.B. Fischer, R.U. Ahmad and M.M. Eibl. 1996. Anti-inflammatory properties of human serum $\operatorname{IgA}$ : induction of IL-1 receptor antagonist and Fc alpha R (CD89)-mediated down-regulation of tumor necrosis factor-alpha (TNF-alpha) and IL-6 in human monocytes. Clinical and Experimental Immunology. 105(3):537-43.

Wright K.A.. 1979. Trichinella spiralis: an intracellular parasite in the intestinal phase. Journal of Parasitology. 65(3):441-5.

Wu L., M. Antica, G.R. Johnson, R. Scollay and K. Shortman. 1991a. Development potential of the earliest precursor cells from the adult mouse thymus. Journal of Experimental Medicine. 174(6):1617-27.

Wu L., R. Scollay, M. Egerton, M. Pearse, G.J. Spangrude and K. Shortman. 1991b. CD4 expressed on earliest $\mathrm{T}$ lineage precursor cells in the adult murine thymus. Nature. 349(6304):71-4.

Wu L., D. Vremec, C. Ardavin, K. Winkel, G. Suss, H. Georgiou, E. Maraskovsky, W. Cook and K. Shortman. 1995.Mouse thymus dendritic cells: kinetics of development and changes in surface markers during maturation. European Journal of Immunology. 25(2):418-25. 
Wynn T.A.. 1997.The debate over the effector function of eosinophils in helminth infection: new evidence from the studies on the regulation of vaccine immunity by IL-12. Memorias do Instituto Oswaldo Cruz. (92) Supp. 2: 105-8.

Xu H., J.A. Gonzalo, Y. St. Pierre, I.R. Williams, T.S. Kupper, R.S. Cotran, T.A. Springer and J.C. Gutierrez-Ramos. 1994.Leukocytosis and resistance to septic shock in intracellular adhesion molecule 1-deficient mice. Journal of Experimental Medicine. 180(1):95-109.

Yokoyama W.M., F. Koning, P.J. Kehn, G.M. Pereira, G. Stingl, J.E. Coligan and E.M. Shevach. 1988. Characterization of cell surface-expressed disulfide linked dimer involved in murine T cell activation. Journal of Immunology. 141(2):369-76.

Yokoyama W.M., S.R. Maxfield and E.M. Shevach. 1989.Very early (VEA) and very late (VLA) activation antigens have distinct functions in T lymphocyte activation. Immunological Reviews. 109:153-76.

Yoshimura T., M. Okita, K. Kawazoe, J. Kakano and Y. Nakao. 1999. Influential factors in elevation of serum creatine phosphokinase for the patients with Kanemi Yusho. Fukuoka Igaku Zasshi-Fukuoka Acta Medica. 90(5):246-50.

Zidek Z.and K. Masek. 1998. Erratic behavior of nitric oxide within the immune system: illustrative review of conflicting data and their immunopharmacoloical aspects. International Journal of Immunopharmacology. 29(7):319-43.

Ziegler S.F., F. Ramsdell and M.R. Alderson. 1994.The activation of antigen CD69. Stem Cells. 12(5):456-65.

Zimmermann W.J.and E.D. Hubbard. 1969. Trichinosis in Wildlife in Iowa. American Journal of Epidemiology. 90(1):84-92. 